

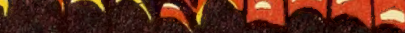

ลิธิ์ Mnần

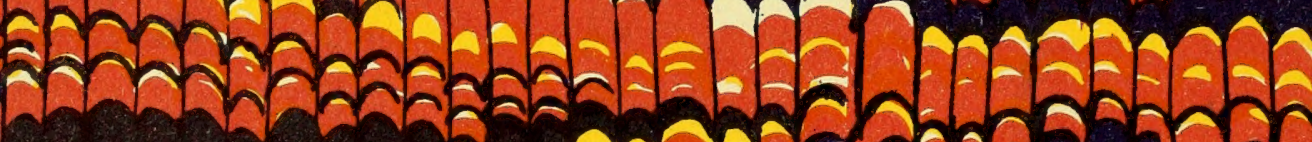

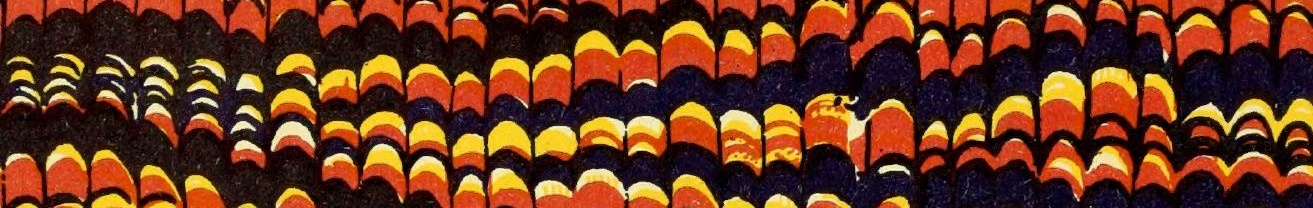

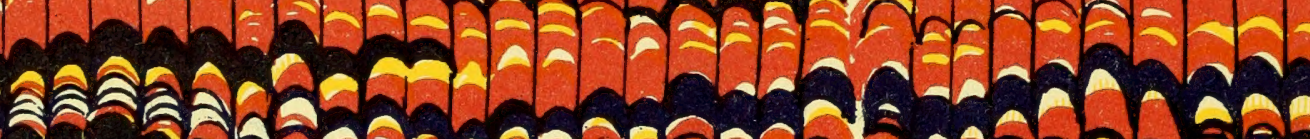

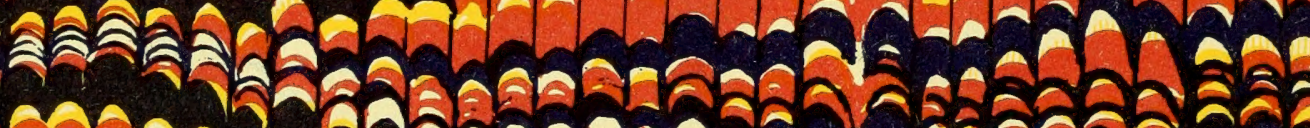

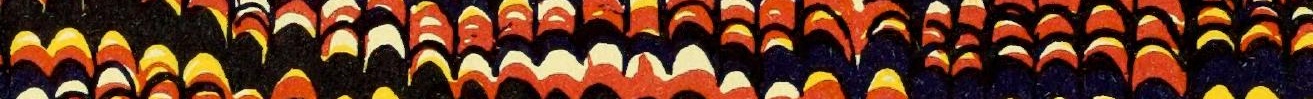
ล

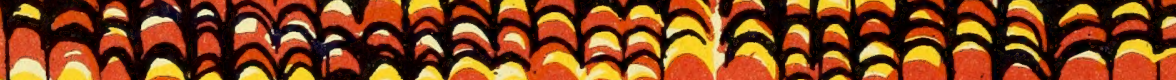

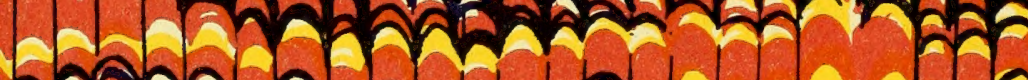

a t

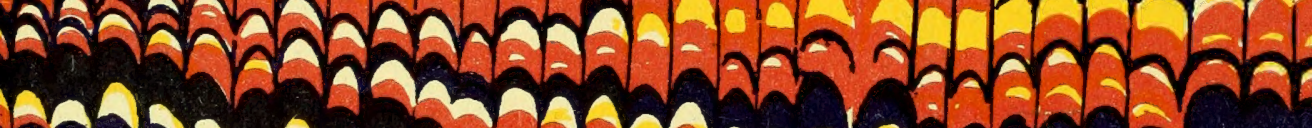

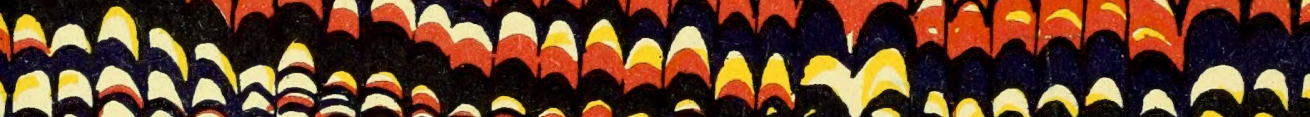
Imammañẫ

- 12 C-1.2 10u (1)

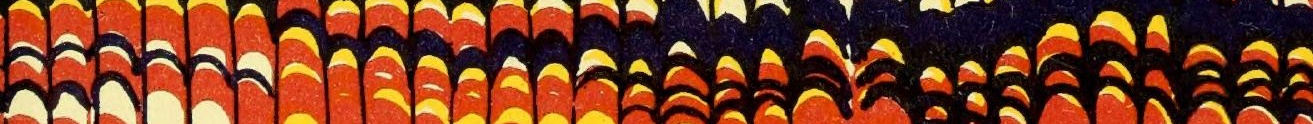
สล - than

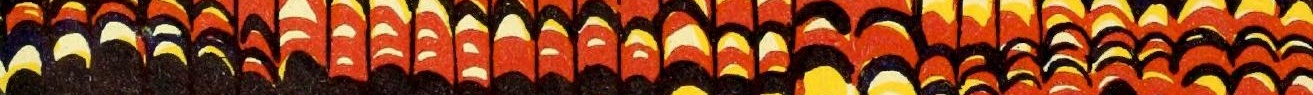
-

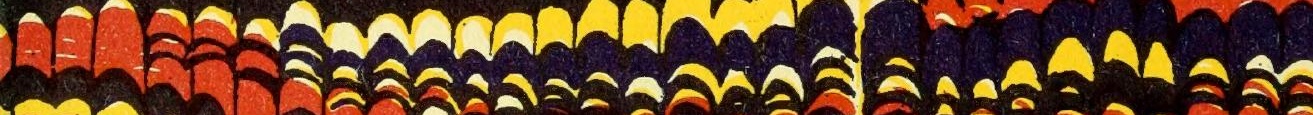
GOMn

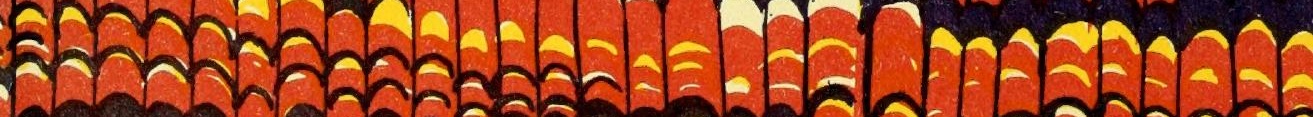




$$
\frac{0}{2}
$$




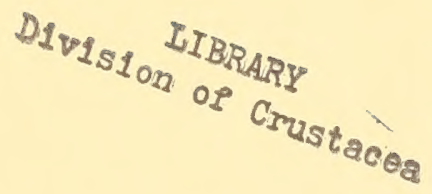

$$
\text { DIVISIOA OP Crustaces }
$$





Abhandlungen zur geologischen Specialkarte von Preussen und den Thüringischen Staaten. Band VI, Heft 3.

\section{Die Fauna}

\section{samländischen Tertiärs}

von

Dr. Fritz Noetling,

Privatdocent au der Universität Königsberg i. Pr.

\section{Theil.}

Lieferung I: Vertebrata.

Lieferung II: Crustacea und Vermes.

Lieferung VI: Echinodermata.

Nebst Tafelerklârungen und zwei Texttafeln.

Herausgegeben

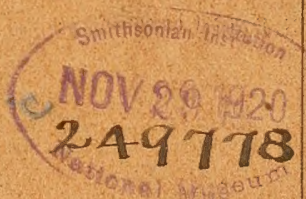

von

der Königlich Preussischen geologischen Landesanstalt.

Hierzu ein Atlas mit 27 Tafeln.

B E R I IN.

In Commission bei der Simon Sehropp'schen Hof-Landkartenhandlung.

(J. H. Neumann.)

1885. 


\section{Publicationen der Königl. Preussischen geologischen Landesanstalt.}

Die mit + bezeichneten Karten $u$. Schriften sind in Commission bei Paul Parey hier; alle übrigen in Commission bei der Simon Schropp'schen Hoflandkartenhandlung (J. H. Neumann) hier erschienen.

\section{Geologische Specialkarte von Preussen u. den Thüringischen Staaten.}

Im Maafsstabe von 1:25000.

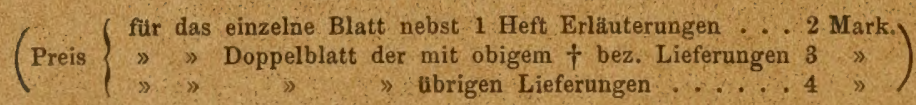

Lieferung 1. Blatt Zorge, Benneckenstein, Hasselfelde, Ellrich, Nordhausen, Stolberg .. . . . . . . $12-$

2. " Buttstedt, Eckartsberga, Rosla, Apolda, Magdala, Jena

» 3. „ Worbis, Bleicherode, Hayn, Ndr.-Orschla, Gr.-Keula, Immenrode . . . . . . . . . .

» 4. \ Sōmmerda, Cölleda, Stotternheim, Neumark, Erfurt, Weimar .................. $12-$

5. » Gröbzig, Zörbig, Petersberg • • • • • • • :

6. „ Ittersdorf, *Bouss, *Saarbrüeken, *Dudweiler, Lauterbach, Emmersweiler, Hanweiler (darunter $3 *$ Doppelblätter)

7. „ Gr.-Hemmersdorf, *Saarlouis, *Heusweiler, *Friedrichsthal, *Neunkirchen (darunter $4 *$ Doppelblätter) .

8. \ Waldkappel, Eschwege, Sontra, Netra, Hönebach, Gerstungen . . . . . . . . . .

9. Heringen, Kelbra nebst Blatt mit 2 Profilen durch das Kyffhäusergebirge sowie einem geogn. Kärtehen im Anhange, Sangerbausen, Sondershausen, Frankenhausen, Artern, Greussen, Kindelbrück, Schillingstedt

»10. $\gg$ Wincheringen, Saarburg, Beuren, Freudenburg, Perl, Merzig............ . . .

"11. " + Linum, Cremmen, Nauen, Marwitz, Markau, Rohrbeck

» 12. 》 Naumburg, Stössen, Camburg, Osterfeld, Bürgel, Eisenberg . . . . . . . . . .

13. » Langenberg, Grossenstein, Gera, Ronneburg . . .

14. 15. + Oranienburg, Hennigsdorf, Spandow
15. baden, Hochheim - . . . . . . .

16. „ Harzgerode, Pansfelde, Leimbach, Schwenda, Wippra, Mansfeld . . . . . . . . . .

17. »Roda, Gangloff, Neustadt, Triptis, Pörmitz, Zeulenroda

18. » Gerbstedt, Cönnern, Eisleben, Wettin . . . .

19. „ Riestedt, Schraplau, Teutschenthal, Ziegeiroda, Querfurt, Schafstädt, Wiehe, Bibra, Freiburg . . .

》 20. $\gg+$ Teltow, Tempelhof, *Gr.-Beeren, *Lichtenrade, Trebbin, Zossen (darunter * mit Bohrkarte und 1 Heft Bohrtabelle) . . . . . . . . . . . .

„21. „Rödelheim, Frankfurt a. M., Schwanheim, Sachsenhausen. . . . . . . . .

22. " + Ketzin, Fahrland, Werder, Potsdam, Beelitz, Wildenbruch

24. 》. Tennstedt, Gebesee, Gräfen-Tonna, Andisleben .

25. 》 Mühlhausen, Körner, Ebeleben

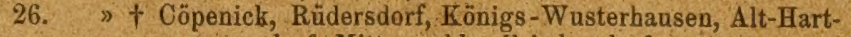
mannsdorf, Mittenwalde, Friedersdorf : . * $12-$

27. „ Gieboldehausen, Lauterberg, Duderstadt, Gerode -

28. „ Osthausen, Kranichfeld, Blankenhain, Cahla, Rudolstadt, Orlamünde - • • : * • • .

ఎ29. " + Wandlitz, Biesenthal, Grünthal, Schönerlinde, Bernau, Werneuchen, Berlin, Friedrichsfelde, AIt-Landsberg, sãmmtlich mit Bohrkarte und Bohrregister 


\section{Abhandlungen}

zur

\section{geologischen Specialkarte \\ von}

\section{Preussen}

und

\section{den 'Thüringischen Staaten.}

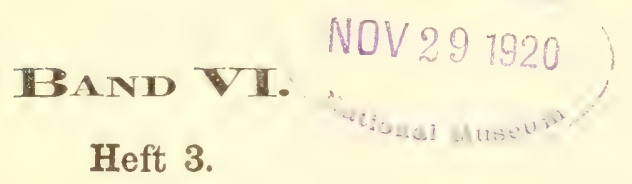

B E R L I N.

In Commission bei der Simon Schropp'schen Hof-Landkartenhandlung.

(J. H. Neumann.)

1885 . 



\section{Die Fauna \\ des}

samländischen 'Tertiäs

Y(1)1

\section{Dr. Fritz Noetling,}

Privatdocent an der Universitït Königsterg i. Pr.

I. 'Theil.

Lieferung I: Vertebrata.

Lieferung II: Crustacea und Vermes.

Lieferung VI: Echinodermata.

Nebst Tafelerklärungen und zwei Texttafeln.

Herausgegeben

von

dep Käniglich Prenssischen geologischen Landesanstalt.

Hierzu ein Atlas mit 27 Tafeln.

B E R L IN.

In Commission bei der Simon Schropp'schen Hof-Landkartenhaudlung.

(J. H. Neumanx.)

1885. 



\section{Vorbemerkung.}

Die geognostischen Verhältnisse des ostpreussischen, speciell samländischen Tertiärs sind seiner Zeit eingehend von ZADDACI dargelegt worden, jedoch fehlte eine Monographie der Fauna bis jetzt. Die Fossilien finden sich in der Bernsteinformation in einer der Bernstein-führenden Lage benachbarten Schicht. Es ist das grosse Verdienst des verstorbenen Prof'essor ZADDACH gewesen, eine umfangreiche Sammlung dieser Versteinerungen, welche sich jetzt im Mineralogisehen Museum der Universitï Kö̈nigsberg befindet, zusammengebracht zu haben. Der ehrenvolle Auftrag, eine Bearbeitung dieser Fauna vorzunehmen, wurde mir durch den bisherigen Director des Museums, Herrn Professor Dr. M. Bauer (jetzt in Marburg), zu Theil. - Der grosse Umfang des Materials liess es räthlich erscheinen, die einzelnen Thierklassen gesondert für sich zu betrachten, so dass die Darstellung einer jeden eine in sich abgeschlossene Lieferung bildet, aber alle zu einem Ganzen verbunden ein rollständiges Bild dieser eigenartigen Fauna geben. Das ganze Werk zerfällt mithin in sechs Lieferungen, und zwar Lieferung I: Vertebrata, Lieferung II: Crustacea und Vermes, Lieferung III: Gastropoda, Lieferung IV: Pelecypoda, Lieferung V: Bryozoa, Lieferung VI: Echinodermata. Von diesen Lieferungen erscheint hiermit der erste Theil, nämlich die Lie- 
ferungen I, II und VI, während der zweite Theil, nämlich die Lieferungen III, IV und $V$, mit der am Schluss zu gebenden Darstellung der aus der Untersuchung dieser Fauna erfolgenden paläontologischen und geoguostischen Resultate im nächsten Jahr veröffentlicht werden wird.

Königsberg, im März 1885.

Fritz Noetling. 


\section{In halt.}

Aétobates Dixoni . . . . . . . . . . . . . . 24 [294]

irregularis . . . . . . . . . . . . . . 27 [थ97]

sp. . . . . . . . . . . . . 29 [299]

Alopias Hlassei . . . . . . . . . . . . . . . . 75 [345]

ef. Hisssei . . . . . . . . . . . . 78 [348]

Astrape (?) media . . . . . . . . . . . . . . . . . . 36 [306]

Balanus unguiformis . . . . . . . . . . . . . . 111 [381]

Bateria . . . . . . . . . . . . . . . . . . . 184 [454]

» Agassizii . . . . . . . . . . . . . . . . 185 [455]

"geometrica . . . . . . . . . . . . . . 186 [456]

Calappilia . . . . . . . . . . . . . . . . . . 122 [392]

$\gg$ perlata . . . . . . . . . . . . . . . . . . 125 [395]

Carcharodon angustidens . . . . . . . . . . . . . . 82 [352]

" obliquus. . . . . . . . . . . . . . . . . 84 [354]

sp.

balticum . . . . . . . . . . . . . . . . . . 148 [418]

Credneri . . . . . . . . . . . . . . 146 [416]

granulosum . . . . . . . . . . . . . . . . . 145 [415]

Reidemeisteri . . . . . . . . . . . . . 145 [415]

taunicum . . . . . . . . . . . . . . . . . . 146 [416]

vigil . . . . . . . . . . . . . . . . . . 145 [415]

Coelopleurus Zaddachi . . . . . . . . . . . . . . . . . . 181 [451]

Crenaster poritoides . . . . . . . . . . . . . 215 [485]

Crocodilus sp. . . . . . . . . . . . . . . 107 [377]

Ditrupa strangulata . . . . . . . . . . . . . 176 [446]

Dromilites suceini . . . . . . . . . . . . . . . 162 [432]

Echinarachnins . . . . . . . . . . . . . 197 [467]

germanicus . . . . . . . . . . . . . . . 200 [470]

Echinocyamus piriformis . . . . . . . . . . . . 190 [460]

Echinolampas subsimilis . . . . . . . . . . . . 203 [473]

Edaphodon Bucklandi . . . . . . . . . . . . . . . 3 [273]

Elasmodus Hunteri . . . . . . . . . . . . . . . . . 11 [281]

Galeocerdo dubius . . . . . . . . . . . . . . . 97 [367]

sp. . . . . . . . . . . . . . . . . . . . 99 [369] 
Hoploparia Klebsii

Seite:

Ilia

$166 \quad[436]$

» corrodita

$130 \quad[400]$

Laevipatagus .

132 [402]

$211 \quad$ [481]

$$
\gg \text { bigiblus }
$$

Lambrus Bittneri

Lamna elegans

61 [331]

69 [339]

Lenita

$193 \quad$ [463]

3) patc

193 [463]

Maretia Grignonensis . . . . . . . . . . . . . 209 [479]

$\gg$ Sambiensis . . . . . . . . . . . . . . . 207 [477]

Micromaja .

$112[382]$

spinosa . . . . . . . . . . . . . . . . 113 [383]

Myliobates toliapiens . . . . . . . . . . . . . . 19 [289]

sp., ef. toliapicus (Flossenstachel) . . . . . . . . 22 [292]

$\gg$ 》 $\gg($ Wirbel) . . . . . . . . . 23 [293]

Noticlanus primigenius . . . . . . . . . . . . . 17 [287]

Notidanidae . . . . . . . . . . . . . . . . . 16 [2S6]

Odontaspis Hopei . . . . . . . . . . . . . . . . . . 71 [341]

Oxyrhina sp. . . . . . . . . . . . . . . . 57 [327]

» xiplodon . . . . . . . . . . . 50 [320]

Pagurus Damesii . . . . . . . . . . . . . . . . 164 [431]

Psammocarcinus . . . . . . . . . . . . . $136[406]$

$\gg$ laeris . . . . . . . . . . . . . . 141 [411]

$\gg$ multispinatus . . . . . . . . . . 138 [408]

Psendosphaerodon . . . . . . . . . . . . . . . . . . 102 [372]

$104[374]$

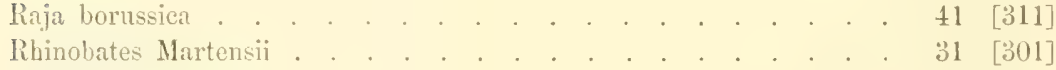

Salenia Pellati . . . . . . . . . . . . . . . . 189 [459]

Schizaster acuminatus . . . . . . . . . . . . . . . 204 [474]

Seutellina Michelini . . . . . . . . . . . . . . . . 195 [465]

Scyllium Hanchecornei . . . . . . . . . . . . . . . . 93 [363]

$»$ sp., ef. Hauchecornei . . . . . . . . . . . . . 96 [366]

Selache glauconitica . . . . . . . . . . . . . . . . . 49 [319]

Serpula exigua . . . . . . . . . . . . . . . . . . . 174 [444]

» tlagelliformis . . . . . . . . . . . . . . . . . 173 [443]

$\gg$ leptagona . . . . . . . . . . . . . . 175 [445]

Spinax sp. . . . . . . . . . . . . . . . . 19 [289]

Squatina Berrichi . . . . . . . . . . . . . . 45 [315]

Uroloplus (\%) bicuneatus . . . . . . . . . . . . . . . : 34 [304] 
Lieferung I.

\section{Vertebrata.}

Taf. I-XI. 



\title{
$\mathrm{P}$ is c e s.
}

\section{Holocephali.}

\section{Edaphodon Bucklandi Agassiz.}

\author{
T:at. I, Fïg. 1 a, 1 h, 1 ,
}

1843. Edaphodon Bucklandi Agassiz, Recherches sur les poissons fossiles Bd. III, pag. 351, tab. $40 \mathrm{~d}$, fig. 2 t (typus) non fig. $9-12$.

1850. Edaphodon Bucklendi Dixos, Geology and Fossils of the tertiary and cretaceous Formations of Sussex tab. 10, fig. 20 (ohne Beschreibung).

Das Fragment einer rechten Postdentalplatte ${ }^{1}$ ) von etwa $30^{\mathrm{mm}}$ Länge und nahezu gleicher Breite, $28,5^{\mathrm{mm}}$, lïsst sich trotz seiner

1) Tch kann Newtos (Monograph of the Chimaeroid fishes ete. Momoirs of the Geological Survey. Monogr. IV, London 1878, pag. 4) nicht beipflichten, wenn er die auf uns überkommenen Reste des Gehisses fossiler Holocephalen als Ober-, Unter- und Zwischenkiefer hezeichnet. Dass dieselben keineswegs den Kieferknochen homolog sind, was ïberdies ja auch NEwTos selbst zugiebt, davon konnte ich mich durch das Studium des Gebisses ron Chimaera monstrosa überzengen. Diese unter obiger Benennung (Agassiz spricht ebenfalls von maxillaires supérieures etc.) gehenden Kanwerkzenge waren, wie das Gebiss von Chimcerc lehrt, ganz analog wie die Zähne aller anderen Selachier zu Lebzeiten des Thieres vermittelst einer zähen Membran auf dem Kiefer befestigt, von welchem sie sich nach dem Tode des Thieres leicht ablösen konnten. Sie bilden also keinen integrirenden Bestandtheil der Kiefer, mithin kann ihnen eine solche Bezeichnung auch nicht zulsommen, und es empfiehlt sich, dieselbe fallen zu lassen, da sie nur zu leicht Veranlassung zil Irrthämern werden kann. Es dürfte wohl kaum bestritten werden, dass diesen sogenannten Kieferknochen die Funetion des Zerkleinerns der Nahrung obliegt, sie mithin den Dienst von Zühnen versehen; da aber, ihrer augenschoinlich zusammengesetzten Beschaffenheit wegen, die einfache Becennung "Zahı« nicht passend erscheint, so möchte ich die Bezeichnung 》Dentalplatte« für diese Kauapparate vorschlagev. Diese Benennung hat jedenfalls den Vorzug, dass sie ron der Function, welcher das fragliche Organ dient, bergeleitet ist, also irgend welchen Irrthum zu erregen nicht im Stande ist. Nach meinem persönlichen Dafürhalten sind die Dentalplatten der Holoce- 
Kleinheit sehr gut auf diese Art beziehen. Wenn auch die Form ${ }^{1}$ ) derselben nicht mehr erkennbar ist, so sieht man doch (Taf. I, Fig. 1), dass dieselbe sich nach vorn beträchtlich verschmälerte. Der Symphysialrand läuft in gerader Richtung von hinten nach vorn, dabei fällt die glatte Symphysial- oder Innenseite senkrecht nach unten ab. Der Aussenrand (Oralrand NEwTON's) läuft in gerader, aber schräg nach Innen gerichteter Linie, während die glatte, oder doch uur schwach grestrcifte Aussen-(Oral-) seite schrïg nach unten gerichtet abfüllt. Die Dicke des Fragmentes ist nicht unbedeutend, sie beträgt an der hinteren Bruchfläche unter dem hinteren Innenzahne (Taf. I, Fig. 1b) insgesammt $18^{\mathrm{mm}}$, wovon 5 auf die Dicke des Zahnes, 13 auf die Dicke der Knochensubstanz kommen. Am vorderen Bruchrande (Fig. 1a) ist die Dicke jedoch bedeutend geringer, hier betrïgt sie mit Einschluss des $3^{\mathrm{mm}}$ dicken vorderen Innenzahnes nur noch $12^{\mathrm{mm}}$.

Die drei für Edaphodon charakteristischen plattenförmigen Zähne sind sämmtlich, wenn anch nur als mehr oder minder grosse Bruchstücke erhalten. Sie bestehen aus compacter Zahnsubstanz (bei dem vorliegenden Stïcke von lichtbräunlicher bis weisser Farbe), welche von zahlreichen, unter sich parallelen Verticalkanälchen durchsetzt wird, deren Mündungen auf der Kaufläche in Form kleiner Vertiefungen von rundlichem oder länglich ovalem Umriss erscheinen. Zuweilen, namentlich auf den hinteren

phalen den Zähnen der anderen Selachier homotog, aber als ein Zahneomplex zu denten, der dadurch entstanden ist, dass die Wurzeln ursprünglich vorhandener Einzelzähne so innig mit einander verschmolzen, dass sie ein homogenes Ganze von knochenartiger Beschaffenheit bilden, in welchem die emailbedeckte Krone eingebettet liegt, resp. aus welchem sie hervorragt. Da das Gebiss wohl aller Holocephalen sich aus sechs einzelnen solcher Dentalplatten, wovon vier im Oberkiefer and zwei im Unterkiefer liegen, zusammensetzt, so spreche ich von einer reehten und einer linken Dentalplatte des Unterkiefers; beim Oberkiefer nenne ich die beiden vorderen Prädentalplatten, die beiden hinteren Postdentalplatten und unterseheide wieder zwischen rochts- und linksseitigen. Zur besseren Erlïuterung gebe ich eine Skizze des Gebisses ron Chimaera mediterranea mit den eingeschriebenen Bezeichnungen. (Vergl, die zusammengehörenden Figuren 1 u. 1 a der Texttafel I. Der Unterkiefer ist nach oben gekehrt, wodurch das Rechts und Links besser hervortritt.)

1) In der Abbildung ist der Umriss des besseren Verständnisses halber punktirt ergünzt. 
Partieen der Zahnplatte, verfliessen mehrere benachbarte Grübchen miteinander, so dass kurze, wellige Furchen entstehen, die jedoch anscheinend nur in der Quer-, niemals in der Längsrichtung sich ausbilden.

Auf den vorderen Partieen sind die Grübchen jedoch allseitig durch breite Zwischenräume fester Zahnmasse geschieden. Die Kanfliche der Zühne zeigt daher jene charakteristische chagrinartige Beschaffenheit, an welcher auch lose Zahnfragmente leicht kenntlich sind. Bei meinem Exemplar sind die Verticalkanälchen mit einer schwärzlichen Substanz erfüllt, die zuweilen, namentlich gegen die Basis des Zahnes hin, ausgewittert ist. Auf den Bruchflächen tritt daher durch den Gegensatz der lichten Zahnsubstanz und der dunklen Ausfüllungsmasse der Kanälchen die innere Structur der Zähne sehr dentlich hervor. Bemerkenswerth erscheint es, dass die Verticalkanälchen fast die ganze Dicke der Zähne durchsetzen, und nur am hinteren Innenzahne lässt sich ganz an der Basis desselben (Taf. I, Fig. 1 b) eine schmale Zone erkennen, in welcher die Kanälchen horizontal gerichtet sind.

Vom vorderen Innenzahne (a) ist nur der hintere Theil auf eine Länge von $11^{\mathrm{mm}}$ bei einer Breite von $9^{\mathrm{mm}}$ erhalten, wobei seine Dicke (an der vorderen Bruchfläche gemessen) $3^{\text {mm }}$ beträigt. Der Zahn selbst liegt etwas vom Symphysialrand abgerückt und besitzt einen geraden, jenem nahezu parallel laufenden Innen- resp. Aussenrand. Der Hinterrand, d. h. diejenige Linie, in welcher die Knochensubstanz der Dentalplatte gegen den Zahn abschneidet, bildet eine fast gerade, sehr schwach nach vorn convexe Linie. Am vorderen Ende ist die Kaufläche schwach gewölbt, nach hinten plattet sie sich etwas $a b$, indem sie sich gleichzeitig etwas nach Innen neigt.

Wahrscheinlich ist jedoch dieser im Gebrauch befindliche, frei aus dem Knochen hervorragende Zahn nur die vordere Partie eines mit dem grösseren hinteren Theil in der Knochensubstanz steckenden Zahnes. Man sieht nämlich (Taf. $1 \mathrm{c}$ und 1b) an der hinteren Bruchfläche, genau in der Fortsetzung des 'Zalumes (a), nach hinten unter dem hinteren Innenzahn (b) den Querschnitt eines allseitig von Knochensubstanz umhüllten Zahnes ( $\left.b^{\prime}\right)$, der in seiner 
Breite und der Wölbung seiner einstigen Kaufläche so genau mit dem vorleren Innenzathn übereinstimmt, dass ich nicht zweifle, dass wir in diesem Zathnquerschnitt die Fortsetzung dieses, und nicht etwa sinen licservezahn für den dirüber befindliche'n hinteren Innenzahn zu erhlicken hahen; gegen letztere Annahmespräche die hedeutend geringere Breite des muthmaasslichen Ersatzzahnes. Der stricte Beweis der Zusammengehörigkeit des Zahmuerschnittes mit dem Zahne a wird jedoch nur nach der Entfernung der darüber befindlichen Knochensubstanz nebst hinterem Inuenzahn zu führen sein, da man dann wird entscheiden können, ob beide zusammenhängen oder nicht; allein diesen Beweis kann ich an dem einzigen mir zu Gebote stehenden Exemplar nicht führen.

Wäre aber meine Annahme gerechtfertigt, und ich habe vorläufig keinen Grund daran zu zweifeln, so erreichte der Zahn a mit Hinzurechnumg des Fohlenden mindestens die Iänge von 30"m, wovon allerdings beinahe zwei Drittel im Knochen stecken. Dabei wäre dann der Zahn in seiner Längsrichtung sehr stark von vorn nach hinten geneigt.

Dicht hinter dem soeben beschriebenen Zahne, und zwar hart am Symphysialramde liegend, befindet sich der hintere Imnenzahn (b), von welchem der vordere Theil auf etwa $12^{\mathrm{mm}}$ Länge erhalten ist; am hinteren Bruchrande beträgt die Breite etwas mehr als $12^{\mathrm{mm}}$. Seine grösste Dicke nahe dem Symphysialrande heträgt $5^{\text {mm }}$, doch nimmt dieselbe in Folge der Neigung der Kaufläche nach innen allmählich bis zu 2.mm at). Sellostrerständlich lässt sich auch hier der thatsächliche Unmiss des Zalmes nur durch Combination ergänzen. Man sieht, dass der Aussenrand in ziemlich gerader Richtung verläuft, während der Vorderrand sehr schräg nach hinten gerichtet ist und kurz, bevor er in einer abgerundeten, stumpfwinkeligen Ecke mit dem Innenrand zusammenstösst, eine ziemlich starke Einbuchtung erleidet. Daher nimmt der vorn nicht sehr breite und stumpf gerundete Zahn nach hinten schnell an Breite zu, und in Folge der Buchtung des Vorderrandes kann man bei ihm eine schmale vordere Partie, welche zugleich flach gewölbt ist, von einer breiteren, hinteren, abgeplatteten Partie unterscheiden. Die Abplattung rührt auch hier wie vorher von der leichten Neigung 
der Kaufläche nach Innen her. Betrachtet man die Dentalplatte im Profil etwa von der Symphysialseite her (Taf. I, Fig. 1c), so sieht man, dass vom vorderen zum hinteren Innenzahme die Dicke der Knochensubstanz schnell und in ziemlich bedentendem Maasse wächst. Dadurch kommt die Kaufläche von b beträchtlich höher zu liegen als diejenige von a, und zwischen beiden bildet sich ein steiler, treppenartiger Absturz der Knochenmasse aus.

Eine anfangs tiefe, später flach vorwärts geneigte Längseinsenkung der Knochensubstanz trenut die beiden Innenzähne vom Aussenzahn c (Taf. I, Fig. 1, la u. 1b). Dieser, der eine ziemlich schmale Kaufläche frei aus der Knochenmasse herausragen lässt, ist auf eine Länge von etwa $20^{\mathrm{mm}}$ erhalten. Sein Aussenrand ist leicht concav, der Innenrand beinahe gerade; letzterer bildet mit dem gleichfalls geraden, aber schrïg nach aussen laufenden Hinterrand einen flach gekrümmten Bogen. Dadurch erscheint es, als ob der am vorderen Ende sehr schmale Zahn zunächst rückwärts an Breite zunimmt, sodann aber und zwar ziemlich schnell sich wieder verschmälert. Betrachtet man jedoch das Stück von der rückseitigen Bruchfläche, so sieht man, dass diese Verschmälerung nur eine scheinbare ist, und dass im Gegentheil die Breite rückwärts zunimmt, nur dass der 'Lahn zum grösseren Theil in der Knochenmasse verborgen liegt. Charakteristisch für den Aussenzahn (c) ist die starke Neigung der abgeplatteten Kaufläche nach Innen, von welcher nur die vorderste flach gewölbte Spitze ausgenommen ist.

Vorkommen: In England in den Bagshot- und BrackleshamSands, im Samlande sehr selten in der Zone $\mathbf{A}_{1}$.

Bemerkungen: Es existiren von Edaphodon Bucklandi wohl mehrere vorzügliche Abbildungen, aber, "so weit mir bekannt, keine genauen Beschreibungen derselben. AGsissiz hat die Art aufgestellt und eine Reihe Abbildungen der Postdentalplatten nebst den muthmaasslich hierzu gehörigen Prädental- und Dentalplatten gegeben. Welche Gründe AGAssiz veranlasst haben, diese verschiedenen Reste unter einem gemeinsamen Namen zusammenzufassen, ist Mangels einer ausführlichen Beschreibung nicht zu ermitteln. An sich ist ja die Wahrscheinlichkeit, dass die verschiedenen Dental- 
platten einer Species angehören, sehr gross; der stricte Beweis wird aber doch nur dann geführt werden können, wenn einmal ein ganzes zusammengehöriges Gebiss gefunden wird.

Drxon giebt ebenfalls eine vorzügliche Abbildung einer Postdentalplatte unserer Art, gleichfalls aher ohne Beschreibung, und wahrscheinlich gehört E(iErTox: ${ }^{1}$ ) fig. 2 (eine Postdentalplatte, leider ohne specifische Bestimmung) hierher.

Unser Fragment entspricht in Grösse und Form am besten Dixon's fig. 20; auch Agassiz's fig. 24 zeigt eine sehr gute Uebereinstimmung in Bezug auf Gestalt und Lage der Zähne, jedoch scheint das betreffende Exemplar einem bedeutend grösseren Individuum angehört zu haben, als es Drxon's oder das samländische waren. Auffällig ist die grosse Differenz in der Form der Postdentalplatte, welche zwischen Inox's und Eerertox's Abbildungen einerseits und Agassiz's fig. 24 andererseits existirt.

Bei Letzterem besitzt dieselbe einen unregelmässig vierseitigen Umriss, d. h. sie ist an ihrem vorderen Ende nur um Geringes schmäler als am hinteren; bei Dixon und EGErTon zeigt sie jedoch die Gestalt eines nahezu rechtwinkeligen Dreiecks, d. h. von beträchtlicher Breite hinten, verschmälert sie sich nach vorn und endet in einer Spitze. Die Abbildungen der beiden letzteren Autoren dürfen wohl einen grösseren Anspruch auf Richtigkeit in der Wiedergabe des Umrisses erheben, da sie denselben vollständig gleich darstellen, als AGAssiz's, und es scheint daher die Annahme begründet, dass die Postdentalplatte, welche Agassiz's fig. 24 zu Grunde lag, irgendwie beschädigt war, und zwar war jedenfalls das vordere Ende abgebrochen.

Betrachtet man nümlich die Abbildungen, welche Newton ${ }^{2}$ ) von verschiedenen cretaceischen Species gegeben hat, so sieht man, dass die rechtwinkelig dreieckige Form mit mehr oder minder gerundeter Spitze für die Postdentalplatte von Edaphodon die Regel ist. Man sieht ferner sowohl bei Newron z. B. tab. 1, fig. 4 oder

1) Egerton, On the Nomenclature of the fossil Chimaeroid fishes. Quarterly Journ. of Geol. Soc. 1847, Bd. 3, pag. 350, tab. 13, fig. 2.

2) The Chimaeroid fishes of the British Cretaceous rocks. Memoirs of the Gcological Survey of the U. Kingdom. Monograph N. IV. 1878. 
tab. 6, fig. 2, als bei Drxon's und Egerton's Abbildungen, dass die Spitze des vorderen Innenzahnes stets in ziemlicher Entfernung ron der Kieferspitze ist, dass also vor derselben ein beträchtliches Stück Knochen liegt.

Bei Agassiz dagegen liegt die Spitze des vorderen Innenzahnes fast dicht am vorderen Ende des Kiefers; es entbehrt diese Abbildung demnach eines sicheren generischen Merkmales; da aber auf Grund der Zühne AGAssiz's fig. 24 ganz unzweifelhaft zu Edaphodon gehört, so lag derselben wohl nur ein grösseres Fragment einer Postdentalplatte zu Grunde, deren Umriss demnach im Sinne von Drxox's und EGERTon's Abbildungen zu ergänzen ist.

Ist somit die Ursache in der Differenz des Umrisses ergründet, so bleibt nur noch die Form der einzelnen Zähne der beiden Abbildungen zu vergleichen, und hierin vermag ich keinen Unterschied zu erkennen, es sei demn, dass bei Dixon der vordere Innenzahn etwas spitzer zuläuft als bei AGAssiz; bei letzterem ist jedoch die Möglichkeit nicht ausgeschlossen, dass auch der vordere Innenzahn an seiner Spitze etwas verletzt ist.

Da aber unser samländisches Exemplar auch nur fragmentarisch ist, so ist es auf seine Verwandtschaft mit den beiden anderen tertiären Species E. leptognathus AGAss. und $\boldsymbol{E}$. eurygnathus Drx. zu untersuchen, und festzustellen, ob ein solches Bruchstück genügt, die Art sicher bestimmen zu lassen.

E. Teptognathus unterscheidet sich, wie ein Vergleich der beiden nebeneinanderstehenden Figuren 18 und 24 bei Agassiz lehrt, zunächst durch die grössere Schmalheit der Innenzähne, die bei E. Bucklandi eine mehr in die Breite gedehnte Gestalt besitzen. Ausserdem aber, und dies scheint mir das wesentlichste Unterscheidungsmerkmal zu sein, ist die Gestalt des vorderen Innenzahnes bei beiden Species eine durchaus verschiedene. Bei E. Bucklandi besitzt er einen nahezu rechtwinkelig dreieckigen Umriss, wobei der Hinterrand eine fast vollkommen gerade oder nur wenig gebuchtete Iinie bildet. Bei E. leptognathus ist jedoch nicht nur der Hinterrand tief ausgeschnitten, sondern der Zahn verlängert sich an seiner innern Ecke in eine schmale Spitze, die um den vorderen Theil des hinteren Innenzahnes vollständig herumgreitt. 
Es genügt also der hintere Theil des vorderen Innenzahnes fast ausschliesslich, um E. Bucklandi von E. leptognathus selbst in kleinen Bruchstücken unterscheiden zu können.

E. Bucklandi und E. Teptognathus, die beide in derselben Schicht vorkommen, zeigen, abgesehen von dem Unterschiede in der Form des vorderen Innenzahnes, dennoch eine so grosse Aehnlichkeit, dass ich die Frage in Erwägung zog, ob nicht beide zu vereinigen seien. Der Hinterrand der Zühne ist ja nur ein scheinbarer, bedingt durch das Hervorschieben der Zahnplatte aus dem Kieferknochen. Es könnte nun leicht möglich sein, dass die eigenartige Form des vorderen Innenzahnes von E. leptognathus nur eine individuelle Erscheinung ist, hervorgerufen vielleicht durch einen steileren Absturz des Kieferknochens. Betrachtet man auch Dixon's, Egerton's, Agassiz's und meine Abbildung von E. Bucklandi genauer, so sieht man, dass bei allen diesen eine zipfelartige Verlängerung der Innenecke, wenn auch nur selır schwach, angedeutet ist; am schärfsten ist sie noch bei AGassiz's fig. 24 ausgesprochen. Sollte es sich durch spätere Untersuchung, z. B. dadurch, dass man allmähliche Uebergänge zwischen beiden Typen auffände, bestätigen, dass die Form des vorderen Innenzahnes bei $E$. leptognathus nur auf individueller Wachsthumserscheinung beruhe, so wäre diese Art allerdings einzuziehen. Da ich aber diese Frage nicht entscheiden kann, so muss ich die Selbständigkeit von Agassiz's E. leptognathus vorläufig noch für erwiesen annehmen und mich damit begnügen, auf die Analogieen mit E. Bucklandi hinzuweisen.

E. eurygnathus unterscheidet sich von beiden erstgenannten sofort dadurch, dass dem hinteren Innenzahne die für jene beiden so charakteristische plötzliche Verbreiterung rückwärts fehlt; derselbe zeigt bei Dixon eine mehr länglichovale Gestalt, ja er scheint sogar nach hinten zu an Breite abzunehmen. Demnach ist auch hier die Unterscheidung beider Arten leicht. Da also unser Fragment weder einen rückwärts in eine Spitze verlängerten Innenzahn besitzt, noch der hintere Innenzahn sich rückwärts verschmälert, vielmehr eine plötzliche Breitenzunahme zeigt, so scheint mir auch die specifische Stellung desselben hinlünglich begründet. 


\section{Elasmodus Hunteri Owen sp.}

Taf. 1, Fig. $2-2$ b, Fig. $3-3$ b; Taf. II, Fig. $6-6$ b.

1452. Elasmodus Hunteri Egrntox, Memoirs of the Geolog. Survey of the United Kingdom. Decade VI, pag. 1, tab. 1, fig. 1-10.

Sofern die sämmtlichen, auf diese Form bezogenen Reste in der That zu einander gehören, hat unser samländisches Tertiär die sämmtlichen Theile eines Gebisses, nänlich drei rechte Dentalplatten, eine linke Prädental- und eine rechte Postdentalplatte geliefert; die beiden letzteren, sowie zwei Exemplare der ersteren sind ausgezeichnet erhalten, eines dagegen sehr stark abgerollt.

(c) Dentalplatte (Taf. I, Fig. 3, 3a u. 3b).

Die Dentalplatte besitzt die Gestalt eines stumpfwinkeligen Dreiecks, dessen Basis durch den Hinterrand, die beiden Seiten durch den Vorder- resp. Symphysialrand gebildet werden. Der Hinterrand, der eine ziemlich gerade Linie bildet, misst $43^{\mathrm{mm}}$ Lünge; der leicht gekrümmte Symphysialrand ist $36^{\mathrm{mm}} \mathrm{lang}$, doch dürfte er etwas länger gewesen sein, da man deutlich sieht, dass die Dentalplatten an der Innenseite vorn in eine Spitze ausliefen, die aber bei allen Exemplaren weggebrochen ist. Der Vorderrand bildet eine schräg nach hinten gerichtete, vielfach ausgeschnittene Linie und ist im Gegensatz zu den andern Rändern scharf und schneidend. Seine Gesammtlänge mag etwas mehr als $53^{\mathrm{mm}}$ betragen haben.

Die Dicke der Knochensubstanz ist nur gering; ihre grösste Stärke unter dem medianen Hauptzahn beträgt $8^{\mathrm{mm}}$; sowohl nach aussen als nach innen von diesem ist sie beträchtlich schwächer, und zwischen Median- und Symphysenzahn besitzt sie nur etwa $4-5^{\mathrm{mm}}$ Stärke. Während die Knochensubstanz am Vorderrande ein dichtes und festes Gefüge zeigt, wird sie rückwärts allmählich etwas lockerer. Die Unterseite der Dentalplatte ist vollkommen flach, selbst etwas concav, die Oberseite ziemlich unregelmässig gewölbt.

Die Zähne sind ihrer Structur nach von zweierlei Art: solche die aus compacter und solche die aus lamellös geschichteter Zahn- 
substanz bestehen. Von ersterer Art ist nur ein einziger, der mediane oder Hauptzahn (a) vorhanden, dagegen gehören sämmtliche seitwärts von demselben gelegenen Zähne, deren Zahl 10 beträgt, zur zweiten Art.

Der Haupt- oder Medianzahn liegt etwa in der Mitte der Dentalplatte, schrïg von hinten und aussen nach vorn und innen gerichtet. Er stellt sich im Grossen und Ganzen als eine etwa $12-13^{m m}$ breite Platte von geringer Dicke, mit parallelem Aussenund Innenrande dar, welche vom Hinter- bis zum Vorderrande reicht. Der grössere, etwa $24^{\mathrm{mm}}$ lange hintere Theil ragt mit seiner gesammten flach gewölbten Kaufläche frei aus der Knochensubstanz hervor; der vordere ca. 12 $2^{\mathrm{mm}}$ lange Theil dreht seine Kaufläche dermaassen von aussen nach innen und unten, dass nicht mehr diese, sondern sein Vorderrand nach oben gekehrt ist. Der Zahn besteht wie bei Edaphodon aus festem Dentin von grauer oder bräunlicher Farbe, das von zablreichen Verticalkanälchen durchsetzt wird, die auf der Oberfläche münden und dadurch die chagrinartige Sculptur erzeugen.

Vom Medianzahn durch eine flache, breite Einsenkung der Knochensubstanz geschieden liegr am Symphysialrande der eigenthümlich gebante Symphysenzahn c, zwischen beiden die drei inneren Seitenzähne b, zu welchen sich noch etwa sechs Seitenzähne, nach Aussen vom Medianzahn gelegen, gesellen. Alle diese 'Zähne besitzen die gemeinsame Eigenthümlichkeit, dass sie aus zahlreichen dünnen Lamellen von Dentin, die durch zwischengelagerte Knochensulstanz geschieden werden, zusammengesetzt sind. Am Dentlichsten zeigt die Unterseite des Symphysenzahnes (Tat. I, Fig. 3b) diese Structur; das noch erhaltene Stück desselben besteht aus ca. 28-30 Einzellamellen von etwa $0,75^{\mathrm{mm}}$ Dicke, aber beträchtlicher Länge, etwa $14-15^{\mathrm{mm}}$, von welcher jedoch nur ein sehr geringer Theil anf der Oberseite (c in Fig. 3) sichtbar ist. Die Lamellen sind sehr (iigenartig gekrimmt: die hinteren sind rerzerrt Z-förmigr gebogren, der untere $\Lambda$ st übertriftit den oberen bedeutend an Länge und wendet sich sehr schräg nach hinten; nach vorn zu reducirt sich die Länge des oberen Astes immer mehr, so dass die vorderen Lamellen nur einfach stumpfwinkelig greknickt sind. 
Die zwischen Symphysen- und Medianzahn, sowie die ausserhalb des letzteren gelegenen Seitenzähne bauen sich aus weit kürzeren, aber breiteren Lamellen auf.

Auf der Oberseite ist vom Symphysen- wie von den Seitenzähnen nur wenis zu sehen: von ersterem nur die am Rand gelegenen oberen Theile der Einzellamellen, von letzteren nur die nach aussen vom Medianzahn gelergenen Zähnchen, welche meisselartig am Vorderrande vorspringen.

Bemerkenswerth erscheint die flache Aushöhlung des Kieferknochens am Vorderrande zwischen Median- und Symphysenzahn.

B) Postdentalplatte (Taf. I, Fig. 2, 2a, 2b).

Die Postdentalplatte gleicht in auffallender Weise den Dentalplatten von Edaphodon; sie stellt sich als ein ca. $50^{\mathrm{mm}}$ langer, schnabelförmig gekrümmter Knochen dar, dessen Kaufläche drei Zähne trägt, deren Zahl somit den Unterschied von genanntem Genus sofort beweist. Hinten besityt die Postdentalplatte eine beträchtliche Dicke, etwa $26^{\mathrm{mm}}$, nach vorn nimmt dieselbe jedoch rasch $a b$ und endigt in einer kurzen, meisselförmigen Schneide. Die flache Aussenseite ist ziemlich hoch (Fig. 2 b u. 2a) und fällt fast senkrecht, oben etwas übergeneigt, nach unten. Mit der schmalen, nach oben und hinten laufenden und dabei schräg nach aussen abfallenden Lnterseite (Fig. 2 at) stïsst jene in stumpf-gerundeter Kante zusammen. Der vordere Theil der Unterseite ist auf eine Länge von etwa $12^{\mathrm{mm}}$ flach, der hintere aber durch eine breite und tiefe Längsfurche ausuehöhlt. I) ie Innen- oder Symphysenfläche (Fig. 2) besitzt geringere Ilöhe als die Aussenflïche, hinten fällt sie in ihrer (iesammthöhe senkrecht nach unten, gegen die Spitze hin neigt sich jedoch der obere Theil schräg nach innen und oben, unter Bildung einer wenig markirten Kante. Daher sind die Spitzen der beiden Postdentalplatten genau wie bei Chimaera durch einen rückwärts sich verengenden Spalt getrennt, und erst im hinteren Theil stossen die Postdentalplatten fest aneinander. Mit der Unterseite bildet die Innenseite eine schiefe Kante.

Der Aussenrand ist in der Mitte schwach concav, steigt aber anch vorn etwas stïrker als nach hinten in die Höhe; der durch 
das Zusammenstossen der Innen- und Unterseite gebildete Vorderrand ist kurz und scharf.

Die Oberseite (Fig. 2) trägt drei Zähne verschiedener Structur, zwei davon, der mittlere oder Median- und der Symphysenzahn, bestehen aus compacter Zahnmasse, der dritte, der Aussenzahu, aus lamellös geschichteter Zahnsubstanz.

Letzterer (a) besitzt eine beträchtliche Länge, denn er reicht lïngs des Aussenrandes von der Spitze der Dentalplatte bis nahe zu deren hinterem Ende; jedoch ist er ungemein schmal und unterscheidet sich durch seine lamellös geschichtete Structur von den beiden anderen Zähnen. Auf der Aussenseite, da, wo die Knochensubstanz etwas abgerieben ist, kann man besonders deutlich den Aufbau aus einzelnen vertical übereinander gelagerten, etwa eine Breite von $2^{m m}$ erreichenden Lamellen erkennen. Bemerkenswerth ist die grosse Höhe des in der Knochensubstanz steckenden Zahnes, während nur ein sehr geringer Theil frei herausragt.

Hart am Innenrand und nur vorn davon etwas abgerückt liegt der Symphysenzahn (b) von noch beträchtlicherer Länge, ca. $41^{\mathrm{num}}$, als erstgenannter, da er von der Spitze bis hart zum Hinterrande reicht. Seine Breite mit etwa $6^{\mathrm{mm}}$ übertrifft die des Zahnes a um das Dreifache. Seine entsprechend der Biegung leicht gekrümmten Ränder laufen ziemlich parallel. Die Kaufläche ist vorn stark, hinten flacher gewölbt und zeigt die vorher beschriebene chagrinartige Sculptur. Am Vorderende verschmilat der Symphysenzahn vollständig mit dem Aussenzahn, und hier ist dem in sehr interessanter Weise der Uebergang der compacten in die lamellös geschichtete Zahusubstanz zu verfolgen. Etwa $12^{m m}$ von der Spitze entfernt, sendet der Symphysenzahn an seinem Innenrand kurze, übereinander liegende Lamellen aus, von welchen die vordersten vier oder fünf frei am Aussenrand endigen, während die hinteren, Lamelle für Lamelle, mit den in gleicher Höhe befindlichen Lamellen des Aussenzahnes ohne sichtbare Naht verschmelzen. Der Symphysenzahn besitzt ebenfalls eine sehr bedentende Höhe, steckt aber auch zum grössten Theil in der Knocheumasse, wie man hinten deutlich sieht. Mit allmählich abnehmender Dicke durchläuft er in schrägr nach Aussen gewendeter 
Richtungr die ganze Höhe der I entalplatte, und sein unteres Ende verschmilzt anscheinend ebenfalls wieder mit dem Aussenzahn.

Zwischen Aussen- und Innenzahn liegt durch schmale Streifen von Knochenmasse getreunt der Medianzahn (c); seine $22^{\mathrm{mm}}$ lange Kinuflialhe zcigt rinen linsenförnigen Lmriss, indem sie sowohl nach vorn als nach hinten spitz zuläuft. Am Hinterrande sieht man, dass der Medianzahn eine weit geringere Höhe als die beiden vorher erwähnten Zähne besitzt, da sein dort zwischen jenen eingekeilter Querschnitt eine Höhe von nur $10^{\mathrm{mm}}$ hat.

r) Prädentalplatte (Taf. II, Fig. 6, 6a, 6 b).

Die Prädentalplatte stellt ein etwa $23^{\mathrm{mm}}$ langes prismatisches Knochenstück von geringer Dicke dar, das wahrscheinlich am Vorderrande in einer kurzen Spitze endigte. Die Aussenseite ist ziemlich hoch, im unteren Theil bis auf eine Höhe von $11^{\mathrm{mm}}$ flach, oben durch eine breite Längsfurche ausgehöhlt; mit der niedrigen, flachen Symphysenfläche stösst sie in scharfer Kante zusammen. Die Innenseite ist schwach concav, die eigentliche Kaufläche etwas stärker vertieft.

Am Aussenrand befand sich ein schmaler, lamellös geschichteter Zahn, der die ganze Länge desselben einnahm. Neben dem Innen. (Symphysialrand) bemerkt man die chagrinartige Oberfläche eines kleinen, flach gewölbten Zahnes aus fester Zahnmasse, an dessen Aussenseite sich wahrscheinlich noch einige Seitenzähnchen anschlossen.

Vorkommen: In England selten in den Sheppey-Thonen und Bracklesham-Sands, im Samlande selten in der Zone $A_{1}$.

Bemerkungen: Wenn auch einzelne Unterschiede zwischen unserer Form und Egerton's Abbildungen bestehen, so beziehen dieselben sich doch anf kaum mehr als anf den Verlauf der Seitenxänder der Zähne. Da diese jedoch als Folge grösserer oder geringerer Abnutzung der Zähne einen sehr wechselnden Verlauf haben, so möchte ich hierauf kein grosses Gewicht legen.

Den grössten Untersehied erblicke ich darin, dass bei EGEITTON der Medianzalnu der Postdentalplatte eine bedentend grössere Kaufläche besitzt als bei unserem Exemplar; allein, denkt man sich 
bei letzteren den Zahn etwas mehr aus der Knochenmasse herausgewachsen und die über dem hinteren Theile desselben noch lagernde Knochenmasse abgestossen, so kommt die Lünge des Medianzahnes beider Exemplare auf das gleiche Maass heraus.

Das Vorkommen dieses seltenen Holocephalen ist in deutschen Tertiarablagerungen, soweit mir bekamnt, his jetzt norh nirht constatirt worden.

\section{Plagiostomi.}

Fam. Notidanidae Müller und Henle.

Die Zoologen unterscheiden seit langer Zeit in der Familie der Grauhaie nach der Zahl der Kiemenspalten zwei leicht kenntliche Genera: Heptanchus RaF. und Hexanchus RaF. Da dieses Unterscheidungsmerkmal für den Paläontologen nicht verwerthbar ist, so wurden die fossilen Notidanidenzähne schlechtweg mit dem generischen Namen Notidanus bezeichnet, die Frage ihrer Zugehörigkeit zu dem einen oder andern Genus musste aber eine offene bleiben, oder konnte vorläufig nicht nïher in Lirwägung gezogen werden.

Nun hat aber Gegenbaur ${ }^{1}$ ) nachgewiesen, dass in Bezug auf den Bau des Schädels und der Schultergürtelhälften Hexanchus wesentlich tiefer steht als Heptanchus, und neuerdings hat $\mathrm{HASSE}^{2}$ ) durch seine schönen Untersuchungen der Wirbelsäule bestätigen können, dass die Differenzirung derselben bei beiden Gattungen so weit verschieden ist, dass, während bei Heptanchus in der Schwanzregion bereits Verkalkungen in Form amphicoeler Doppelkegel anftreten, bei Hexanchus jede Andeutung solcher noch vollkommen fehlt.

Da sich mithin in der Organisation des Skelets beider Genera tiefer gehende Unterschiede nachweisen lassen, so wäre vielleicht

1) Das Kopfskelet der Selachier. Untersuchungen zur vergleichenden Anatomie der Wirbelthiere.

2) Natürliches System der Elasmobranchier. Besonderer Theil, pag. 36 u. 37. 
zu erwarten, dass sich diese Differenz auch in der feineren Structur der Zähne kundgiebt ${ }^{1}$ ); leider konnte ich mir nicht genügendes Material zur Anfertigung der zur Entscheidung dieser Frage nöthigen Dünnschliffe beschaffen. Es wäre eine sichere. Entscheidung hierüber nicht nur für den praktischen Paläontologen, sondern anch entwickelungsgeschichtlich von grosser Bedeutung, denn dann wird es sich ergeben, ob eine Trennung der Notidaniden bereits in früheren Perioden existirte oder nicht. Sollten sich nun unter den fossilen Zähnen unsere heutigen Typen nachweisen lassen, so wäre es ferner sehr interessant zu wissen, ob entsprechend der Ansicht von der niedrigeren Organisation von Hexanchus dieser auch die geologisch ältere Form darstellt, und wann etwa die jüngere Form Heptanchus zuerst sicher nachweisbar ist.

Vielleicht finde ich späterhin einmal Gelegenheit, diese Untersuchung an hinreichendem recenten und fossilen Material wieder aufzumehmen, vorläufig aber müssen wir Mangels einer definitiven Kenntniss über diesen Gegenstand die generische Bezeichuung Notidames als Nothbehelf beibehalten.

\section{Notidanus primigenius Agassiz.}

Taf. I, Fig. 4 und Fig. 5-5a.

18.3. Notidanus primigenius Agassiz, Recherches sur les poissons fossiles. Bd. III, pag. 218 , tab. 27 , fig. $4-8$ und fig. $13-17$.

Notidanus-Zähne sind unter unserer Fauna sehr spärlich vertreten, es haben mir im Ganzen nur sechs Stücke, darunter keines von nur annähernder Vollständigkeit zur Untersuchung vorgelegen;

1) Einigermaassen eine Bestätigung scheint diese Ansicht dadureh zu erhalton, dass Agassiz 1. c. pag. 218 zugiebt, dass die Unterkieferzähne von Ieptanchus cinereus sehr wesentlich verschieden von denjenigen des Hexanchus griseus sind. Allein da Heptanchus indicus wieder Ziihme besitzen soll, die denjenigen von Hexanchus gleichen, so glaubt Agassiz, die generische Trenung dieser Formeu nicht aufrecht erhalten zu können. Jedeufills ist damit diese Frage nicht erledigt; sie lässt eine genauere Untersuchung der Zähne der betreffenden Arten nur um so wünschenstrerther erscheinen. Soweit ich ans Abbildungen zu urtheilen vermag, möchte ich mich mit aller Reserve dahin aussprechen, dass die ältesten jurassischen Notidanus-Zühne wohl zu Hexanchus gehören. 
darunter sind rier. die kaum mehr als die beiden ersten Spitzen zeigen und somit ansser Betracht bleiben, und an den beiden andern ist die Krone wohl ziemlich rollständig, dagegen fehlt die Wurzel.

Das eine Zähnchen (Fig. 4) ist etwa $18^{\mathrm{mm}}$ lang und besitzt sechs niedrige, stumpfe Spitzen, die ron den rordersten, $5^{\mathrm{mm}}$ hohen, nach hinten ganz allmählich an Höhe abnehmen und in gleichmässig schräger Richtung rückwärts gerichtet sind. Die Aussenseite der Spitzen ist nur unmerklich flacher als die Innenseite. die Seitenränder sind scharf und schneidend, jedoch reichen sie nicht ganz bis zur Basis der Einzelspitzen hinab. Die erste Spitze trägt auf ihrer Torderseite $3-4$ undeutliche Secundärzacken, die ron unten nach oben an Grösse zunehmen. Das Email grenzt in gerader und auch unterhalb der vordersten Spitze nur wenig gebogener Linie gegen die W urzel ab. Einen etwas andern Habitus zeigt das Zähnchen Fig. 5 ; die vier Zacken sind durchgängig böher und spitziger; der vorderste ist wie gewöhnlich der grösste, doch ist er nicht so schräg nach hinten geneigt wie die folgenden. Die untere Hülfte seines Vorderrandes ist mit fünt stumpfen, nach oben an Grösse ałnehmenden Secundärzähnchen besetzt. Die Aussenseite der Spitzen ist, wenn auch gewölbt, so doch beträchtlich flacher als die Innenseite. Vorder- und Hinterrand der einzelnen Zacken ist scharf und schneidend; bemerkenswerther Weise besitzen die beiden letzten Hauptzacken an der Basis des Torderrandes noch ein kleines, kaum sichthares Secundürzähnchen (Fig. 5 id, rergrössert).

Vorkommen: Lie Art scheint rom älteren bis in das jüngste Tertiär hinaufzureichen. In Samlande ziemlich selten in der Zone A.

Bemerkungen: Für die specifische Lnterscheidung der Aofidanu-Zühne ist zur Zeit noch keine sichere Grundlacge grewonnen, und sie wird eben noch so lange nicht mit wünschenswerther Sicherheit auszuführen sein, als nicht das Geljiss der letenden Arten im Detail mit allen Varietäten der Zübne beschrieben ist. Dass diejenigen Merkmale, nach welchen man bisher die einzelnen Arten zu unterscheiden pflegte, sich bei genauerer Intersuchung als nicht stichhaltig erweisen werden, unterliegt für mich nicht dem geringsteu Zweifel. So führt Arsissiz \%. B. als 
charakteristisches Merkmal des Lotidanus mimivenius an, dass seine Zähne die grössten unter den bekannten lebenden wie fossilen Arten seien. Dass aber die Grösse gerade bei Haifischzähmen rom allergeringsten Werth ist, steht Tohl fest.

Tnsere Fig. 5 dürfte ihr bestes Analogon in AGıssiz fig. 13 finden: die secundären Zähnchen an der Forderseite der beiden binteren Zacken kömnen insofern keinen specitiscben Luterschied berriunden, als ich dieselben ameh bei zahlreichen Zühnen des N. Mimigenim aus dem Mainzer Tertiär beobachtet habe.

\section{Spinax sp.}

Da dieser ron Hasse bestimmte Wirbel im Königsberger Prorinzialmuseum anfbewalut wird, so war es mir zu meinem grossen Bedanern nicht nüglich, denselben untersuchen zu können. Das sicher constatirte Torkommen des Genus Syina im samländischen Tertiär ist ron ungemein grossem Interesse, da dasselbe. abgesehen rou einem nicht ganz einwurfstreien Wirbelfiagment aus der Molasse ron Baltringen ${ }^{1}$ ) sonst fossil noch nicht bekannt ist.

Vorkommen: Sehr selten in der Zone $\perp_{1}$.

Bemerkungen: Zühne habe ich unter meinem Material nicht finden kömen: bei der Kleinheit derselben ist das Fehlen in der Sammlung nicht besonders atufiallend.

\section{Mryliobates toliapicus Ag.asiz.}

$$
\text { Taf. 11. Fig. } 1-1 \text { it. }
$$

1536. Myliohates toliapiens Acassi\%. 1. c. pag. 321.

Neben zahlreichen einzelnen, firamentarischen Medianplatten besitze ich ein auscgezeichnet erhaltenes gröseres Bruchstück der

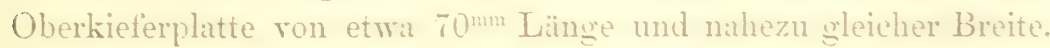
Disselbe besteht aus sechs rollstïndig und zwei nur theilweise erhaltenen Medianplatten nebst zwei heihen der entsprechenden Seitemplättchen: die dritte, äusserste heihe fehlt jedoch. Am vorderen Ende ist die Platte durch den Grobrach sehr stark abge-

1) H.sse, Ststem der Elizmobranchier; pag. s1. 
nutzt, so dass auf der ersten Medianplatte das Email fast vollständig zerstört ist; auf den drei nächstfolgenden sieht man als Spuren des Gebranchs feine, scharfe Längskritzen, die nach vorne convergiren.

Die grossen Medianplatten messen ca. $50-52^{\mathrm{mm}}$ Breite und $9^{\mathrm{mm}}$ Länge, so dass also das Verhältniss von Länge zu Breite sich wie $1: 5,7$ oder rund $1: 6$ stellt; Vorder- und Hinterrand sind, abgesehen von leichten, secundüren Biegungen, ziemlich gerade. Die Aussenseiten sind stumpf zugeschärft. In der Mitte läuft eine ziemlich tiefe, von hinten nach vorn an Stärke abnehmende Längsfurche; hierdurch erscheint, im Profil gesehen (Taf. II, Fig. 1a), die Oberfläche der Gaumenplatte in der Mitte eingesenkt, während die flach gewölbten Seitenhälften sowohl gegen Aussen als Innen sanft abfallen. Die inneren Rindplättchen sind in der Zahl von acht vorhanden; die hinteren besitzen noch ziemlich regelmässig sechsseitige Gestait, während die vorderen mehr in die Länge gestreckt sind. Noch stärker in die Länge gezogen sind die Plättchen der zweiten, bei diesem Stück äussersten Reihe, so dass sie stark verzerrte Sechsecke darstellen. Das glatte und glänzende Email der Kaufläche ist mit feinen, aber kurzen, ineinander greifenden Lüngsfurchen bedeckt, die eine sehr feimrunzelige Obertläche erzeugen. Bei dem abgebildeten Stïck sind dieselben am deutlichsten auf der dritten bis sechsten Medianplatte zu sehen, auf den beideu letzten, sowie auf den Seitenplättchen, sind sie jedoch verwischt. Die Kronensubstanz ist in der Mitte sehr dick, sie misst hier etwa $15 \mathrm{~mm}$, nach dem Seitenrande zu nimmt ihre Dicke datdurch, dass die Unterseite in der Querrichtung ziemlich stark gewölbt ist, schnell ab. Bei dem abgebildeten Exemplar lïsst sich am Hinterende (Fig. 1a) sehr schön die von AGassiz beschriebene röhrige Structur erkennen. Die Wurzel fehlt grössten Theils; da man jedoch an mehreren Stellen die Einzelkïmme noch vollständig erhalten sieht, so geht zweifelsohne daraus hervor, dass die Zahnkrone unverhältnissmässig dicker war als die Wurzel; ich schätze bei meinem Exemplar das Verhältniss der Dicke von ersterer zu letzterer auf etwa $15: 3$. 
Vorkommen: Nicht selten, jedoch meist in einzelnen Platten in der Zone $A_{1}$, nach Agassiz, Dixos und Anderen im Londonclay von Sheppey häufig. Neuerdings wird sie auch von GeINItz aus den Phosphoriten von Helmstedt genannt.

Bemerkungen: Das vorliegende Exemplar stimmt am Besten mit dem von GEINITZ ${ }^{1}$ ) aus den Hehnstedter Phosphatgruben beschriebenen Oberkiefer überein. Hier wie dort zeigt die Zahnkrone eine unverhältnissmässige Dicke im Gegensatz zur Wurzel; bei beiden ist in Folge eimer medianen Längsfurche die Kaufläche in der Mitte schwach vertieft und erscheint somit, im Querprofil geschen, doppelt gewölbt, und schliesslich ist die Uebereinstimmung der verzerrten Seitenplättchen unverkennbar. Das Verhältniss von Länge zu Breite beträgt bei Geinitz 1:5,44, bei meinem Exemplar 1:5,7; mithin ist auch hierin die Uebereinstimmung verhältnissmässig gut.

Leider giebt AGAssiz nur Abbildungen des Unterkiefers von Myliobates toliapicus, und mit diesen stimmt unser Exemplar keineswegs überein. Abgesehen von der Form der Medianplatten und der regelmässigeren Gestalt der Seitenplättchen unterscheiden sich AGAssiz's Exemplare auf' den ersten Blick dadurch, dass, wie seine profilarische fig. 20 sehr gut zeigt, die Kaufläche vollkommen glatt ist, ganz besonders aber dadurch, dass, wenn auch die Zahnkrone dicker ist als die Wurzel, dies nicht in so unverhältnissmässigem Grade wie bei unserm oder Gennitz's Exemplare stattfindet. Das Verhältniss beträgt bei AGAssiz 3,5:6,5, bei unserm Exemplar $3: 15$, bei Geinitz 3,5:15.

Soweit ich aber aus AGAssiz's Beschreibung des Oberkiefers schliessen kamn, ist das samländische sowie das Helmstedter Exemplar dem M. toliapicus zuzuzählen. Wenn sich jedoch Gernitz behufs Erweisung der Identität auf Dixox's tab. 10, fig. 3 u. 4 beruft und dabei sagt, sdass die Seitemplatten des Unterkiefers fast regelmässige Sechsecke bilden, während jene des Oberkief'ers

1) Ueber neue Funde in den Phosphoritlagern ron Helmstedt etc. Abhandl. der Gesellsch. Isis in Dresden, 1883, pag. 38, tab, 2, fig. 2 und 2 a. 
etwas lang gestreckt sind", so kann dieser Schluss insofern nicht zulässig erscheinen, als Dixon pag. 199 ausdrücklich bemerkt: \$The specimen figured tab. 10, fig. 3 is from the lower jaw and fig. 4 is the under surface.»

\section{Myliobates sp., ef. toliapicus AGassiz. (Flossenstachel.)}

Taf. II, Fig. 2-2c.

-Neben der verhältnissmässig grossen Zahl von Zahnfragmenten hat sich nur ein Bruchstück eines diesem Genus angehörigen Flossenstachels von etwa $62 \mathrm{~mm}$ Lünge gefunden. Am proximalen Ende beträgt dessen Breite 9, $5^{\mathrm{mm}}$, die Dicke $5^{\mathrm{mm}}$; am distalen $4^{\mathrm{mm}}$ resp. $2^{\mathrm{mm}}$. Die mit glänzendem Schmelz überzogene Vorderseite ist flach gewölbt und durch zahlreiche, tiefe Längsfurchen, die zuweilen in einander verfliessen, grob gerunzelt. Etwa $10^{\mathrm{mm}}$ vom proximalen Ende entfernt beginnt eine besonders tiefe, mediane Längsfurche, die bis zum Ende des Fragmentes zu verfolgen ist. Daraus dürfte wohl hervorgehen, dass der proximale Theil des Stachels einer Medianfurche entbehrte, ja es scheint mir sogar bei vorliegendem Fragment, als ob sie hier durch einen Kiel ersetzt wurde. Die Hinterseite des Stachels ist durchschnittlich etwas stärker gewölbt und feiner längsgerunzelt als die Vorderseite und ohne Schmelzüber\%ur. sondern rauh: pratallet dem seitenrande, und dicht neben ihm laufen zwei ganz besonders tiefe Längsfurchen anscheinend von der Basis bis zur Spitze des Stachels. Der scharfe Rand ist mit einer Reihe kleiner, spitziger, etwas comprimirter Zähnchen besetzt, die dicht gedrängt und in proximaler Richtung geneigt auf einander folgen. Auf dem Rücken eines jeden Zähnchens läuft von der Spitze bis zur Basis ein feiner, scharfer Kiel.

Vorkommen: Sehr selten in der Zone $\mathbf{A}_{1}$.

Bemerkungen: Es ist leicht möglich, dass die vorbeschriebene Kauplatte und der Flossenstachel zusammengehören, ebenso gut ist aber auch das Gegentheil wahrscheinlich, ja, wenn man vollkommen correct handeln wollte, so müsste man schreiben Mylio- 
bates? sp). da das nahe verwandte Grenus Aïtobates wohl ähnliche Stacheln wie Myliobates besit»t, mithin die generische Zugehörigkeit des hier abgebildeten Stachels zu diesem Geschlechte nicht ausgeschlossen ist.

Ich bin hier dem Vorgange von AGassiz gefolgt, der im III. Bande auf taf. 45 eine ganze Reihe solcher Stacheln alogebildet und mit dem Namen Myliobates belegt hat. Vielleicht giebt cine spätere Untersuchung darüber Auf́schluss, ob es möglich ist, die Stachehn der verschiedenen Generi, welche die Familie der Myliobatidue bilden, auf mikroskopischem Wege gut zu unterscheiden. AGAssiz hat die Flossenstacheln, welche er abbildet, auf eine Reihe derjenigen Arten bezogen, von welchen er Kauplatten abbildet und beschrieb, ob aber mit Recht, bezweifelt er selbst. Der samländische Stachel stimmt mit keiner von AGassiz's Abbildungen ganz genitu, wohl aber vereinigt er die Charaktere verschiedener derselben in sich.

\section{Myliobates sp., cf. toliapicus Agassiz. (Wirbel.)}

Taf. VIII, Fig 1-1a und Fig. 2-2c.

Nur zwei, sehr stark abgerollte und am Rand beschädigte Wirbel liessen sich nach dem Durchschneiden auf Myliobates beziehen. Beide Exemplare haben nahezu gleiche Grösse; ihre Höhe beträgt etwa $10-11^{\mathrm{mm}}$, die Breite $11-12$ und die Länge etwa $5{ }^{\mathrm{mm}}$. Soweit sich unter Berücksichtigung des Erhaltungszustandes sehen liess, zeigten die Wirbel in der Frontalansicht querovalen, nahezu kreisförmigen, in der Seitenansicht hoch rechteckigen Umriss. Eine Orientirung der Wirbel ist ohne Kenntniss des Querschnittes nicht gut möglich, da die Seitenflächen sich sehr indifferent verhalten; man sieht nur eine etwas cingesenkte, unregelmässig grubige Fläche zwischen den heiden Doppelkegelhälften.

Die Wirbelhöhlung ist flach eingesenkt, die anscheinend ziemlich weite Durchbohrung für die Chorda scheint central zu liegen. Der Doppelkegel ist dick, am Rande abgerundet, und die Aussenflächen sind grob concentrisch gestreift. 
Der Querschnitt bietet ebenfalls sehr wenig charakteristisches; die Durchbohrung für die Chorda wird von dem ziemlich dicken Doppelkegel umgeben, der in Fig. 1 als dunkler Ring erscheint. Um diesen legt sich als etwas hellerer Ring von gleicher Breite die Innenlage der Aussenzone. Die Aussenlage ist grob concentrisch geschichtet und setzt sich aus helleren Bändern, welche mit dunkleren Streifen abwechseln, zusammen. Gegen den Rand hin folgen letztere dichter auf einander als im centralen Theil, wo sie weiter von einander stehen. Die dunkleren Streifen sind unregelmässig gewellt, auf der Dorsalseite beschreiben sie jedoch in der Mitte einen von zwei seitlichen Einsenkungen begrenzten schmalen Bogen nach vorn. Von der Peripherie her dringen unregelmässige kurze Spalten gegen das Centrum hin vor, ohne jedoch, wie es scheint, die regelmässige Schichtung zu alteriren.

Vorkommen: Selten in der 'Lone $\mathbf{A}_{1}$.

Bemerkungen: Fossile Wirbel aus der Familie der Myliobatidae sicher und scharf zu unterscheiden, ist ungemein schwierig, sofern nicht reichliches recentes Vergleichsmaterial definitiv darüber entscheiden lässt, welchem Genus der betreffende Wirbel angehört, denn Abbildungen, weluhe die Bestimmungen erleichterten, existiren leider noch zu wenig. Ich stütze mich daher hinsichtlich der generischen Zugehörigkeit unserer Wirbel auf die Autorität HAssE's, der dieselben als Myliobates-Wirbel bestimmte.

\section{Aëtobates Dixoni Agassiz sp.}

Taf. II, Fig. $3-3$ b.

1843. Myliobates Dixoni Agassiz, Recherches sur les poissons fossiles Bd. III, pag. 319 .

1850. Myliobates Dixoni Drxon, Geology of Sussex pag. 198, tab. 11, fig. 14 und 7 (non tab. 10, fig. 1 und 2; tab. 12, fig. 3).

Von dieser Art besitze ich nur eine einzelne Zahnplatte, vielleicht die vorderste, oder jedenfalls eine der vorderen des Oberkiefers; dieselbe ist stark bogenförmig gekrümmt und am Hinterrand, in der Sehne gemessen, ca. $90^{\mathrm{mm}}$ breit; ihre Länge beträgt in der Mitte etwa $12^{\mathrm{mm}}$, so dass sich das Verhältniss von Länge 
zur Breite etwa wie 1:S stellt. Vorder- und Hinterrand der Zahnkrone sind stark bogenförmig nach hinten gekrümmt und laufen einander parallel bis nahe zu den Seiten, wo der Vorderrand, ohne eine scharfe Ecke zu bilden, mit dem Hinterrand zusammentriftt. Daher behält die Zahnkrone ihre Länge beinahe auf die ganze Breite bei, und nur an den Seiten verschmälert sie sich unbedentend. Die Zahnkrone erreicht in der Mitte am Hinterrande gemessen nur die geringe Dicke von $4,5^{\mathrm{mm}}$, seitlich aber sowohl wie nach vorn nimmt letztere noch bedentend ab. Der dreikantige Kiel an der Hinterseite der Zahnkrone, welcher in eine entsprechende Furche der Vorderseite des nächstfolgenden Zahnes eingreift, ist sowohl nach oben als nach unten scharf abgesetzt und reicht bis zu den Seiten; die Furche an der Vorderseite verschwindet jedoch in ciniger Entfernung von denselben. Die Kaufläche ist flach gewölbt, nach vorn abschïssig und in Folge des Gebrauchs grob und unregelmässig längsgefurcht.

Die Wurzel besitzt die gleichbleibende Dicke von $7^{\text {mun }}$; vorn und hinten ist sie abgeschrïgt, auf der Unterseite horizontal und zeigt die bekannte kammartige Zusammensetzung, vorn jedoch undeutlicher als unten und hinten.

Vorkommen: Nicht selten in den Brackelskam-Sands, in der Zone $\mathbf{A}_{1}$ des Samlands dagegen sehr selten.

Bemerkungen: Es schien mir anfangs etwas unsicher, eine einzelne Zahnplatte specifisch zu bestimmen, allein das betreffende Exemplar entspricht namentlich in Bezug auf sein Verhältniss von Länge zu Breite sowie auf seine starke Krümmung sehr gut der ersten Platte von Drxon's fig. 14. Drxon und auch Agassiz bemerken nun, dass das Verhältniss von Länge zu Breite bei dem Typus von Myliobates Dironi 1/5 betragen soll, allein bei der Controlle dieser Angabe an Drxon's fig. 14 ergab sich der Quotient der ersten Platte zu 1/8 (11:92), der zweiten Platte zu 1/7 (13:95), der dritten Platte zu 1/6 (16:95), wobei jedoch zu berücksichtigen

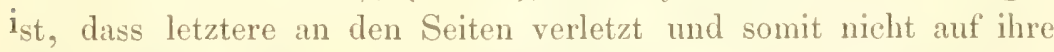
ganze Breite erhalten ist; bei tab. 11, fig. 7, einer einzelnen Platte, die ohne Zweifel auch zu dieser Art gehört, stellt sich der Quotient gar zu 1/9. Ganz anders aber ergiebt sich das Verhältniss, 
wenn man die Messungen an Drxon's tab. 10, fig. 1 u. 2 oder tab. 11, fig. 3 anstellt; hier resultirt in der That ein Quotient, der zwischen $1 / 4$ und $1 / 5$ schwankt.

Aus diesen Zahlen und unter Berücksichtigung der weit stïrkeren Krümmung der Zahnplatten von tab. 11, fig. 14 muss man zur Vermuthung gelangen, dass letztere z. B. tab. 10, fig. 1 oder 2 zwei specifisch verschiedene Formen darstellen, und demgemäss zu trennen seien. Allein nicht nur dieses ist der Fall, sondern auch Drxon's fig. 14 ist höchst wahrscheinlich gar kein Myliobates, sondern zu dëtobates zu stellen, denn die Ränder der vollständig erhaltenen Platten sprechen nicht dafür, dass sich neben ihnen noch Seitenplättchen befanden, sie sind einfach gerundet wie Zahnplatten von Aëtobates.

Bei tab. 10, fig. 1 u. 2 oder tab. 12, fig. 3 dagegen sind die Seitenränder der Medianplatten ausgezeichnet stumpf zugeschärft und würden somit das Vorhandensein von Seitenplättchen ohne Weiteres darthun, wenn dieselben nicht noch zum Ueberfluss bei den tab. 10, fig. 1 u. 2 vorhanden wären.

Da es somit erwiesen sein dürfte, dass Dixon's tab. 11, fig. 14 dem Genus Ä̈tobutes angehört, eine Ansicht, die durch das damit identificirte samländische Exemplar bestätigt wird, so ist nur die grenerische Form zu ändern und dasselbe als Aëtobates Dixoni zu bezeichuen.

Vielleicht ist auch mit unserer Art der A. sulcatus Agassiz 1. c. fig. 4 u. 5 ident, sicher kann ich dies jedoch nicht behaupten; wach fig. 5 scheint sich $A$. sulcatus von A. Dixoni durch noch stärker gekrümmte Zahnplatten, die sich an den Seiten förmlich zuspitzen, zu unterscheiden. Allein die Profilansicht Fig. 4 stellt die Platten nicht nur nicht so stark nach rückwärts gekrümmt, sondern auch viel weniger seitlich zugespitzt dar, als dies nach fig. $5 \mathrm{zu}$ vermuthen wäre. Unter diesen Umständen kann auch der Quotient von Länge und Breite, der sich aus fig. 5 zu $1 / 6$ ergiebt, von nur geringem Werthe sein, der sonst wohl gegen eine Vereinigung sprechen dürfte.

Von A. irregularis unterscheidet sich A. Dixoni sehr leicht; eimmal sind bei letzterem die Zahnplatten viel stärker gekrümmt, 
als bei ersterem, dann bricht bei $A$. irreguluris an den Seiten der Vorderrand in einer scharfen Ecke nach hinten um, so dass ein wenn auch nur kurzer gerader Seitenrand entsteht, während dies bei A. Dixoni nicht stattfindet; ferner, und darin scheint mir der wichtigste Unterschied zu liegen, ist bei A. irregularis die Zahnkrone viel dicker als bei A. Dironi. Am besten wird dies an der Abbildung der lïickseite beider Arten klar, andererseits aber auch, wenn man das Verhältniss der Dicke der Wurkel zu derjenigen der Zahnkrone vergleicht. Bei A. Dixoni verhält sich erstere zu letzterer wie $4: 7$, bei $A$. irregularis dagegen wie $6: 5$.

Aëtobates irregularis Agassiz.

Taf. II, Fig. $4-4 b$, Fig. $5-5 b$.

18.13. Aëtobatis irremularis Agassza, Recherehes sur les poissons fossiles Bd. Ill, tab. 47 , fig. $3-5$.

1850. Aëtubates irregularis Drxon, Geology of Sussex pag. 199, tab. 10, fig. 7: tab. 11, fig. $2-4$ (non fig. 15!).

Neben mehreren Bruchstücken einzelner Platten, die sich in unserer Sammlung befinden, konnte ich Dank der Freundlichkeit des Herm KuEbS drei noch im Zusammenhang befindliche, allerdings nur zur Hälfte erhaltene Unterkieferplatten dieser Species untersuchen. Nach dem Vorderrande der ersten Platte zu urtheilen gehört das Fragment, da die Kaufläche derselben nicht nach vorn abschüssig ist, den mittleren oder hinteren Partieen der Gaumenplatte an. Die erste der Platten ist auf eine Breite von etwa $41^{\mathrm{mm}}$ erhalten, aber nur $7,5^{\mathrm{mm}}$ lang; die zweite ist $37^{\mathrm{mm}}$ breit und $8,5^{\mathrm{mm}}$ lang, die dritte von gleicher Breite wie die vorhergehende, aber $9^{m m}$ lang. Die beiden letzten Platten mögen gerade die Hälfte der Gesammtbreite darstellen, die sich mithin auf etwa $74^{\mathrm{mm}}$ beJäuft; daraus ergiebt sich der Quotient zwischen Länge und Breite zu $1 / 10-1 / 8$, welch letztere Grösse sehr gut mit dem Resultate der Messungen an Drxon's tab. 11, fig. 2 stimmt.

Die einzelnen Platten sind schwach bogenförmig geliümmt; die unregelmässig gewellten Vorder- und Hinterränder laufen ein- 
ander parallel bis zu den Seiten, so dass eine jede auf ihre Gesammtbreite eine, sich fast vollkommen gleich bleibende Länge besitzt. An der Seite biegt sich der Vorderrand in einer seharfen Ecke nach hinten, so dass eine Art kurzen und geraden Seitenrandes entsteht. Die Zahnkrone ist ziemlich dick und steigt von den Seiten gegen die Mitte zu an, so dass also die. Gaumeuplatte im Ganzen in querer Richtung leicht gewölbt ist; ihre durchschnittliche Dicke in der Mitte beträgt etwa $6^{\mathrm{mm}}$. Die Kaufläche ist vollkommen horizontal und mit glänzend glattem, etwas rissigem Email bedeckt. Der scharf abgegrenzte Kiel an der Hinterseite zeigt vierkantigen Querschnitt und reicht ebenso wie die vordere Furche bis an den Seitenrand.

Die Wurzel ist vorn und hinten abgeschrägt, anf der Unterseite horizontal; in der Mitte ist ihre Dicke am grössten; dieselbe beträgt bei der dritten Platte etwa $4,5^{\mathrm{mm}}$; es rerhält sich also die Dicke der Zahnkrone zu derjenigen der Wurzel wie $6: 4,5$; nach den Seiten nimmt jedoch die Stärke der Wurzel bis auf boinahe $2^{\mathrm{mm}} \mathrm{ab}$.

Bemerkenswerth ist ferner das Fragment einer Unterkieferplatte (Fig. 5, 5a, 5b), das jedenfalls der vorderen Partie angehörte, wenn nicht gar die vorderste Platte selbst darstellt. Die Form weicht von den Oberkieferplatten insofern ab, als dieselbe in der Mitte gerade ist und sich nur an den Seiten, aber ziemlich stark rückwärts krümmt. Die Länge der Platte beträgt ca. 9, ihre Breite $74^{\mathrm{mm}}$, also ergiebt sich das Verhältniss etwa 1:8. Da die Kaulfläche nicht nur seitlich, sondern auch ziemlich stark nach vorn geneigt ist, so nimmt die Dicke, welche in der Mitte des Hinterrandes $5^{\mathrm{mm}}$ beträgt, nach vorn ziemlich schnell, nach den Seiten etwas langsamer ab. Der Kiel an der Hinterseite ist nach oben nur undeutlich abgesetzt, die Furche an der Vorderseite kaum bemerkbar.

Die Wurzel, welche vorn etwas stärker abgeschrägt ist als hinten, besitzt eine Dicke von $3,5^{\mathrm{mm}}$, welche sie, ohne abzunehmen, von der Mitte bis zu den Seiten beibehält. Ihre kammartige Structur zeigt sich bei diesem Exemplar ausgezeichnet schön; die 
Oeffunngen der Hauptnervenkanäle ${ }^{1}$ ) liegen zahlreich an der Grenze zwischen Wurzel und Zahnkrone, sowohl an der Vorder-als Hinterseite; auch auf der Unterseite sieht man in den Furchen zwischen den einzelnen Kämmen mehrere unregelmässig zerstreute Nervenöffnumgen.

Vorkommen: Häufig im Sheppey-Thone; seltener in der Zone $\mathbf{A}_{1}$ des Samlandes.

\section{Aïtobates sp.}

Taf. VIII, Fig. $3-3$ e, Fig. $4-4$ h, Fig. $5-5 \mathrm{~b}$.

Wie die Mytiobates-Wirbel sind auch diese ziemlich schlecht erhalten, weshalb die äussere Form mit Bestimmtheit nicht angegeben werden kann. Die Höhe der Wirbel beträgt $8-10^{\mathrm{mm}}$, die Breite ist anscheinend etwas geringer, 8-9mm, und die Länge betrug etwa $4^{m m}$. In der Frontalansicht wird der Umriss wahrscheinlich hoch-oval, vielleicht etwas eckig gewesen sein, während or in der Seitenansicht hoch-rechteckige Gestalt zeigte.

Da die Wirbel allseitig ein nahezu gleiches Bild gewähren, so ist eine Orientirung ungemein schwer, und in einzelnen Fïllen ohne Durchschneidung überhaupt nicht ausführbar. Bei dorsaler, ventraler und seitlicher Ansicht sieht man in der Mitte jeder Seite eine schmale, flache Längsleiste, welche seitlich von zwei wenig tiefen, spaltförmigen Lücken begrenzt ist; je eine dorsale und laterale, resp. ventrale und laterale Spalte ist wiederum durch eine, zwei bis drei Mal breitere Längsleiste getrennt. Man

1) Da allgemein bei den Elasmobranchiern ein jeder Zahn nur eine grössere Oeffunng für den Eintritt des Hauptnervenstammes besitzt, so scheinen die zahlreichen grösseren Nervenkauäle bei deu Zahmplatten der Myliobatiden dafïr zu sprechen, dass diese aus der Verschmelzung zahlreicher Einzelzühne hervorgegangen sind. Ja, da bei dem betreffenden Exemplar, wemn auch nicht regelmässig, auf je 2 Wurzellkïmme ein Hauptnervenloch kommt, so scheint damit die Entstehung aus doppeltkammigen, rechenähnlichen 'Zähnehen angedeutet. Dir unser Excmplar etזa 60 Wurzelkämme besessen haben mag, so wären also die Zahnplatten aus der innigen Verschmelzung von dreissig Einzelzilhnchen entstanden zu denken. 
zählt also im Ganzen acht spaltförmige Lücken: zwei ventrale, zwei dorsale und je zwei laterale, welche vier schmale mediane von vier breiteren, zwischen ersteren liegenden Längsleisten trennen.

Dieses normale Bild wird durch Oberflïchenrerkalkungen etwas modificirt, wodurch in gewissen Fällen die Orientirung etwas erleichtert wird. Vielfach sind nämlich die ventralen Lücken durch Oberflächenverkalkung geschlossen, so dass die Ventralseite eine gleichmässige, zusammenhängende, wenn auch unebene Fläche zeigt (Fig. 3). Zuweilen können auch die unteren Laterallücken durch Oberflächenverkalkung verdeckt sein, so dass man äusserlich nur die dorsalen und oberen lateralen Lücken erkennt. Gewöhnlich sind auch die dorsalen Spalten am tiefsten, ebenso wie auch die dazwischen liegende Längsleiste stärker als die übrigen ausgebildet ist.

Die mässig tiefe Wirbelhöhlung wird von der Chorda central durchbohrt.

Der Doppelkegel ist dick, seine Ränder sind ziemlich abgerundet und die Aussenflïchen grob und unregelmässig concentrisch gestreift.

Der Querschnitt zeigt in der Mitte die verkalkte Innenzone (Fig. 5 b), umgeben von dem helleren Ring des Doppelkegels. Die Aussenzone ist undeutlich concentrisch geschichtet, häufig aber kann man Innen- und Aussenlage unterscheiden. Am Rande ist die letztere durch kurze spaltförmige Einschnitte sehr regelmässig zertheilt. Am constantesten sind zwei Einschnitte, welche dorsal und ventral je eine schmale mediane Lamelle abtheilen; gewöhnlich ist die dorsale etwas stärker entwickelt. In der Mitte der Seiten befinden sich entweder ebenfalls zwei Linschnitte, welche eine schmale Lamelle zwischen sich fiassen, wie in Fig. 3e (vergrössert) und $4 \mathrm{~h}$ (vergrössert), oder es tritt nur ein Einschnitt auf, und dann entsteht das Querschnittsbild Fig. 5b (vergrössert).

Vorkommen: Ziemlich häufig in der Zone A.

Bemerkungen: Nach Herm Hasse gehören diese Wirbel dem Genus Zygobates an; allein mit liücksicht darauf, dass die Wirbel der Genera Zygobates, Aötobates und Cephaloptera sehr 
schwierig, vielleicht gar nicht zu unterscheiden sind, möchte ich, da im samländischen Tertiär Zühne des Genus Aëtobates gar nicht selten sind, die vorbeschriebenen Wirbel diesem Genus zuzählen.

\section{Rhinobates Martensii sp. n.}

Taf. VII, ,Fig. $1-1$ b.

Die Squatinorajidae sind in unserer Fauna durch einen oinzigen Wirbel, welcher dem Genus Rhinobates angehört, vertreten, während Zähne fehlen. Leider wurde es verabsäumt, die äussere Gestalt des Wirbels vor dem Durchschneiden zu fixiren, und somit kann ich hierüber nur wenig sagen.

Der $8,75^{\mathrm{mm}}$ hohe und $8,5^{\mathrm{mm}}$ breite Wirbel besitzt in der Frontalansicht nahezu kreisförmigen Umriss, der sich aber bei unserem Exemplar in Folge theilweiser Abrollung ziemlich unregelmässig gestaltet. Die Durchbohrung für die Chorda ist ziemlich weit und etwas excentrisch dorsalwärts gelegen. Eine Randfläche scheint kaum ausgebildet gewesen zu sein; bei seitlicher Betrachtung sieht man jedoch, dass der Rand ziemlich stark aufgeworfen ist. Dabei ist die Wirbelhöhlung ziemlich tief, zeigt aber nur wenige und undeutliche concentrische Streifen.

Auf dem Querschnitt erscheint der centrale Doppelkegel (d) als dünne Schicht rings um die Durchbohrung für die Chorda, welche sich durch ihre hellere Farbe scharf gegen die dunkleren Partieen der Aussenzone abhebt.

Rings um denselben liegt eine ziemlich breite, sehr fein lamellös geschichtete Zone, die Imnenlage ( $a_{1}$ ) der Aussenzone.

Die periphere Lage (a) der Aussenzone ist noch bedeutend feiner geschichtet und in acht radiüre Strahlen zerlegt, die sich in je einem ventralen und dorsalen und je drei seitlichen Strahlen gruppiren. Der dorsale Strahl ist kurz aber breit, ohne sich gegen Aussen zu verdicken; im Gegensatz hierzu ist der ventrale Strahl lang und schmal, aber auch er bleibt stets gleichmässig breit.

Von den Seitenstrahlen sind die dorsalen wie die ventralen Schrägstrahlen sehr schmal, es zeigt sich aber auch hier wieder der Gegensatz, dass die dorsalen kürzer und plumper sind, als die 
längeren und schlankeren ventralen; aber weder die einen noch die andern nehmen nach aussen an Breite zu.

Die mittleren, eigentlichen Seitenstrahlen sind die breitesten von allen und verdicken sich bedentend gegen aussen hin, so dass sie gegen die anderen stark überwiegen.

Durch diese verschiedene Breite der einzelnen Strahlen sind im dorsalen Abschnitt die Zwischenräume schmal und wenig tief, im ventralen dagegen ziemlich breit und tief.

Deutlich sieht man besonders am Ventralstrahl, dass dieser, sowie die Seitenstrahlen mit, wenn auch nicht sehr ausgedehnten, plattenförmigen Oberflächenverkalkungen verwachsen waren.

Vorkommen: Sehr selten in der Zone A des Samlandes; sonst hat sich Rhinobates nach HASsE im Senon von Ciply und Maestricht, sowie im belgischen Eocän und in der Kreide des Libanon gefunden.

Bemerkungen: Das Bild des Querschnittes unseres Wirbels liisst denselben als eine Mittelform zwischen den beiden lebenden Arten Rh. Horkelii Müll. und Rh. cemiculus G. ST. HnLL., die beide von HAsse sorgfältig abgebildet und beschrieben sind, erscheinen. Doch scheint die Verwandtschaft mit letzterem eine grössere; die nächsten Beziehungen zeigt jedoch unsere F'orm mit einem Wirbel aus dem belgischen Eocän (HASSE, tab. 15, fig. 46) der anch von HASsE mit $R h$. cemiculus in enge Verwandtschaft gebracht wird.

Zur besseren Erläuterung der folgenden Auseinandersetzung wird es zweckdienlich sein, HASsE's Figuren zu reproduciren, und zwar wähle ich von $R h$. Horkelii die fig. 27 , sowie fig. 35 , erstere (Texttafel Lief. I, Fig. 2) den Querschitt der recenten Form darstellend, letztere (Texttafel Lief. I, Fig. 3) den Querschnitt eines Wirbels aus dem Locïn von Etterbeck, der nach HASSE auf den Typus des Rh. Horkelii zu beziehen ist; von $R h$. cemiculus fig. 41 das Querschnittsbild der recenten Form (dies. Tafel, Fig. 4) und fig. 46 den Querschnitt eines Wirbels aus dem Eocän von Litterbeck (dies. Tafel, Fig. 5), der nach Hasse nach dem Typus des Rh. cemiculus gebaut ist.

Man sieht hierans sofort, dass Rhinobates Horkelii durch ungemein breite Strahlen mit relativ schmalen Zwischenräumen der peripheren Lage $\left(a_{1}\right)$, sowie durch eine breite Innenlage (a) der 
Aussenzone charakterisirt ist. Rh. cemiculus zeichnet sich durchweg durch die Schlankheit und Dünne seiner Strahlen, welche folglich durch grössere und breitere Zwischenrüume getrennt sind, aus; die Innenlage der Aussenzone (a) ist als relativ schmaler Ring ausgebildet.

Von den fossilen Wirbeln zeigt nun Fig. 3 genau den Habitus des lebenden Rh. Horkelii, Fig. 5 zeigt in der Schmalheit der dorsalen und ventralen Strahlen, mit demgemäss breiten Zwischenräumen, in der Entwickelung von Oberflächenverkalkungen am dorsalen, sowie an den beiden Seitenstratlen Annäherung an $R h$. cemiculus; mit Rh. Horkelii verbindet sie jedoch die ungemeine Entfaltung der beiden Seitenstrahlen, sowie die breite Inneulage (a), wie auch HASSE bereits erkannt und hervorgehoben hat.

Vergleichen wir nun hiermit das Bild unseres Wirbels, so sehen wir zunächst, dass die Schmalheit und Schlankheit der Dorsal- und Ventralstrahlen ihn dem Rh. cemiculus nahe rückt, die Breite der Seitenstrahlen aber, sowie diejenige der Innenlage der Aussenzone (a) auf Beziehmngen zu Rh. Horkelii dentet.

Unter den fossilen Formen entspricht num dieser Zwischenstellung am besten der Querschnitt des von Hasis aus dem Eocän von Etterbeck abgebildeten Wirbels, während die üussere Form beider zu differiren scheint. Aber auch im Querschnitt ist die Uebereinstimmung keine absolute; die dorsalen Strahlen erscheinen bei unserer Form im Vergleich zu den entsprechenden Strahlen des belgischen Wirbels plump, während wiederum die ventralen viel schlanker ausgebildet sind. Der Gegensatz also, der sich bei unserer Form in der Dicke der Ventral- resp. Dorsalstrahlen kundgiebt, ist bei dem belgischen Wirbel kamm vorhanden. Ausserdem bleiben jedoch bei unserem Exemplar die Strahlen bis zu ihrem Ende von gleichmässiger Dicke, während sie sich bei dem belgischen gegen das Ende hin, wenn auch nur unbedeutend verdicken.

Ein weiterer Unterschied liegt in der starken Entwickelung der Oberflächenverkalkung bei dem belgischen Exemplar; dadurch erscheint dasselbe oberflächlich nur vierkanmerig (cf. HAsse, tab. 15, fig. 43, 44 und 45), während unser Wirbel bei nur geringer Ausbildung der Oberflächenverkalkung, in der Seiten-, resp. 
Ventral-, resp. Dorsalansicht die vier Zwischenräume jederseits, also ringsum acht Kammern nebst den entsprechenden Strahlen deutlich erkennen lässt.

Auch die sichere Constatirung dieses Genus verdanken wir den schönen Untersuchungen HASSE's. Es wird nun Aufgabe der P'alaiontologen sein, den Nachweis hierher gehöriger Zühne zu liefern $\left.{ }^{1}\right)$.

Urolophus (?) bicumeatus sp. n.

Taf. VII, Fig. 8-8b; Taf. VIII, Fig. 11.

Der in seiner äusseren Form sehr sonderbar gestaltete Wirbel besitzt eine Höhe ron $27^{\mathrm{mm}}$; seine Breite ist jedoch verschieden, je nachdem man dieselbe auf der Vorder-oder Hinterseite ermittelt: die kleinere Breite beträgt $25^{\mathrm{mm}}$, die grössere $30,5 \mathrm{~mm}$. Ebenso ist die Länge an der Dorsal- resp. Ventralseite verschieden: die dorsale Länge betrïgt $13,5^{\mathrm{mm}}$, und da sich der Wirbel in ventraler Richtıng ziemlich rasch verkürzt, so betrïgt die ventrale Länge nur $7^{\mathrm{mm}}$.

Es ist daher die Frontalansicht des Wirbels, je nachdem man ihn von vorn oder von hinten betrachtet, durchaus verschieden. Auf der einen Seite zeigt er die Form eines in dorso-ventraler Richtung leicht comprimirten Querovals, auf der andern Seite kreisförmigen in ventraler Richtung leicht zugespitzten Umriss. In der Seitenansicht ist der Umriss keilförmig.

Auf der Dorsalseite sieht man in der Mitte einen etwa $7,5^{\text {mm }}$ langen und $3^{\mathrm{mm}}$ breiten Spalt von elliptischer Form, der durch zwei dünne Lamellen von zwei dicht neben ihm befindlichen Oeffnungen getrennt ist. Durch secundäre Kalkablagerungen ist jedoch die regelmässige Gestalt dieser Lücken sehr modificirt und daher in der Abbildung nicht recht deutlich.

Sowohl von der Ventralseite als in der Seitenansicht sieht man nur eine zusammenhängende, von keinen Lücken unterbrochene, aber vielfach grubige, rauhe und von kleinen Löchern

1) Leider ist mir üher den interessanten Rhinobatus maronitu, welchen Frass (Aus dem Orient II, pag. 92) ans den Schiefern des Hackel nemt, Näheres uicht liekannt. 
durchsetzte Fläche. Darans dürfte wohl hervorgehen, dass die Apophysen nicht mit dem Wirbelkörper verwachsen waren.

Die Wirbelböhlung ist beiderseits ziemlich tief eingesenkt, jedoch ist auf der querovalen Seite die Aussenfläche des Doppelkegels in seitlicher Richtung, auf der andern Seite in dorso-ventraler Richtung gebogen. Die Durchbohrung für die Chorda liegt genau in der Mitte. Der centrale Doppelkegel ist ziemlich dicht an den Rändern etwas abgebogen und gerundet; die eine Aussenfläche ist sehr fein und regelmässig concentrisch gestreift, auf der andern sind die Wachsthumsringe gröber und unregelmässiger.

Im Querschnitt sieht man die verkalkte Innenzone in Form eines kleinen etwas excentrisch nach der Dorsalseite gelegenen schwarzen Kreises, den ein etwas hellerer Ring, der durchschnittene centrale Doppelkegel, umgiebt.

Die Aussenzone scheidet sich in die ziemlich scharf gegeneinander abgegrenzte Innen- und Aussenanlage; erstere, mit einem Durchmesser von etwa $8^{m m}$, welche sich nun an den Doppelkegel anlegt, stellt sich als dunkle, dichte Masse dar, die nur dorsal- und ventralwärts zwei hellere Partieen zeigt. Die Aussenlage ist etwas heller, undeutlich concentrisch geschichtet und wird von zwei keilförmigen, diametral gegenüberliegenden Partieen hellerer Substanz, welche von der Peripherie bis nahe zum Centrum reichen, auf der Dorsalund Ventralseite durchsetzt, von welchen die dorsale, nicht völlig ausgefüllte Partie etwas breiter ist, als die ventrale. Ursprünglich mögen sich an dieser Stelle mit Knorpel erfüllte Lücken befunden haben, welche späterhin durch secundäre Verkalkung ausgefüllt wurden; für diese Ansicht spricht wenigstens die nur theilweise ausgefüllte dorsale Partie.

Bei geeignet auffillendem Lichte, daher in der Abbildung ohne Uebertreibung schwer anzugeben, sieht man nun noch eine Differenzirung der Aussenlage in der Art, dass in den beiden seitlichen Theilen, welche durch die hellen medianen Partieen geschieden sind, dicht neben letzteren und zu beiden Seiten derselben dunklere keilförmige Partieen gegen einen mittleren, etwas helleren Theil abgesetzt sind, olne dass jedoch eine scharfe Grenze zwischen beiden zu zichen wäre. 
Vorkommen: Sehr selten in der Zone A.

Bemerkungen: Was zunächst die äussere Form des Wirbels angeht, so glaube ich nicht, dass dieselbe auf Abrollung zurïckzuführen, sondern als ursprünglich anzusehen ist; denn nicht nur die liänder des Doppelkegels, sondern auch die Seitenfläthen sind vollkommen intact.

Herr HAssE hatte diesen Wirbel als Myliobates-Wirbel bestimmt, jedoch ergab sich nach der Durchschneidung ein Querschnittsbild, das nach meinem Dafürhalten eine Vereinigung mit Myliobates unzulässig erscheinen liess. Das Querschnittsbild war ein so fremdartiges, dass ich unter allen von HAssE abgebildeten recenten Wirbeln kein ähnliches Object, dessen Hauptcharakter in dem Hervortreten der helleren ventralen resp. dorsalen keilförmigen Partie besteht, auffinden konnte.

Die einzige Analogie gewährt ein Urolophus-Wirbel aus dem Eocän von Etterbeck, tab. 19, fig. 14, der ein ähnliches Querschnittsbild zeigt; des besseren Vergleiches halber reproducire ich die Figur (Vergl. Texttafel Lief. I, Fig. 6):

Man sieht bei demselben je eine dorsale und ventrale Partie sich durch ihre hellere Fürbung gegen seitlich daueben liegende dunklere Theile abheben, welche wiederum durch eine hellere Zone geschieden sind. Bei dem belgischen Wirbel sind aber die Grenzen ungleich schärfer, als bei dem unsrigen, der eigentlich nur die medimen gegen die seitlichen Partieen scharf abgesetzt zeigt.

Diese Aehnlichkeit hat mich bewogen, unsern Wirbel fraglich bei Urolophas unterzubringen.

\section{Astrape (?) media sp. n. \\ Taf. VIII, Fig. $6-9$ a.}

18S4. Torpedo sp. Hasse, Einige seltene palaeontologische Funde. Palaeontographica Bd. XXI (3. Folge Bd. 7), pag. 5, tab. 1, fig. 6 und 7.

Der Umriss der Rumpfwirbel (nur solche hatte ich Gelegenheit zu untersuchen) scheint sehr zu variiren; man kann nur sagen, dass er in Allgemeinen polygonal gerundet ist; stets aber sind die Wirbel breiter als hoch, wenn auch die Differenz zuweilen nur gering ist. 
Der Fig. 6 abgebildete Wirbel zeigt in der Frontalansicht cinen gerundet achtseitigen Umriss in Folge der geraden Ränder des Doppelkegels; seine Breite beträgt 13, seine Höhe $10^{\mathrm{mm}}$.

Anders ist die Gestalt des Wirbels Fig. 7; hier nimmt in Folge einer ventralen Zuspitzung, sowie des deutlich eckig gebrochenen Ventral- resp. Dorsalrandes der Wirbel eine breitherzförmige Gestalt an; seine Breite beträgt 12, seine Höhe $10^{\mathrm{mm}}$.

Gerade die umgekehrte Form besitzt der Wirbel Fig. 8; hier erfolgt die Verschmälerung nicht in ventraler, sondern in dorsaler Richtung, daher bei gleicher Orientirung der Wirbel Fig. 6 u. 8 der letztere eine umgekehrt breit herzförmige Gestalt zeigt. In der Seitenansicht zeigt der am besten erhaltene Wirbel Fig. 6 eine rechteckige Gestalt; seine Länge ist relativ bedentend, nämlich 7,5m!.

Die Wirbelhöhlung ist ziemlich tief eingesenkt und wird geuau im Mittelpunkt von der Chorda durchbohrt.

Der centrale Doppelkegel ist ziemlich dünn, an den liäudern nicht aufgeworfen, wohl aber etwas abgeschrägt. Seine Aussenflächen sind, entsprechend der starken Vertiefing, ziemlich geneigt und zeigen eine regelmässige, concentrische Streifung.

Die Oberflächenverkalkung umzieht als glatte, ziemlich f'este Schicht die Aussenzone und war einerseits mit den Apophysen, andererseits mit den beiden Hälften des Doppelkegels innig verwachsen. Die Lücken, welche die Haftstellen der Neurapophysen anzeigen, sind ziemlich gross und liegen an den Seiten, gerade über dem Seitenstrahl der Aussenzone, auf der Dorsalseite cinander etwas näher und durch einen geringer breiten Zwischemaum geschieden, als auf der Ventralseite. Da die Oberflächenverkalkung weiter keine Lücken zeigt, so vermuthe ich, lass dic Hämapophysen nicht mit ihr verwachsen waren.

Bemerkenswerth ist eine ziemlich breite und flache, durch scharfe Kanten seitlich begrenzte Längsrinne (Taf. VIII, Fig. 6b) und 6), welche auf der Ventralseite in die Oberflächenverkalkung eingesenkt ist, da sie ein sehr gutes Hülfsmittel zur Orientirung eines nicht durchschnittenen Wirbels abgiebt.

Im Querschnitt erscheint der centrale Doppelkegel (d) (Fig. Sb) und 9a) als ziemlich schmaler, dunkler Ring, welcher die Durchbohrung für die Chorda umgiebt; diese ist zuweilen durch die ver- 
kalkte Innenzone völlig ausgefillt. Die Innenlage der Aussenzone erscheint als ein etwas breiterer ling von hellerer Farbe; die verkalkte Aussenlage der Aussenzone zerfällt in vier keilförmige Radialstrahlen: einen dorsalen, einen rentralen und je einen Seitenstrahl, welche durch schmälere, bei Lebzeiten des Thieres mit Knorpel ausgefüllte $Z$ wischenrüume, Interradiallüuken, getrennt sind. Dur allgemeine Charakter der Struhlen ist der, dass der dorsale Strahl stets am schmalsten und kürzesten, die beiden Seitenstrahlen etwas breiter sind und der Ventralstrahl am breitesten ist; doch variiren bei den einzelnen Wirbeln die Grössenverhältnisse der einzelnen Strahlen; dennoch möchte ich hierin nur einen durch die Lage der Wirbel bedingten Unterschied sehen.

Am unveränderlichsten zeigt sich der dorsale Strahl: seine Seitenflächen bilden stets einen sehr spitzen Winkel; auch die Seitenstrahlen scheinen bei allen Exemplaren eine constante Breite zu besitzen; dagegen ist bei zwei Wirbeln der rechte Scitenstrahl am Aussenrande gegabelt, bei dem Wirbel Fig. 7 deutlicher als bei dem andern Fig. 9. Der Ventralstrahl zeigt eine solche Breite bei dem Wirbel Fig. 7, dass seine Seitenflächen nahezu einen Wiukel von $180^{\circ}$ bilden; bei dem Wirbel Fig. $S$ ist er betrïchtlich schmäler, und seine Seitenflichen bilden noch einen spitzen Winkel mit cinander. Dem entsprechend sind die Interradiallücken ron verschiedener Breite, aber stets sind die ventralen schmäler als die dorsalen.

Sowohl der Ventral- als der Dorsalstrahl sind an den Seiten innig mit den Oberflächenverkalkungen verwachsen; diese sind aber durchweg bei ersterem etwas länger, so dass die rentralen Interradiallücken mach aussen hin fast vollstïndig abgeschlossen sind und nur ein schmaler Spalt zwischen den Seitenstrahlen offen bleibt. In der Seitenansicht Fig. $6 \mathrm{c}$ sieht man daher da, wo durch die Zerstörung der Apophysen eine Lïcke in der Oberflächenverkalkung entstanden ist, nur den Seitenstrahl und zwei schmale Spalten als Andeutungen der Interradiallücken. Bei Fig. $S$ ist gleichzeitig die Oberflächenverkalkung so stark rerdickt, dass sie das Lumen der ventralen Interradiallücken fast völig ausfüllt. 
Der Aufbau der Aussenlage der Aussenzone atus concentrischen Schichten zeigt sich besonders schön dadurch, dass hellere und dunklere Streifen mit einander abwechseln. Bei dem dorsalen und den beiden Seitenstrahlen bilden die Querschnitte der Schichten einfache, etwas wellige Kreislinien; bei dem Ventralstrahl digegen biegen sich die einzelnen Lamellen in der Mitte gegen das Wirbelcentrum hin ein, so dass sich ihr Querschnitt als eine doppeltS-förnig gebogrene Linie darstellt. Es ist wohl ganz unzweifelhaft, dass durch diese Einbiegung die mediane Rinne der Ventralseite erzeugt wird, wie man übrigens auch an den Abbildungen deutlich sieht.

Vorkommen: Nicht selten in der Zone $\mathbf{A}_{1}$.

Bemerkungen: Auf Grund des Aufbaues der Aussenzone scheint allerdings die Identität unserer Wirbel mit solchen des Genus Astrape noch sehr in Frage gestellt, und ich war ursprünglich geneigt, auf dieselben ein nenes Genus zu begründen. Allein ich habe nach eingehender Besprechung mit Herrn Hasse den generischen Namen Astrape beibehalten, einmal weil im Aufbau der Aussenzone unsere Wirbel diesem Genus am nächsten stehen, sodamn weil nach Herrn HASSE die elektrischen Rochen noch sehr ungenügend auf den Bau ihrer Wirbelsïule hin untersucht sind, mithin die $\mathrm{W}$ ahrscheinlichkeit, dass unsere Wirbel mit der einen oder andern recenten Form identisch sein könnten, nicht ausgeschlossen ist.

Eines aber steht ganz fest, mögen nun unsere Wirbel einem neuen Genus angehören oder nicht, sie stellen, wie der Vergleich mit den recenten Formen zeigt, eine Mittelform zwischen Astrape und Torpedo dar.

Zur besseren Erläuterung des Nachfolgenden gebe ich hier ('Texttafel Lief. I) aus HAssE's Elasmobranchiern wieder: die Durchschnitte eines Schwanzwirbels von Astrape dipterygia (HAsse, tulb. 23, fig. 3) - Fig. 7 -, denjenigen eines fossilen Astrupe-Wirbels aus dem Senon (HAsse, tab. 23, fig. 5) - Fig. 8 -, den eines Rumpfwirbels von Torpedo marmorata (HAsse, tab. 23, fig. 11) - Fig. 9-, und denjenigen zwei fossiler Torpecto-Wirbel aus dem Crag (HAsse, tab. 23, fig. 14 und fig. 18) - Fig. 10 u. 11 -. 
Man sieht aus obigen Figuren, dass der Unterschied ron Astrape und Torpedo hauptsächlich darin beruht, dass bei ersterer die keilförmigen Strahlen noch keine Spur einer Gabelung zeigen, während bei letzterer sïmmtliche Strahlen gegabelt sind, wobei die Theilung beim rentralen und in Fig. 9 auch dorsalen Strahl so weit vor sich gegangen ist, dass diese aus zwei einzelnen Aesten bestehen, die nur noch nahe dem Centrum zusammenhängen.

Von diesem Extrem entfernen sich die Wirbel aus dem Crag etwas: wohl sind noch die Seitenstrahlen sowie der ventrale Strahl getheilt, wobei zu beachten ist, dass eine Spaltung des letzteren nur etwa bis zur Mitte reicht; der dorsale Strahl dagegen verräth noch nicht die geringste Spur einer Gabelung.

Betrachtet man nun den Querschnitt der Wirbel von Astrape (?) media, so zeigt der Dorsalstrahl ebenfalls nicht die geringste Spur einer Theilung, dagegen sind zweimal und auffallender Weise gerade wie bei dem Wirbel Fig. 10 der Texttafel die rechten Seitenstrahlen gegabelt. Der Ventralstrahl scheint ungetheilt, aber die mediane Einbiegung der concentrischen Schichten der Aussenzone scheint eine solche Theilung gewissermaassen vorzubereiten, und wir sehen bei Fig. 6 u. 6d (Taf. VIII) den Ventralstrahl durch die starke Buchtung seines Randes schwach zweitheilig.

Somit ist das Quersehnittsbild von Astrape (?) media am nächsten mit Fig. 11 der Texttafel, dem Torpedo aus dem Crag, verwandt, eine Beziehung, die um so enger erscheint, wenn man die gleichartige Ausbildung der Oberflächenverkalkung im dorsalen und ventralen Strahl beider Formen in Betracht zieht.

Vergleicht man aber die Wirbel in Bezug anf Breite der Strahlen und der Interradiallücken mit einander, so sieht man, dass bei Astrape dipterygia der Dorsalstrahl betrïchtlich schmäler ist als die anderen, ebenso wie die dorsalen Interradiallücken breiter sind als die ventralen, dass dagegen die Differenz in der Breite der Seitenstrahlen und des Ventralstrahles nur eine sehr geringe ist. Ziemlich ähnlich ist das Verhältniss der Strahlenbreite bei dem senonen Wirbel Fig. 8 der Texttafel, nur dass hier die seitlichen Strahlen noch an Breite zu überwiegen scheinen. Bei Torpedo ist jedoch kaum mehr ein Unterschied in der Breite der Strahlen 
vorhanden, wenn auch immerhin nicht zu verkennen ist, dass der Ventralstrahl etwas breiter ist als der dorsale; dagegen sind die Interradiallücken sehr breit.

Unsere Wirbel zeigen nun stets einen ganz ausgeprägten Gegensatz in der Breite der Dorsal- resp. Ventralstrahlen, wenn aber auch wie Taf. VIII bei Fig. 7 und 9 die letzteren die Seitenstrahlen an Breite bedeutend übertreffen, so ist doch bei Fig. 3, analog wie bei der recenten Form (Texttafel, Fig. 7), die Differenz in der Breite beider eine nur geringe, weshalb also auf diesen Unterschied wohl nur wenig Werth zu legen ist. Schliesslich verhalten sich die Interradiallücken wie bei A. dipterygia, d. h. die dorsalen sind breiter als die ventralen.

Es stehen also die Wirbel von Astrape(?) media in Bezug auf Theilung der Strahlen den Wirbeln von Torpedo sp. aus dem Crag am nächsten, in Bezug aber auf das Verhältniss der Breite der Strahlen und der Interradiallücken untereinander waltet die Differenz, welche Astrape zeigt, bei unserer Form noch in viel ausgeprägterem Maasse vor.

Die Wirbel von Astrape (?) media repräsentiren somit einen Typus, der genau die Mitte zwischen Astrape und Torpedo hält, so dass man sie auch ebenso gut mit letzterem generischen Namen belegen könnte. Jedenfills dürften dieselben einen Beweis mehr für die enge Verwandtschaft beider Gattungen und die wahrscheinliche Entwickelung von Torpedo aus Astrape darstellen, wie HAsse annimmt. Die Abzweigung von Torpedo kann aber frühestens im Mittel-Oligocän stattgefunden haben, so dass wir nach unseren jetzigen Erfahrungen nicht hoffen dürfen, echte Torpedines in älteren denn mitteltertiären Schichten auzutreff'en.

\section{Raja borussica sp. n.}

Taf. IX, Fig. $1-1$ h, Fig. $2-2$ d, Fig. $3-3$ b, Fig. $4-4$ g, Fig. $3-5$ e.

Trotz ihrer Kileinheit sind Rochenwirbel ziemlich häufig, meist aber nicht sonderlich gut erhalten; Rochenzähne habe ich aber bis jetzt nicht auffinden könuen. 
Die Höhe des am vollständigsten erhaltenen Wirbels beträgt $8^{\mathrm{mm}}$, seine Breite $7,5^{\mathrm{mm}}$ und seine Länge etwa ebensoviel, nämlich $7^{m m}$. Das Verhältniss von Breite zu Länge stellt sich also nahezu wie $1: 1$, und es ist diese bedeutende Länge im Verhältniss zur Breite resp. Höhe eine hervorragende Eigenthümlichkeit der Rochenwirbel.

Allerdings scheint es, als ob bei den übrigen Wirbeln die Länge nicht so bedeutend sei, wie bei Fig. 1; leider aber lässt sich der unvollkommenen Erhaltung wegen das Verhältniss von Breite zu Länge kaum annäherungsweise ermitteln, sicher ist jedenfalls, dass die übrigen Wirbel etwas kürzer waren als Fig. 1.

In der Frontalansicht zeigt Fig. 1 einen schwach hochovalen Umriss mit fast unmerklicher ventraler Zuspitzung, in der Seitenansicht quadratische Form. Eine Orientirung ist ziemlich schwer, da Dorsal- und Ventralseite katum von einander abweichen. Auf der Dorsalseite sieht man in der Mitte zwei dicht neben einander liegende, nur durch einen schmalen Zwischenraum getrennte, etwa $1 / 2^{\mathrm{mm}}$ starke Längslamellen; bei allen übrigen Wirbeln sieht man an der gleichen Stelle nur eine Längslamelle, bei Fig. 3 ist jedoch deutlich erkennbar, dass zwei Lamellen durch Oberflïchenverkalkung zu einer einzigen verschmolzen sind. Seitlich davon befinden sich zwei grosse, halbkreisförmige Lücken, die bei Fig. 1 in der Mitte etwa $3^{\text {mm }}$ breit, leider aber mit Gestein ausgefüllt sind. Im Grunde dieser Lücken erkennt man bei Fig. 2, 3 u. 5 je eine kurze, kaum bemerkbare Längslamelle, welche aber bei Fig. 4 eine bedeutende Länge erlangt und bis zum Rand des Doppelkegels reicht.

Die Ventralseite zeigt bei allen Wirbeln in der Mitte nur eine schmale Längslamelle, welche zwei seitlich gelegene grosse Lïcken scheidet; im Grunde derselben sieht man wiederum je eine Lamelle, bei Fig. $2 \mathrm{~b}$ und deren Vergrösserung $2 \mathrm{~d}$ auf der einen Seite sogar deren zwei, welche bei den einzelnen Wirbeln wiederum durch verschiedene Länge ausgezeichnet sind; bei Fig. 5 sind sie überhaupt nur angedeutet, bei Fig. 1 u. 2 erreichen sie nicht die Peripherie des Doppelkegels, während sie bei Fig. 4 bis zu derselben heranreichen. 
Bei seitlicher Betrachtung sieht man in der Mitte der Höhe eine ventral- und dorsalwärts halbkreisförmig atusgeschnittene Lamelle, welche sich vor den übrigen stets durch bedeutend grössere Breite auszeichnet; bei Fig. 1 misst sie an der schmalsten Stelle in der Mitte 2,5 $5^{\mathrm{mm}}$.

Die Wirbelhöhlung ist sehr tief, spitz kegelförmig eingesenkt, die Durchbohrung fiur die Chorda liegt genau central.

Der dünne centrale Doppelkegel besitzt leicht abgerundete oder ziemlich scharfe Ränder und seine Aussenflächen zeigen einige grobe concentrische Schichtungsringe.

Das Querschnittsbild der einzelnen Wirbel ist ungemein verschieden, Verschiedenheiten, die sich hauptsächlich in der Gestaltung der Aussenzone aussprechen. Die zuweilen verkalkte, und dann als dünner schwarzer Kreis ('Taf. IX, Fig. 3c u. $4 \mathrm{~g}$ ) erscheinende Innenzone wird von dem Doppelkegel, der sich ebenfalls als clünner, aber heller Ring darstellt, nugeben.

Bei Fig. 1 in h zeigt die Aussenzone eine centrale helle Partie in Form eines hochkantig gestellten Rechteckes, dessen Seiten leicht eingedrückt und dessen Ecken abgerundet sind. Diese letzteren entsprechen den Längslamellen, welche bei ventraler Ansicht, Fig. 1f, in den Lücken sichtbar sind. Eine dunkle Schicht, welche innig mit der centralen Partie verschmolzen ist, liegt zwischen dieser und vier peripheren von einander isolirten Particen, die sich wieder durch eine hellere Farbe auszeichnen, und daher scharf gegen die schwarze Schicht absetzen, mit welcher sie gleichwohl innig verschmolzen sind. Die peripheren Partieen scheiden sich in zwei laterale und je eine ventrale resp. dorsale, diese letztere gegabelt. Ob und wie diese peripheren Theile mit der centralen Partie in Verbindung standen, lässt sich nicht ermitteln. Vielleicht waren es einfache Oberflïchenverkalkungen, vielleicht auch standen sie entlang der Innenflächen der Doppelkegelhälften mit der centralen Partie in Connex und waren in der Mitte durchbrochen.

Fig. 5 stellt sich völlig davon abweichend dar; hier entwickeln sich (Fig. 5a u. b) in der Aussenzone vier Radialstrahlen, je ein dorsaler, ventraler und zwei laterale, die in Abständen von $90^{\circ}$ von einander stehen. Im centralen Theil verdicken sie sich bedeutend 
gegen die Peripherie hin, wo sich die Lateralstrahlen mehrfach, aber unregelmiässig spalten. Zwischen diesen befinden sich vier kurze Fortsät\%, die etwa den Ecken eines Rechteckes entsprechen.

Das am meisten differirende Bild zeigt Fig. 4; hier entwickelt die Aussenzone acht bis zur Peripherie reichende Strahlen (Fig. $4 \mathrm{~d} \mathrm{u.g}$ ), von welchen vier, nämlich der dorsale, ventrale und die beiden lateralen ein rechtwinkliges Krenz bilden, während die vier andern die Zwischenräume halbiren. Alle sind von nahezu gleicher Stärke und verdicken sich gegen den Rand hin nur wenig.

Vorkommen: Nicht sehr selten in der Zone $A_{1}$.

Bemerkungen: Die einzelnen Wirbel differiren in ihrem Querschnittsbild und daher auch in ihrem ïusseren Ansehen sehr beträchtlich. Diese Differenzen sind, wie bereits bemerkt, auf die verschiedenartige Gestaltung der Aussenzone zurückzuführen. Ich bin nun nicht ganz sicher, ob ich hierin specifische Unterschiede oder Abweichungen in der Lage des Wirbels in der Wirbelsäule, je nachdem die Wirbel mehr nach dem Kopf oder dem Schwanz hin liegen, erblicken soll. Ja es will mir sogar scheinen, als ob der Wirbel Fig. 4 mehr Aehnlichkeit mit Rhinobates oder Trygonorkina ${ }^{1}$ ) als mit Raja besitze. Ich habe nun,

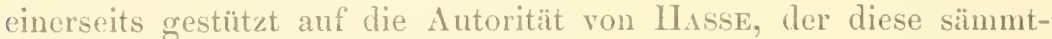
lichen Wirbel als $R$ aja-Wirbel bestimmte, andererscits darum, weil das Querschnittsbild der einzelnen Wirbel, möge es noch so verschieden sein, nicht ohne zu grossen Zwing sich auf einen gemeinsamen Grundtypus zurückführen lïsst, die Wirbel unter einem gemeinsamen Namen bezeichnet. Weun man vom Wirbel Fig. 1 als dem einfachsten Bilde ausgeht, so sind bei Fig. 5 die vier peripheren Particen bereits mit dem centralen Theil verschmolzen, während sich, wenn auch nur schwache, Andentungen der schrägen Strahlen geltend machen; bei Fig. 2 sind diese bereits viel stärker ausgebildet (leider wurde verabsäumt, einen Querschnitt anzufertigen) und bei Fig. 4 reichen sic endlich bis zum Rande.

Wollte ich die Wirbel anseinander halten, so müsste ich jeden Wirbel mit einem besonderen Namen belegen; aber hierzu wäre

1) Vergl. Hasse, System der Elasmolsranchier talb. 15. 
zu bemerken, dass bis jetzt die Wirbelsäule der recenten RajaArten noch viel zu wenig bekannt ist (HAsse giebt im Ganzen nur vier Querschnittsbilder, darunter nur zwei von recenten Formen), als dass sich hierüber etwas Bestimmtes entscheiden liesse. Um aber allen ctwa später sich erhebenden Unklarheiten vorzubeugen, so möchte ich diesen Fall im Auge halten und dann die oben neu eingeführte specifische Benennung Raja borussica nur für den Wirbel Fig. 1a-h angewendet wissen.

\section{Squatina Beyrichi sp. n.}

$$
\text { Taf. VII, Fig. 2-7a. }
$$

Nach der Zahl der vorhandenen Wirbel zu schliessen, muss Squatina Beyrichi einer der hänfigsten ${ }^{1}$ ) Fische des damaligen Meeres gewesen sein, denn etwa 50 pCt. aller Wirbel entfallen auf diese Art. Merkwürdiger Weise ist im Gegensatz zu diesem grossen Wirbelreichthum auch nicht ein einziger Zahn gefunden worden, obgleich Squatina-Zähne gerade nicht so zerbrechlich oder klein sind, dass ihre Conservirung als unmöglich angesehen werden müsste. Ich habe alles mir zu Gebote stehende Material (es sind (in paar hundert Zähne) gerade mit Rücksicht auf Squatina-Zähne aufmerksam durchforscht, ohne eine Spur oder Fragment eines solchen zu finden; es würden mir'die ausserordentlich charakteristischen und leicht kenntlichen Zähne keinenfills entgangen sein, wenn sie vorhanden gewesen wären.

Die Wirbel dieser Art, wie überhanpt des Genus Squatina im Allgemeinen, lassen sich von allen anderen mit ihnen zusammen vorkommenden Wirbeln auf den ersten Blick an der bedeutenden Entwickelung des Wirbelkörpers in die Breite bei nur geringer Höhe unterscheiden. Es ist dies eine Eigenthümlichkeit, die, wie

1) Da nach HAsse (System der Elasmobranchier pag. 133) Squatina eine ungemein geringe Wirbelzahl, nämlich 41 , besitzt - es wird diese geringe Zahl der iso Wirbel besitzenden $S$. accunthoderma gegenüber betont - so würde sich der Wirbehreichthum dann nur durch eine grosse Individuenzahl erklären. Nach ciner nicht genannten Quelle wird von Hurrecrit (Bross, Classen und Urdnungen Bd. VI, Abth. I, pag. (60) die Zahl der Wirbel ron Syuetina mit 117 angeguben, was allerdings in starkem Widerspruch zu Hasse's Angabe steht. 
HASSE mit Recht betont, das hervorragendste Charakteristicum in der äusseren Form der Wirbel darstellt, und in diesem Grade bei keinem andern Elasmobranchier wiederkehrt. Einige Zahlen mögen diese Angabe näher erlïutern, es beträgt bei:

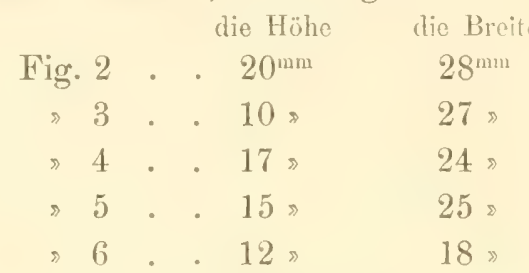

Die Ilöhe des Wirbels beträgt mithin $2 / 3-^{3 / 4}$ seiner Breite ${ }^{1}$ ). Die Rumpfwirbel zeigen somit in der Frontalansicht einen querelliptischen Umriss, der aber selten ganz gleichmässig ausgebildet ist, sondern mancherlei Abänderungen unterworfen ist; so z. B. dadurch, dass, wenn sich die Ansatzstellen der Apophysen bemerklich machen, der Wirbelrand an den betreftenden Stellen etwas eingedrückt erscheint, wodurch dann eine gerundet vierseitige Form (Fig. 2) erzeugt wird. Die Ventralseite ist bei der Mehrzahl der Wirbel gerade, oder vielleicht in der Mitte ganz schwach vertieft; die Seiten sind in flachem Bogen gekrümmt und die Dorsalseite ebenfalls wieder horizontal oder auch in der Mitte stark eingebuchtet. Dadurch erscheinen dann die Wirbel gleichsam in dorsoventraler Richtung etwas comprimirt. Prägt sich die mediane Einbuchtung der Dorsal- resp. Ventralseite stark aus, so nimmt der Wirbel eine Gestalt an, die HAsse bisquitförmig nennt.

Die Schwinzwirbel unterscheiden sich von den Rumpfwirbeln dadurch, dass die Dorsal- und Ventralseite flach gekrümmt sind, daher erscheinen die Wirbel weniger comprimirt und ihr Umriss stellt ein regelmässigeres Oval dar.

In der Seitenansicht erscheinen dadurch, dass die Seitenflächen weder eingesenkt noch emporgewölbt, sondern vollkommen flach sind, die Wirbel rechteckig, wobei die Lünge derselben etwa ihrer halben Höhe gleichkommt, öfter auch, namentlich bei den Schwanzwirbeln, etwas mehr beträgt.

1) Bei cinem Rumpfwirbel der recenten S. vulyaris ist das Missverhältniss noch anffäliger; es betrug hier die Breite 24, die Höhe $15^{\text {mun }}$, wonach sich also die letztere zu nur $5 / 8$ der ersteren ergiebt. 
Die Wirbelhöhlung ist bei den Rumpfwirbeln ziemlich flach, bei den Schwanzwirbeln jedoch meist etwas stärker vertieft. Bei den Rumpfwirbeln beginnt sie aber nicht am Rande des Doppelkegels, sondern in einiger Entfernung von demselben; hierdurch entsteht rings un die Wirbelhöhlung ein schmaler, flacher Saum, welcher den zarteren 'Theilen des Intervertebralgewebes zur Anheftung diente. Bei den Schwanzwirbeln scheint jedoch dieser Randsaum nur wenig oder gar nicht zur Ausbildung gelangt zu sein, und auch bei den Rumpfwirbeln variirt die Schärfe seiner Ausbildung insofern, als er nicht immer durch eine markirte Kante gegen die Wirbelhöhlung abgegrenzt ist; sebr scharf ist er z. B. bei Fig. 2 ausgebildet, weniger deutlich zeigen ihn die anderen Wirbel; auch scheint es, als ob der Saum am ventralen und dem Seitenrand etwas breiter ist als am dorsalen.

Die Durchbohrung für die Chorda liegt genau in der Mitte der Wirbelhöhlung. Der centrale Doppelkegel ist dick, und seine Dicke nimmt selbst gegen das Centrum hin nur sehr wenig ab; sein Rand ist jedoch nicht aufgeworfen und bei seitlicher Betrachtung wenig oder gar nicht sichtbar, da er von der Oberflächenverkalkung beinahe völlig überwuchert ist. Die Aussenflächen sind, entsprechend der flachen Wirbelhöhlung, ziemlich stark ansteigend, glatt, aber nicht concentrisch gestreift.

Die Oberflächenverkalkung ist ungemein stark entwickelt; sie bildet zwischen den beiden Hälften des Doppelkegels eine rauhe, runzelige, von zahlreichen Gefässen durchbohrte Schicht, welche jedoch gerne abbröckelt und dann die concentrischen Lamellen der Aussenzone sehen lässt. Die wenigstens an der Basis verkalkt gewesenen Apophysen sind so innig mit ihr verschmolzen, dass dieselben sich nicht vom Wirbelkörper isoliren lassen, ohne in der Oberflächenverkalkung Lücken zu hinterlassen. Diese Lücken, von unregelmässig länglichem Umriss, besitzen stets mehr oder minder aufgeworfene Ränder und sind für die Orientirung, wenigstens der Rumpfwirbel, sehr wichtig.

Die Lücken oder Ansatzstellen der Neurapophysen (nn) liegen auf der Dorsalseite, ziemlich nahe in der Mitte, durch nur wenig breite Brücken der Oberflächenverkalkung getrennt, Fig. 3a; die Haftstellen für die Hämapophysen $(h \mathrm{~h})$ sind von der Ventralseite, 
wo sie sich bei den Schwanzwirbeln befinden, bei den Rumpfwirbeln in dorsaler Richtung auf die Seitenflächen hinauf gerückt und daher, da beide nahezu diametral gegenüber liegen, durch einen beinabe die IIälfte des L'mfanges betragenden Theil der Obertlïchenverkalkung getrennt.

Der Querschnitt zeigt in Fig. 5a etc. den charakteristischen inneren Aufbau der Squatina-Wirbel. Rings um die verkalkte Innenzone (i) stellt sich der centrale Doppelkegel (d) als breiter, dunkler Streifen von dichter Structur dar. Um diesen lagern sich die dünnen, concentrischen Lamellen der Aussenzone (a), im Centrum etwas dichter als an der Peripherie. Ich zihle bei meinem Exemplar mindestens 40 solcher Lamellen; es mögen aber wohl zwischen 40 und 50 gewesen sein, genau lässt sich das nicht mehr angeben. Dieselben werden von radialen Strahlen durchkreuzt, welche von der Peripherie gegen das Centrum hin vordringen und nach HASsE die verkalkten Wandungen von Gefïssstïmmen darstellen.

Vorkommen: Sehr häufig in der Zone $A_{1}$.

Bemerkungen: Es war mir von grossem Werthe, die Wirbel der recenten Squatina vulgaris mit unserer Art vergleichen und somit die Unterschiede feststellen zu können, welche die specifische Selbständigkeit der let»teren zu begründen scheinen. Leider konnte ich, da mir nur lumpfivirbel zn Gebote standen, den Vergleich blos auf diese, nicht aber auch auf die Schwanzwirbel bezichen. Zur besseren Erläuterung des nachfolgenden gebe ich die Abbildung des sechsten Rumpfwirbels von Squatina vulgaris, der sich in meiner Sammlung befindet (Texttafel Lief. I, Fig. 12).

Der Hauptunterschied liegt in der verschiedenen Form der Rumpfwirbel beider Arten: bei $S$. vulgaris stellt der Umriss ein schönes, schmales Oval, bei S. Beyrichi eine breitere, gewissermaassen plumpere Ellipse dar. Während bei letzterer der Wirbel in Folge des flachen Dorsal- resp. Ventralrandes in dorso-ventraler Richtung comprimirt erscheint und die Seiten in flachem Bogen gekrümmt sind, ist bei $S$. vulgaris die Ventralseite, namentlich aber die Dorsalseite, stark gekrümnt, wogregen die rechte und linke Seite einen sehr spitzen Bogen beschreiben. Die Rumpfwirbel der recenten Form gleichen somit mehr den Schwanzwirbeln der S. Beyrichi, doch sind diese immer noch relativ höher als jene, wie ein Vergleich 
der Fig. 12 der Texttafel mit Taf. VII, Fig. 3 lehrt; abgesehen davon unterscheiden sie sich anch durch die Lage der Apophysen. Ausserdem muss bei unserer Art die Zahl der concentrischen Lamellen der Aussenzone mindestens doppelt so gross gewesen sein, wie bei S. vulgaris, da HAsse deren Zahl bei letzterer zu etwa zwanzig angiebt, während bei S. Beyrichi (Taf. VII, Fig. 5) mehr als vierzig vorhanden waren.

Unter den fossilen Formen, welche durch Hasse beschrieben sind, zeigt dessen tab. 18, fig. 22 von Squatina sp. aus der oberen Kreide eine gewisse Uebereinstimmung mit unserer Art, da sowohl der Dorsal- als der Ventralrand des Doppelkegels beinahe gerade laufen, und die Seitenränder in flachem Bogen gekrümmt; allein der Kreidewirbel ist in dorso-ventraler Richtung noch viel mehr comprimirt als Squatina Beyrichi, daher seine Form niedrig vierseitig erscheint; ferner liegt bei ihn die Durchbohrung für die Chorda excentrisch, etwas nach der Dorsalseite gerückt, und schliesslich ist die Breite des Randsaumes insofern abweichend, als dieser bei dem Kreidewirbel seitlich sehr breit, dorsal und ventral aber schmal ist. S. Beyrichi besitzt einen durchweg schmalen Randsaum.

Ueber das Verhältniss von S. Beyrichi zu dem an Alter nächststehenden Wirbel aus dem Oligocän von Ofterweddingen vermag ich nichts zu sagen, da IIASSE von demselben nur ein Quersehnittsbild mittheilt.

\section{Selache glanconitica sp. n.}

1851. Selache sp. Hasse, Einige seltene palneontologische Funde; Palneoutogratphica Bd. XXXI, pag. 10, tab. 2, fig. 10.

Von diesem Wirbel, der in der Sammlung des Provinzialmuseums anfbewahrt wird, giebt HASSE nur eine Abbildung, die bedanerlicher Weise nicht durch eine Beschreibung näher erläutert wird. Da es mir nicht vergönnt war, diesen interessanten Wirbel ans eigener Anschauung studiren und somit IlAsse's Abbildung crgänzen zu können, so muss ich mich auf den literarischen Hinweis beschräuken; um aber Verwirungen vorzubengen, lege ich der Form obigen Namen bei. 
Vorkommen: Sehr selten in der Zone $\mathbf{A}_{1}$.

Bemerkungen: Bei der Kleinheit der Selache-Zähnchen kann es nicht befremden, dass solche nicht nachgewiesen werden konnten.

\section{Oxyrhina xiphodon Agassiz.}

Taf. III, Fig. $1-10$ a.

1843. Oxymhina xiploodon Agassiz, Recherches sur les poissons fossiles Bd. III, pag. 278.

Ein grosses Gebiss der recenten Oxyrhinc glauca, welches ich der Freundlichkeit des Herm Hilgendonf in Berlin verdanke, war mir bei der Untersuchung des fossilen Materials von ausserordentlichem Nutzen. Es setzte mich in den Stand, Mittel- und Seitenzähne ${ }^{1}$ ) sowohl des Ober- als des Unterkiefers genau unterscheiden und hierdurch ein annähernd vollständiges Gebiss dieser Art reconstruiren zu können. Die Mittelzähne des Ober- resp. Unterkiefers sind leicht anseinander zu halten, schwieriger wird es bei den Seitenzähnen, und man erkennt hier den Werth eines recenten Gebisses, das jederzeit zum Vergleich herangezogen werden kann, ganz besonders.

Von Oxyrhina xiphodon finden sich entsprechend dem Verhältniss der Zähne bei der recenten Art die Seitenzïhne natürlich häufiger, als die Mittelzähne.

c) Mittelzähne.

Die Mittelzähne charakterisiren sich durch eine schlanke, an der Basis schmale Krone und eine dementsprechend schmalere Wurzel.

1) Ich muss hier der Bemerkung Pronst's (Würtembergische naturw. Jahreshefte 1S7s, pag. 129), dass zwischen den Seitenzühnen des Ober- resp. Unterkiefers kein Unterschied sei, widersprechen. Das Gebiss der Oxyrhina glaucu zeigt sehr deutlich, dass weun auch die Seitenzïhne beider Kiefer sehr älılich sind, die Form derselben in nachbeschriebener Weise verschieden ist. Man wird vielleicht bei einem einzelnen Zahn, der den hinteren Partieen der Kiefer angehört, im Zweifel sein können, verfügt man aber über grösseres Material, sn wird mau leicht die Typen ausseheiden können. 
1. Unterkiefer.

Die Mittelzähne des Unterkiefers sind leicht kenntlich an der schmalen langästigen Wurzel, deren Aeste in seitlicher Richtung comprimirt sind und einenspitzen Winkel mit einander bilden, und der schlanken nach Innen gebogenen Krone. Der am besten erhaltene Zahn (Fig. 1) besitzt eine Gesammthöhe von $35^{\mathrm{mm}}$, davon kommen auf die Krone, deren Spitze jedoch etwas verletzt ist, $20^{\mathrm{mm}}$, also etwa $3 / 5$ der Gesammthöhe. Wurzel und Krone sind nicht scharf gegeneinander abgesetzt, sondern erstere geht allmählich in letztere über. Die Wurzel besitzt etwa $20^{\mathrm{mm}}$ Breite und eine grösste Höhe von $15^{\mathrm{mm}}$, die in der Mitte bis auf $10^{\mathrm{mm}}$ abnimmt. Die grösste Dicke, $10^{\mathrm{mm}}$, liegt in der Mitte etwas oberhalb der Eintrittsöffnung für den Hauptnerv; nach den Seiten ermässigt sich die Dicke jedoch ungemein rasch. Die ziemlich hohe Externfläche ist in der Mitte tief concav, scitlich dagegen flach, selbst etwas gewölbt. Die schräge Neuralfläche ist eigentlich nur in der Mitte ausgebildet, wo sie übrigens leicht vertieft ist; seitlich versehmälert sie sich so stark, dass Ligament- und Externfläche fast zusammenstossen. Demgemäss ist auch die Ligamentkante nur in der Mitte etwas dentlicher, während sie seitlich verschwindet. Der grösste Theil der Internseite wird vou der hohen Ligamentfläche eingenommen, die in der Mitte gewölbt, seitlich dagegeu flach und ziemlich schräg gegen die Spitze geneigt ist. Der Neuralrand ist an den Seiten kantig gerundet, in der Mitte abgeflacht und tief paraboliseh gebuchtet, daher die Wurzel lang zweiästig; die beiden Aeste sind flach comprimirt, an Vorder- und Hinterrand abgerundet.

Da die Stelle, wo der Hauptnerv in die Wurzel eintritt, etwas verletzt ist, so ist die eigentliche Oeffinung nicht scharf zu beobachten; man sieht jedoch, dass sie in der Mitte hart an der Ligamentkante liegt. Der Eindruck der Befestigungsmembran ist im Ganzen ziemlich undentlich und nur auf der Innenseite besser zu verfolgen. Er stellt sich hier als ein in der Mitte schmales, gegen die Seiten breiter werdendes Band dar, das anf der Externseite in der Mitte stark eingeschnürt ist. 
Die Krone besitzt an der Basis nur $10^{\mathrm{nm}}$ Breite; in Rücksicht auf die doppelt so grosse Höhe gleicht ihr Umriss einem schmalen gleichseitigen Dreieck; sie ist ziemlich stark nach Innen geneigt, die oberste Spitze jedoch wieder schwach nach Aussen gebogen. Die Externseite ist flach, die Internseite hoch gewölbt und nach den Seiten steil, beinahe senkrecht abfallend; der Querschnitt wird hierdurch halbkreisförmig. Vorder- und Hinterrand sind gerade, gleich lang und ihrer ganzen Lünge nach mit einem glatten schneidenden Kiele besetzt. Die Dicke der Krone beträgt an der Basis $8^{m m}$ und nimmt anfaugs ziemlich rasch, später allmählich ab. Die Emailgrenze läuft auf der Innenseite hoch bogenförmig, auf der Aussenseite in flach doppelt-S-förmig gekrümmter Linie.

2. Oberkiefer.

Die Mittelzähne des Oberkiefers sind leicht kenntlich an der etwas breiteren, weniger tief gegabelten Wurzel und der vollkommen verticalen Krone.

Der am besten erhaltene Zahn (Fig. 2) besitzt eine Gesammthöhe von etwa $37^{\mathrm{mm}}$; davon kommen auf die Krone allein etwa $28^{m m}$, die demnach etwa :/4 der Gesammthöhe einnimmt. Es stimmt diese Angabe übrigens recht gut mit Messungen an dem recenten Exemplar, und es kann als weiteres Kennzeichen der Mittelzähne des Oberkiefers die verhältnissmässig höhere Krone aber niedrigere Wurzel gegenüber den Mittelzähnen des Unterkiefers gelten.

Die Wurzel besitzt eine Breite von $26^{\mathrm{mm}}$ und eine Höhe von $9^{m m}$; ihre grösste Dicke in der Mitte beträgt etwa ebenso viel, nimmt jedoch gegen die Seiten, wenn auch nicht sehr rasch, ab. Die Externfläche ist nicht sehr hoch, in der Mitte nur wenig eingesenkt, seitlich flach, ja selbst etwas gewölbt. Die Neuralfliche ist ebenfalls nicht sehr hoch, wenig schräg gerichtet und vollkommen flach. Die Ligamentkante ist in der Mitte scharf markirt, gegen die Seiten etwas verwischt. Die Ligamentfläche ist hoch, aber wenig gegen die Spitze geneigt, in der Mitte gewölbt, seitlich abgeflacht. Der Neuralrand ist flach hyperbolisch gebuchtet, daher die Wurzelïste nur wenig hervortreten und kurz sind. 
Die Eintrittsstelle für den Hauptnerv liegt in der Mitte der Neuralfläche hart an der Ligamentkante. Der Eindruck der Bef'estigungsmembran ist auf' der Internseite undeutlich ausgeprägt; er wird jedoch in der Mitte nur sehr schmal bandförmig gewesen sein und hat sich gegen die Seiten schwach verbreitert. Auf der Externseite ist er schärfer und stellt ein ziemlich breites, in der Mitte stark eingeschnürtes Band dar, dessen Unterrand durch eine tiefe Furche bezeichnet wird, während der Oberrand weniger scharf markirt wird.

Die Krone ist an der Basis $17^{\mathrm{mm}}$ breit, besitzt die Form eines schlanken gleichschenkeligen Dreiecks und ist vollkommen gerade gerichtet, nur die äusserste Spitze ist unmerklich nach Aussen gebogen. Die Externseite ist eben, die Intermseite stark gewölbt, nach den Seiten steil abfallend, aber in der Mitte etwas abgeflacht. Vorder- und Hinterrand sind gerade, gleich lang und von der Spitze bis zur Basis mit scharfem glatten Kiele versehen. Die Dicke der Krone an der Basis beträgt bei Fig. $28^{m m}$ und nimme gegen die Spitze hin sehr allmählich ab.

Die Emailgrenze ist auf der Internseite flach nach oben gekrümmit, auf' der Externseite nahezu horizontal.

(j) Seitenzähne.

Die Seitenzähne sind charakterisirt durch eine an der Basis sehr breite, aber dünne Krone und dem entsprechend breite, nur sehwach gegabelte Wurzel, sind aber an der Form der Krone leicht zu unterscheiden, sofern man über grösseres Material gebieten kann.

1. Unterkiefer.

Bei den Seitenzåhnen des Unterkiefers ist nur die oberste Spitze leicht nach rückwärts gezogen.

Die vorderen Seitenzähne des Unterkiefer's besitzen eine Gesammthöhe von $28-30^{m m}$, bei den hinteren Seitenzähnen sinkt die Höhe bis zu $11,5^{\mathrm{mm}}$ herunter, davon kommen etwa $3 / 4$ auf die Höhe der Krone. Wurzel und Krone sind nicht scharf gegeneinander abgesetzt, sondern gehen allmählich in einander ïber. 
Die Wurzel besitzt bei den vorderen Zïhnen eine Breite von 22 - $25^{\mathrm{mm}}$ und eine Höhe von etwa $7^{\mathrm{mm}}$. Ihre grösste Dicke, $7^{\mathrm{nm}}$, nimmt von der Mitte gegen die Seiten hin langsam ab.

Die Externfläche ist ziemlich hoch und fast vollkommen eben, da sie in der Mitte kaum eingesenkt ist. Die ebenfalls sehr hohe Neuralfliathe ist sehr schräg nach uben grerichtet und ebenfalls vollstïndig aben. Die Ligamentkinte ist sehr undeutlich ansgeprä̈gt, lïuft jedoch dem Neurahrande beinahe parallel. Die Liganentflitehe ist ungewöhnlich schmal, nur bei Fig. 4 etwas breiter und nicht sehr schrïg gegen die Krone geneigt. Der ziemlich scharfkantige Neuralrand ist stumpfwinkelig gebrochen, und da Vorder- und Hinterrand ebenfalls ziemlich scharfkantig sind, so ist die Wurzel ausgezeichnet meisselförmig gestaltet. Bei der schwachen Einhiegrung des Neuralrandes sind eigentliche Wurzeläste kaum vorhanden.

Die Oefinung für den Hauptnerv liegt anf etwa halber Höhe in der Mitte der Neuralfläche, bei einem Exemplar sehr deutlich auf einem kurzen, flachen Verticalkiele, der sich in breiter, seichter Einsenkung erhebt (Fig. 4) ${ }^{1}$ ).

Der Eindruck der Befestigungsmembran ist bei keinem meiner Exemplare dentlich; auf der Internseite muss er sehr schmal bandförmig gewesen sein mit geringer Verbreiterung gegen die Seiten, auf der Externseite stellt er ein vorn und hinten ziemlich breites Band dar, das in der Mitte fast bis zur Unkenntlichkeit eingeschnürt ist. Der Unterrand ist nach unten convex, der Oberrand lang doppelt-S-förmig gebogen. Bei einem Exemplar (Fig. 5) ist derselbe noch mit einer dünnen, braunen, matten Haut überzogen.

Die Breite der Krone schwankt bei den vorderen Seitenzähnen von $21-24^{\mathrm{mm}}$, nimmt aber nach hinten bis $\mathrm{zu} 10,5^{\mathrm{mm}}$ ab. Die

1) Dass diese Lage des Nerrenloches nicht etwa zufällig, sondern charakteristisch für das Genus Oxyrhina ist, scheint aus meinem recenten Vergleichsmaterial hervorzugehen, bei welchem dieselbe an allen Zähnen am oberen Ende eines zuweilen selhr deutlich markirten Verticalkieles liegt, der sich aus leichter Einsenkung erhebt. Andeutungen des Kieles und der Einsenkung sind übrigens bei fast allen meinen fossilen Zühnen vorhanden. 
vertical gerichtete Krone, deren Spitze häufig nach aussen gekrümmt ist, gleicht einem breiten, nahezu gleichschenkeligen Dreieck, dessen Spitze jedoch aus der Mitte schwach nach hinten gezogen ist. Die Externseite ist eben, zuweilen in der Mitte leicht grekielt; die Internseite ist stärker gewölbt, aber seitlich nicht sehr steil abfallend und in der Mitte, vielfach sogar ziemlich bedeutend, abgeflacht. Vorder- und Hinterrand sind in ihrer Länge nur um weniges verschieden, doch ist ersterer länger als letzterer, dabei etwas schräg nach hinten gerichtet, gerade oder leicht convex; letzterer ist gegen die Basis convex und im oberen Theile beinahe vertical laufend. Beide sind von der Spitze bis zur Basis mit dïnnem scharfen Kiele besetzt. Eigentliche Nebenspitzen fehlen, doch ist die Krone an der Basis vorn und hinten in kleine schmale Zipfel ausgezogen, deren hinterer nach innen, der vordere nach aussen gedreht ist.

Das Email ist sowohl auf der Intern- als Externseite in flachwinkelig gebrochener Linie ausgeschnitten.

2. Oberkiefer.

Die Seitenzähne des Oberkiefers sind leicht daran kenntlich, dass die ganze Krone sehr schief nach rückwärts gerichtet ist.

Bei der Beschreibung kann ich mich kürzer fassen, da sie in den Hauptmerkmalen mit den vorigen übereinstimmen, und nur die Form eine abweichende ist. Ihre Gesammthöhe schwankt zwischen $25-30^{\mathrm{mm}}$, wovon etwa $3 / 4$ auf die Krone kommen.

Die Wurzel ist womöglich noch mehr in die Breite gezogen, aber anscheinend ungleich-ästig, indem wenigstens bei Fig. 9 der hintere Ast etwas länger ist als der vordere; dabei ist der Vorderrand sehr schräg nach hinten gerichtet, der Hinterrand beinahe senkrecht. Es war ferner die Ligamentfläche durchweg etwas breiter als bei den vorigen.

Die senkrecht gerichtete Krone besitzt den Umriss eines schiefwinkeligen Dreiecks, dessen Spitze aus der Mitte so weit nach hinten gerückt ist, dass sie beinahe über dem Hinterrand der Wurzel steht. Dadurch ist der lang-S-förmige, sehr schräg nach hinten gerichtete Vorderrand viel länger als der senkrecht 
errichtete Ilinterrand, der an der Basis concav oder stumpfwinkelig geknickt ist.

Vorkommen: Häufig in der Zone $A_{1}$, sonst allgemein verbreitet im unteren, vielleicht auch mittleren Tertiär.

Bemerkungen: Obwohl ich hier Zahnformen unter einer specifischen Bezeichnung Oxyrhina wiphodon vereinigt habe, die in ihrer Gestalt beträchtlich ron einander abweichen, so hege ich dreh übre deren Zusimmengehörigkeit nicht den geringsten Kweifel, nachdem ich die hier beschriebenen Typen am Gebiss der recenten Oxyshina glanca rereinigt wieder gefunden habe.

Die Mittelzähne des Oberkiefers dürften etwa AGassiz's Oxyyrhina hastalis, diejenigen des Unterkiefers seiner Oxyrhina Desori entsprechen; für die Seitenzähne erachte ich die Identität mit Oxyrhina xiphodon als vollständig, da Agassiz als bezeichnendstes Merkmal dieser Art die Abflachung der Internseite der Krone angiebt; daher habe ich diesen Namen als specifische Bezeichnung gewählt.

Ich kann es hier nicht als meine Aufgabe betrachten, zu untersuchen, welche und ob die ron AGassiz unter den verschiedensten Namen beschriebenen Arten zusammengehören. Einerseits sind seine Abbildungen für diesen Zweck zu wenig präcis, und dann müsste man für jeden Zahn genau das Niveau und den Fundort kennen, um die zusammengehörigen methodisch untersuchen zu können, wenn eine solche Discussion einigen Erfolg haben sollte.

Herr Probst ${ }^{1)}$ hält dafür, dass die Arten O. Desori Agass., $O$. wiphodon AGsiss. und O. hastilis A Gass. thatsächlich verschieden seien und beschreibt diesen Arten angehörige Zahnreihen. Allein ich kann in diesem Falle den Ansichten des treftlichen Forschers nicht vollständig beipflichten, da Herr Pronst Ober- und Unterkieferzähne nicht scharf geschieden hat. Ich möchte annehmen, als ob seine fig. 17, 18 u. 19 (O. xiphodon Probst) Seitenzähne des Oberkiefers, fig. 3, 4 u. 5 (O. hastalis Probst) Seitenzähne des Unterkiefers, fig. 1 u. 2 (O. hustilis Pronst) Mittelzähne des

1) Württembergische naturw. Jahreshefte, Jahrgang 1879 , pag. $129 \mathrm{ff}$., tab. 2, fig. $1-19$. 
Oberkiefers und fig. 7 u. 8 (0. Desori Probst) solche des Unterkiefers einer und derselben Art darstellten. Welcher Name für diese Art zu wählen und ob dieselbe mit unserer O. wiphodon ident sei, wäre allerdings noch näher zu untersuchen, da die Zähne der Oxyrhina-Arten, wie der Vergleich der O. xiphodon mit der recenten O. glauca dargethan hat, in so geringfügigen Merkmalen differiren, dass nur der directe Vergleich der Originale, wemn nicht ganz erschöpfende Besçhreibungen und Abbildungen vorliegen, eine Unterscheidung ermöglicht.

Der beste Unterschied der $O$. wiphodon gegen die $O$. gluncu besteht in der durchweg bedeutenderen Grösse der crsteren, sowie in der niedrigeren, aber stäker vertieften Externflïche der Wurzel letzterer.

\section{Oxyrhina sp.}

Taf. X, Fig. 5-5d.

Ausser einem prächtig erhaltenen liumpfwirbel besitze ich noch einige kleinere, weniger gut erhaltene Wirbel, die nach HAsse der hinteren Partie des Schwanzes angehören.

Der Rumpfiwirbel besityt eine Iöhe von 29mm und Breite $32,5^{\mathrm{mm}}$, aber eine relativ bedentende Länge, nämlich $14,5^{\mathrm{mm}}$, also gerade die Hälfte seiner Höhe. In ventraler Richtung ist der Wirbel schwach zugespitzt und in der Mitte der Dorsalseite leicht eingesenkt, daher zeigt er in der Frontalansicht herzförmigen, in der Seitenansicht hoch rechteckigen Umriss. Eine Orientirung des Wirbels ist sehr leicht, da Ventral- resp. Dorsalseite verschieden aussehen.

Die Lücken für die Knorpelzapfen der Neurapophysen sind $11^{\mathrm{mm}}$ lang und haben eine grösste mittlere Breite von etwa $11^{\mathrm{mm}}$, die jedoch in Folge der mehr oder minder stark bogenförmig gekrümmten Aussenflächen nach vorn und hinten abnimmt. Der Querschnitt der Lücken gleicht in Folge der etwas gebogenen Aussenflächen einer vorn und hinten gerade abgeschnittenen Ellipse, doch ist das Lumen sehr stark durch secundäre parietale Knochenablagerungen verengt. Ihre Rïnder sind stark verdickt und etwas aufgeworfen. Die beiden Lücken stehen etwa $17^{\mathrm{mm}}$ auseinander, und es finden sich zwischen ihnen, wie der Querschnitt zeigt, etwa 
1 theilweise vergabelte Lamellen, die jedoch so durch oberflichliche Verkalkung verschmolzen sind, dass eine stark poröse Knochenhaut entsteht, welche die Lamellen ïusserlich verhïllt. In der Mitte ist diese Knochenhaut leicht vertieft, seitlich etwas gewölbt.

Bei ventraler Ansicht sieht man ziemlich dicht neben einander und nahe der Mittellinie die Lü̈cken für die Knorpelzapfen der Hämapophysen; dieselben sind etwa $11^{\mathrm{mm}}$ lang und $7^{\mathrm{mm}}$ breit und besitzen somit einen lang rechteckigen Querschnitt, der jedoch durch parietale Verkalkung etwas modificirt sein kann. Die Ränder sind wenig verdickt und nur schwach aufgeworfen. Auffallender Weise ist die eine der Knorpelzapfenlücken durch Oberflächenverkalkung gänzlich geschlossen:

Die beiden Lïcken (Fig. 5b) werden durch einen etwa $7^{\mathrm{mm}}$ breiten Zwischenraum geschieden, in welchem sich zwei Längslamellen finden, die eine mittlere, etwa $3^{\mathrm{mm}}$ breite Kammer von zwei seitlichen, schmäleren, etwa $1,5^{\text {mus }}$ breiten, spaltförmigen Kammern trennen.

In der Seitenansicht sieht man auf der einen Seite (Fig. 5 c) etwa 10 ziemlich dünne, an beiden Enden jedoch verbreiterte und zerschlitzte Längslamellen, welche durch etwas breitere spaltförmige Zwischenräume getrennt werden. Auf der andern Seite (Fig. 5d) sind diese Lamellen vollständig durch eine poröse Knochenhaut, das Product der Oberflächenverkalkung, überkleidet und so dem äusseren Anblick entzogen.

Die Wirbelhöhlung ist tief eingesenkt und die Durchbohrung für die Chorda liegt genau in der Mitte.

Der centrale Doppelkegel ist ziemlich dick und seine Ränder sind abgerundet, aber nur wenig aufgeworfen. Die Aussenflächen zeigen in der centralen Partie einige wenige, grobe, concentrische Wachsthumsringe.

Bei centralem Querschnitt erscheint in der Mitte die verkalkte Innenzone als kleiner dunkler Kreis von etwa $0,5^{\mathrm{mm}}$ Durchmesser und um dieselbe herum der Durchschnitt des centralen Doppelkegels als hellerer Ring von etwa $1^{m m}$ Breite.

Die kreisförmige, etwa $10^{\mathrm{mm}} \mathrm{im}$ Durchmesser haltende Verkalkungssschicht 1 m den centralen Dopredkegel ist mit den primären 
Hauptstrahlen der Aussenzone so innig versehmolzen, dass deren centrale Partieen nur noch als dunkle Streifen auf hellem Grunde erscheinen.

Die Zahl der primären Hauptstrahlen beträgt 12, drei dorsale, drei ventrale und je drei laterale; von diesen verkümmert jedoch der mittlere dorsale resp. ventrale Strahl, so dass wir im Ganzen nur zehn primäre Strahlen haben, welche die Peripherie erreichen.

Die Lücken für die Knorpelzapfen der Neurapophysen werden von je einem dorsalen und dem oberen lateralen, diejenigen der Neurapophysen von je einem ventralen und dem unteren lateralen Strahl begrenzt und zeichnen sich vor den übrigen Zwischenräumen durch grössere Breite ans, weswegen sie besonders in die Augen fallen. Ebenso verdicken sich die sie begrenzenden Strahlen im peripheren Theil sehr stark und zeichnen sich hierdurch vor den übrigen, sowohl den mittleren lateralen, als den durch Spaltung entstandenen Secundärstrahlen, aus, während diese lamellenartig dünn bleiben oder doch nur um weniges gegen aussen an Stärke zunehmen.

Sämmtliche Primärstrahlen gabeln sich nun, und die so entstandenen Secundärstrahlen können sich wiederum spalten, so dass wir also vier Strahlenbüschel haben, welche durch die Knorpelzapfenlücken getrennt sind; diejenigen der beiden lateralen Büschel sind am zahlreichsten mit etwa 8-10 Strahlen, dam folgt der dorsale Büschel mit 6 und schliesslich der ventrale mit vier Strahlen.

Diejenigen Stellen, welche die Knorpelzapfenlücken begrenzen, sind an ihren gegenseitig zugewandten Flächen mehr oder minder regelmässig fiederartig verzweigt, während die zwischenliegenden Strahlen gewöhnlich nur an Ende noch einmal gespalten sind.

Sämmtliche Strahlen sind auf ihren Aussenflächen grob längsgerunzelt und zeigen daher im Quersehnitt fein wellige Grenzlinien.

Ein von Hasse selbst als Oxymhina bestimmter Rumpfwirbel ist leider nur zur Hälfte erhalten; seine Höhe betrïgt gegen $19^{\mathrm{mm}}$, die Breite etwa $21^{\mathrm{mm}}$ und die Länge etwa 9,5 $5^{\mathrm{mm}}$; das Verhältniss von Länge zu Höhe gestaltet sich also genau wie bei dem Wirbel Taf. X, Fig. 5. Im Uebrigen bietet der Wirbel 
weder hinsichtlich der iusseren Ansicht noch des Querschnittes besonders Bemerkenswerthes, vielleicht nur insofern, dass diejenigen Strahlen, welche die Knorpelzapfenlücken begrenzen, relativ stark verdickt sind und die Zahl der lateralen Strahlen geringer ist, als bei vorigem Wirbel, eine Erscheinung, die jedoch mit der greringeren Grösse zusammenhängen mag. Das Querschnittsbild ist ziemlich undeutlich und nu nach Vergleich mit dem besser erhaltenen Wirbel zu entziffern.

Die Schwanzwirbel sind so schlecht erhalten, dass Beschreibung und Abbildung nicht gegeben werden kann.

Vorkommen: Sehr selten in der Zone $\mathbf{A}_{2}$.

Bemerkungen: Herr Hasse batte den Wirbel Fig. 5 als Otochs-Wirbel bestimmt, allein ich konṇte dieser Bestimmung nicht beipflichten, da Otochs-Wirbel nach meiner Auffassung mehr als hypothetisch sind. Ich habe mich hierüber weiterhin (vergl. ('archarodon pag. 84) ausgesprochen, und es bleiben mir nur noch die Gründe anzuführen, warum ich den Wirbel Fig. 5 als OxiyrhinaWirbel ansehe, da sein Querschnittsbild doch von dem durch H ASSE $^{1}$ ), tab. 31, fig. 41 u. 42, mitgetheilten abweicht.

Es kann überhaupt nur Zweifel darïber entstehen, ob wir es mit einem Carcharodon- oder einem Oxymhina-Wirbel zu thun haben, Lamna, Selache und Alopias sind ohne weiteres ausgeschlossen. Gegen Carcharodon spricht vor allem die äussere Gestalt und die centrale Durchbohruug für die Chorda; HAsse sagt ausdrücklich vom Genus Carcharolon pag. 226: "Schon die Wirbelhöhlung ist bemerkenswerth. Sie wird nämlich bei allen Carcharodonten von der Chorda excentrisch durchbohrt und zwar liegt die Durchbohrung der ventralen Fläche näher.《 Unser Wirbel, der eine genau centrale Durchbohrung für die Chorda besitzt, kann mithin gemäss dieser Angabe kein CarcharodonWirbel sein.

Es bleibt also für unseren Wirbel nur noch die Möglichkeit ciner Zugehörigkeit zu Oxyrhina übrig, und stimmt er in seiner ¿̈usseren Form recht gut mit HassE's fig. 44 überein. Es ist nur

1) Natürliches System der Elasmobranchier. 
zu bedauern, dass HAsse von diesem Wirbel aus dem Oligocïn von Flonheim keinen Qnerschnitt mitheilt, so dass wir bei dem Vergleich der Querschnitte nur auf seine fig. 41 resp. 42 augewiesen sind.

Hinsichtlich des Quorschnittes muss ich allerdings gestehen, dass unser Wirbel von dem recenten Oxyrhina-Wirbel fig. 42 insofern verschieden ist, als er eine viel stärkere Entwickelung von Radialstrahlen wie jener zeigt. Hierdurch nähert er sich wiederum dem Carcharodon-Wirbel bei HAsse, tab. 30, fig. 30. Allein nachdem ich mich überzengt, dass diese reichliche Entfaltung der Radialstrahlen nur auf secundäre Spaltung der Primärstrahlen zurückzuführen ist, so hat auch diese Erscheinung für mich nichts befremdliches mehr, da auch unser Wirbel genau wie die Oxyrkina zehn Primärstrahlen besitzt.

Sollten aber spätere Untersuchungen dennoch für eine Zugehörigkeit unseres Wirbels zu Charcharodon sprechen, so unterscheidet derselbe sich jedenfalls durch eine grössere Länge im Verhältniss zur Höhe und daher plumpere Gestalt, tiefere Wirbelhöhlung, sowie centrale Durchbohrung für die Chorda von den auf Taf. $\mathrm{X}$, Fig. 1 und 2 abgebildeten Wirbeln, die ich als echte Carcharodon-Wirbel ansehe und die eine in Verhältniss zur Höhe geringere Länge und daher schlanke Gestalt, flachere Wirbelhöhlung und excentrisch nach der Ventralseite gelegene Durchbohrung für die Chorda, äusserlich sofort von unserem Wirbel trennt.

Auch das Querschnittsbild zeigt Abweichungen, wie cine Vergleichung der beiden Abbildungen lehrt.

\section{Lamma elegans Agassiz.}

Taf. IV, Fig. 1-9 und A u. B.

184\%. Lamna eleyans Agassiz, liecherehes sur les poissons fossiles Bd. III, pag. 289, tab. 35 , fig. $1-7$ and tab. 37 a, fig. 58 und 59.

Diese Species ist am allerhäufigsten unter den Elasmobranchiern des samländischen Tertiärs vertreten; es haben sich Mittel- und Seitenzähne sowohl des Ober- wie des Unterkiefer's 
gefunden und mit Hülfe eines recenten Gebisses unterscheiden lassen. Da die verschiedenen Zahntypen genau in gleicher Weise wie bei Oxyrhina ausgebildet sind, so brauche ich deren bezeichnende Charaktere ${ }^{1}$ ) nicht mehr zu wiederholen, sondern verweise anf die vorhergehende Beschreibung der Oxyrhina xiphodon.

a) Mittelzähne.

1. Unterkiefer (Taf. IV, Fig. $1-1 \mathrm{~g}$ ).

Vollständig erhaltene Zähnchen sind unter dem grossen, mir vorliegenden Material nur zwei vorhanden, allen übrigen fehlt die Wurzel entweder ganz oder theilweise. Das eine der Zühnchen (Fig. 1) besitzt eine Gesammthöhe von $21^{\mathrm{mm}}$; davon kommen auf die Hauptspitze $14^{\mathrm{mm}}$; das andere besitzt $18^{\mathrm{mu}}$ Gesammthöhe, wovon die Hauptspitze etwa $13^{\mathrm{mm}}$ einnimmt, in beiden Fällen beträgt also die Höhe der Hauptspitze ${ }^{3} / 4$ der Gesammthöhe. Bei den übrigen Zähnchen schwankt deren Höhe zwischen 12 und $20^{\mathrm{mm}}$, mithin dürften dieselben $16-26^{\mathrm{mm}}$ hoch gewesen sein; am häufigsten sind Zähnchen von 14-- $15^{\mathrm{mm}}$ Hauptspitzenhöhe, was einer Gesammthöhe von $18-20^{\mathrm{mm}}$ entspricht.

Wurzel und Krone sind wenigstens auf der Internseite ziemlich scharf gegen einander abgesetzt, auf der Externseite jedoch allmählich in einander übergehend.

Die Wurzel besitzt bei dem Zähnchen Fig. 1 eine grösste Breite von $11^{\mathrm{nm}}$, die jedoch nach oben beträchtlich abuimmt, und eine Höhe von etwa $7^{\mathrm{mm}}$, die sich jedoch in der Mitte bis zu $4,5^{\mathrm{mn}}$ reducirt. Ihre grösste Dicke betrügt in der Mitte $6^{\mathrm{mm}}$, nimmt aber in Folge der starken Neigung der Ligamentfläche nach den Seiten hin rasch ab. Die ziemlich hohe Externfläche ist ihrer ganzen Breite nach tief concav und nach Innen gebogen. Die

1) Es giebt übrigens ein ziemlich einfaches, wenn auch rein mechanisches Mittel, das aber nichtsdestoweniger gute Resultate liefert, um die Mittelzähne des Oberund Unterkiefers dieser Art (vielleicht auch der anderen Lamna- und GryrhinaArten) schnell ron einander zu unterscheiden. Man legt die Zähne mit der Externseite auf eine ebene Flache, Tisch- oder Glasplatte oder dergl. Liegen sie mit der ganzen Lixternseite der Krone platt darauf, so gehören sie dem Oberkiefer an, hebt sich jedoch die Seite davon ab und berührt die Externseite nur theilweise die Unterlage, so sind es Zähne des Unterkiefers. 
schräg nach oben gerichtete Neuralfläche ist seitlich ungemein schmal, nur in der Mitte etwas höher und zugleich schwach eingesenkt. Die abgerundete Ligumentkante ist nur wenig deutlich markirt. Die breite, leicht gewölbte Ligamentfliche nimmt den grössten Theil der Internfläche ein; in der Mitte ist sie fast senkrecht gegen die Hauptspitze geneigt, seitlich dagegen mehr schräg und zugleich steil nach unten abfallend. Eine eigentliche Neuralkante ist nicht vorhanden oder wenigsteus sehr verwischt, aber der Neuralrand ist tief parabolisch gebuchtet; daher ist die Wurzel lang zweiästig und beide Wurzeläste sind in seitlicher Richtung comprimirt. Vorder- und Hinterrand der Wurzel sind kantig gerundet.

Die Eintrittsstelle für den Hauptnerv liegt in einer nicht sehr tiefen Verticalspalte, nahe dem Ligamentrand.

Der Eindruck der Befestigungsmembran ist aber wie bei überhaupt allen Lamn-Arten ungemein scharf, namentlich auf der Externseite, ausgeprägt. Er stellt sich auf der Internseite als ziemlich breites, etwas vertieftes Band dar, das sich längs der Krone an den Seiten bis auf halbe Höhe der Wurzel hinabzieht, dabei sehr stark an Breite zunimmt, die Nebenspitzen allseitig umgiebt und auf der Externseite gegen die Mitte hin eingeschnürt ist, zugleich aber wulstartig sich erhebt und grob vertical gerunzelt ist. Ausserdem ist auf der Externseite bei gut erhaltenen Exemplaren der Eindruck mit einer glatten, glänzenden Haut überzogen, die jedoch leicht zerstört wird, und jedenfalls auch an der Internseite vorhanden war. Eine stets deutlich und scharf markirte Furche bezeichnet den Unterrand, welcher der Oberrand, die Emailgrenze, nicht parallel lïuft.

Die schlanke, schmale Hauptspitze hat an der Basis 5,5 $5^{1 m+1}$ Breite, einen gleichschenkelig-dreieckigen Umriss und biegt sich ziemlich stark nach innen; der obere Theil ist jedoch wieder mehr oder minder nach aussen gewendet. Die glatte Externseite ist flach oder leicht gewölbt, an der Basis zuweilen mit einer seichten Medianeinsenkung. Die hochgewölbte Internseite füllt seitlich sehr steil ab und ist mit regelmässigen, scharfen Verticalfalten geziert, welche in der Mitte, an der Basis beginnend, 
bis etwa zu halber Höhe reichen, gegen die Seiten aber an Grösse abnehmen. Vorder- und Hinterrand sind gerade, gleich lang und mit scharfem, glattem Kiele besetzt, der jedoch in einiger Entfernung von der Basis verschwindet. Der Querschnitt der Hauptspitze ist nahezu halbkreisförmig, und ihre Dicke, welche an der Basis etwa 3,5-4 $4^{\mathrm{mm}}$ beträgt, nimmt gegen die Spitze hin Anfangs rasch, später nur allmählich ab.

Die Nebenspitzen sind sehr klein, dornförmig, von kreisrundem Querschnitt, nicht gekielt, vollständig ron der Hauptspitze abgeschnürt und schräg gegen dieselbe gestellt.

Die Emailgrenze läuft auf der Internseite in tlach nach oben gekrümmter, auf der Externseite in nahezu horizontaler Linie.

2. Oberkiefer (Fig. $3-3 \mathrm{e}$ ).

Die Mittelzähne des Oberkiefers sind durchweg besser erhalten als die vorigen. Die beiden grössten Zähnchen besitzen eine Gesammthöhe ron 21 resp. $22^{\mathrm{mm}}$; davon kommen auf die Hauptspitze allein $14 \mathrm{resp} .15^{\mathrm{mm}}$; kleinere Exemplare besitzen eine Höhe von $15,16,5,17$ und $18^{\text {mm }}$, wovon $11,5,14,14$ und $14,5^{\text {mm }}$ auf die Hauptspitze entfallen, die somit etwa $2 / 3{ }^{3} / 4$ der Gesammthöhe einnahm. Die Grösse der Zähnchen schwankt nach den mitgetheilten Zahlen somit zwischen $15-22^{\text {mu }}$ Gesammthöhe, am hüufigsten sind solche von $16-18^{\mathrm{mm}}$.

Wurzel und Krone sind auf der Internseite scharf gegeneinander abgesetzt, auf der Externseite jedoch allmählich ineinander übergehend.

Die Wurzel besitzt eine grösste Breite von $11-13,5^{m m}$ (natürlich ist sie bei kleineren Zähnchen entsprechend geringer) und verschmälert sich nach oben ziemlich betrïchtlich. Ihre Höhe, $1 / 3-1 / t$ der Gesammthöhe, reducirt sich in der Mitte noch auf die Hälfte dieser Grösse. Ihre grösste Dicke beträgt je nach Grösse $3-5^{\text {mm }}$ und nimmt von der Mitte gegen die Seiten ziemlich langsam ab. Die ziemlich hohe Externfläche ist nicht sehr stark, jedenfalls beträchtlich weniger, als bei den Unterkieferzähnen eingesenkt, Neural- und Ligamentfläche wie bei jenen ausgebildet, nur dass erstere etwas schrïger geneigt ist und letztere seitlich weniger steil abfält. Der Neuralrand ist weniger tief und mehr hyper- 
bolisch gebuchtet; daher bilden die beiden Aeste einen flacheren Winkel mit einander, als bei den Unterkieferzähnen, und die Wurzel erscheint somit durchweg breiter, als es bei diesen der Fall ist; ebenso sind die beiden Aeste mehr von aussen nach innen, als in seitlicher Richtung comprimirt.

Die Eintrittsstelle für den Hauptnerv und der Eindruck der Befestigungsmembran wie bei den Unterkieferzähnen.

Die Hauptspitze hat an der Basis eine Breite von $4,5-7^{\mathrm{mm}}$, schmal gleichschenkelig-dreieckigen Umriss und ist vollkommen vertical, nur ist bei vielen das äusserste Ende schwach nach anssen gekrümmt. Die glatte Externseite ist flach und eben, an der Basis öfters mit kurzer medianer Einsenkung versehen. Die Internseite ist boch gewölbt, aber im Vergleich zu den Unterkieferzähnen etwas flacher und seitlich weniger steil geneigt, der Querschnitt daher auch mehr elliptisch. Die Internseite ist in gleicher Weise wie bei den vorigen vertical geringelt, nur sind die Falten durchweg kürzer und auf den untersten Theil der Mittelspitze beschränkt. Vorder- und Hinterrand gerade, gleich lang und von der Spitze bis zur Basis scharf gekielt.

Nebenspitzen wie bei rorigen, nur noch nicht so vollständig von der Mittelspitze abgeschnürt und, wie wenigstens ein Exemplar dentlich zeigt, längs des Innenrandes gekielt.

Emailgrenze wie bei den Unterkieferzähnen.

B) Seiteuzähne.

1. Unterkiefer (Fig. 4-4d).

Es ist ziemlich schwierig, Seitenzïhne des Unterkiefers, welche nicht vollständig erhalten sind, ron Wittelzähnen des Oberkiefers zu unterscheiden, da der Contrast in der Breite der Hauptspitze beider Zahutypen, welcher bei gut erhaltenen Exemplaren sofort in die Augen fällt, bei isolirten Mittelspitzen viel weniger klar hervortritt. In zweifelhaften Fällen dürfte man die kleineren Hauptspitzen mit flacherem Querschnitt als Seitenzähne ansehen; sind übrigens die Zähne gut und vollständig erhalten, so bietet die Unterscheidung nicht die geringste Schwierigkeit. 
Die. Zähne besitzen eine geringere durchschnittliche Höhe als die Mittelzähne, indem ihre Gesammthöhe nur etwa $10-17^{\text {mn }}$ beträgt; davon kommen, wie einige allerdings nicht ganz zuverlässige Messungen ergeben haben (entweder fehlt bei den Zähnchen ein Theil der Hauptspitze oder der Wurzel) etwa $5 / 7$ auf die Höhe der Krone. Man sieht übrigens auch aus den Abbildungen, dass das Verhältniss der Höhe der Krone zur Höhe der Wurzel zu Ungunsten der letzteren sich geändert hat.

Die Wurzel besitzt eine bedentende Breite, die nahezu der Gesammthöhe des Zähnchens gleichkommt. Es ergiebt dieselbe sich bei einem Zähnchen zu 13 resp. 14 resp. $16^{\mathrm{mm}}$, nach oben verschmälert sie sich nur wenig. Die Dicke ist ebenfalls gering, in der Mitte nicht über $4{ }^{\mathrm{mm}}$, und reducirt sich an den Sciten noch bedentend. Die Externfläche ist seitlich flach, in der Mitte leicht eingesenkt. Die Internfläche ist viel weniger aufgetrieben, als bei den Mittelzähnen, und der grösste Theil derselben wird von der hohen, flachen, nur in der Mitte etwas gewölbten Neuralfläche eingenommen, welche ziemlich schräg ansteigt, seitlich jedoch nur wenig abfällt, und meist durch eine gut markirte Kante von der Ligamentflïche geschieden ist. Diese letztere ist sehr schmal, schräg gegen die Krone geneigt, seitlich wenig abfallend und wird fast gänzlich von dem Eindruck der Bef'estigungsmembran eingenommen. Der Neuralrand ist an den Seiten kantig gerundet, in der Mitte abgeflacht stumpfwinkelig und nicht sehr tief gebuchtet. Die beiden Wurzeläste sind daher bei der geringen Höhe der Wurzel kurz, öfters von verschiedener Länge, stark von innen nach aussen comprimirt und am Vorder- und Hinterrande abgerundet kantig.

Die Eintrittsstelle für den Hauptnerv liegt im Grunde einer zicmlich tiefen Verticalspalte, aber immer noch äusserlich sichtbar.

Der Eindruck der Befestigungsmeml)ran ist wie bei den Mittelzähnen, nur entsprechend der grösseren Breite der Zühne mehr in die Breite gezogen und daher längs der Internseite flacher.

Die Hauptspitze zeigt an der Basis eine beträchtliche Breite, bei Fig. 4 ca. $5,5^{\mathrm{mm}}$, verschmälert sich jedoch anfangs rasch, später mehr allmählich nach oben, so dass die Seitenrïnder keine genau greraden Linien bilden, sondern unten etwas coneav, sonst aber 
gerade, gleich lang und von der Spitze bis zur Basis mit scharfem Kicle besetzt sind. Doch wird durch diesen Verlauf der Ränder der breit gleichsehenkelig-dreieckige Umriss der Hauptspitze wenig beeinflusst, die im Uebrigen vollkommen vertical gerichtet, in einzelnen Fällen auch leicht nach hinten geneigt ist. Die Externseite ist glatt und flach, die Internseite gewölbt, seitlich wenig steil abfillend, daher der Querschnitt bei der verhialtnissmässig geringen Dicke flach halbelliptisch. Die Schmelzfalten der Internseite sind sehr kurz, nur auf den untersten Theil der Mittelspitze beschränkt, öfters auch, namentlich bei abgerollten Zähnchen, kaum sichtbar. Die Dicke ist gering, an der Basis 2,5-3 $3^{\mathrm{mm}}$ betragend, und nimmt gegen oben hin nur langsam ab. Die Nebenspitzen sind noch nicht von der Hauptspitze völlig abgeschnürt, sondern noch mit ihr vereinigt und fast parallel oder doch sehr wenig schräg gegen dieselbe geriehtet, in Bezug auf Grösse allerdings bei einigen Zühnchen stark reducirt; zuweilen sind auch noch ganz verkümmerte Zühnchen zweiter Ordnung vorhanden. In ihrer Gestalt gleichen sie der Mittelspitze und sind wie jene an beiden Rändern gekielt.

Emailgrenze verlänft sowohl auf Extern- als Internseite beinahe geradlinig.

2. Oberkiefer (Fig. $5-5 \mathrm{e}$ ).

Die Gesammthöhe der Oberkieferseitenzähne schwankt zwischen 13,5-18mm, woron etwa $1 / 4$ auf die Höhe der Wurzel, 3/4 auf die Mittelspitze kommen. Ihre specifischen Merkmale sind die gleichen, wie jene des Unterkiefers, und sie unterscheiden sich von diesen nur durch die ziemlich schräg nach linten geneigte Hauptspitze und in Folge dessen verschiedene Länge der Seitenränder; ferner ist die verticale Faltung der Internseite des Schmelzes fast völlig verwischt, oft nur leicht angedeutet.

Vorkommen: Häufig in der Zone A; sonst namentlich im oberen Eocän verbreitet, während das Vorkommen im Unteroligocän zweifelhaft erscheint.

Bemerkungen: Unter der specifischen Benennung Lamna elegans habe ich hier eine Reihe von Zahnformen vereinigt, die man sonst in palaeontologischen Werken mit besonderen. Namen, 
wie Lamna elegans (Fig. 1), Lamna dubia (Fig. 2) und Lamna compressa (Fig. 4 oder 5) belegt findet.

Die Gründe für die Vereinigung dieser Zahntypen sind dieselben, welche mich bewogen haben, das Gebiss der andern hier beschriebenen Lamniden zu reconstruiren: die Thatsache, dass man an einem recenten Gebiss genau die gleichen Typen unterscheiden kamn, wie sie sich unter dem fossilen Material finden. Es wäre doch jedenfalls sehr sonderbar, dass, wenn man die verschiedenen Zahntypen mit eigenen Namen belegen wollte, sich von einer Art Lamna elegans Zähne gefunden haben, die ihrem Habitus nach unzweifelhaft der vorderen Partie des Unterkiefers angehörten, oder von einer andern, Lamna compressa, nur solche, die sicher auf den hinteren Kieferpartieen sassen. Es würde wohl schon die einfache Constatirung dieser Thatsache genügen, um die specifische Verschiedenheit dieser „Arten« zu erschüttern. Es zeigen aber noch weiterhin alle diese Zähnchen, möge ihre Gestalt noch so verschieden sein, eine grössere oder geringere Faltung der Internseite des Emails. Diese Verschiedenheit in der Entwickelung der Schmelzfalten ist aber eine ganz gesetzmässige, sie sind längrer und hervorragender ansugebildet bei Zähnen, welche dem Unterkiefer angehörten, als bei solchen des Oberkiefers, und wiederum schwächer bei den Seitenzïhnen, als bei den Mittelzähnen.

Wenn sonach ein Zweifel über die Zusammengehörigkeit dieser Zähne meiner Ansicht nach nicht mehr obwalten kann, so wïre nur noch zu untersuchen, welcher Name für sie zutreffend wäre. Es ist nun ziemlich gleichgültig, ob man die Benennung Lamna cleguns AGass, oder Lamnu compressu Agass. wählt; beides ist richtig, demn die Mittelzähne des Unterkiefers sind genau ident mit ersterer Art, und die Seitenzähne entsprechen volkommen der letzteren. Ich habe die Bezeichnung Lamna elegans vorgezogen, einmal weil gerade diese Zahntypen, für welche Agassiz die Art aufgestellt, ohne Schwierigkeit kenntlich sind, und dann, weil dic Seitenzähne so ziemlich aller Lamniden gewissermaassen dic Bezeichnung scompressus verdienen.

$\mathrm{Ob}$ jedoch alle die Formen, welche ron den verschiedenen Autoren als Lamma compressa, elegans oder dubia beschrieben sind, 
zu vereinigen seien, mag vorläufig dahingestellt bleiben. Man kann aber mit ziemlicher Gewissheit darauf rechnen, dass, wenn diese drei Arten von ein und demselben Fundort genannt werden, ihre Zusammengrehörigkeit bei eingehender Prüfung zweifellos erscheint. Hier jedoch eine eingehende Kritik dieser Arten zu üben, würde einerseits zu weit führen, andrerseits doch nicht sehr ergiebig sein, da ich zu dem Zwecke die Originale kennen müsste, denn die Abbildungen sind hierzu bei weitem nicht ausreichend.

\section{Lamna sp.}

Taf. X, Fig. $4-4$ c.

In merkwürdigem Gegensatz zu der Zahl von grossen LamnaZähnen des samländischen Tertiärs konnte nur ein einziger Rumpfwirbel unter meinem reichlichen Material aufgefunden werden. Der an der einen Seite stark abgerollte, überhaupt am Rande vielfach verletzte Wirbel besitzt eine Höhe von $30^{\mathrm{mm}}$ und eine Breite von $31^{\mathrm{mm}}$, aber nur eine sehr geringe Länge, nämlich $9^{\mathrm{mu}}$, also etwa $1 / 3$ der Höhe. Soweit sich wegen des verletzten Randes ein Urtheil über die Form des Wirbels abgeben lässt, so scheint derselbe in der Frontalansicht einen schwach querelliptischen, beinahe kreisförmigen Umriss besessen zu haben. In der Seitenansicht ist die Form hoch rechteckig; dabei ist zu erwähnen, dass die Seitenflächen leieht eingesenkt sind.

Eine Orientirung des Wirbels ist nicht leicht, da das Bild der Dorsal- und Ventralseite ein sehr gleichartiges ist. Die Lücken für die Knorpelzapfen der Neurapophysen sind etwa $4^{\text {min }}$ lang, höchstens $3^{\text {mm }}$ breit, und durch parietale Knochenablagerung sehr stark verengt, so dass die Oeffnung eine schmal elliptische Form zeigt. Die Ränder sind kaum verdickt und nicht aufgeworfen. Die beiden Apophysenlücken stehen etwa $7^{\text {wm }}$ weit auseinander, und zwischen beiden befinden sich zwei ziemlich dicke, an beiden Enden noch verbreiterte, aber hier wie auf der Oberfläche zerspaltene Längslamellen, welche einen mittleren breiten Spalt von zwei seitwärts zwischen diesem und den Apophysenlücken gelegenen, etwas schmäleren Kammern scheiden. 
Auf der Ventralseite sehen wir fast das gleiche Bild, nur dass die Lücken für die Knorpelzapfen der Hümapophysen weniger weit, nämlich nur $4,5^{\mathrm{mm}}$ auseinander stehen. Die zwischen denselben befindlichen Lamellen sind sehr dünn und die drei Kammern gleich breit.

In der Seitenansicht (Fig. 4c) sieht man etwa 15 Querlamellen, die Endflächen verkalkter Radialstrahlen der Aussenzone; diese Lamellen, in der Mitte kaum $1^{\mathrm{mm}}$ dick, verbreitern sich vorn und hinten etwas, indem sie sich gleichzeitig spalten; eine Spaltung macht sich bei einigen auch in der Nitte bemerkbar.

Die Wirbelhöhlung ist flach eingesenkt, die Durchbohrung für die Chorda, welche vielleicht sehr gross war, liegt grenau in der Mitte. Der centrale Doppelkegel ist sehr dick, etwa $2^{\mathrm{mm}}$ stark und an den Rändern leicht abgerundet; seine Aussenflächen sind grob und unregelmässig concentrisch gestreift.

Im Querschnitt sieht man den Doppelkegel als ziemlich dicken Ring die weite Durchbohrung für die Chorda umgeben, während wahrscheinlich die Innenzone nicht verkalkt war. Sämmtliche Radialstrahlen der Aussenzone sind, auf etwa $5^{\mathrm{mm}}$ vom Doppelkegel an gerechnet, durch interradiale Knochenablagerung so fest verschmolzen, dass die einzelnen Strahlen kaum mehr zu erkennen sind und nur noch als schattenhafte dunklere Linien auf hellem Grunde erscheinen. Daher ist die Zahl der Primärstrahlen, da dieselben sich in kurzer Entfernung vom Centrum gabeln, sehr schhwierig zu ermitteln, ja es gelingt überhaupt nur mit Sicherheit, zwei dorsale, zwei ventrale und je einen oberen und unteren Primärstrahl nachzuweisen, da diese zu je.zweien, die Knorpelzapfen der Apophysen seitlich begrenzend, sich durch grössere Dicke und mehr säulenförmige Gestalt vor den übrigen secundären Strahlen auszeichnen.

Die Gabelung der Primärstrahlen findet in sehr regelmässiger Weise statt; und die so entstandenen Secundärstrahlen zeichnen sich durch ihren geraden Verlauf aus; sie sind dünn, stellenweise und am peripheren Ende knopfförmig verdickt und durch etwa doppelt so breite Zwischenräume geschieden; ihre Aussenflächen sind grob, längs geringelt. Durch die vier ziemlich schmalen 
Knorpelzapfenlüicken, von welehen die beiden dorsalen etwas weiter anseinander liegen als die ventralen, wie man hier deutlicher, als bei äusserer Betrachtung sicht, werden somit vier Strahlenbüschel geschieden: ein ventrales resp. dorsales und zwei laterale, von welchen die beiden ersteren vier, die letzteren etwa 16 Strahlen aufweisen.

Vorkommen: Sehr selten in der Zone $A_{1}$.

Bemerkungen: In gleicher Weise, wie sich der fossile Oxyrhina-Wirbel von dem recenten unterscheidet, weicht auch der fossile, übrigens von HASSE selbst als soleher bestimmte Lamna-Wirbel, von dem recenten, von ihm auf tab. 28 , fig. (6 abgebildeten, durch reichere Strahlenentfiltung in der Aussenzone ab. Bei der recenten Form zeigen die Primärstrahlen nur eine geringe Tendenz zur Gabelung, bei dem fossilen Wirbel ist dieselbe so stark ansgebiluet, dass sogar die mittleren lateralen Primärstrahlen in geringem Abstand vom Centrum nicht mehr als solche zu erkennen sind.

Von dem Oxyrhinu-Wirbel unterscheidet sich der LumnaWirbel äusserlich durch eine geringere Länge bei nahezu gleicher Höhe und Breite, sowie durch schmalere Knorpelzapfenlücken, im Querschnitt durch die sehr regelmässigen, geraden, hier und da knopfförmig verdickten Radialstrahlen, während der OxyrhinaWirbel leicht gewellte, namentlich aber fingerförmig verzweigte Radialstrahlen besitzt.

\section{Odontaspis Hopei Agassiz.}

Taf. V, Fig. $1 a-d$, Fig. 2a-b, Fig. $3 a-b$.

1842. (Mdonterpis IIopei Agassiz, Recherehes sur les poissons fossiles Bd. IIl, pag. 293 , tab. 37 a, fig. $27-30$.

Unter meinem ziemlich spärlichen Material dieser Art vermag ich nur Mittelzähne des Unterkiefers und Seitenzïhne des Oberkiefers bestimmt zu unterscheiden, vorausgesetzt, dass auch bei Odontaspis die Zähne je nach ihrer Lage in gleicher Weise differiren, wie bei der nahe verwandten Oxyrhina oder Lamna. Ich kamn mich hierüber nicht bestimmt üussern, da mir ein vollstïndiges Gebiss von Odontaspis zur Zeit nicht zu Gebote steht. Bei dieser 
Annahme wären die schmalen Zähne, deren Wurzel tiefgegabelt und deren Hauptspitze stark nach innen gekrümmt ist, als Mittelzähne des Unterkiefers, die breiteren Zähne mit wenig gebuchtetem Neuralrand und stark nach hinten geneigter Hauptspitze als Seitenrähne des Oberkiefers aufzufassen.

a) Mittelzähne.

Die Zähnchen sind wenig gut erhalten, da ihnen zumeist die Wurzel fehlt; das am besten erhaltene Zähnchen (Fig. 1) (es fehlt ihm nur eine Nebenspitze) besitzt eine Gesammthöhe von $22^{m i n}$; davon entfallen auf die Mittelspitze allein etwa $18^{\mathrm{mm}}$, da deren Höhe somit ungeführ $2 / 3$ der Gesammthöhe betragen würde. Da bei den übrigen Zähnchen die Höhe der Mittelspitze sich zwischen 14 und $18^{\mathrm{mm}}$ bewegt, so dürfte die Gesammthöhe der Mittelzähne etwa $21-22^{\mathrm{mm}}$ betragen. Wurzel und Krone sind auf der Innenseite scharf gegen einander abgesetzt, auf der Aussenseite jedoch allmählich ineinander übergehend.

Die Wurzel besitzt 12,5 $5^{\mathrm{mm}}$ grösste Breite, die nach der Krone hin wenig abnimmt; ihre grösste Höhe von $7^{\mathrm{mm}}$ füllt in der Mitte auf $5^{\mathrm{mm}}$. In Folge der hoch angeschwollenen Innenseite ist ihre Dicke sehr bedeutend, und zwar beträgt sie in der Mitte nahezu $9^{\text {mun }}$, doch vermindert sie sich nach den Seiten hin rasch und beträchtlich. Die Externfläche ist nicht sehr hoch, aber ihrer ganzen Breite nach tief concav und nach Innen gebogen. Die Neuralfläche ist an den Seiten schräg nach oben gerichtet, aber so schmal, dass Ligament- und Externfläche fist zusammenstossen, in der Mitte wird sie jedoch bedeutend breiter und ist in beinahe horizontaler Richtung nach Innen übergebogen. Die Ligamentkante ist abgerundet und demnach nicht sehr scharf markirt. Die Ligamentfläche ist stark entwickelt, in der Mitte beinahe senkrecht gegen die Krone gerichtet, seitlich schräger, aber steil nach unten abfallend. Der Neuralrand ist tief parabolisch gebuchtet, eine eigentliche Neuralkante ist jedoch nicht ausgebildet; die Wurzelïste sind ziemlich lang, von vorn nach hinten comprimirt. Die Eintrittsstelle für den Hauptnerv liegt im Grunde einer hohen, sehr tiefen Verticalspalte, welche fast die ganze 
Wurzel bis nahe zur Krone hin durehsehneidet und deshalb bei der Ansicht von oben auf der Ligamentfläche sichtbar ist.

Der Eindruck der Befestigungsmembran stellt sich auf der Internseite als ein etwa 1,5 breites, scharf begrenztes, etwas vertieftes Band dar, das die Mittelspitze halbkreisförmig umgiebt, zwischen dieser und den Nebenspitzen scharf geknickt ist, an letzteren entlang ziehend rasch an Breite zunimmt, dam auf die Externseite übertritt und gegen die Mitte wieder schmäler wird. Die Krone besitzt incl. Nebenspitzen an der Basis eine Breite von etwa $10^{\mathrm{mm}}$; davon kommen auf die Hauptspitze allein $6^{\mathrm{mm}}$, welche schmal-gleichschenkelig - dreieckigen Umriss besitzt und dabei ihrer ganzen Länge nach stark nach innen gebogen ist. Die Externseite ist flach, die Internseite stärker, im Querschnitt beinahe halbkreisförmig, gewölbt und seitlich senkrecht abfallend. Nur im oberen Theil stossen beide winkelig zusammen, unten gehen sie germudet in einander über. Vorder- und Hinterrand sind gerade, gleich lang und mit scharfem, glattem Kiele besetzt, der jedoch nur von der Spitze bis zu $2 / 3$ der Höhe herabreicht und dann verschwindet. Die Dieke der Mittelspitze an der Basis betrïgt $5^{\text {mmu}}$; dieselbe nimmt gegen die Spitze anfangs sehr schnell, später jedoch nur allmählich ab.

Die beiden mit der Mittelspitze vereinigten Nebenspitzen sind verhältnissmässig hoch, ca. $4,5^{\mathrm{mm}}$, und gegen erstere hin gekrümmt; da ihre Extern- und Internfläche stark gewölbt sind, so sind sie im Querschnitt beinahe kreisförmig und beinahe $2^{m m}$ dick. Die Emailgrenze läuft auf der Innenseite flach nach oben gekrümmt, auf der Aussenseite, wo sie jedoch sehr undentlich ist, horizontal.

$\beta$ ) Seitenzähne.

Nach der Biegung der Mittelspitze gehören die Seitenzähne theils dem rechten, theils dem linken Oberkiefer an. Das am vollständigsten erhaltene rechte Oberkieferzähnchen (Fig. 2) besitzt eine Gesammthöhe von $18^{\mathrm{mm}}$, davon kommen auf die Mittelspitze allein $13^{\mathrm{mm}}$, es stellt sich somit das Verhältniss der Höhe von Hauptspitze zu Wurzel wie bei den Mittelzähnen. Nach hinten erniedrigt sich die Höhe der Zähne, das kleinste misst etwa $13^{\text {min. }}$. 
Wurzel und Krone sind wenigstens auf der Innenseite scharf gegen einander abgesetzt, auf der Aussenseite gehen sie allmählich in einander über.

Die Wurzel besitzt nur geringe Höhe, nämlich $5^{\mathrm{mm}}$, welche in der Mitte auf $4^{m m}$ herunter geht, aber desto grössere Breite, nämlich $12,5^{\mathrm{mm}}$, welche gegen oben nur wenig abnimmt. Die Internfläche ist weniger stark aufgetrieben als bei den Mittelzähnen, die Dicke der Wurzel daher relativ greringer, bei Fig. 2 b $5,5^{m m}$. Die nicht sehr hohe Externfläche ist wenig eingesenkt, Neuralund Ligamentfläche verhalten sich wie bei den Mittelzïhnen, nur dass letztere seitlich weniger steil abfällt. Der Neuralrand ist flach gebuchtet, und die beiden kurzen Wurzeläste sind gerundet.

Die Eintrittsstelle für den Hauptnerv liegt in analoger Weise wie bei den Mittelzähnen im Grunde einer tiefen Verticalspalte. Ebenso verhält sich der Eindruck der Befestigungsmembran wie vorher, nur dass der seitliche Knick zwischen Haupt- und Nebenspitzen weniger scharf ausgebildet ist. Er ist übrigens bei dem einzigen Zühnchen, an welchem er überhaupt wahrnehmbar ist, wegen der etwas verwitterten Wurzel sehr wenig deutlich.

Die Krone besitzt bei Fig. 2 a incl. Nebenspitzen eine Breite von $11^{\mathrm{mm}}$; davon kommen auf die Hauptspitze allein $8,5^{\mathrm{mm}}$; diese ist ziemlich vertical gerichtet, aber mit der Spitze so weit rückwärts gezogen, dass letztere fast über der binteren Nebenspitze steht, ihr Umriss wird somit schiefwinkelig dreieckig. Die Externseite ist leicht gewölbt, an der Basis in der Mitte zuweilen flach vertieft; da die Internseite nicht viel stärker gewölbt ist und seitlich nur wenig steil abfällt, so wird der Querschnitt flach halbelliptisch. Der Vorderrand ist länger als der Hinterrand, lang S-förmig gebogen und schräg nach hinten gerichtet; der kürzere Vorderrand ist leicht concar und im oberen Theile nahezu senkrecht. Beide sind der ganzen Lünge nach von der Spitze bis zur Basis scharf und glatt gekielt. Die Dicke der Hauptspitze ist bei der geringen Wölbung der Internseite unbedeutend, bei Fig. 2 b $3,5^{\mathrm{mm}}$, und nimmt gegen die Spitze hin sehr langsam ab. 
Die Nebenspitzen verhalten sich wie bei den Mittelzähnen, doch sind ausser den Nebenspitzen erster Ordnung noch häufig kleine verkümmerte Nebenspitzen zweiter Ordnung vorhanden.

Die Emailgrenze verläuft auf der Intern- wie Externseite in flach nach oben geschwungener Linie.

Vorkommen: Nach Agassiz sehr häufig im Sheppey-Thon; in der Zone $A_{1}$ ziemlich selten.

Bemerkungen: Die Identität unserer Art mit Agassiz's Lamna (Odontaspis) Hopei dürlte sicher sein; es wäre also nur noch die Frage zu erörtern, mit welchem generischen Namen dieselbe zu belegen sei. Ich habe num die Bezeichnung Odonfaspis gewählt, obgleich mir kein recentes Gebiss dieses Genus zum Vergleiche zu Gebote stand, weil unsere Zähne sicherlich von Lamna verschieden sind. Die eigenartige Innervirung der Wurzel begrïudet einen so vortreftlichen Unterschied gegen Lamnct-Zähne, dass selbst Bruchstücke, an welchen nur ein kleiner 'Theil der Wurzel erhalten ist, hieran sehr leicht kenntlich sind ${ }^{1}$ ).

\section{Alopias Ilassei sp. n.}

Taf. V, Fig. 4a-f.

Da bei der einzigen recenten Art Alopias vulpes die Zähne, sowohl des Ober-resp. Unterkiefers als auch diejenigen der vorderen resp. seitlichen Particen der Kiefer ungemein ähnlich sind, so hält es schwer, den Platz eines einzelnen Zähnchens, welches sich im sumländischen Tertiär gefunden hat, mit Sicherheit zu bestimmen. Nach dem Vergleich mit der recenten Art könnte es möglicherweise dem Oberkiefer und zwar der linken Seite angehören.

1) Soweit ich bis jetzt übersehen kann, dürften die drei Genera: Lamina, Oxyrhina und Odontespis, deren Unterscheidung den Palacontologen seither viel Schwierigkeiten bereitet hat, sehr leicht an der Art der Innervirung kenntlich und sicher auseinander zu halten sein. Bei Oxyrlina liegt die Eintrittsöffuuug für den Hauptnerv auf einem flachen Verticalkiele, der sich inmitten einer breiten seichten Vertiefung erhebt, bei Lamna in einer nicht sehr tiefen Verticalspalte, so dass dic Oeffnung noch sichtbar ist, und bei Odontaspis im Grunde einer sehr tiefen, die Wurzel beinahe halbirenden Verticalspalte, so dass also die eigentliche Eintrittsöffnung unsichtbar ist. 
Die Gesammthöhe des Zähnchens betrïgt $10^{\mathrm{mm}}$, davon kommen anf die Krone allein etwa 7,5mm. Wurzel und Krone sind besonders auf der Externseite scharf gegen einander abgesetzt, wo der Unterrand der Krone etwas übersteht.

Die Wurzel ist im Allgemeinen niedrig, aber stark in die Breite gedehnt; auf der Internseite betrïgt ihre Gresammthöhe etwa $3,5^{\mathrm{mm}}$, während die Externfläche noch niedriger, nämlich $2,5^{\mathrm{mm}}$ ist; ihre Breite betrïgt dagegen $12,5^{\mathrm{mm}}$. Ihre grösste Dicke $\left(3,5^{\mathrm{mm}}\right)$ bleibt eine Strecke lang gleich, nimmt aber dann rasch gegen die Wurzelenden hin ab. Die niedrige Externfläche ist flach, aber gleichmässig ausgehöhlt. Die ziemlich schräg gerichtete hohe Neuralfläche ist leicht gewölbt und bildet mit der Ligamentfläche cine nur wenig markirte, abgerundete Ligamentkante. Die Ligamentfläche ist in der Mitte schmal, vorn und hinten etwas breiter und nur wenig gegen die Spitze geneigt. Ihre Mittelpartie liegt ziemlich horizontal, die Seiten fallen dagegen schräg ab. Der ziemlich scharfkantige Neuralrand ist nur wenig gebuchtet, daher die Wurzel nur undeutlich zweiästig; Vorder- und Hinterrand abgerundet.

Der Eindruck der Befestigungsmembran stellt sich auf der Internseite als eine sehr schmale, vertiefte Rinne dar, deren parallele Ränder scharf markirt sind; auf der Externseite ist er nur schwach angedentet und stellt ein vorn und hinten breites, in der Mitte sehr schmales Band dar, das mit einer glatten, nicht glänzenden Schicht überzogen ist. Der Oberrand ist sehr schwach ausgeprägt und läuft nahezu gerade, der Unterrand ist leicht nach oben gekrümmt.

Die Oeffinung für den Hauptnerv war nicht zu beobachten, da die Wurzel gerade an dieser Stelle etwas verletzt ist, allein nach Analogie des recenten A. vulpes wird dieselbe in der Mitte der Neuralfläche nahe der Ligamentkante am oberen Ende einer kurzen Verticalrinne gelegen haben.

Die hakenförmige Krone, deren Spitze stark rückwärts gezogen ist, besitzt unten eine Breite von etwa $10^{\mathrm{mm}}$ und ist vollkommen gerade, nur mit der äussersten Spitze fast unmerklich nach innen gekrümmt. Die flach gewölbte Externseite fällt leicht nach den 
Seitenrändern $a b$ und stösst mit der stärker gewölbten Internseite winkelig zusammen. Der Querschnitt gleicht somit einer flachen, einseitig eingedrückten Ellipse. Der Vorderrand ist sehr flach S-förmig gekrümmt und beträchtlich länger als der tief concave Hinterrand. Vorder- und Hinterrand sind ihrer ganzen Länge nach mit einem scharfen, glatten Kiele besetzt. Die Dicke ist nicht bedentend (3min $)$ und nimmt gegen die Spitze nur laugsam ab.

Eigentliche Seitenspitzen ${ }^{1}$ ) fehlen, doch ist die Basis der Krone schmal zungenförmig nach vorn und hinten verlängert.

Vorkommen: Sehr selten in der Zone $A_{1}$.

Bemerkungen: Alopias-Zähne sind ausserordentlich leicht an der auf der Externseite etwas gegen die Externfläche der Wurzel überstehenden Krone zu erkennen. Auch die hakenförmige Gestalt der Krone wäre in gewissem Sinne bemerkenswerth, doch ist sie charakteristisch nur bei den Seitenzähnen ausgebildet, während sie bei den Mittelzähnen mehr verwischt ist, aber immerhin kann sie auch hier noch als gutes Kennzeichen gelten.

Fossile Alopias-Zühne sind bis jetzt mit völliger Gewissheit noch nicht bekannt. Herr PRoBsT2) beschreibt zwar aus der schwäbischen Molasse zwei Arten, A. acuarius und A. gigas, allein ich vermisse sowohl in seiner Beschreibung als namentlich bei seinen Abbildungen das charakteristische Merkmal der AlopiasZähne: die auf der Externseite gegen die Wurzel etwas überstehende Krone. Nach meiner Ansicht dürfte A. gigas Probst cher eine Oxymhina-Art darstellen, denn das Argument, welches llerr PRonș für die Zugehörigkeit dieser Zähne zu Alopias beibringt, ist sehr unsicher. Wenn aber die letztgenannte Art thatsüchlich zu Alopias gehörte, so würde sie allerdings einen gigantischen Vertreter, der seinen Namen mit Recht verdiente, repräsentiren. Noch zweifelhafter erscheint mir die erstere Art. Jedenfalls aber, mögen die von Probst beschriebenen Zühne nun zu Alopicus gehören oder nicht, mit der samländischen Form besitzen sie nicht

1) Bei dem recenten Alopius vulpes sind übrigons, namentlich an den hinteren Seitenzähnen deutliche, weun auch stark verkïmmerte, Seitenspitzen vorhanden.

2) Württemhergische naturw. Jahroshefte Jahrg. 1579, pag. 140 und 141 . 
die geringste Aehnlichkeit. Alopias Hassei zeigt vielmehr die grösste Uebereinstimmung mit dem recenten Alopias vulpes, und zwar ist die Aebnlichkeit so überrasehend, dass es fast schwer hält, Untersehiede aufzufinden. Nach sorgfältiger Vergleichung ergab sich jedoch, dass sich Alopias Hassei durch beträchtlichere Grösse, vielleicht etwas gedrungenere Krone und deren gewölbte Externseite sowie durch eine schmalere Ligamentfläche von A. vulpes unterscheidet. Dieser ist durchweg kleiner, die Krone schlanker mit vollkommen flacher Externseite und Ligamentfläche breit.

\section{Alopías ef. Hassei sp. n.}

Taf. X, Fig. $3-3 \mathrm{c}$.

1582. Alopias sp. Hasse, System der Elasmobranchier pag. 223, tab. 29., fig. 22 und 23.

Der einzige Wirbel, ein Rumpfwirbel, welchen ich auf Alopias beziehen kann, besitzt eine Höhe von $30,5^{\mathrm{mm}}$ und nur wenig geringere Breite, nämlich 29,5 ${ }^{\mathrm{mm}}$, seine Länge beträgt nur ein Drittel der Höhe, nämlich $10^{\mathrm{mm}}$. In dorsaler Richtung ist der Wirbel etwas verschmälert und auf der Dorsalseite abgeflacht, in ventraler Richtung verbreitert, aber gleichzeitig gegen die Mitte hin etwas zugespitzt. Daher gleicht der Wirbel in der Frontalansicht einem abgerundeten Fünfeck, das eine Seite dorsalwärts und die gegenüberliegende Spitze ventralwärts kehrt. In der Seitenansicht ist der Umriss hoch rechteckig.

Dorsal- und Ventralseite sind verhältnissmässig leicht zu unterscheiden, da die Lücken für die Knorpelzapfen sehr verschiedenen Querschnitt zeigen. Auf der Dorsalseite (Fig. 3a) besitzen die Lücken eine nahezu quadratische Form, da ihre Länge $\left(7,5^{\mathrm{mm}}\right)$ nur um $1,5^{\mathrm{mm}}$ die Breite übertrifft. Jedoch wird das Lumen durch secundäre Knochenablagerungen sehr stark verengt und daher der normale Umriss etwas alterirt; die Oeffnungen besitzen danu lang-ovalen oder rechteckigen Umriss. Die Ründer sind schwach verdickt. Die beiden Lücken liegen ziemlich nahe, nämlich nur durch einen Zwischenraum von $7^{\text {mm }}$ Breite getrennt. Genau in der Mitte desselben liegt ein sehmaler, etwa $2^{m m}$ breiter Spalt von spit\%-ovalem 
Querschnitt. Zwischen letzterem und den beiden Apophysenlïcken stehen etwa drei Lamellen der Aussenzone, welche jedoch durch oberflächliche Verkalkung fast gänzlich mit einander verschmolzen sind.

Die Lücken für die Knorpelzapfen der Hämapophysen (Fig. 3b) besitzen querrechteckige Form in Folge Ueberwiegens der Breite gegen die Länge; erstere betrïgt nämlich $9^{\mathrm{mm}}$, letztere nur $6,5^{\mathrm{mm}}$. Die Rïnder sind leicht aufgeworfen und das Lumen etwas durch parietale Knochenablagerungen verengt. In den Lücken treten zwei ziemlich dicke Lamellen auf, welche drei nahezu gleich grosse Kammern abtheilen. Zuweilen findet sich in den beiden Aussenkammern noch je eine kürzere und düunere Lamelle. Die beiden Lücken liegen fast dicht nebeneinander und sind nur durch einen $2,5^{\mathrm{mm}}$ breiten, aber $7^{\text {mm }}$ langen Spalt von schmal-elliptischem Umriss getrennt.

In der Seitenansicht (Fig. 3 c) sieht man als Ausdruck der verkalkten Radialstreifen der Aussenzone zahlreiche, ziemlich dicke Längslamellen, deren genane Zahl sich nicht ermitteln lässt, weil sie meis $\frac{\iota}{\imath}$ durch Oberflächenverkalkung miteinander vereinigt sind; es mögen aber mindestens zwanzig gewesen sein. Die Lamellen sind auf der Oberfläche vielfach längsgeschlitzt und an beiden Enden unregelmässig zerspalten.

Die Wirbelhöhlung ist schwach eingesenkt, auf der einen Seite am Rande leicht abgeflacht. Die Durchbohrung für die Chorda liegt kaum merklich aus dem Centrum nach der Dorsalseite hingerïckt; das Verhältniss beider Abstïnde stellt sich etwa wie 14:16.

Der centrale Doppelkegel ist dick, mit leicht aufigeworfenen und abgerundeten Rändern. Die Aussenflächen sind sehr regelmässig concentrisch gestreift. In der centralen Partie sind die Wachsthumisringe stärker und liegen weiter auseinander, als in dem peripheren Theil, wo sie allmählich feiner werden und dichter gedrïngt stehen.

Im Querschnitt erscheint die verkalkte Innenzone als kleiner, schwarzer Kreis von etwa 1,5 $5^{\text {mm }}$ Durchmesser, der von einem lichten, nach aussen wenig scharf abgegrenzten ling von beinahe $2^{m m}$ Breite, dem centralen Doppelkegel umgeben wird. 
Die Aussenzone zeigt vier durch die Knorpelzapfenlücken getrennte Strahlenbüschel, nämlich einen ventralen, einen dorsalen und zwei laterale. Die beiden erstgenannten enthalten nur zwei Radialstrahlen, die aber gegen die Peripherie hin sehr stark an Dicke zunehmen und an den Aussenseiten fiederartig, bis zur Abspaltung kurzer Secundärstrahlen, ausgeschnitten sind. Die Lateralbüschel zählen etwa neun Radialstrahlen, von welchen die beiden äussersten, d. h. diejenigen, welche die Knorpelzapfenlücken begrenzen, vor den übrigen durch grössere Stärke ausgezeichnet sind. Die zwischen diesen beiden liegenden Strahlen sind auf ihre ganze Länge hin lamellenartig dünn, können sich aber gegen die Peripherie hin noch ein bis zwei Mal gabeln.

Die lateralen Strahlenbüschel lassen sich jedoch auf drei primäre Strahlen zurückführen, aus deren Gabelung sie entstanden sind. Es waren daher im Ganzen zehn Primärstrahlen, je zwei dorsale resp. ventrale und je drei laterale vorhanden, die in der centralen Partie der Aussenzone als dunkle Streifen auf lichtem Grunde erscheinen, da ihre Zwischenräume bis auf' etwa $4^{\mathrm{mm}}$ Entfernung vom Doppelkegel durch secundäre Kalkablagerung, welche innig mit den ersteren verschmolzen ist, ansgefüllt sind.

Unter den durch die Radialstrahlen abgetheilten Zwischenrüumen unterscheidet man sofort die Lücken für die KnorpelZapfen der Apophysen an der grösseren Breite sowohl wie an der Begrenzung durch stärkere Radialstrahlen. Die Lü̈cken für die Knorpelzapfen der Hämapophysen sind breiter als für die Neurapophysen, aber fast völlig durch secundäre Verkalkung, welche in Gestalt ziemlich unregelmässig concentrischer Blätter auftritt, ausgefüllt; übrigens fehlt eine derartige Verkalkung den Neurapophysenlücken nicht völlig, nur ist sie hier viel schwächer ausgebildet. Die übrigen Zwischenräume sind schmal, zum Theil durch concentrische Verkalkungsblitter, welche sich in den Radialstrahlen ansetzen, verengt.

Vorkommen: Sehr selten in der Zone $A_{1}$.

Bemerkungen: Nach Vergleich mit einem in meiner Sammlung befindlichen Wirbel des recenten Alopias vulpess ergiebt sich zweifelsohne die Zugehörigkeit unseres Wirbels zu Alopias. 
Namentlich möchte ich die Uebereinstimmung der Ventralseite des recenten und unseres fossilen Wirbels besonders hervorheben, da der Querschnitt der Hämal-Knorpelzapfenlücken, soweit ich beurtheilen kann, für Alopias ungemein charakteristisch ist und dieser Charakter die Bestimmung fossiler Alopias-Wirbel sehr erleichtert.

Ich gebe zu dem Zweck eine Abbildung der Dorsal- und Ventralseite eines Rumpfwirbels von Alopias vulpes (Texttafel Lief. I, Fig. 13 u. 13a), wodurch zu gleicher Zeit auch die Verschiedenheit beider Seiten veranschaulicht wird. Was aber die Ventralseite angeht, so sieht man bei dem recenten Wirbel, dass die Lücken für die Knorpelzapfen der Hämapophysen stark quer ausgedehnt sind, da ihre Breite mit 11,5 die Länge, $6^{\mathrm{mm}}$, beinahe um das Doppelte übertrifft, dass somit der Umriss eine quer rechteckige Form zeigt. In beiden Lücken treten noch je zwei secundüre Lamellen auf.

Genau die gleiche, ungemein in die Breite entwickelte Form der Hämapophysenlücken, zeigt anch der fossile Wirbel (Taf. X, Fig. 3b), und ebenso fehlen die beiden, bei dem recenten Wirbel vorhandenen Längslamellen nicht.

Der einzige Unterschied liegt nur darin, dass bei dem recenten Wirbel die Lücken dicht neben einander liegen und ihre Wände nur durch einen ganz schmalen, medianen Spalt getrennt sind, während die bei dem fossilen Wirbel weiter von einander abstehen, zugleich aber der mediane Spalt grössere Breite besitzt. Ich glaube jedoch auf diese Differenz keinen Werth legen zu sollen, da sie möglicherweise in der Stellung der Wirbel in der Wirbelsäule begründet ist. Wichtiger ist jedenfalls die grosse Uebereinstimmung in der Form der Hämapophysenlücken.

Herr HASSE hat leider keinen Durchschnitt oder eine Ventralansicht des von ihm beschriebenen und abgebildeten AlopiasWirbels aus dem samländischen Tertiür gegeben, ich vermuthe aber, dass derselbe mit dem von mir hier beschriebenen Wirbel ident ist, da seine Beschreibung auch auf ihn völlig zutrifft. Die Unterschiede dieses Wirbels gegen den recenten Alopias hat Herr Hasse sehr richtig hervorgehoben: sie bestehen in einer grösseren Zahl von Längslamellen der Seitenflächen, d. h. in einer grösseren Zahl lateraler Strahlen bei dem fossilen, als solche 
bei dem recenten Wirbel vorhanden sind, eine Differenz, die Herr HASSE geneigt ist, dem grösseren Alter und der gewaltigeren Grösse der fossilen Thiere zuzuschreiben. Ich finde diesen Unterschied rollkommen bestätigt und möchte noch hinzufügen, dass sich der fossile Wirbel von dem recenten durch bedeutendere Höhe, aber weit geringere Länge, sowie durch beträchtlich kleinere Neurapophysenlücken unterscheidet, wie der Vergleich der Abbildungen darthut.

\title{
Carcharodon angustidens Agassiz.
}

\author{
Taf. VI, Fig. $1-3 b$.
}

1843. Carcharodon angustidens Agassiz, Recherehes sur les poissons fossiles Bd. III, pag. 255 , tab. 28 , fig. $20-25$; tab. 30 , fig. 3.

Von dieser Species besitze ich nur wenige, nicht sonderlich gut erhaltene Zähne, deren Wurzel entweder völlig fehlt oder doch sehr stark verletzt ist. Daher ist bei denselben die Unterscheidung, ob Mittel- oder Seitenzähne, sehr schwierig, und ich muss es daher vorläufig dahingestellt sein lassen, ob meine Bestimmung richtig ist oder nicht. Ich habe hier die im Verhältniss zur Höhe schmalen Zühne als Mittelzähne, die breiteren als Seitenzähne gedeutet.

a) Mittelzähne.

Den beiden vorliegenden Mittelzähmen fehlt die Wurzel bis auf ein kleines Stück dicht an der Basis der Krone fast gänzlich. Bei beiden Exemplaren sieht man noch einen Theil des in der Mitte etwa $4,5^{\mathrm{mm}}$ breiten, nach den Seiten etwas schmäler werdenden, schwach vertieften Eindruckes der Befestigungsmembran. Der obere Rand derselben ist in der Mitte stumpfwinkelig gebrochen, der untere Rand einfach gekrümmt. Bei dem abgebildeten Exemplar (Fig. 1-1b) ist derselbe noch mit einer dümnen, glatten, nicht glänzenden Emailschicht überzogen, die bei dem andern, auch bei den Seitenzähnen, zerstört ist. Die Höhe der Krone schwankt zwischen 40 und $45^{\mathrm{mm}}$, während die Breite gegen $30^{m m}$ beträgt. Ilır Umriss kann nahezu gleichschenkelig dreieckig genannt werden, doch ist die Spitze etwas aus der Mitte nach rückwärts gezogen und gleichzeitig leicht nach aussen gekrümmt, während die Krone im Uebrigen vertical ist. Die Extern- 
seite ist fast vollkommen flach, nur in der Mitte unmerklich gewölbt, zuweilen an der Basis mit einer leichten medianen Einsenkung versehen. Die Internseite ist bedentend stärker gewölbt, aber nach den Seiten nicht sehr steil abfallend, wenn sie anch mit der Externseite in scharfer Kante zusammenstösst. Der Querschnitt gleicht hierdurch einer halben, ziemlich flachen Ellipse. Die Dicke der Krone ist an der Basis nicht sehr bedentend und nimmt gegen die Spitze hin langsam ab. Der Vorderrand ist leicht convex und etwas lïnger als der schwach concave Hinterrand. Beide Ränder sind ihrer ganzen Länge nach mit kleinen, meisselförmigen Kerbzähnchen besetzt, deren Aussen- resp. Innenseite flach gewölbt und deren Schneide elliptisch gebogen ist. Eine Grössenabnahme der Kerbzähnchen gegen die Spitze hin ist kaum wahrnehmbar.

Das Email scheint auf der Externseite nur sehr flach, vielleicht etwas winkelig, auf der Internseite spitzbogenförmig ausgeschnitten gewesen zu sein. Ob Nebenspitzen vorhanden waren, vermag ich nicht anzugeben.

(B) Seitenzähne.

Die Gesammthöhe des an besten erhaltenen Seitenzahnes (Fig. 2 bis 2b) beträgt zu $60^{\mathrm{mm}}$, wovon etwa $45^{\mathrm{mm}}$ auf die Mittelspitze entfallen, während die Wurzel allein, soweit sie noch erhalten, etwa $15^{\mathrm{mm} \mathrm{m}}$ hoch ist; ihre Breite beträgt dagegen nahezu $50^{\mathrm{mm}}$. Von der Wurzel ist nichts weiter zu sagen, als dass der Neuralrand sehr wenig gebuchtet, eine Gabelung daher eben nur angedentet ist.

Die Krone besitzt inclusive Nebenspitzen anf der Externseite cine grösste Breite von etwa 50 allein etwa $35^{\mathrm{mm}}$ entfallen. Diese gleicht in ihrer frorm genau den Mittelzähnen, nur ist die Internseite noch flaçher gewölbt, die Dicke daher gering und der Querschnitt noch flacher, elliptischer als bei ersteren. Die Externseite zeigt bei manchen einen ganz schwachen Kiel (Fig. 2), der gegen die Spitze etwas stärker wird.

Nur die hintere Nebenspitze ist erhalten, deren Breite etwa $8^{m m}$, die Höhe etwa $6^{\mathrm{mm}}$ beträgt. Ihr Umriss ist unregelmässig halbkreisförmig, die Externseite flach, die Interuseite gewölbt und beide Ränder mit Kerbzähnchen besetzt. 
Vorkommen: Ziemlich selten in der Zone $\mathbf{A}_{1}$, sonst in Tertiärschichten allgemein verbreitet.

Bemerkungen: Agsssiz hat unter verschiedenen Namen, wie Carcharodon lanceolatus, heterodon, turgidus, megalotis etc. Carcharadon-Zähne beschrieben, die Gibies ${ }^{1}$ ) mit Recht einzieht und mit $C$. angustidens vereinigt, der von AGAssiz anscheinend auf Mittelzähne hegrïndet war. Die Unterschiede dieser Arten sowohl untereinander als gegen $C$. angustidens waren wesentlich in der äusseren Form begründet, die bei allen Haifischen von sehr untergeordneter Bedeutung ist, da sie je nach Lage der Zähne variirt.

C. angustidens dürfte seinen nächsten Verwandten im recenten C. Rondeleti haben, dessen Zähne sich jedoch, wie meine Exemplare zeigen, durch eine weit geringere Dicke der Krone, sehr flache Internseitr und daher sehr flach dliptischen (2uerschnitt ron den Zälınen des $C$. angustidens unterscheiden.

\section{Carcharodon obliquis Agassiz sp. ${ }^{2}$ ).}

Taf. VI, Fig. $4-4$ d.

1843. Otodus obliquus Agassiz, Rechorches sur les poissons fossiles Bd. III, pag. 267, tab. 31 und tab. 36 , fig. $22-27$.

Die Zähne dieser Species sind, wenn auch sehr häufig, doch nicht sonderlich gut erhalten, da sie entweder stark abgerollt oder

1) Monograph of the fossil Squalidae of the United Stantes (Journ. of the Academy of Natur. Sc., Philadelphia, 1StS) pag. 9.

2) In einem besonderen Aufsatz, welcher demnächst in der Zeitschrift der Deutschen geologischen Gesellschaft erscheinen wird, gedenke ich ausführlich darzulegen, dass das Genus Otodus Agassiz einzuzichen ist, da es wahrscheinlich ein Conglomerat von Lamna-, Oryplina- und Carcharodon-Zähnen darstellt. Der Typus des Geschlechts, Otodus obliquus, ist wenigstens nichts anderes als ein glattrandiger Carcharodon. Um übrigens Einwïnden gegen diese Auffassung von voruherein zu begegnen (man könnte mir jal entgegenhalten, dass für die glattrandigen Carcharodon-Zähne die Benenumug (Jtodus beizubehalten sei', so möehte ich bereits hier mittheilen, dass meine Studien an recenten Haifischen ergeben haben, dass der Kerbung der Kronenränder kaum specifischer, geschweigo demm generischer Werth beizumessen sei. Ich nenne als Beispicle Scymnus lichia, der im Unterkiefer gekerbte, im Oberkiefer glatte Zähne besitzt, oder llemimristis elongatus, dessen Mittelzälno glattrandig, die Seitenzälne gekerbt sind. 
an der Wurzel mit Sand inkrustirt sind, so dass wichtige Merkmale, wie der Eindruck der Befestigungsmembran oder die Eintrittsöftnung für den Hauptnervenstamm, nur sehr ungenägend beobachtet werden konnten. Der Beschreibung dienen wesentlich die abgebildeten Exemplare; es versteht sich von selbst, dass die übrigen Zähne, je nach der Stellung im Rachen, an Grösse und Form variiren.

a) Mittelzähne.

Die Mittelzähne sind leicht an der schlanken, schmalen, nahezu verticalen Hauptspitze und der schmalen, verhälnissmässig tiefgegabelten Wurzel zu erkennen. Der grösste und am besten erhaltene Mittelzahn (Fig. 4-4d) besitzt eine Gesammthöhe von $66^{\mathrm{mm}}$, wovon etwa $47^{\mathrm{mm}}$ auf die Haupt-

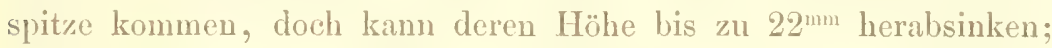
$35^{\text {mm1 }}$ dürfte als durchschnittliche Höhe gelten. Wurzel und Krone sind nicht scharf gegen einander abgesetat, sondern gehen allmählich in einander über, so dass nur der Beginn des Emails die Grenze zwischen beiden bezeichnet.

Die Wurzel besitzt ca. $41^{\mathrm{mm}}$ Breite und eine mittlere Höhe von etwa $20^{\mathrm{mm}}$. Thre Dicke ist sehr bedeutend, am stärksten in der Mitte der Grenze zwischen Ligamentfläche und Neuralfläche, wo sie etwa $20^{\mathrm{mm}}$ betrïgt; gegen die Wurzelenden nimmt jedoch die Dicke stark ab. Die hohe Externfläche ist in der Mitte tief ausgehöhlt, vorn und hinten flach; die Neuralfläche ist sehr schräg nach oben gerichtet, flach und besitzt nahezu die gleiche Höhe wie jene, mit der sie am Vorder-, Hinter- und Neuralrand in ziemlich scharfer, jedoch abgerundeter Kante (Fig. 4b u. c) zusammenstösst. Die flach gewölbte Ligamentflïche ist schräg gegen die Spitze hin abfallend, in der Mitte am breitesten, gegen die Seiten hin schnäler werdend und bildet mit der Neuralfläche eine flach nach oben gekrümmte, nicht sehr scharf markirte Kante, die Ligamentkante.

Der Neuralrand ist in der Mitte tief ausgeschnitten, daher die Wurzel zweiästig; die beiden Aeste sind nicht sehr lang, zuweilen von verschiedener Grösse und in Folge der flachen Aussenresp. Neuralfläche von aussen nach innen comprimirt. 
Die Oeffnung des Hauptnervenkanals war sehr klein und liegt in der Mitte der Wurzel auf der Neuraltläche sehr nahe der Ligamentkante.

Der Eindruck der Befestigungsmembran ist nur auf der Internseite zu sehen, er stellt sich hier als ein in der Mitte ziemlich breites, nach vorn und hinten verschmälertes glattes Band dar, dessen Uberrand stumptwinkelig colorochen ist, während der Luterrand nur flach gebogen ist.

Die Krone besitzt inclusive Nebenspitzen auf der Externseite an der Basis eine. Breite von 32m, wovon auf die Hauptspitze allein etwa $24^{\mathrm{mm}}$ kommen. Die Hauptspitze zeigt schlank gleich-

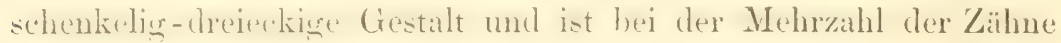
vollkommen gerade, bei einigen leicht nach innen gekrümmt. Die Externseite ist nicht vollkommen flach, sondern in der Mitte, wenn auch sehr schwach, gewölbt.

Die Internseite ist hoch gewölbt, nach vorn und binten steil abschüssig und stösst mit der Externseite in scharfem Winkel zusammen. Der Querschnitt gleicht daher mehr oder minder einem Halbkreis. Vorder- und Hinterrand sind vollkommen gerade und ihrer ganzen Länge nach von der Spitze bis zur Basis glatt und scharf gekielt. Die Dicke ist an der Basis am stärksten und nimmt gegen oben hin langsam und gleichmässig ab.

Die Nebenspitzen zeigen eine mehr gedrungen gleichseitigdreieckige Gestalt; ihre Höhe beträgt nämlich $9^{\text {mm }}$ und ihre Breite an der Basis etwa ebensoviel. Sie sind noch mit der Hauptspitze vereinigt, aber schrär dagegen gerichtet und entweder leicht nach aussen oder nach innen gebogen. Im übrigen sind sie das genaue Abbild der Hauptspitze, also aussen flach, innen hoch gewölbt, vorn und hinten scharf gekielt.

Das Email ist auf der Internseite hoch spitz-bogenförmig, auf der Externseite flacher gekrümmt, bisweilen stumpfwinkelig ausgeschnitten.

ק) Seitenzähne.

Mit der Beschreibung der Seitenzähne kann ich mich kürzer fassen, da sie genau nach demselben Typus wie die Mittelzähne ge- 
baut sind und nur in der Form abweichen. Sie unterscheiden sich von den Nittelzähnen sofort durchihre gedrungene breite Gestalt und eine stark rückwärts gekrümmte Hauptspitze. Die Gesammthöhe bewegt sich bei den mir vorliegenden Zähnen in den Grenzen von $40-50^{\mathrm{mm}}$, wovon etwa ein Drittel auf die Höhe der Wurzel, und zwei auf die Höhe der Hauptspitze kommen. Das abgebildete Exemplar (Fíg. $6-6$ d) dürfte etwa $42^{\mathrm{mm}}$ hoch gewesen sein, wovon $25^{\mathrm{mm}}$ auf die Höhe der Hauptspitze, $17^{\mathrm{mm}}$ auf die Wurzel entfallen.

Die Wurzel ist im Vergleich zu ihrer Höhe viel breiter als bei den Mittelzähnen, ind̄em die Breite nahezu der Gesammthöhe des Zahnes gleichkommt; bei dem abgebildeten Exemplar beträgt sie etwa 39 $39^{\mathrm{mm}}$; dagegen ist die Dicke etwas geringer, sie beträgt kaum über $15^{\mathrm{mm}}$. Die Aussenfläche ist entweder flach oder nur sehr leicht ausgehöhlt; die Neuralflïche ist schrïg nach oben gerichtet, und die Ligamentkante meist gut markirt. Die Ligamentfliche ist ziemlich hoch, meist etwas concav. Vorder-, Hinter- und Neuralrand sind gerändert, letzterer nicht sehr tief ausgeschnitten, daher die Wurzel nur undentlich zweiästig.

Der Eindruck der Befestigungsmembran und die Lage des Hauptnervenkanals wie bei den vorigen.

Die Krone besitzt inclusive Seitenzähnen eine durchschnittliche Breite von etwa $40^{\mathrm{mm}}$; bei dem abgebildeten Exemplare genauer $39^{\mathrm{mm}}$; davon kommen etwa $\% / 3$, also $26^{\mathrm{mm}}$, auf die Hauptspitze. Diese zeigt eine schiefwinkelig-dreiseitige Gestalt dadurch, dass die Spitze stark rückwärts übergebogen ist, so dass sie mit dem Hinterrand der Wurzel nahezu in einer Linie liegt. Bei der Mehrzahl der Zähne ist sie vollkommen gerade, bei einigen aber auch schwach nach aussen gekrümmt. Die Externseite ist flach, nur in der Mitte etwas gewölbt, die Internseite bedeutend stärker, jedoch lange nicht so stark, wie bei den Mittelzähnen grewölbt und seitlich nicht so steil abschüssig; daher der Querschnitt ein halbelliptischer. Der Vorderrand ist gerade oder selbst leicht convex schief gerichtet und stets etwas länger, als der schwach concave, nahezu senkrecht laufende Hinterrand; beide sind ihrer ganzen Länge nach glatt und scharf gekielt. 
Die Nebenspitzen gleichen in ihrer Form derjenigen der Mittelzïhne, zuweilen sind sie nur wenig von der Hauptspitze getrennt. Bei dem abgebildeten Exemplar beträgt ihre Höhe $7^{m m}$, ihre Breite ca. $8^{\mathrm{mm}}$.

Das Email ist auf der Externseite flach, in winkelig gebrochener, auf der Internseite etwas stärker, meist in bogenförmiger Linie ausgeschnitten.

Vorkommen: Häufig in der Zone A, sonst verbreitet im obereu Eocän und unteren Oligocäin.

Bemerkungen: Da ich leider nicht in der Lage bin, ein vollständiges C'archarodon-Gebiss untersuchen zu können, so vermag ich nicht zu sagen, ob Ober- und Unterkieferzähne so weit verschieden gebaut sind, dass sie auch in vereinzelten Exemplaren unterschieden werden können. Aus der Analogie mit anderen Lamniden möchte diese Unterscheidung für die Seitenzähne wohl sehr schwierig sein; leichter dürften vielleicht die Mittelzähne auseinander zu halten sein.

Carcharodon obliquzs ist sehr leicht an den glatten scharfgekielten hïudern der Krone ron den Careharodonten vom Typus des recenten C. Rondeletii M. I. H. zu unterscheiden. Wie er sich jedoch zu andern glattrandigen Carcharodonten verhält, vermag ich hier mangels an Vergleichsmaterial nicht zu sagen. Aus dem Tertiär sind mir unzweifelhafte glatte Carcharodonten nicht weiter bekmnt, und über die cretaceischen Formen habe ich kein Urtheil. Vielleicht könnte Otorlus appendiculatus der nächste Verwandte unserer Art sein, ron dem sie sich aber olne Weiteres durch die bedeutende Grösse unterscheidet. Auch AGAssiz giebt als Hauptcharakteristik seines Otodus obliquus die Grösse, massive Gestalt und mächtig entwickelte Wurzel an.

\section{Carcharodon sp.}

Taf. X, Fig. 1-2d.

Die beiden Wirbel, welche ich zu Carcharodon angehörig betrachte, repräsentiren die grössten Exemplare unter allen mir aus dem samländischen Tertiär bekannten Wirbeln. Beide, zweifels- 
ohne liumpfirirbel, besitzen eine Höhe von $37^{m m}$, eine gleich grosse Breite, aber dabei nur eine Länge von 11,5 $5^{\mathrm{mm}}$. In der Frontalansicht sind beide etwas rerschieden gestaltet; der eine Wirbel, Fig. 1, besitzt nahezu kreisförmigen Umriss, jedoch mit einer leichten ventralen Zuspitzung, der andere, Fig. 2, einen mehr senkrechtovalen Umriss in Folge ziemlich ausgeprägter dorsaler Zuspitzung und leichter ventraler Verschmälerung. In der Seitenansicht ist der Umriss rechteckig.

Dorsal- und Ventralseite sind wegen der in den Lücken des Knorpelkreuzes auftretenden secundären Lamellen schwierig zu unterscheiden. Auf der Dorsalseite besitzen die Lüuken für die Knorpelzapfen der Neurapophysen bei Fig. 1 etwa 9,5m Länge und etwa 5,5mm Breite; ihre rechteckige Oeftinung hat ziemlich stark aufgeworfene Rïnder, wird jedoch durch eine parietale Verknöcherung häufig stark rerengt und nimmt dann eine in der Längsachse des Thieres gestreckte ovale Form an. Zuweilen, wie bei Fig. 2, treten innerhalb der Lücken von deren Wänden entspringend ein bis zwei secundäre Lamellen auf. Die beiden Lücken liegen etwa $14^{m m}$ (Fig. 1) auseinander, und zwischen beiden befinden sich etwa sechs Längslamellen, von welchen die beiden mittelsten dicht nebeneinander stehen, während die anderen durch breitere Zwischenräume getrennt sind.

Auf der Ventralscite besitzen die Lücken für die Knorpclzapfen der Hämapophysen eine quadratische Oeffnung, indem die Breite nur wenig geringer ist als die Länge (bei Fig. 1 die Breite 7, die Länge $9^{\mathrm{mm}}$ ). Im Uebrigen besitzen sie wie vorige verdickte aufgeworfene Ränder und secundäre Verknöcherung im Lumen. Sie unterscheiden sich jedoch von jenen dadurch, dass beide einander näher stehen; ihre Entfernung beträgt bei Fig. 1 nur $8^{m m}$. Die zwischen ihnen liegenden Längslamellen scheinen constant durch theilweise Oberflächenverkalkung miteinander verschmolzen zu sein. In der Seitenansicht sieht man als Ausdruck der verkalkten Strahlen der Aussenzone sehr regelmässige, etwa $3 / 4-1^{m m}$ starke Längslamellen, welche sich an den Enden leicht verdicken und durch etwas breitere lang-ovale Zwischenräume getrennt werden; ich zähle jederseits etwa 20 solcher Lamellen. 
Die Wirbelhöhlung ist ungemein seicht, am Rande abgeflacht und nur in der Mitte etwas stärker eingesenkt. Die Durchbohrung für die Chorda liegt excentrisch gegen die Ventralseite hingerückt, und zwar im Verhältniss von etwa $5: 4$.

Der centrale Doppelkegel ist ziemlich dick am Rande, leicht aufgeworfen und scharf gegen die Verkalkungen der Aussenzone abgesetzt, aber dennoch innig mit denselben verbunden. Seine Aussenfläche ist sehr regelmässig und ziemlich eng concentrisch gestreift. Die Wachsthumsringe sind in der centralen Partie am schärfsten ausgebildet, weil sie hier ziemlich grob sind und nicht so enge stehen; gegen die Peripherie hin folgen sie dichter aufeinander, werden jedoch mehr und mehr feiner und undentlicher.

Im Querschnitt erscheint die verkalkte Innenzone (i) als dunkler, scharf begrenzter Kreis von etwa $2^{\text {mm }}$ Durchmesser, und um denselben herum der centrale Doppelkegel (d) als breiter, heller, nach aussen nicht sehr scharf abgegrenzter Ring. Die Aussenzone zeigt die vier Strahlenbüschel, einen dorsalen und einen ventralen, sowie zwei laterale, welche durch die Knorpelzapfenlücken getrennt sind. Unter den liadialstrahlen zeichnen sich wiederum diejenigen, welche die Knorpelzapfen seitlich begrenzten, durch eine grössere Stärke vor den übrigen aus, indem sie gegen die Peripherie hin an Dicke zunehmen, während alle übrigen lamellenartig dünn sind und auf ihre ganze Länge bis zum Rande hin gleichbleibende Stärke besitzen.

Der dorsale Büschel zählt sechs Strahlen, entstanden aus der Gatbelung von zwei Primärstrahlen, der ventrale deren vier, die ebenfalls auf zwei Primärstruhlen zurückzuführen sind; einzelne der Strahlen zeigen noch eine weitere Zersplitterung. Die lateralen Büschel zählen je etwa 12 Strahlen, welche auf 6 Primärstrahlen zurückgeführt werden können und sich mit wenigen Ausnahmen kurz vor dem Rande noch einmal gabeln.

Die Primärstrahlen waren somit in der Zahl von 14 vorhanden, und man erkennt sie am besten bei Fig. 1 d in der centralen Partie der Aussenzone, als leicht hingehauchte dunkle Streifen auf hellem Grunde, da ihre Zwischenräume durch Kalkablagerungen in Form dünner concentrischer Ringe völlig ausgefüllt sind. Die Ausfüllung 
der Zwischenrïume reicht übrigens bis etwa $7^{\mathrm{mm}}$ Entfernung vom Doppelkegel, nur dass gegen das Ende hin die concentrischen Ringe etwas weiter auseinanderstehen.

Die Knorpelzapfenlïcken zeichnen sich durch grössere Breite gegen die übrigen spaltförmigen Zwischenräume aus, doch auch sie sind durch parietale Knochenablagerungen zum Theil ausgefüllt. Deutlich sicht man, dass die ventralen ( $h \mathrm{~h}$ ) einen spitzeren Winkel mit einander bilden, als die dorsalen ( $\mathrm{nn}$ ), mithin einander näher stehen als jene, die weiter auseinander gerückt sind.

Vorkommen: Nicht selten in der Zone $\mathbf{A}_{1}$.

Bemerkungen: Herr Hasse bestimmte die hier beschriebenen Wirbel als Otodus-Wirbel, allein ich vermag dieser seiner Bestimmung aus folgenden Grïnden nicht beizupflichten. Agassiz hat das Genus Otodus nur auf lose gefundene Zühne fossiler Elasmobranchier begründet, das darf nicht ausser Acht gelassen werden. Da nun aber bis jetzt noch kein Merkmal bekannt, ist, welches mit unumstösslicher Sicherheit die generische Zusammengehörigkeit beliebiger Haifischzähne und - Wirbel darthut, so muss es sehr gewagt erscheinen, gewisse fossile. Wirbel anf ein Genus zu beziehen, das nur auf fossile Zähne begründet wurde. Anders stände es natürlich, wenn von Otodus auch recente Vertreter bekannt wären; man könnte dann auf Grund der Merkmale der recenten Wirbel die fossilen mit Bestimmtheit in Beziehung zu den entsprechenden Zähnen bringen.

Ich kann auch Herm HAssE's Deductionen hinsichtlich der Otodus-Wirbel (pag. 206) im »System der Elasmobranchier nicht beipflichten. Herr HAsse sagt hier Folgendes: „Ich habe für die jetat zu beschreibenden Wirbel mit Vorbedacht die Bezeichnung Otodus gewählt, einmal, weil ich, den Fundorten wach zu urtheilen, in welchen die Zähne zahlreich vertreten sind, annehmen muss, dass dieselben diesem ausgestorbenen Geschlechte angehören, und dann, weil, wenn auch die Form und der gewebliche Aufbau der Wirbel dem der vorbeschriebenen Scylliolamuiden (s. Ginglymostoma, Stegostoma, Crossorhinus) sich eng anschliesst, dennoch so mancherlei Abweichungen in der Zusammensetzung, namentlich in der Gestaltung des Struhlenbildes sich zeigten, dass ein einfaches Zurück- 
führen auf die Vertreter Stegostoma, Crossorhinus und Ginglymostoma nicht ohne Weiteres thunlich erscheint."

Hieraus folgt doch nichts weiter, als dass Herr Hasse fossile Wirbel untersucht hat, die eine gewisse Analogie im geweblichen Aufbau mit den Scylliolamniden zeigen; das ist aber kein Grund, diese Wirbel mit einem generischen Namen zu belegen, der nur für Zülhne aufgestellt wurde. Dass diese Wirbel sich in Schichten finden, in welchen Otodus-Zähne zahlreich vorkommen, darf auch nicht als beweisend angesehen werden: mit den OtodusZühnen zusammen kommen noch zahlreiche Zähne anderer Elasmobranchier ror, auf welche sich mit gleichem Rechte die betreftenden Wirbel beziehen liessen.

Herr HAsse hat, als ich mich brieflich in dieser Angelegenheit an ihn wendete, geäussert, dass auch die Zähne der Scylliolamniden sich rollkommen den fossilen Otodus-Zähnen anfügten; aber auch dieser Anschauung rermag ich nicht beizutreten. Es war mir Dank der Freundlichkeit der Herren ros Martens in Berlin und Oberstudienrath Dr. Kratsss in Stuttgart vergönnt, Zähne dieser Haiformen studiren und mich von der Verschiedenheit der Scylliolamnidenzähne gegenüber den OtodusZähnen überzeugen zu können. Erstere, namentlich C'rossorhinus, zeigen vielmehr eine grosse Analogie mit Squatina-Zähnen.

Hier nur so viel über diese Frage, auf welche ich in einer besonderen Abhandlung, wie ich Eingangs bemerkt, zurückkommen werde.

Da ich also die Bezeichnung sOtochus" für die obigen Wirbel nicht zu acceptiren vermag, so würde es sich fragen, welchem Genus dieselben angehörten, und da scheint es mir dann kaum mehr zweifelhaft, dass unsere Wirbel dem Genus Carcharodon angehörten. Sowohl HAsse's Beschreibung der ïusseren Form der Wirbel, namentlich die excentrische Durchbohrung für die Chorda, als anch das ron ihm auf tab. 30, fig. 30, mitgetheilte Querschnittsbild harmoniren vortrefflich mit unseren Wirbeln. Eine Abweichung ist insofern nur zu constatiren, als bei den fossilen Wirbeln die Zahlen der Radialstrahlen eine bedeutend grössere ist als bei dem recenten Wirbel, und ferner, dass ersteren die durchgehende, ring- 
förmige Verbindungsleiste der Radialstrahlen, welche letzterer besitzt, fehlt. Ich glaube aber auf diese Abweichungen nicht allzugrossen Werth legen zu dürfen, da ich in ihnen nur specifische Unterschiede erblicken möchte. Die grössere Zahl der Radialstrahlen ist aul cine weitergehende Gabelung der Primärstrahlen zurückzuführen und Andentungen ringförmiger Verbindungsstreifen sind auch bei unsern Wirbeln vorhauden, wenn dieselben auch keine so starke Ausbildung wie bei dem recenten Wirbel zeigen.

Ebenso unterscheiden sich unsere Wirbel, und zwar in noch höherem Maasse als von denen des $C$. Rondeletii, von dem Carcharoclon-Wirbel aus dem Crag ron Antwerpen, welchen IMAsse auf taf. 30, fig. 34 und 35 abbildet, wie cin einziger Blick auf die Abbildungen darthut.

\section{Scyllium Hanchecornei sp. n.}

Taf. V, Fig. $5 a-$ e.

Bei den recenten Scyllien sind Ober- und Unterkieferzähne vollkommen gleichartig entwickelt; daher lässt sich auch nicht sagen, welchem Kiefer das einzige Zühnchen, welches ich aus dem samländischen Tertiär besitze, angehört. Die Anwesenheit von Nebenspitzen dentet jedoch auf ein Seitenzähnchen, da bei meinem Gebiss von Scyllum stellaris nur bei den Seitenzähnen solche vorhanden sind, während sie den Mittelzähnen fehlen.

Die Gesammthöhe des Zähnchens beträgt $8,5^{\mathrm{mm}}$, davon entfallen auf die Hauptspitze allein $7^{\mathrm{mm}}$. Krone und Wurzel sind auf Intern- und Externseite scharf gegeneinander abgesetzt.

Die IVurzel besitzt sehr geringe Höhe, etwa $1,5^{\mathrm{mm}}$, aber eine bedeutendere Entwicklung sowohl in die Breite, nämlich 9, $5^{\mathrm{mm}}$, als in die Dicke, nämlich $5^{\text {mm }}$, daher eine plattenförmige Gestalt. Die Externfläche ist ungemein niedrig, in der Witte schwach vertieft. Der grösste Theil der Internfläche wird von der hohen, flachen und nicht sehr schräg geneigten Neuraltläche eingenommen, die sowohl mit der Ligament- als mit der Externfläche ausgeprägte Kanten bildet. Die Ligamentfläche ist sehr schmal in der Mitte senkrecht gegen die Krone gestellt, scitlich dagegen schräg und 
ziemlich steil nach unten abfallend und grob gerumzelt. Der Neuralrand ist ziemlich stark gebuchtet, ohne dass es jedoch zur Ausbildung von Wurzelästen käme.

Die innere Eintrittsstelle für den Hauptnerv liegt anscheinend in der Mitte der Ligamentkante, die äussere auf der Externfläche nahe dem Neuralrand.

Der Eindruck der Verwachsungsmembran war nicht zu beobachten, derselbe kann jedoch nur ein schmales Band gewesen sein.

Die Krone ist an der Basis sehr breit, indem sie beinahe die ganze Breite der Wurzel, nämlich $9^{m m}$ eimnimmt (Fig. 5d, vergrössert); ihre Höhe ist etwas geringer, $7,5^{\mathrm{mm}}$, und da sowohl Unter-, als Vorderund Hinterrand gebrochen sind, so erscheint auf der Externscite ihr Umriss in Form eines dreizackigen Sternes. Die Breite der Krone nimmt anfangs nur langsam, aber etwa in der Höhe der inneren Nerveneintrittsöflnung rascher ab, so dass sich eine schlanke, vertical gerichtete Hauptspitze entwickelt, welche beiderseits je eine dentliche und mehrere rudimentäre Nebenspitzen besitzt. Die Externseite ist ziemlich flach gewölbt, stärker jedoch im oberen Theile als an der Basis. Da auch die Internseite hoch gewölbt ist und seitlich steil abfitlt, so besitzt die Hauptspitze beinahe kreisförmigen Querschuitt. Vorder- und Hinterrand sind gleich lang, aber in der Mitte ihrer Höhe stumpfwinkelig gebrochen. Der obere Theil derselben ist mit einem fadenförmigen, lang $\mathrm{S}$-förmig gebogenen Kiele besetzt, der untere trägt die Nebenspitzen. Von diesen sind nur diejenigen erster Ordnung, welche dicht neben der Hauptspitze stehen, klein, aber deutlich ausgebildet und von stumpfkegelförmiger Gestalt. Die übrigen, vier an der Zahl, erscheinen mehr als stumpfe Knnötchen, hervorgerufen durch eine grobe Faltung des Randes, wie sie ja, wenn auch in weit schwächerem Maasse, Scyllium stellare an der gleichen Stelle besitzt.

Die Dicke der Hauptspitze ist an der Basis ziemlich bedentend, $3^{\text {mm }}$, nimmt aber gegen oben rasch ab.

Die Emailgrenze läuft an der Externseite in flacher, stumpfwinkelig gebrochener, auf der Internseite in hoch nach oben gekrïmmter Linie.

Vorkommen: Sehr selten in der Zone $\mathbf{A}_{1}$. 
Bemerkungen: Unter den mir bekannten Abbildungen fossiler Scyllien-Zähne finde ich keine Form, welche sich mit der unserigen identificiren liesse.

ProBst ${ }^{1}$ ) beschreibt aus der schwäbischen Molasse dreierlei Arten: Scyllium distans, Scyllium acie und Scyllium guttatum; dass dieselben jedoch in der That specifisch verschicden sind, möchte ich bezweifeln. Herr Proiss scheint ganz besonderes Gewicht auf die Nebenspitzen zu legen, allein deren Vorhandensein kann keine Bedeutung beigemessen werden, da das Gebiss von Scyllium stellare zeigt, dass Nebenspitzen nur bei den hinteren Seitenzïhnen und bei den Symphysenzähnen des Unterkiefers vorhanden sind, während die Mittelzähne (1.-6. Reihe im Unterkiefer und 1.-5. Reihe im Oberkiefer) solcher entbehren.

Jedenfalls unterscheiden sich die beiden erstgenannten von der samländischen Art durch die niedrigere, breitere Hauptspitze, überhaupt durch eine plumpere, gedrungenere Gestalt.

Einige Aehnlichkeit in Bezug auf die schlanke, gerade Hauptspitze zeigt S. Hauchecomei mit der dritten schwälischen Art, hinsichtlich welcher ich jedoch eine wünschenswerthe Schärfe der Abbildung und eine ausgiebige Beschreibung vermisse, um den Vergleich grenauer durchtühren zu können.

Was schliesslich das Verhältniss von unserer Form zu der einzigen mir zu Gebote stehenden recenten Art, S. stellare, angeht, so unterscheidet sich erstere sofort durch die bedentendere Grösse, da die Zühne von S. Huuchecornei beinahe dreimal so hoch sind, als die der recenten Art; fermer ist bei letzteren die Mittelspitze an den Seiteurändern nicht gekielt, sondern glatt, und schliesslich sind die secundären Nebenspitzen nur noch durch feine Faltung der Ründer angedentet. Es ist ferner bei S. stellare der Unterrand der Krone auf der Externseite sehr regelmässig senkrecht gerumzelt, und ausserdem ist durch tiefe Buchtung sowohl des Neuralrandes als der beiden Schenkel der Ligamentkante die Wurzel förmlich dreizipfelig, während sie bei unserer Art eimen trapezförmigen Umriss zeigt.

1) Württembergische Naturw. Jahreshefte Jahrg. 1S79. 


\section{Scyllium sp., ef. Hanchecornei sp. n. \\ Taf. VIII, Fig. $10-10 \mathrm{c}$.}

1SS4. Seyllium catulus (?) HAsse, Einige seltene palaeontologische Funde. Palacontographica Bd. XXI (3. Folge Bd. VII), pag. 7, tal. 2, fig. 12.

Leider ist von dem einzigen Wirbel, welcher sich als ScylliumWirbel bestimmen liess, nur die eine Hälfte erhalten; ausserdem ist der Rand etwas beschädigt und die Wirbelhöhlung mit nicht ablösbarer Gesteinsmasse erfüllt. Die Beschreibung kann daher nicht sehr ausführlich sein und muss sich auf kurze Angabe der Charaktere beschränken, $u m$ so mehr, als ein Anschleifen des Wirbels, um den Querschnitt genauer zu studiren, nicht thunlich erschien.

Die Breite des Wirbels betrïgt $15^{\mathrm{mm}}$, seine Höhe $14^{\mathrm{mm}}$; wie gross aber seine Länge gewesen sein mag, lässt sich nur annäherungsweise angeben; wahrscheinlich betrug sie $14^{\mathrm{mm}}$, da unser Wirbelbruchstück, das etwa der Hälfte eines Wirbels entspricht, auf der Dorsalseite $7^{\mathrm{mm}}$ lang ist. In der Frontalansicht besass der Wirbel wohl nahezu kreisförmigen Umriss, vielleicht mit schwacher ventraler Zuspitzung.

Auf der Dorsalseite sieht man zwei etwa $5^{\mathrm{mm}}$ breite tiefe Lïcken von rechteckigem Umriss, welche durch eine schmale mediane Wand geschieden und seitlich von zwei zienlich dicken Leisten begrenzt sind. Ventral- und Seitenfläche lassen sich nur annäherungsweise beschreiben; bei Betrachtung der ersteren zeigte sich wahrscheinlich eine breite, dicke Medianwaud, welche zwei schmale seitliche Lücken, in deren Tiefe man je eine kurze Längslamelle bemerkte, trennte. Die Betrachtung der letzteren zeigte wahrscheinlich nur eine einzige Vertiefung, welche die ganze Höhe und Länge des Wirbels einnahm.

Die Bruchfläche gewährt ein verhältnissmässig gutes Bild des Querschnittes. In der Mitte sieht man die verkalkte Innenzone in Form eines schwarzen Punktes, welcher von dem Querschnitt des dünnen Doppelkegels ringförmig umgeben wird. Die Aussenzone zeigt die breiten seitlichen periostalen Keile, sowie einen 
dünnen dorsalen und einen gegen die Peripherie stark an Dicke zunchmenden ventralen Keil. In den schmalen Lücken für die Knorpelzapfen der Apophysen sieht man zwei kurze resp. dorsale Schrägstrahlen.

Vorkommen: Sehr selten in der Zone $\mathbf{A}_{1}$.

Bemerkungen: Dieser von HASSE selbst bestimmte Wirbel stimmt sehr gut mit den Querschnittsbildern, welche HASSE in seinem System der Elasmobranchier auf tab. 33, fig. 2 und fig. 5 von Scyllium maculatum und marmoratum giebt. Es ist nur zu bedanern, dass HASSE nicht anch einzelne Wirbel in verschiedenen Ansichten gezeichnet hat, um einen Vergleich unseres fossilen Exemplares mit den recenten Arten hinsichtlich der äusseren Erscheinung zu ermöglichen.

Möglicherweise gehört der von Hasse als Sc. catulus bestimmte Wirbel von Palmnicken auch hierher.

\section{Galeocerdo dubius sp. n.}

Taf. V, Fig. $6 a-c$.

Ich besitze nur einen einzigen Zahn, dessen Wurzel uicht ganz vollstïndig erhalten ist, und von dem ich aus Mangel an recentem Vergleichsmaterial nicht sagen kann, welchem Kiefer er angehört.

Seine Gesammthöhe beträgt $16^{\mathrm{mm}}$, die Breite ist um Geringes grösser, nämlich $17 \mathrm{~mm}$. Wurzel und Krone sind nicht scharf gegeneinander abgesetzt, und nur der Beginn des Emails würde die Grenze zwischen beiden bezeichnen. Diese läuft auf der Innenseite in Form einer stark nach oben gekrümmten Linie, deren höchster Punkt ca. $8^{\text {mm }}$ über dem scheinbaren Neuralrande, ziemlich in der Mitte der Breite, liegt; nach vorn senkt sie sich in steiler, nach hinten in flacher Richtung gegen den Neuralrand, dem ihr hinterer Endpunlit viel näher liegt als der vordere, der bei diesem Exemplar mindestens $4^{\text {mm }}$ davon entfernt ist; dadurch, dass eine gleiche, weun auch nicht so stark nach oben hin gekrümmte Curve auf der Aussenseite die Grenze zwischen Wurzel und Krone bezeichnet, erscheint die Zahnkrone 
am Vorderrande kammförmigr nach unten verlängert. Die Wurzel besitzt demnach auf der Externseite eine geringere Höhe als auf der Internseite und ist dort flach, selbst etwas concav, während sie hier, wenn auch nicht sehr stark, gewölbt ist. Ihre grösste Dicke liegt in der Mitte, hart am Schmelzrande; gegen den Neuralrand wird sie in Folge mleichmässiger Abschrägung allmählich dünner. Die Trennung der Neural- und Ligamentfläche durch eine Kante habe ich hier nicht beobachten können, beide scheinen vielmehr nahezu in einer Ebene zu liegen. Die Anwachsstelle der Befestigungsmembran war nicht zu erkennen, ebenso wenig wie die Lage des Hauptnervenkanales, nur einige kleinere Nervenkanäle liegen auf der Externseite nahe dem Unterrande.

Die Krone ist von innen nach aussen comprimirt; aussen flach, innen leicht gewölbt, an der dicksten Stelle etwa $5^{\text {mm }}$ stark und besitzt eine geknickt dreiseitige Form, mit einer etwas rückwärts übergebogenen Spitze. Der Vorderrand ist hyperbolisch gekrümmt und convex, der Hinterrand stumpfwinkelig gebrochen und concav; indem der kleinere untere Schenkel schräg, der grössere obere vertical gerichtet ist. Beide Ränder sind gekerbt, jedoch reicht die Kerbung auf der Hinterseite bis zur Spitze, während sie auf der Vorderseite in 3 mu Entfernung von derselben verschwindet, so dass der oberste Theil des Vorderrandes einfach glatt und schneidend ist. Die breitmeisselförmigen Kerbzähnchen sind an beiden Rändern in der Mitte am grössten und werden gleichmässig nach oben und unten kleiner.

Vorkommen: Nicht selten in der Zone $\mathbf{A}_{1}$.

Bemerkungen: Es war mir nicht möglich, das hier beschriebene Zähnchen mit Sicherheit bei einer bereits bekannten Art unterzubringen. Die beiden tertiären Formen, G. latidens AG. und G. aduncus AG., unterscheiden sich durch eine schlankere, schmaleve Zahnkrone, eine bedeutend stärker nach hinten geneigte Spitze und einen in Folge dessen spitzwinkelig gebrochenen Hinterrand, dessen unterer Schenkel entweder gleich lang oder sogar länger ist wie der obere.

Die grösste Aehnlichkeit zeigt unser Zähnchen mit demjenigen, welches Agassiz auf tab. 26 a, fig. 4 als Corax falcatus ans der 
weissen Kreide Englands abbildet, da die Krone bei beiden nahezu dieselbe Gestalt besitat und der Hinterrand in auffallender Uebereinstimmung gleich eingeknickt ist; allein ich konnte mich nicht entschliessen, unser Zühnehen, dessen tertiärer Ursprung zweifollos feststeht, mit einer cretaceischen Art zu identificiren.

\section{Galeocerdo sp.}

Taf. IX, Fig. $6-10$ e.

Die Mehrzahl der hierher gehörigen Wirbel sind wahrscheinlich Rumpfwirbel, und nur einer dürfte als Schwanzwirbel zu deuten sein. Die Rumpfwirbel besitzen einen querelliptischen Umriss, der in Folge dorsaler und ventraler Abflachung der Ränder des Doppelkegels öfters gerundet viereckig erscheint. Der muthmaassliche Schwanzwirbel zeigt eine mehr runde Form, welche durch die unbedeutende ventrale und dorsale Abflachung nur wenig alterirt wird.

Die von mir untersuchten Wirbel haben folgende Dimensionen:

\begin{tabular}{|c|c|c|c|c|}
\hline & & Breite & Hölie & Länge \\
\hline 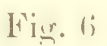 & . & $1: 3$ & 12 мим & 5 tсин \\
\hline 7 & . & 15 & $12,5 \gg$ & $》$ \\
\hline 8 & . & $10,5 \approx$ & 10 & 5 \\
\hline 9 & & $11,5 »$ & 10 & 4,5 》 \\
\hline$\gg 10$ & . & 14 & 12 & $6,5 \gg$ \\
\hline
\end{tabular}

Ein genanes Verhältniss der einzelnen Dimensionen scheint sich aus diesen Zahlen nicht ableiten zu lassen, man sieht aber, dass Höhe und Breite nur eine geringe Differenz zeigen, letztere aber constant, wenn auch oft nur um Geringes die erstere übertrifft. Die Länge der Wirbel mag sich zur Höhe resp. Breite etwa wie $1: 2-2,5$ verhalten, so dass durchschnittlich der Wirbel etwa halb so lang wie breit ist.

Bei seitlicher Betrachtung zeigen die Wirbel einen rechteckigen Querschnitt, mit entweder glatten oder leicht eingeschnürten Seitenflächen. Sowohl auf der Dorsal- als auf der Ventralseite zeigt der Wirbel das gleiche Bild; man sieht eine mediane, mässig breite, oder schmale Lamelle, stets länger als breit, welche zwei seitlich 
davon gelegene Vertiefungen trennt. Dieselben, von nahezu gleicher Breite wie die Zwischenwand, aber ebenfalls länger als breit, werden durch eine in der Tiefe auftretende, nicht gauz bis zur Oberflïche reichende, dünue Scheidewand in je zwei Hälften getheilt.

In der Seitenansicht sieht man eine die ganze Höhe des Wirbels eimnehmende zusammenhängende Fläche, deren Dorsal- resp. Ventralrand schwach ausgeschnitten ist.

Bei dieser gleichartigen Ausbildung der Dorsal- und Ventralseite wäre es ungemein schwierig, einen Wirbel ohne denselben zu durchschneiden zu orientiren, wenn man nicht als ganz constantes Merkmal die grössere Breite der dorsalen Medianlamelle gegenüber der ventralen schmäleren bezeichnen könnte.

Die Wirbelhöhlung ist bei Fig:" 6 ziemlich flach, bei den andern etwas tiefer, und die regelmässig verkalkte Durchbohrung für die Chorda liegt central.

Der centrale Doppelkegel ist dünn und mit seinem nicht aufgeworfenen Rande innig mit den Verkalkungen der Aussenzone verschmolzen; seine Aussenflächen sind steil geneigt und unregelmässig grob concentrisch gestreift.

Im Querschnitt sieht man die verkalkte Innenzone als schwarzen Kreis, der zwar bei den einzelnen Wirbeln verschiedene Grösse zeigt, aber anscheinend nicht nothwendig direct proportional der Grösse des Wirbels zu sein braucht. So ist er z. B. bei dem Wirbel Fig. 6 viel grösser als bei Fig. 7, obgleich letzterer beträchtlich grösser ist als ersterer. Der centrale Doppelkegel erscheint als dünner, heller, scharf abgegrenzter Ring, der mit der Aussenzone innig verschmolzen ist. Die Aussenzone zeigt das rhatrakteristische Bilal dere Gateiden, dats achtstrahlige Doppelkreu\%. das sich aus zwei vierarmigen Andreaskreuzen, aber völlig verschiedener Form aufbaut. Das eine besteht aus einem dorsalen, ventralen und je einem lateralen Strahl, welche durch die Knorpelzapfenlücken geschieden sind. Der dorsale und der ventrale Strahl nehmen gegen den Raud langsam an Dicke zu und besitzen, da ihre Seitenrinder eimen spitzen Winkel mit einander bilden, schmal 
keilförmige Gestalt. Hierbei ist zu bemerken, dass der Dorsalstrahl am Rande stets, wenn auch nur um Geringes breiter ist als der ventrale. Die beiden Lateralstrahlen wachsen sehr rasch an Dicke und zeigen, da ihre leicht gebogenen Seitenründer einen Winkel von 900 und mehr einschliessen, breit-keilförmige Gestalt. Das andere Strahlenkreuz, die sog. Schrägstrablen, die aber niemals bis zum liande reichen wie die vorhergehenden, entwickelt sich in den Lücken für die Knorpelzapfen der Apophysen. Die dorsalen Schrägstrahlen besitzen keulenförmige Gestalt und sind meist etwas dicker als die dünnen lamellenartigen Ventralstrahlen; ein constantes Verhältniss der gegenseitigen Länge seheint aber nicht obzuwalten, denn bisweilen sind beide Strahlenpaare gleich lang oder es überwiegen die ventralen oder es findet auch das Umgekehrte statt.

Sïmmtliche Strahlen zeigen deutlich concentrisch-treschichteten Aufbau.

Die Lücken für die Knorpelzapfen der Apophysen sind ziemlich breit, wobei die dorsalen etwas weiter auscinanderstehen als die ventralen, und werden durch die Schrägstrahlen halbirt.

Vorkommen: Häufig in der Zone $\mathbf{A}_{1}$.

Bemerkungen: Herr Hasse war der Ansicht, dass sämmtliche Wirbel, mit Ausnahme von Fig. 10, den er selbst als Galeocerdo-Wirbel ansieht, dem Genus Carcharias angehörten. Ich bedaure aber, auch in diesem Punkte mit dem geschätzten Forscher nicht gleicher Meinung sein zu können, denn ich vermag trotz sorgtältigster l'rütung einen wesentlichen Lunterschied zwischen dem Wirbel Fig. 10 und den übrigen weder im äusserlichen Ansehen, noch im Aufbau der Aussenzone zu erkennen. Ich habe daher, auch mit Rücksicht auf den Umstand, dass sich im samländischen Tertiär keine Carcharias-Zähne gefunden haben, wohl aher Galeocerdo-Zähne nicht gerade selten sind, sämmtliche Wirbel als Galeocerdo-Wirbel angesehen.

Jedenfalls steht fest, dass sie von Wirbeln des recenten Rionodon glaucus sehr wesentlich verschieden sind; leider aber besitze ich keine Galeocerdo-Wirbel, um sie mit diesen vergleichen zu können. 
Es dürtte die Unterscheidung fossiler Galeocerdo-, Galeus- und rarehuriax- Wirhel die schon recht schwierige Bestimmung der Wirbel aus der Familie der Lamniden an Schwierigkeit noch erheblich übertreffen. Die erstgenannten sind einander so überaus ähnlich, wozu noch der Umstand tritt, dass die Schrägstrahlen häufig verkümmern können, dass ich, wie ich gestehe, zur Zeit noch keine bestimmten Merkmale kenne, fossile Wirbel der vorgenannten drei Genera mit Sicherheit zu unterscheiden.

Man vergleiche bei Hasse die Wirbel tab. 38, fig. 12, (Guleus sp. aus dem Senon), tab. 39, fig. 19 und 20, (Rionodon sp. aus dem Eocäin) und unsere samländischen Wirhel zur Bestitigung des hier Gesagten.

Herr Hasse legt der Biegung der Seitenrïnder der Strahlen einen grossen Werth bei, indem er bei der generischen Unterscheidung darauf sieht, ob dieselben einfach concar oder lang $\mathrm{S}$-förmig ausgeschnitten oder ob sie gerade sind. Dieses Merkmal wird sich aber wohl kaum mit Consequenz festhalten können, denn nicht nur zeigen bei HAsse die Abbildungen fossiler Wirbel erhebliche Abweichungen hinsichtlich dieses Charakters nicht sowohl unter einander, als auch gegen die recenten Wirbel, sondern unsere samländischen Wirbel difteriren hierin so erheblich, dass diese Abweichungen wohl mehr durch die Lage der Wirbel bedingte Unterschiede, denn als generische Differenzen aufzufassen sind.

\section{T'eleostei.}

\section{Psendosphaerodon gen. nov: $\left.{ }^{-1}\right)$.}

Die Kiefer sind mit Pflasterzähnen von zweierlei Form besetıt; entweder sind die Zähne schmal dreiseitig oder undeutlich

1) Ausser den hier beschribbenen Zïhnen von Pseudosphaerodon Hilgendorfi besitze ich noch eine ziemlich beträchtliche Anzahl von Teleostierwirheln. Wahrscheinlich gehört wenigstens ein Theil derselben zu dieser Art; allein da ich hierfür, wie überhupt für die Bestimmung von Teleostierwirbeln, keinen Anhaltspunkt besitze, 80 halte ich eine Beschreibung und Abbildung derselben für zwecklos. 
traperförmig im Umriss, von hetrichtlicher Dicke und besitzen eine nach innen geneigte Oberseite - keilförmige Zähne - oder aber sie sind breit dreiseitig, wesentlich dünner und die Oberseite ist vahezu horizontal: plattenförmige Zähne.

Die Zahnkrone ist imnig mit dem Kieferknochen verwachsen, aber durch eine nicht sehr tiefe Furche davon abgeschnürt; ihre innere Structur (vergl Taf. XI, Fig. 5b) ist ein grobes Vasodentin, das erst am äussern Saume zu echtem Dentin wird. Das Email ist glatt, glänzend, aber sehr dünn, und wird von zahlreichen Sprüngen durchsetzt; es nutzt sich ebenso wie der Zahn ungemein rasch ab, und daher sind fast bei jedem Exemplar im Kieferknochen Reservezïhne vorhanden (z. B. Taf. XI, Fig. la u. b).

Die Zähne stehen nicht dicht neben einander, sondern die benachbarten sind durch schmale Zwischenräume getrennt (vergl. Tat. XI. Fig. (i).

Kiefer ziemlich dick, aus lockerem Knochengewebe bestehend.

Vorkommen: Im samländischen Tertiär, Zone $\mathbf{A}_{1}$.

Bemerkungen: Herr Hilgendorf in Berlin war so liebenswürdig, diese Zähne, die bei flüchtiger Betrachtung einige Aehnlichkeit mit P'samodus-Zähnen besitzen, auf ihre Verwandtschaft mit recenten Teleostiern zu untersuchen und mir seine Ansichten hierüber freundlichst mitzutheilen, die ich hier wiedergebe:

"Ich habe ein Splitterchen geschliffen und eine Structur, sehr ähnlich der von Prammodus, gefunden. Alle Zähne von mir bekamnten Teleostiern, Sphaerodon, Schlundzähne von Pogonias ${ }^{1}$ ), Labroiden-Schlundzähne haben wesentlich andere Structur, nämlich einfache feine Dentinröhrchen, während die samländischen ein grobes Vasodentin zeigen, das erst am äusseren Saume zu echtem Dentin wird; die Gefässkanäle des Vasodentins sieht man schon mit blossem Auge oder doch mit der Lupe. Wenn die Structur nicht so sehr different wäre, würde ich ohne Bedenken Sphaerodon zum Vergleich herangezogen haben. Die drei kleineren Zähne auf

1) Ich hatte aus der Abbildung der Schlundzähne dieses Genus in Guintrier, (Introduction to the study of fishes pag. 428) auf eine mögliche Verwandtschaft desselben mit unseren Resten gesclilossen, und mich in diesem Sinne Herrn Hilgendorf gegenüber ausgesprochen. 
einem Stück mit erhobener Aussenseite könnten recht gut zu einem Kiefer eines Teleostiers passen, wofür ja auch der Ersat $z$ durch unterliegende Zahnkeime und die feste Verwacbsung mit dem Knochen spricht.

Ich habe Placodus geschliffen, der aber ebenfalls fein gedrängte Dentinröhrehen besitzt.

Cyprinoiden-Schlundzähne habe ich mikroskopisch nicht untersucht, doch ist lebend mir keine Form bekannt, die ähnliche makroskopische Verhältnisse wie die samländischen Zïhne zeigt. «

Es ist hiernach als sicher anzunehmen, dass, wenn auch unsere Zähne gewisse Analogieen in der Form mit solchen recenter Arten besitzen, sie sich aber durch ihre Structur sehr wesentlich von diesen unterscheiden, eine Differenz, welche die Aufstellung eines nenen Genus wohl rechtfertigt.

Eine besondere Eigenthümlichkeit scheint die geringe Widerstandsfühigkeit unserer Zähne gegenüber der Abnutzung gewesen zu sein, wodurch augenscheinlich eine öftere Erneuerung nothwendig war. Dies beweisen die Ersatzzähne oder deren Lücken, welche bei allen Exemplaren vorhanden sind, deren Kieferknochen in noch hinlänglicher Dicke erhalten ist. Zweifellos den interessantesten Anblick gewährt Fig. 1, wo der im Gebrauch befindliche Zahn fast bis auf die Basis abgenutzt ist und der direct darunter befindliche Ersatzzahn, vollständig fertig urobildet, in nächster Zeit in Gebrauch genommen werden sollte. Der Abnutzung wurde jedentills dureh dats dümne, splitterige Email und die errobe Structur des Dentins bedeutender Vorschub geleistet.

\title{
Psendosphaerodon Hilgendorfi sp. n.
}

\author{
Taf. XI, Fig. 1-8b.
}

Ein Theil der Zähne besitzt schmal-dreiseitige Form, die sich jedoch auch mehr oder minder deutlich trapezartig gestalten kann, und unterscheidet sich von den übrigen Zähnen durch bedeutende Dicke und starke Wölbung der Krone. Drei solcher Zähne (Fig. 6 bis $6 \mathrm{~b}$ ) sind noch vereinigt, und man sieht, dass dieselben mit den Seitenflächen neben einander liegen, ohne sich jedoch direct zu be- 
rühren; die sehmale Seite war wohl nach aussen und die mehr oder minder abgestumpfte Spitze nach innen gerichtet. Die Aussenseite ist bei der Mehrzahl der Zähne leicht gewölbt, dabei aber schräg zum Kieferknochen gestellt. Rings herum finden sich bei grösseren Zähnen an der Basis der Krone grobe, unregelmässige Verticalfalten, die an den Seitenflichen und an der Innenseite stärker sind als an der Aussenseite.

In der Längsrichtung gesehen zeigen die Zähne ein keilartiges Profil dadurch, dass die grösste Dicke der Krone an der Aussenseite liegt und die Oberseite in zuweilen ziemlich steiler Neigung gegen imnen abfüllt. Die Oberseite ist in seitlicher Richtung riemlich stark gewölbt, bei einem kleinen Zähnchen in der Mitte schwach gekielt (Fig 8), und somit seitlich dachförmig abfallend. Das Email ist glatt und glänzend, aber augenscheinlich sehr dünn, da es bei fast allen Zähnen an einer Stelle zerstört ist. Gegen den Kieferknochen ist die Krone durch eine nicht sehr tiefe Furche abgeschnürt.

Es betragen die Maasse der Zühne bei Fig. 6:

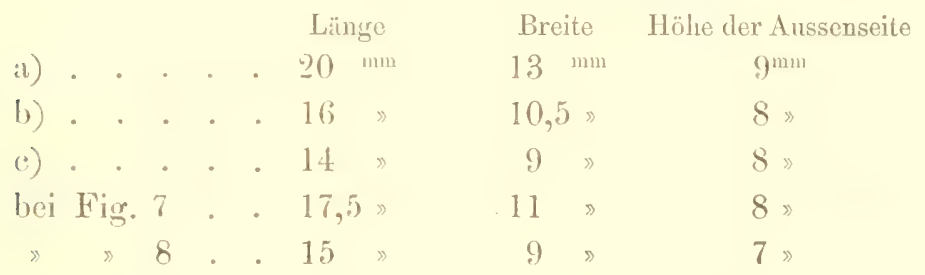

Ein anderer Theil der Zähne zeigt zwar ebenfalls eine dreiseitige Gestalt, jedoch ist ihre Dicke geringer und die Oberseite der Krone fast vollkommen eben oder doch nur flach gewölbt, so dass die Zähne eine mehr plattenförmige Gestalt annehmen. Doch auch bei ihnen variirt der Umriss etwas; so besitzt Fig. 3, möglicherweise auch Fig. 5, eine nahezu gleichschenkelig-dreieckige Gestalt dadurch, dass die beiden geraden Längsseiten von nahezu gleicher Grösse sind und zwei ausgeprägte Ecken mit der nur wenig gebogenen kürzeren Seite bilden. Bei einer andern Form ist nur die eine der Längsseiten gerade und bildet mit der kürzeren Seite eine Ecke; die andere dagegen ist flach gekrümmt und geht 
ohne merklichen Absatz in jene, die ebenfalls flach gebogen ist, über. Diese Form zeigt z. B. Fig. 2, und wahrscheinlich ist Fig. 4 in gleicher Weise zu ergänzen; auch Fig. 1 dürfte ursprünglich so ausgesehen haben. Die Seitenflächen sind entweder nicht oder nur schwach vertical gefaltet. Die Oberseite ist in der Mitte meist vollkommen flach, zuweilen auch etwas stärker gewölbt und nach einer Seite leicht geneigt; gegen die Seiten fällt sie steil ab, ohne dass es jedoch zur Ausbildung von Kanten kommt.

Das glatte, glänzende Email ist von zahlreichen Rissen durchsetzt und daher in kleine eckige Felder zersprungen (vergl. Fig. 4).

Vorkommen: Anseheinend nicht selten in der Zone $A_{1}$.

Bemerkungen: Wollte man die hier beschriebenen Zühne auf Grund der nicht unwesentlichen Abweichungen im Umriss und der Dicke der Zahnkrone verschiedenen Species zutheilen, so wäre man genöthigt, für jeden Zahn eine besondere Art aufzustellen, da keine zwei Exemplare völlig identisch sind. Dass auf die Verschiedenheit der Grösse und des Umrisses wenig Werth zu legen ist, beweist am besten Fig. 6, wo die drei noch im Zusammenhang befindlichen 'Zähne unter einander in Bezug auf die Form so wesentlich abweichen, dass man kaum geneigt sein dürfte, dieselben als einem Individuum angehörig zu erklären, falls sie lose gefunden worden wären. Zwischen plattenförmigen und keilförmigen Zähnen, die in den Extremen ja sehr verschieden sind, existirt auch keine scharfe Trennung, wenigstens wäre Fig. 5 nach Umriss und Grösse den plattenförmigen Zähnen, nach seiner Dicke und Wölbung der Oberseite den keilförmigen Zühnen zuzurechnen. Ich halte es daher für wahrscheinlich, dass die sämmtlichen Zähne einer Art angehörten und die Verschiedenheit der Form und der Dicke durch die Stellung im Kiefer bedingt war. 


\section{11 11 i 1130.}

\section{Crocodilus sp.}

Taf. XI, Fig. 9-10a,

Die beiden einzigen Krokodilzähne, welche das samländische Tertiär geliefert hat, sind so fragmentarisch erhalten, dass eine nur halbwegs genaue. Bestimmung ausgeschlossen ist; doch spricht neben der Structur die vordere resp. hintere Schmelzfalte der Krone für die Zugehörigkeit zu den Krokodiliern.

Der Zahn Fig. 9 ist ea. $26^{\mathrm{mm}}$ hoch und besitzt eine spitzkegelförmige, leicht gebogene Gestalt; sein Querschnitt war wohl breit-elliptisch, und es beträgt die noch messbare Dicke cil. $15^{\mathrm{mm}}$. Der Schmelz ist mit ziemlich groben, verästelten Längsfalten, die sich jedoch nicht bis zur Spitze erstreckt zu haben scheinen, bedeckt; die Längsrippe der Vorderseite ist wenig scharf abgesetzt. Der innere Aufbau des Zahnes ans ineinander steckenden Knochenkegeln ist in Folge der Bruchfliche gut wahrnehmbar.

Der zweite Zahn (Fig. 10 u. 10a) ist ca. 22mm lang, doch ist die Krone zum grössten Theil zerstört und nur noch ein grösseres Stück der Wurzel erhalten; dieser Zahn war seitlich ziemlich stark comprimirt, so dass sein Querschnitt schmal elliptisch ist. Er war wohl ebenfalls von spitzkegelförmiger Gestalt und schwach gekrümmt; die Schmelzfalten scheinen nur hinten dentlich gewesen zu sein, während der Zahn vorn glatt ist und nur die stärkere Längsrippe zeigt.

Vorkommen: Selten in der Zone $A_{1}$. 

Lieferung II.

Crustacea und Vermes. Taf. I-X. 



\section{Crustacea.}

\section{Cirripedia.}

\section{Balanus unguiformis Sow.}

Taf. I, Fig. 1-5b.

Synonymie ef. Darwin, A Monograph of the fossil Balanidae. Palaeontogr. Soc. $1851-1854$, pag. 29 .

Da bei der Erhaltungsweise unserer Fauna alle Kalkschalen, mithin auch die der Balaniden zerstört sind, so ist es ausserordentlich schwierig, sich ein genaues Bild gerade dieser Form zu verschaften, um eine sichere Vergleichung zu ermöglichen. Die Abdrücke sind zu ungenau und die Steinkerne wohl sehr scharf, aber bis jetzt insofern wenig brauchbar, da man nirgends eine Abbildung von Balanidensteinkernen findet.

Sämmtliche Exemplare sind durchweg von geringer Grösse; das grösste misst an der Basis $11^{\text {mm }}$ (Fig. 3a), seine Höhe mag etwa 8,5 bis $9^{\mathrm{mm}}$ betragen. Die dünne Schale besitzt eine schlank kegelförmige bis nahezu eylindrische Gestalt. Die Oberfläche war entweder vollkommen glatt oder nur leicht horizontal gestreift (Fig.4). Die ziemlich grosse, rhombische Mündung, deren Lateraldurchmesser der kleinere ist, ist am Carinalende schmal und spitz, am Rostralende dagegen breit und gerundet.

Vom Operculum sind nur sehr fragmentarische Reste bei einzelnen Individuen erhalten (Fig. 1 u. 1 b, vergrössert), es lässt sich aber wenigstens so viel darüber sagen, dass sie in gleicher Weise wie die englischen Formen sculpturirt waren. 
Die Längsrippen der Innenseite (vergl. Fig. 1b, vergrössert) sind sehr dünn, aber zahlreich; unten, wo sie sich gerne gabeln, sind sie etwas dicker, auch scheint sich eine Spur von Zähnelung bei einigen erhalten zu haben. Die Radii sind ziemlich gross, besitzen schrïg alfallende Oberränder und sind an den Seitenründern feingeziihnelt.

Vorkommen: Sehr hänfig und stets in grösseren oder kleineren Colonien auf anderen Fossilien, z. B. Hoploparia Klebsii aufgewachsen, in der Zone $A_{1}$. Nach Darwin im Eocän Englands nicht gerade selten; ferner wird die Art auch von Klein-Spauwen genannt.

Bemerkungen: Ob die Bestimmung der samländischen Formen eine absolut sichere ist, vermag ich aus den oben mitgetheilten Gründen nicht anzugeben. Unter all den von DARWIN abgebildeten Arten schien B. unguiformis noch die meiste Uebereinstimmung in Grösse und Gestalt mit unserer Form zu besitzen. Ich belegte sie daher mit diesem Namen, da ich gute Unterschiede von der englischen Art nicht hätte angeben können.

$\mathrm{Ob}$ die Fig. 5-5b abgebildeten Fragmente eines Scutums und Tergums zu B. unguiformis gehören, erscheint mir fraglich, da, nach ihnen zu schliessen, die zugehörige Schale eine bedeutende Grösse besitzen müsste, die Schalen des eigentlichen B. unguiformis durchweg aber nur klein sind. Die beiden Schilder sind überdies so fragmentarisch, dass sich Bestimmtes nicht angeben lässt, ja man könnte sogar einigen Zweifel in Bezug auf die generische Stellung erheben, doch schien ihre Form, so weit sich eben erkennen lïsst, am besten dem Genus Balanus zu entsprechen.

\section{Brachyura.}

Micromaja Bittwer emend. Noething.

Der Cephalothorax besitzt eine lang-elliptische Gestalt; die Stirn ist in zwei flache, blattförmige Lappen gespalten, deren jeder an der fast geradlinigen Innenkante ein kleines Seitenzähnchen, am Aussenrande aber eine gerundete Verbreiterung zeigt. (BITtNer.) Augenhöhlen auf der Oberseite von einem breiten äusseren Zahn 
hegrenzt, der von dem Infraorbitalzahne durch eine scharfe Scissur getrennt ist. Mit Ausnahme der scharf ausgeprägten Gastrocardiacalregion eine weitere Lobulirung durch Furchen nur schwach angedentet. Charakteristische Grübchen finden sich an bestimmten Stellen der Gastrocardiacalfurche. Die Oberseite und der vordere Theil der Unterseite mit zahlreichen, mehr oder minder gedrängten, spitzen oder halbkugeligen Höckern besetzt, die zuweilen secundäre Rauhigkeiten tragen. Mundlücke breit viereckig. Basilarglieder der äusseren Antennen frei.

Vorkommen: Bis jetzt nur in alttertiären Ablagerungen, in eigenthümlicher Verbreitung auftretend. Die eine Art, M. tuberculata, findet sich im Eocän von Ober-Italien, die andere, M. spinosa, in der Glankonitformation des Samlandes.

Bemerkungen: Nachdem sich im samländischen Tertiär eine hierher gehörige Art aufigefinden hat, stellte ich, hauptsächlich gestützt auf BiTTNER's Untersuchungen, die obige Charakteristik des Genus auf. Die hierher gehörigen Arten sind schwierig zи unterscheiden und soll eine Discussion derselben bei der Beschreibung der neuen Species erfolgen.

\section{Micromaja spinosa sp. n.}

Taf. I, Fig. 6-6c.

Der Cephalothorax besitzt eine spitz eiförmige oder, besser gesagt, birnförmige Gestalt, indem er nach vorne spitzer als nach hinten zuläuft. Die grösste Breite liegt etwa im hinteren Drittel der Schale; das abgebildete Exemplar misst $14^{\text {mm }}$ Breite anf $18^{\text {mm }}$ Länge, (den Stirnlappen nicht mit eingerechnet).

Die Wölbung ist nicht gerade beträchtlich, in transversaler Richtung etwas stirker als in longitudinaler. Die Frontalregion, ebenso wie die Anterolateralründer sind bei keinem meiner Lxemplare erhalten; von letzteren kann man aber wenigstens noch so viel erkennen, dass sie nicht mit einer Leiste besetzt waren. Die convexen Hinterseitenränder, ebenso wie der nach aussen gebogene Hinterrand waren dagegen von einer Leiste eingefasst, die oben von einer schmalen Furche begleitet war. Diese Leiste tritt in 
der Gegend des Mesobranchiallobus, von der Unterseite kommend, hervor und ist anfangs glatt, später aber trägt sie eine Reihe kleiner Höckerchen, die sich in ziemlich weiten Abständen folgen. Die anfangs tiefe Furche wird nach hinten flacher und scheint am Hinterrande gänzlich verschwunden zu sein.

Die Gastrocardiacalregion stellt einen ziemlich breiten, gewölbten Rücken in der Körpermitte dar, der von der Branchialregion durch zwei Längsfurchen geschieden wird. Diese sind im vorderen Theile scharf und tief ausgeprïgt, nach hinten verflachen sie sich und werden etwas undeutlich. Klemere Vertiefungen treten an bestimmten Stellen in den Längsfurchen auf; je ein grösseres Grübchen von runder Gestalt steht $z$ beiden Seiten der Furche, welche den metagastrischen vom urogastrischen Lobus trennt. Zwei grössere, von etwas länglichem Umriss, getrennt durch mebrere kleinere, finden sich seitlich der vorderen Hälfte des Epicardiallobus, und zwar stehen die ersten jederseits der Furche, welche Gastral- und Cardiacalregion scheidet.

Der Gastrocardiacalrücken wird durch nicht besonders scharfe Furchen in eimzelne Loben zerlegt, die sich meist durch die Stellung der darauf befindlichen Höckerchen gut charakterisiren.

Die protograstrischen Loben sind ziemlich gewölbt, von ovaler, fast runder Gestalt und mit mehreren Höckerchen besetzt. Zwischen beide schiebt sich der schmale Fortsatz des metagastrischen Lobus, der einige kleinere Höckerchen trägt. Der metagastrische Lobus selbst zeigt neben kleineren hart an seinem hinteren Ende ein besouders grosses Höckerchen von stumpf kegelförmiger Gestalt.

In der tiefen Querfurche, welche den urogastrischen Lobus scheidet, treten ebenfalls zwei kleine Grübchen auf, die mit den vorerwähnten der Längsfurchen in gerader Linie stehen.

Unter den Höckerchen des relativ breiten urogastrischen Lobus ragt das in der Mitte stehende durch besondere Grösse hervor.

Die Cardiacalregion wird durch eine tiefe Querfurche von der Gastralregion geschieden und zeigt zwei, wenn auch nicht scharf getrennte Loben. Der grosse Epicardiallobus ist hoch gewölbt und trägt neben den kleineren in seiner Mitte sechs grössere Höckerchen, von welchen vier grosse die Ecken eines Quadrates bilden, zwei kleinere seitlich in der Mitte stehen. 
Der schmälere Metacardiallobus besitzt als besonderes Kennzeichen zwei starke, etwas über den Rand vorspringende 'Tuberkel.

Die Branchialregion ist sehr gross und aufgetrieben, seitwärts steil abfallend. Besonders stark gewölbt ist der Metabranchiallobus, der seitlich etwas über den Rand vorspringt, so dass er, von oben gesehen, den Posterolateralrand etwas verdeckt. Die zahlreichen Höckerchen dieser Region lassen eine regelmässige Anordnung nicht erkennen.

Die Oberfläche des Cephalothorax ist mit Ausnahme der Furchen mit zablreichen, aber nicht dicht stehenden grösseren und kleineren Höckerchen von spitz kegelförmiger Gestalt bedeckt. Wahrscheinlich befanden sich auch solche auf dem vorderen Theile der Unterseite.

Die grösseren Höckerchen unterscheiden sich von den kleineren etwas durch ihre gewöhnlich mehr stumpfe Gestalt, ausserdem aber besonders dadurch, dass letztere glatt sind, diese aber durch die Impe noch eine feine, dichte Granulation ihrer stumpfen Spitze erkennen lassen. Besonders deutlich sind diese granulirten Höckerchen anf der Gastral- und Cardiacalregion; sie fehlen natürlich auch den anderen Regionen nicht, sind hier aber gewöhnlich nicht so gross.

Vielfach sind die grösseren und kleineren Tuberkeln in Reihen zu drei gestellt.

Vorkommen: Selten in der Zone $\mathbf{A}_{1}$.

Bemerkungen: Ich hatte ursprünglich die samländische M. spinosa mit der vicentinischen M. tuberculuta BiтT. vereinigt, und zwar schien mir besonder's die neuere Abbildung BITINER's ${ }^{1}$ ) unserer Form zu entsprechen, während die ältere ${ }^{2}$ ) nicht so genau damit übereinstimmt. Die allgemeine Körperform, das Verhältniss von Lünge zu Breite, die Lobulirung und Sculptur der Oberfläche schienen mir bei beiden vorhanden zu sein. Namentlich

1) Brtwxer, Neue Beiträge zur Kenntniss der Brachyurenfauna des Alt'Tertiitrs ron Verona. Denkschr. d. math.-naturw. Cl. d. Kaiserl. Akad. d. Wiss. 1SS3̈, Bd. XLVI, tab. 1, lig. (ia.

$\left.{ }^{2}\right)$ ibid. 1S75, Bd. XXIV, tal). 2, fig. 2. 


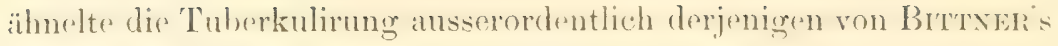
neuerer Abbildung, wo die einzelnen Höckerchen nicht mehr in solch gleichmässigen Reihen wie bei der früheren stehen. Interessant aber, und für mich bis zu einem gewissen Grade beweisend, war die absolute Gleichheit in der Sculptur des Epicardiallobus. Bei BrTrner's fig. 6 a sieht man auf"s deutlichste, dass die sechs Höckerchen in der Mitte dieser Region genau dieselbe Figur bilden, wie ich sie bei unserer Form (Fig. 6 b) beschrieben habe, wenn auch BitTner im Texte diese Sculptur nicht weiter erwähnt. Als hauptsächlichen Unterschied hebe ich die Differenz in der Sculptur der Höekerchen beider Arten hervor, die nach BitTNER's Beschreibung bei seiner Form alle glatt waren, während bei der unserigen glatte und granulirte abwechseln.

Bei aller dieser grossen Aehnlichkeit waren mir doch einige $\mathrm{Z}$ weifel aufigestiegen, und da es mir an Vergleichsmaterial gebrach, so sandte ich meine Exemplare an den competentesten Beurtheiler, Herm Bir'rex in Wien. In zwei längeren Briefen hatte derselbe die grosse Freundlichkeit, mir die feinen Unterschiede beider Formen auseinanderzusetzen, und gebe ich daher in Folgendem seine Mittheilungen ausführlich wieder.

Herr BrTwer schreibt mir unterm 13./1. 84.: "Die samländische Art steht der vicentinischen in der That ausserordentlich nahe, die Uebereinstimmung ist eine geradezu überraschende. Anzahl und Stellung der Höckerchen ist nahezn exact dieselbe mit einem einzigen Unterschiede anf dem Gastrallobus, und zwar dessen metagastrischer Abtheilung. Der grosse Höcker der samländischen Form, der hier kuapp über dem Hinterrande, vor den in der Furche gelegenen Gruben (die den Maxillarmuskelansatzeinstülpungen entsprechen) liegt, ist bei der vicentinischen form nach vorn gerückt und wird von kleineren Höckerchen ungeben, deren linkes hinteres an einem der samländischen Exemplare übrigens andentungsweise ebenfalls vorhanden ist. So gering dieser Unterschied ist, so ist er doch constant. Im übrigen stimmt Zahl und Anordnung der Höcker, wie gesagt, auf's Wunderbarste überein, nur sind die der samländischen Form durchatus viel kleiner und spitziger, die der vicentinischen Form 
breit und sehr stumpf, so das sie einander durchweg fast oder ganz berühren. Der bei der samländischen Form dadurch gewonnene Zwischenraum, resp. die zerstrente Stellung der Höcker, tritt weniger hervor, als dies gegenüber der vicentinischen Form eigentlich zu erwarten wäre, und zwar deshalb, weil die Höcker jeder einzelnen Oberflächenregion gleichsam concentrirter angeordnet sind, wodurch zugleich die einzelnen Zwischenfurchen breit und scharf hervortreten, weitaus mehr, als das bei der vicentinischen Form der Fall ist, bei der diese Zwischenfurchen sehr schwach und verschwommen angedeutet sind.

Die gewissen Grübchen in den beiden Hauptlängsfurchen sind bei der vicentinischen Art genau an denselben Stellen vorhanden, freilich so wenig auffallend, dass man sie übersieht, wenn man nicht die samländischen Stücke zum Vergleiche daneben liegen hat.

Die auffallende Quadratstellung der 4 grossen Höcker des Epicardiallobus ist bei der vicentinischen Form thatsächlich vorhanden, wenn atch nicht so scharf' atusgesprochen wie bei der samländischen Form; die beiden vorderen Höcker davon sind etwas gebuchtet in der Richtung gegen aussen und rückwärts; selbst diese geriugfügige Eigenthümlichkeit scheint sich bei der samländischen Art zu wiederholen.

Die grösseren Höcker (die Unterschiede in der Grösse sind übrigens nicht sehr bedeutend) sind bei der vicentinischen Form glatt wie die kleinen, und lassen nur einzelne, einen oder zwei eingestochene Punkte, als ob sie Borsten getragen hätten, erkennen.

Ausdrücklich sei bemerkt, dass bei der vicentinischen Form die Höckerchen nicht zahlreicher, wohl aber durcbaus grösser sind und deshalb dichter gedrängt erscheinen; auch sind sie stumpf und grösstentheils halbkugrelig. Die Unterschiede, da sie äberaus constant sind, scheinen mir zu einer spevifischen Trennung beider Formen vollkommen hinzureichen.

Noch muss hervorgehoben werden, dass ich ein Fragment einer Micromaja von San Giovanni Ilarione kemme (Samml. der geol. Reichsanstalt), welches sich von allen übrigen Stücken dieser Art dadurch unterscheidet, dass seine Höcker durchweg kleiner 
und viel spitziger sind als bei jenen Stücken, und welches deswegen nicht damit vereinigt werden konnte, seiner schlechten Erhaltung aber, als zur Beschreibung ungeeignet, vorläufig bei Seite gelegt werden musste. Es zeigt sich nun, dass die grösseren Tuberkeln desselben ebensolche Rauhigkeiten besitzen, wie sie bei der samländischen Art vorkommen, in der Ornamentirung des metagastrischen Lobus stimmt es aber mit den übrigen vicentinischen Stücken überein. «

Auf eine nochmalige Anfrage hatte Herr Bitwer die Güte, mir die Unterschiede der vicentinischen von der samländischen Form in folgender Vergleichung zusammenzustellen:

Vicentinische Form.

Alle 'Tuberkeln verhältnissmässig gross, an ihrer Basis einander fast oder gänzlich berührend, und bis auf einige einzelne Poren oder eingestochene Punkte glatt; Furchen und Zwischenråume zwischen den einzelnen Tuberkeln, sowie zwischen den Körperregionen verschwommen. Metagastrischer Lobus mit einem grossen Mittelhöcker und kreisförmig um diesen gruppirten kleipen Höckern.
Samlïndische Form.

Alle Tuberkeln sind verhältnissmässig klein, weit von einander entfernt, fast durchaus sehr spitz und theilweise mit secundären Rauhigkeiten besetzt. Zwischenrïume der einzelnen Tulorkel und Furchen zwischen den einzelnen Körperregionen durchweg breit und scharf hervortretend. Metagastrallobus mit einem grossen Höcker am Hinterende knapl über der ihn gegen rückwärts abschneidenden Querfurche.

Ich hatte in einem meiner Briefe an Herrn BitTner nun die Frage aufgeworfen, ob nicht diese Unterschiede vielleicht auf locale Variation oder auf' sexuelle Differenzen zurückzuführen seien, um so mehr, da ja auch das letzterwähnte Fragment die secumdären Rauhigkeiten der Höcker besitze, mithin doch die Aehnlichkeiten so grosse seien, dass eine specifische Sonderung nicht angebracht sei.

IIerr BrTTNER konnte sich aber meiner Ansicht nicht anschliessen und hob namentlich hervor, dass wenn er auch den 
Werth loculer Variation oder sexueller Unterschiede vollkommen zu würdigen wisse, doch die Möglichkeit ebenso gross sei, nahe verwandte Arten eines und desselben Genus in beiden Formen zu erblicken.

Ich nehme diese von Herrn BrTrxer ausgesprochene Ansicht an und belege daher die Art mit einem neuen Namen, kann aber nicht iumhin, nochmals auf die ausserordentlich intime Verwandtschaft beider Arten hinzuweisen, die eine Unterscheidung nur bei subtilster Vergleichung von Originalexemplaren ermöglichen. Die genannten Unterschiede aus Abbildungen, selbst bei bester Ausführung, herauszufinden, dürtte gewiss seine Schwierigkeiten haben.

\section{Lambrus Bittneri sp. n.}

Taf. I, Fig. 7-10.

Die Exemplare, welche ich von dieser zierlichen Form besitze, sind durchschnittlich nur wenig gut erhalten. Meist fehlt der Hinterrand, bei allen die Frontal- und Orbitalregion und, mit Ausnahme eines Individuums, auch die Schale. Das Fehlen der Stirmregion ist aber insofern nicht von besonderer Bedeutung, als bei einem Exemplar noch soweit Spuren derselben vorhanden sind, dass sich eine Reconstruction ermöglichen lässt.

Der Cephalothorax besitzt eine querelliptische Gestalt; die grösste Breite liegt etwa hinter der Mitte, zwischen den beiden letzten Dornen des Anterolateralrandes; bei dem am besten erhaltenen Exemplar betrïgt sie $13^{\mathrm{mm}}$, die Lïnge vom Hinterrand bis zum Orbitalrand gemessen $10^{\mathrm{mm}}$. Wenn auch die einzelnen Regionen etwas aufgetrieben sind, so ist der Cephalothorax im Ganzen doch recht flach.

An dem verletzten Stirnrande sieht man noch deutlich, dass die Stirn in einen breiten, schwach lïngsgefurchten Lappen auslief. Die Augenhöhlen waren nach aussen von einem ebenfalls breiten, nach vorn gerichteten Orbitalzahne begrenzt, der durch einen kurzen, aber breiten Einschnitt vom Supraorbitalrande getrennt ist. 
Der Orbitalrand war möglicherweise leicht gewulstet. Der sehr fein gekörnelte Vorderseitenrand verläuft in ziemlich gerader Richtung nach hinten und erscheint durch vier kleine Dörnchen leicht gewellt; mit dem ebenfalls geradlinigen, beinahe gleich langen Minterseiteurand bildet er einen nahezu rechten Wiukel. Wo Vorderund Mintersitemrand zusammentretten, steht das letzte und zusleich grösste der erwähnten vier Dörnchen, hinter demselben, zu Beginn des im übrigen glatten Posterolateralrandes, stehen dicht neben cinander drei sehr kleine Höckerchen. Der schwach convexe Hinterrand wird von einem zart granulirten Saume eingefasst und stösst unter einem sehr stumpfen Winkel mit den Hinterseitenrïndern zusammen.

Auf der Oberseite tritt, durch die flachen und breiten Längsfurchen begrenzt, die nur stellenweise etwas eingeschnürte Gastrocardiacalregion als flachgewölbter, schmaler Längsrücken hervor. In vorderen Theile scheiden zwei kaum sichtbare Furchen die flachen, kleinen, protogastrischen Loben von dem metagastrischen; erstere tragen, neben einem in der Mitte befindlichen, etwas grösseren zugerundeten Höckerchen, mehrere kleine, die jenes kreisförmig umgeben.

Auf dem vorderen 'Theil des metagastrischen Lobus stehen zwei Höckerchen gleicher Grösse wie die beiden erwähnten der protogastrischen Loben so neben einander, dass alle vier in gerader Querlinie geordnet sind. Der hintere. Theil des Lobus trägt in der Mitte zwei hinter einander stehende, etwas grössere, aber unter sich wieder verschiedene Höckerchen von halbkugeliger Gestalt, deren Oberfläche unter der Lupe sehr fein gramulirt erseheint. Das grössere hintere ist von einem Kranze kleiner Tuberkelchen umgeben, ron welchen die beiden am weitesten nach der Seite gerïckten, wieder grösser sind als die anderen.

Eine flache Querfurche bildet die Grenze gegen die Cardiacalregion; diese, welche nicht weiter lobulirt ist, stellt sich als längsovaler, gewölbter Hügel dar, der in seiner Mittellinie drei, von vorn nach hinten an Grösse abnehmende Höcker gleicher Beschaftenheit und Gestalt wie die früher erwähnten trägt; auch diese sind von zahlreichen kleineren Höckerchen, welche theilweise ebenfalls 
granulirt sind, kranzförmig umgeben. Der hinterste Theil, wahrscheinlich entsprechend dem Metacardiacallobus, ist vollkommen glatt.

Die Ilepaticalloben zeigen eine für die Oxyrhynchen bedeutende Entwickelung (BITTNER) und tragen einige kleinere Höckerchen; ihnen gehört auch der äussere der beiden Lappen des Vorderseitenrandes an.

Die Branchialregionen sind sehr gross und flach gewölbt, nach hinten steil abfallend; auf ihnen stehen zahlreiche grössere Höckerchen ohne bestimmte Anordnung, die von kleineren in meist unvollstïndigen Kreisen umgeben werden.

Vorkommen: Selten in der Zone $\mathbf{A}_{1}$.

Bemerkungen: Steinkerne, namentlich wenn sie nicht sonderlich gut erhalten sind, besitzen eine so grosse Aehnlichkeit mit Lambmes numuliticus ${ }^{1}$ ), dass ich die oben beschriebenen ursprünglich damit verglich. Namentlich zeigt die Sculptur des Gastrocardiacalrückens insofern grosse Uebereinstimmung, als derselbe bei beiden durch eine Längsreihe von fünf hintereinander stehenden Knötchen geziert ist. Da nun weiter bei Steinkernen die kreisförmige Anordnung der kleineren Höckerchen nie deutlich wahrnehmbar ist, ganz besonders aber das wichtige Merkmal der Sculptur der grösseren Höckerchen fehlt, so war, abgesehen von den Difterenzen, dieser Vergleich naheliegend.

Herr BrTwer hatte aber auch hier die Freundlichkeit, mich auf die Unterschiede aufinerksam zu machen; so unterscheidet Lambrus nummuliticus sich besonders durch seine, in der Längsachse breit-eiförmige Gestalt, während $L$. Bittneri einen querelliptischen Umriss besitzt; weiter ist noch der Grössenunterschied der Hepaticalregion zu erwähnen, die bei ersterer sehr reducirt ist, und schliesslich als gewichtigster Unterschied die verschiedene Sculptur der Branchialregion. L. nummuliticus besitzt auf derselben eine dreihöckerige Mittellinie, deren letzter Ilöcker über den Hinterseitenrand vorspringt; bei $L$. Bittneri ist davon nichts vorhanden.

1) Bitroer, die Brachyuren des Vincentinischen Eocïns pag. 19, tab. 1, fig. $11 \mathrm{a}$ und $b$. 
Calappilia Mune Edwardos emend. Noeturyg.

1573. Calappilia Mrlaxe Edwaros in Bovnué, Palaeontologie de Biarritz pag. 8.

Cephalothorax von kreisförmigem Umrisse, hoch gewölbt. Stirn schmal, zweispitzig. Augenhöhlen gross, nach innen und oben gerichtet. Furchen schwach, mit Ausnahme der beiden, welche die Gastrocardiacalregion begrenzen; Oberfläche ausser feineren Granulationen zahlreiche, halbkugelige Höcker tragend, die auf den Seiten grösser als im medianen Theil sind. Flanken glatt, stellenweise granulirt. Mundlücke gross, vorn nur wenig verschmälert. Sternum viel länger als breit.

Vorkommen: Bis jetzt nur aus alt-tertiären Schichten gekannt.

Bemerkungen: In der citirten Abhandlung hat Herr Milne Edwards das Genus Culappilia mit der Art C. vermeosa aus dem Eocün von Biarritz aufgestellt, ohne jedoch die generischen Kennzeichen genaner zu präcisiren. Es muss daher als glücklicher Umstand betrachtet werden, dass die samländische Crustaceen-Fauna eine Art enthält, die zweifellos diesem Genus zugezühlt werden muss. Auf Grund eines Vergleichs beider Arten lässt sich nun die obige generische Charakteristik feststellen. Da das genannte Werk wohl nicht allgemeiner verbreitet ist, so "gebe ich hier des besseren Vergleiches halber die Abbildung der C. vermocosa wieder (siehe unten die Texttafel, Fig. 1).

Die samländische Form stimmt in der allgemeinen Gestalt und Wölbung mit der französischen sehr gut überein; beide zeigen eine schmale zweispitzige Stirn.

Die Längsfurchen laufen genau in derselben Weise und begrenzen bei beiden einen Gastrocardiacalrücken gleicher Gestalt.

Die Tuberkulirung der Oberfläche ist genau dieselbe; hier wie dort sind die Tuberkeln der Branchialregion grösser als diejenigen der Gastrocardiacalregion, und zwar stehen bei beiden die grössten Höcker der Branchialregion in inneren Theile derselben. Dicht am hinteren Ende des Posterolateralrandes springt bei der französischen, wie bei unserer Form ein besonders grosser Höcker vor. 
Die Orbitalregion war angenscheinlich bei dem französischen Exemplar nicht gut erhalten, während an unserem der Hinterrand fehlt; zwischen diesen Theilen lässt sich also kein Vergleich anstellen.

Die Charaktere, in welchen beide Formen abweichen, sind nu specifischer Art und werden weiter unten besprochen werden.

Es erübrigt noch die Erörterung der Frage, welche systematische Stellung Calappilia zuzuweisen ist. Milne Edwards hat sich hierüber folgendermaassen ausgesprochen:

"Le crustacé pour lequel je propose l'établissement de cette nouvelle coupe générique doit prendre place dans la famille des Oxystomes à coté des Calappes et des Mursies. Mais il se distingue nettement des premiers, parceque la carapace ne se prolonge pas en manière de bouclier au-dessus des pattes ambulatoires et des seconds par l'absence de grandes épines latérales, prolongeant en dehors le bouclier cephalo-thoracique«...... Ferner: "La carapace est très-bombée et sous ce rapport elle ruppelle celle des Calappes ou mème celle de certains représentauts de la famille des Lencosiens. *

Milne Lowardos hat also, trotzdem er die Mundregion nicht. beobachtet hat, geschlossen, dass Calappilia der Familie der Oxystomen angehöre, und nur die Frage offen gelassen, welcher der in dieser Fimilie unterschiedenen Gruppen dieselbe zuzutheilen sei. Aus dem Namen geht wohl hervor, dass Mulne EDwaros den nächsten Verwandten im Genus Calappe sieht.

M. Mnne Edwards ${ }^{1}$ ) theilt die Familie der Oxystomen in zwei grosse Gruppen, je nach dem vor dem ersten Fusspaare die spaltförmigen Oefinungen zum Austritt des verbrauchten Wassers aus den Kiemenhöhlen liegen, oder nicht; die letztere Abtheilung begreift nur die Lencosiaden in sich, die erstere die Calappiden, Corystiden und Dorippiden.

Demmach konnte nur die Untersuchung der Unterseite Aufschluss über die Stellung gewähren. Das beste Exemplar der unten beschriebenen C. perlata zeigt mun ganz deutlich, dass sich

1) Histoire naturelle des Crustacés, Bd. II, pag. 99. 
vor dem ersten Fusspare solche Kiemenspalten befunden haben müssen, wenn auch die dicken Verlängerungen des ersten Kieferfusspares fehlen.

Ich habe zum Vergleich bei einem Exemplar der C'alappa gronulata die äusseren Kieferfüsse nebst ihren Fortsätzen entfernt, und es zeigte sich der Rand des Cephalothorax da, wo sich die Spalten befinden, genau in derselben Weise abgeschrägt, wie es das fossile Exemplar erkennen lässt, so dass ein Zweifel über das Vorhandensein vou Kiemenspalten vor dem ersten Fusspare von Calappilia nicht mehr obwalten kann.

Hiernach ist das Genus C'alappitia also der ersten Abtheilung beizuzählen, in welcher es jedoch einen besonderen Typus repräsentirt, da es sich in der Gestalt und Sculptur des Cephalothorax mit keinem der oben angeführten Triben gut in Einklang bringen lässt; das einzige Genus, welches noch zum Vergleiche herangezogen werden kann, ist C'aluppa.

Von Calappa unterscheidet es sich aber vor Allem durch den Umriss und das relativ breitere Sternum; es zeigt jedoch insofern wieder sehr grosse Aehnlichleit mit diesem Genus, als der Hinterseitenrand, wenn auch nur wenig, nach aussen vorspringt, so dass sich auf den Flanken eine Andentung jener Vertiefung findet, die bei Calappa in so starkem Maasse ausgeprägt ist.

Auch in der Gestalt der Mundlücke herrscht grosse Uebereinstimmung mit Calappa, nur dass dieselbe bei C'alappilia vorn viel breiter ist.

Ferner habe ich bei Calappa in den Längsfurchen, welche die Gastrocardiacalregion begrenzen, eben solche Grübchen an denselben Stellen beobachtet, wo sie sich bei C' perlatc finden, und zwar, was mir das Allerbemerkenswertheste erscheint, zeigen diejenigen, welche am Ende der gastrischen resp. am Anfang der Cardiacalregion stehen, genau denselben Typus der Gestalt und Aufeinanderfolgen. -

Hieraus geht hervor, dass Calappilia, wenn auch wesentlich von Caluppa unterschieden, eine nicht zu leugnende Verwandtschaft mit diesem Genus besitzt, wie das MuLne Lowards mit feinem paläontologischen Tact schon betont hat. 


\section{Calappilia perlata sp. n.}

Taf. II, Fig. 1-1e.

Ein bis auf den Stirn- und Hinterrand prächtig erhaltener Cephalothorax cicut vorzugsweise der Beschreibung dieser Species. Derselbe besitzt gerundet füf'seitigen Umriss. Länge und Breite waren beinahe gleich; das erwähnte Exemplar misst bei verletztem Hinterrande $31^{\mathrm{mm}}$ Länge und $33^{\mathrm{mm}}$ Breite. Die grösste Breite liegt etwas vor der Körpermitte und entspricht einer Linie, welche die beiden letzten Knötchen des Vorderseitenrandes verbindet. Die Wölbung der Oberseite ist so stark, dass sie beinahe als halbkugelig bezeichnet werden kömnte. Der Punkt höchster Wölbung liegt in der Mitte des hinteren Theiles des metagastrischen Lobus, und von hier aus fillt die Schale allseitig gleich stark, nur nach vorn etwas steiler, ab.

Der Vorderseitenrand ist gerade, oder doch nur sehr unmerklich convex, und zum grössten Theile mit kleinen Granulationen besetzt; an seinem hinteren Ende stehen drei grössere Körnchen der Art, wie sie den Posterolateralrand besüumen. Unter sehr stumpfem Bogen geht der Anterolateral- in den geradlinigen, rückwärts convergirenden Posterolateralrand über; dieser, etwa ebenso lang als ersterer, ist mit 8 stumpf-kegelförmigen Knötchen besetzt, die nach hinten bis zum sechsten an Grösse zunehmen; die beiden hinter jenen stehenden sind wieder kleiner als jenes.

Posterolateral- und Hinterrand stossen unter stumpfem Winkel, aber in scharfer Ecke zusammen. Der Hinterrand selbst fehlt, es lässt sich aber aus den Bruchflächen noch schliessen, dass seine Breite etwa der Hälfte der grössten Körperbreite gleichkam, dass er seitlich steil abwärts gebogen und seine Mitte ziemlich convex war.

Die wichtige Stirn- und Orbitalregion ist leider bei keinem Exemplare in wünschenswerther Deutlichkeit erhalten, und man kamn auch hier nur aus Andeutungen auf deren Verlauf schliessen.

I) ie Stirn selbst, das ist sicher, war nur schmal und sprang nicht über das Existom hervor; wahrscheinlich endigte sie in zwei Spitzen und war wenig oder gar nicht herabgezogen. Ihre 
Seitenrïnder sind stark gewulstet und bilden den inneren Theil der Augenhöhlen. Der Supraorbitalrand war in seinem äusseren Theile fein granulirt; der Aussenwinkel der Augenhöhlen liegt in etwas tieferem Niveau als die Stirn. Die ersteren waren relativ gross, zweifelsohne nach oben und innen gerichtet.

Die Regionen der Oberseite sind, mit Ausnahme der Gastrocardiacalregion, welche, von zwei tiefen, breiten Längsfurchen begrenzt, als hochgewölbter Lüngsrücken hervortritt, nur wenig deutlich. Die Längsfurchen, welche Anfangs noch nicht sehr tief sind, nehmen ihren Anfang etwa in der Mitte des Orbitalrandes, convergiren in starkem Bogen bis zu dem Punkte, wo eine seichte Furche sich abzweigt, welche den metagastrischen von dem mesogastrischen Lobus scheidet; dieser Punkt ist durch ein grösseres Grübchen bezeichnet. Von hier aus laufen sie in ziemlich gerader likchtung, nur in der Cardiacalregion noch einmal schwach nach aussen gebogen, dem Hinterrande zu, indem sie gleichzeitig tiefer und breiter werden. Grübchen treten noch mehrmals in den Furchen auf, zuerst eines von runder Gestalt in der Gegend des urogastrischen Lobus, dahinter ein ziemlich grosses schräg gerichtetes, von länglicher form, hinter welchem eine Rieihe kleiner, quergerichteter, spaltförmiger Vertiefungen folgt. Ganz am Ende der Längsfurchen finden sich noch einige kleine, runde Grübchen zerstreut.

Der Gastrocardiacalrücken zeigt nur im vorderen Theile, durch schwache Furchen angedentet, eine weitere Lobulirung, während im hinteren Theile die gastrische mit der Cardiacalregion vollständig verschmolzen ist. Gastral- und Cardiacalregion unterscheiden sich aber insofern, als letztere zahlreiche grosse Höcker trïgt, welche ersterer fehlen.

Im vorderen Theile scheiden die bereits oben erwähnten scichten Furchen die verschmolzenen proto- und mesogastrischen Loben von dem metagastrischen Lobus, der sich mit seinem sehmalen, dolchförmigen Fortsatz dazwischenschiebt. Erstere besitzen gerundet dreiseitige Gestalt und sind nur flach gewölbt, letzterer ist dagegen stark aufgetrieben und zeigt im hinteren Theile zwei schwache, schrïg gekrümmte Furchen, die sich in 
der Mitte nicht vereinigen. Die Gastralregion trägt ausser den zahlreichen Granulationen uur kleinere, flache Höckerchen.

Die Cardiacalregion ist, wie gesagt, nicht durch eine Querfurche von der Gastralregion geschieden; ihr Beginn wird jedoch durch das Auftreten von sechs grösseren, flach-kugeligen Höckern bezcichuet, welche in zwei, etwas unregelmässigen Längsreihen dicht neben einander stehen und vielleicht den Epicardiallobus kenntlich machen. Dann würde der Metacardiallobus durch fünf etwas kleinere Höcker bezeichnet werden, wovon vier den Ecken eines Rechteckes entsprechen, während der fünfte in der Mitte steht.

Die Hepaticalregion ist klein, nur nach aussen durch eine schwache Furche begrenzt; drei Höckerchen, ein grösseres und zwei kleinere, zieren dieselbe.

Die Branchialregion ist sehr gross, gewölbt, im hinteren Theile stark nach abwärts gezogen; dentliche Furchen, welche die einzelnen Loben scheiden, sind nicht wahrzunehmen. Zahlreiche grössere und kleinere Höcker besetzen dieselben. Eine klare Anordnung dieser Höcker ist nicht genan ersichtlich, jedoch sind die grösseren mehr auf den inneren und vorderen Theil der Region beschrïnkt, um welche die ïbrigen anscheinend sehr unregelmässige concentrische Reihen bilden. Die Abbildung veranschaulicht dies besser als Worte.

Die ganze Oberfläche war überdies mit kleinen runden Granulationen besäet, die, im Allgemeinen nicht sehr dicht stehend, anf den halbkugelförmigen Höckerchen sich jedoch gerne häufen. Der vordere und der hintere Theil des Cephalothorax sind in Bezug auf diese Granulation etwas verschieden: vorn stehen sie dichter und sind grösser, hinten stehen sie viel spärlicher und sind kleiner; eine scharfe Grenze lässt sich jedoch nicht ziehen: so reichen erstere in der Medianregion weiter nach hinten als auf den Seiten.

Die Flanken des Cephalothorax fallen hinten in schräger lichtung steil ab und sind etwas concav; vorn legen sie sich jedoch fast völlig horizontal und sind dabei stark gewölbt. An der vorderen Ecke der Mundlücke beginnt eine stumpfe, anfangs dicht gekörnelte, später glatte Kante, die in leicht geschwungenem 
Bogen nach hinten bis zur Ecke des Antero- und Posterolateralrandes läuft, wo sie verschwindet. Oberhalb derselben ist die Schale fein gekörnelt. Die Mundlïcke ist sehr gross, von beinahe quadratischer Form; ihre, von einem schwach granulirten Saume eingefassten Ränder convergiren bis nahe an ihr vorderes Ende nur wenig, hier aber verschmälert sich die Mundlücke ganz beträchtlich.

Von den Kieferfüssen oder der Antennarregion war nichts erhalten.

Das Sternalplastron ist, so weit erkennbar, ron lang-elliptischer Gestalt, beträchtlich länger als breit und in der Mitte stark ausgehöhlt. Die kleine vordere Spitze zeigt stark gewulstete, dicht granulirte Ränder; das folgende Blatt ist gross, etwa so lang wie die übrigen zusammen; die Furchen des vorderen Theils sind tief eingeschnitten und nach vorn gekrümmt; vor ihnen ist der Rand ebenfalls emporgewulstet und granulirt. Die folgenden Theile des Sternums sind zu fragmentarisch erhalten, als dass sie genauer beschrieben werden könnten; man sieht aber, dass das nächste Segment schmal dreieckige Gestalt besitzt, während die folgenden eine mehr rechteckige Form annehmen, alle aber in schräger Richtung zur Medianachse standen.

Bemerkenswerth ist die Sculptur der Unterseite; das Sternalplastron ist fein gestichelt. Die Flanken des Cephalothorax erscheinen dem unbewaffineten Auge glatt, unter der Lupe kann man jedoch zwei, wenn auch sehr fein granulirte Particen erkennen. Die eine befindet sich im vorderen Theil neben den Rïndern der Mundlücke; hier ziehen sich die Granulationen, immer feiner werdend und weiter auseinander rückend, von der erwähnten Kante bis zur Mundlücke hin; die zweite liegt hinter dem ersten Fusspaar, wo etwas gröbere Granulationen ein schmales Band bilden, das über die ganze Breite der Flanke reicht. Von den Gehfüssen sind nur Fragmente der Hüftglieder des ersten Paares erhalten, welche neben starken Seitendornen auch einige feine Körnchen besitzen.

Vorkommen: Selten in der Zone $\mathbf{A}_{1}$. 
Bemerkungen: Von C. vermeose unterscheidet sich C.perlata einmal durch den mehr fünfseitigen Umriss, der hauptsächlich dadurch hervorgerufen ist, dass der Antero- und Posterolateralrand eine deutliche, wenn auch stumpfe Ecke bilden; bei der französischen Form beschreiben sie dagegen einen gleichmässig gerundeten Bogen.

Ferner ist die Anordnung der grösseren Höcker der Gastrocardiacalregion bei der französischen Art eine andere, wie ein Vergleich beider Abbildungen dies erläutert. Ein Hauptunterschied scheint darin zu liegen, dass sich auf der gastrischen Region bei (: verrucosa Höcker gleicher Grösse wie auf der Cardiacalregion finden, während dies bei unserer Art nicht der Fall ist. Ferner fehlen der C. verrucosa die sechs, in zwei Längsreihen gestellten Höcker im vorderen Theil der Cardiacalregion; statt dessen sicht man hier eine gleichartige Anordnung der Höcker wie auf dem hinteren Theil dieser Region.

Auffallend ist allerdings die Uebereinstimmung im hinteren Theile der Cardiacalregion; man sieht hier deutlich, dass die Höcker bei beiden Arten in dieser Weise

angeordnet sind.

Es ist zu bedauern, dass bei $C$. perlata der Hinterrand nicht crhalten ist und demnach dieser wichtige Theil sich nicht vergleichen lässt.

Ob die kleinere Form und die anscheinend etwas feinere Tuberkulirung der C. verrucosa als specifischer Unterschied anzusehen ist, oder nur in der Grösse des Individuums begründet ist, vermag ich nicht zu ermitteln.

Ebenso weiss ich nicht, ob C. vermocosa in ähnlicher Weise eine feinere Granulation der Oberseite besitzt wie unsere Art, denn falls diese fehlen sollte, so wäre in diesem Mangel ein gutes unterscheidendes Merkmal zu erblicken. Die Achulichkeit beider Arten ist im Uebrigen so gross, dass die Frage aufitieg, ob die sam- 
ländische Form von der französischen specifisch überhaupt zu trennen sei, was ich aus den oben besprochenen Gründen für angezeigt halte.

\section{Ilia LEACH.}

1817. Ilia Lraci, Zoological miscellanea, Bd. III.

1837. Ilia Mrine Edwatids, Histoire naturelle des Crustacés, Bd. II, pag. 123.

Der hochgewölbte Cephalothorax besitzt einen nahezu kreisförmigen Umriss; die breite Stirn ist in Form zweier kurzer, stumpfer, etwas gewölbter Lappen ausgebildet, die durch einen mässig breiten, wenig tiefen Einsehnitt getrennt sind. Augenhöhlen sehr klein, nach oben und innen gerichtet. Supraorbitalrand doppelt geschlitzt. Vorder- und Hinterseitenrand einen gleichmässig flachen Bogen von etwa $180^{\circ}$ Bogenlänge bildend; ersterer durch die verlängerte Branchiohepaticalfurche schwach, aber deutlich ausgeschnitten. Hinterrand schmal. Die Regionen der Oberseite meist wenig deutlich geschieden; gewöhnlich sind nur die Gastrocardiacalfurchen, besonder's im hinteren Theil des Cephalothorax, schärfer ausgeprägt; die Branchiohepaticalfurche ist nur eben angedeutet.

Der Metacardiallobus trägt dicht über dem Hinterrande 2 bis 3 stumpf-konische Höcker; zuweilen ist ein ebensolcher anf dem Metabranchiallobus vorhanden (I. nucleus). Oberflïche mit mehr oder minder zahlreichen kleinen Granulationen bedeckt.

Vorkommen: Fossil in der alttertiären Glaukonitformation des Samlandes; recent sehr häufig im Mittelmeer. Angeblich soll anch eine Art (I. punctuta) bei Jamaica leben; nach meinem Dafürhalten ist dieselbe jedoch eher dem Genus Myra zuzuzählen.

Bemerkungen: Ich habe eingangs die Charakteristik des Genus Iliu etwas erweitert, indem ich hierbei wesentlich die Merkmale im Auge hatte, welche dem Paläontologen am meisten dienen, nämlich diejenigen des Cephalothorax. Bei Beschreibung recenter Formen ist derselbe gewöhnlich etwas stiefmütterlich behandelt, da man sich eben bei diesen auf systematisch werthvollere Cha- 
raktere stützen kann, die hei den fossilen gar nicht oder nur in den seltensten Fiallen zu beobachten sind.

Ursprünglich konnte ich mich nicht entschliessen, einzig auf Grund der Abbildungen hin die nachfolgend beschriebene Art des Samlandes mit dem recenten Genus Ilic zu vereinigen. Es schienen mir nicht unwesentliche Abweichungen zu bestehen, die ich namentlich bei dem Fehlen der Gastrocardiacal- und der Branchiohepaticalfurche bei der recenten Form glaubte wahrnehmen $7 u$ müssen, da diese auf keiner der Abbildungen markirt waren. Nachdem ich jedoch durch die Liebenswürdigkeit des Herm Prof: CHun in Königsberg Gelegenheit hatte, die recenten Krebse der dortigen zoologischen Sammlung genauer zu studiren, wurde ich gewahr, dass die Gastrocardiacalfurchen anch der lebenden Ilia mucleus nicht fehlen, wennschon dieselben auch nur sehr schwach angedentet sind; sie besitzen aber genau denselben Verlauf, wie ihn die fossile $I$. corrodata, nur schärfer ausgeprägt, zeigt. Ja bei einem weiblichen Exemplar der I. mucleus war nicht nur die Branchiohepaticalfurche, sondern auch die Querfurche, welche Gastral- und Cardialregion scheidet, deutlich, wenn auch nur schwach, ausgeprägt.

Da somit eine vollkommen übereinstimmende Lobulirung des Cephalothorax der fossilen und der recenten Form vorhanden ist, die Stirn und Orbitalregion absolut gleich sind, ebenso wie Umriss und Wölbung des Cephalothorax äbereinstimmen, ein gleicher Ausschnitt des Anterolateralrandes hier wie dort vorhanden ist, so habe ich nicht lïnger gezögert, die fossile Form dem recenten Genus einzureihen.

Das sicher constatirte Auftreten eines heute noch lebenden Crustaceengenus in alttertiären Schichten gewinnt ein um so urrösseres Interesse, wenn man bedenkt, wie wenige der fossilen Krabben mit genügender Sicherheit auf lebende Genera bezogen werden kömmen. Weiterhin scheint es mir von nicht nuwesentlichem Interesse, dass, wenn man von der etwas zweifelhaften I. punctatu absieht, der nüchste Nachkomme unserer fossilen Art eine der charakteristischen Mittelmeerformen ist. 


\section{Ilia corrodata sp. n.}

Taf. II, Fig. 2-5a.

Dieser kleine Krebs besitzt einen Cephalothorax von fast kreisförmigem Umriss, der sowohl nach vorn als nach hinten stark verschmälert ist. Das abgebildete Exemplar misst $13 \mathrm{~mm}$ Länge und $13^{\mathrm{mm}}$ Breite; die grösste Breite liegt etwas vor der Mitte. Die Oberseite ist beinahe kalbkugelig gewölbt, mit ziemlich gleichmässigem Abfall in longitudinaler, wie in transversaler Richtung. Die leicht convexen gekörnelten Anterolateralränder beschreiben, ehe sie sich mit den Hinterseitenrändern vereinigen, einen verhältnissmässig grossen Ausschnitt; die IInterseitenränder sind stark convex. In ihrer Gesammtheit bilden Antero- und Posterolateralrand eine parabolische Curve. Der Hinterrand ist granulirt, ziemlich convex, aber schmal, und schliesst sich in stumptem Winkel, aber scharfen Ecken, an letzteren an.

Die Orbital- und Frontalregion ist klein, ihr Gesammtdurchmesser mag etwa $1 / 3$ der Cephalothoraxbreite betragen haben. Von diesem Raum nahm die Stirn selbst den grössten Theil für sich in Anspruch, so dass die Augenhöhlen demnach sehr schmal waren. Die Stirn springt in Form eines breiten, vorn gerade abgeschnittenen Lappens vor, der durch eimen Medianeinschnitt zweitheilig ist; doch ist sie nicht abwärts gekrümmt, sondern vollkommen horizontal, nur dass jeder der beiden Lappen etwas bauchig gewölbt ist.

Die Augenhöhlen waren, wie bereits erwähnt, sehr schmal; am Supraorbitalrand stehen zwei starke Dornen; ein kleinerer innerer und ein etwas grösserer äusserer, unter sich sowohl, als auch vom Stirnlappen durch tiefe Einschnitte getrennt; vom letzten Dorn ab biegt sich der Supraorbitalrand nach unten und innen und endigt wahrscheinlich in einem dritten Dorn.

Eine leichte Furche scheidet Stirn und Orbitalregion vom rückwärtigen Theil des Cephalothorax.

Deutliche, namentlich im hinteren Theil der Schale scharfe und tiefe Furchen trennen die einzelnen Regionen. Die Längs- 
furchen, welche die Gastrocardiacalregion als ziemlich breiten, gewölbten Rücken von den Branchialregionen scheiden, beginnen anfings nur schwach zwischen den beiden inneren Dornen des Supraorbitalrandes. In ziemlich gerader lichtung divergiren sie sodumn nach hinten, bis zu dem Punkte, wo sich eine tiefe, in gerader Linie nach der hinteren Ecke des Anterolateralrandes laufende Furche abzweigt. Von hier an convergiren sie in Form flacher, nach aussen convexer Bögen bis zum Ende der gastrischen liegion, wobei sie immer tiefer und breiter werden, laufen damn in paralleler Richtung dem Hinterrande zu, biegen sich aber, ehe sie diesen erreichen, noch einmal scharf nach aussen.

Die flachgewölbte, sehr grosse gastrische Region ist nicht weiter lobulirt, bietet auch sonst nichts Bemerkenswerthes.

Eine tiefe Querfurche scheidet die Cardiacalregion, die wiederum durch eine breite, nach hinten convexe Furche in zwei verschiedene Loben zerlegt wird. Der grössere Epicardiallobus ist ausserordentlich hoch, fiast kugelig aufgebläht und trägt drei nur auf den Steinkernen deutlicher sichtbare Höckerchen, von welchen zwei in einer Querlinie, das dritte etwas weiter nach hinten in der Mitte steht. Der Metacardiallobus ist klein und schmal; auf ihm erheben sich jedoch drei grosse, in einer Querreihe gestellte stumpfe Höcker, die bei dem steilen Abfall der Hinterseite etwas über den Hinterrand vorspringen, auf welchem sie zu stehen scheinen.

Die Hepaticalregion nicht sehr gross, aber scharf begrenzt; auf ihr erheben sich, hart neben dem Anterolateralrand, zwei kleine, dicht hinter einander stehende IIöckerchen, die gewöhnlich nur bei Steinkernen deutlich sichtbar sind, auf Exemplaren mit der Schale sich jedoch kaum markiren. Die Brancbialregion ist gross und ziemlich gewölbt.

Die Flanken fallen im hinteren Theile steil ab, legen sich nach vorn aber fast horizontal; eine tiefe breite Furche entspricht hier dem Ausschnitt des Anterolateralrandes. Der Unterrand des Cephalothorax war auf seiner ganzen Länge mit Körnchen besetzt.

Die Mundlücke muss wohl verhältnissmässig gross gewesen sein und hat sich nach oben nur wenig verschmälert. 
Die ganze Oberfläche, die Flanken mit inbegriften, ist mit zahlreichen runden und flachen kleinen Höckerchen besäet, die unter sich aber wieder von verschiedener Grösse sind. Sie stehen nicht sonderlich dicht und fehlen in den Furchen.

Von den Beinen oder der Unterseite konnte nichts beobachtet werden.

Vorkommen: Anscheinend nicht selten in der Zone $\mathbf{A}_{1}$.

Bemerkungen: Die Mehrzahl der Exemplare zeigt einen ganz eigenartigen Erhaltungszustand, der leicht «u Irrthümern Veranlassung geben könnte. Die betreffenden Individuen, Steinkerne, besitzen nämlich keine glatte, oder, wie zu erwarten stände, granulirte Oberfläche, sondern zahlreiche, mehr oder minder runde Grübchen, in deren Mitte zuweilen noch ein kleines Pünktchen steht, stossen dicht an einander, und erzengen auf diese Weise eine grubige, zerfressene Oberfläche, die sich an besten mit dem Vulgïrausdruck "pockennarbig« bezeichnen lässt.

Glücklicher Weise besitze ich nun einige Exemplare, welche die an sich etwas räthselhafte Erscheinung einigermaassen erklïren. Wären dieselben nicht vorhanden, so würde man zweifelsohne die beiden Erhaltungszustände als verschiedene Species beschreiben. Man bemerkt nämlich bei Individuen, welche noch die Schale besitzen und von der Verwitterung etwas angegriffen sind, dass zunächst die Höckerchen leiden. Ihre Oberfläche wird zerstört, und nun sieht man, dass sie mit einer weissen, kreidigen Substanz erfüllt sind; sie zeigen sich dann als weisse Pünktchen, die sich von der im Uebrigen schwarzen Oberflïche des Cephalothorax scharf abheben.

Die Verwitterung schreitet nun weiter in der Weise, dass einerseits die weisse Substan\% weggeführt wird und schliesslich nur noch ein kleines Körnchen in der Mitte übrig bleibt, andererseits der Umfang der so entstandenen Grübchen sich vergrössert, und endlich entsteht, wenn die Schale noch weiter abgerieben und auch der letzte Rest der weissen Substanz verschwunden ist, die pockennarbige Oberfläche. 
Mit dieser Erscheinung etwa Vergleichbares hat BITTNER ${ }^{1}$ ) bei Phymatocarcimes speciosus beobachtet.

Von der lebenden Ilia mucleus unterscheidet sich I. corrodatn durch die durchschnittlich geringere Grösse, die schieferen, tieferen Furchen auf der Oberseite, den dreidornigen Metacardiallobris und das Fehlen eines Höckers anf' der Metabranchialregion.

Unter den fossilen Formen steht Leucosia Prevostiuna DesMAREST ${ }^{2}$ ) unserer Art am nächsten. Leider ist jedoch die Abbildung der genannten Art zu dürftig und die Beschreibung nicht ausführlich genug, um ein sicheres Urtheil hierüber fällen zu können. Es ist, abgesehen von dem allgemeinen Körperumriss und der Granulation, die rauhe Lobulirung der Oberfläche durch scharfe Furchen ausgeprägt, welche beide F'ormen nahe rückt. Namentlich ist die Querfurche, welche Gastral- und Cardiacalregion scheidet, sehr deutlich, und ebenso gewahrt man, dass bei L. Prevostiana der Epicardiallobus wie bei I. corrodata hoch anfgetrieben war. Leider aber lässt sich über die Beschaffenheit des Metacardiallobus der frunzösischen Art nichts Bestimmtes ermitteln, so wichtig auch gerade die Kenntniss dieser Region für die Vergleichung wäre.

So weit aus Abbildung und Beschreibung hervorgeht, scheint sich L. Prevosticna von der samländischen Art durch das Vorhandensein dreier, schwach angedeuteter Höcker auf der Gastralregion zu unterscheiden.

Dass L. Prevostiana keinenfalls dem Genus Leucosia angehört, brauche ich wohl nicht weiter zu erörtern; es hat auch bereits Mrine Edwards ${ }^{3}$ ) seinem Zweifel hierüber Ausdruck verliehen. Durch ihre Verwandtschaft mit dor samländischen Form scheint sie sich ebenfills als ein fossiler Vertreter des Grenus Ilia zul documentiren.

1) Sitzungsber, der Wiener Kaiserl. Akad. der Wissensch., 1. Abth., AprilHeft 1877, pag. 9.

2) Histoire naturelle des Crustacés fossiles, pag. 14t, tab. 9, fign. 13.

3) Histoire naturelle des Crustacés, Bd. II, pag. 123. 


\section{Psammocarcimus Milne Edwards emend. Noetling.}

1861. Histoire des Crustacés podophthalmaires fossiles. Tome I, pag. $151 \mathrm{ff}$. Annales des sciences naturelles. 4. série, vol. XIV.

Cephalothorax in beiden Richtungen anfangs gleich lang, vorn breit, hinten stark verschmälert, Stirn schmal, dreispitzig; Supraorbitalrand entweder glatt oder geschlitzt; Infraorbitalrand mit langem Dorn an der Innenseite. Der Anterolateralrand trägt vier oder fünf Dornen, deren erster die Augenhöhle nach aussen begrenzt und deren letzter auffällig verlängert, drehrund und scharf zugespitzt ist, zuweilen auch ein secundäres Zähnchen trägt. Hinterseitenrand entweder glatt oder mit 1-2 grösseren Dornen besetzt, am Hinterrande nicht gebuchtet, eine scharfe Ecke mit dem Hinterrande bildend. Oberseite durch zahlreiche und tiefe Furchen in die einzelnen Regionen und Loben zerlegt; stärkere Höcker können vorhanden sein ( $P$. multispinatus) oder vollkommen fehlen ( $P$. Hericarti und laevis). Wahrscheinlich fanden sich bei allen noch feine Granulationen. Epistom nicht gewulstet; letztes Fusspaar zu Schwimmfüissen umgewandelt.

Vorkommen: Die drei Vertreter dieses Genus sind auf alttertiäre Schichten beschrinkt. In Fraukreich hat sich bis jetzt nur eine Art, P. Hericarti, gefunden, die im "Calcaire grossier", namentlich aber in den "Sables de Beauchamps ${ }^{1}$ ), in grosser Menge vorkommt. In Deutschland hat die Glaukonitformation des Samlandes zwei Arten, P. multispinatus Noetr. und P. laevis Noetl., geliefert.

Bemerkungen: Die Species, auf welche Milne Edwards 1. c. sein Genus Psammocarcinus gründete, ist bereits seit langer Zeit bekannt; schon in Jahre 1822 wurde sie von DEsmanest ${ }^{2}$ ) unter dem Namen Portums Hericartii beschrieben und abgebildet. Unter dem gleichen Namen ist sie in PicteṬ's Traité de Paléontologie übergegangen.

1) Vergl, Goubert, Bull. de la société géolog. de France, 2. Serie, Bd. XVII, pag. 445.

2) Histoire naturelle des Crustacés fossiles, pag. 87, tab. 5, fig. 5 . 
Milne Edwarids hat ausführlich die systematische Stellung seines neuen Genus discutirt und namentlich den eigenartigen Hinterseitenrand betont, der sich durch den Mangel eines Ausschnittes am Hinterrande, wie er sonst allen Portuniden zukommt, auszeichnet. Ich habe eingangs die von Milne Edwards gegebene Charakteristik des Genus mit einigen Erweiterungen, die sich als nöthig erwiesen, wiedergegeben; es bliebe hier nur noch kurz das Verhältniss der simländischen Arten zu der französischen zu erörtern. Diese beiden weichen vom Typus P'. Hericarti hauptsächlich dadurch ab, dass bei ihnen der Supraorbitalrand geschlitzt ist, wïhrend er bei jener glatt und nicht eingeschnitten ist. So wichtig an sich auch dieses Merkmal wïre, so glaube ich doch nicht, dass es grenügte, unsere beiden Arten einzig hierauf hin als neues Genus abzutrennen, da zu zahlreiche gemeinsame Churaktere der einen Differenz gerenüberstehen. Hier ist vor Allen die fist vollkommen gleiche Gestalt des Cephalothorax, die Uebereinstimmung in der Stirn und in der Bezahnung des Vorderseitenrandes, namentlich des langen letzten Anterolateralzahnes, und die Gleichheit der Lobulirung hervorzuheben. Die specifischen Unterschiede scheinen sich in der Lahl der Dornen des Antero- und Posterolateralrandes, der Form des letzten Anterolateralzahnes und dem Vorhandensein oder Fehlen von Höckerchen auf den hegionen des Cephalothorax auszusprechen.

Wenn die Zahl der Anterolateraldornen ein generisches Merkmal wäre, so müsste man die beiden samländischen, eng verwandten Formen zwei verschiedenen Genera zutheilen, da jis die eine, I'. laevis, deren fünt, die andere, $P$. multispinata, deren vier besitzt. Da aber auch die Dornenzahl des Hinterseitenrandes variirt, von gïnzlichem Fehlen bis zur Zweizahl, so glaube ich, dass hiermit der nur specifische Charakter dieses Merkmales genügend angedeutet ist.

Am weitesten entfernt sich 1'. multispinatus durch seine grobtuberkulirte Oberfläche, sowie durch die Bedornung des ganzen Seitenrandes vom Typus I'. Hericarti; er ist aber wiederum so eng mit dem $P$. laevis verbunden, der seinerseits sich von dem P. Hericartii, abgesehen von dem geschlitzten Supraorbitalrand, 
nur durch den Mangel eines secundären Dörnchens am letzten Anterolateraldorn sowie durch das Vorhandensein von Dornen am Hinterseitenrande unterscheidet, dass alle drei trotz ihrer Abweichungen in einen und denselben Formenkreis passen. In diesem Sinne habe ich auch die Gattungsdiagnose erweitert.

Es geht leider aus Milne EDwards's Beschreibung der Schalsculptur nicht mit völliger Gewissheit hervor, ob der Cephalothorax in der That vollkommen glatt ist, oder ob nicht diese Glätte nur als Folge des Erhaltungszustandes anzusehen ist. Die Granulation unserer samländischen Arten ist ïberaus fein und zart, so dass der Cephalothorax seine Gestalt noch vollkommen bewahrt haben kaun, während jene längst verschwunden ist. Es wird vielleicht weiteren Nachforschungen gelingen, auch bei P. Hericarti diese feine Granulation nachzuweisen.

Ich möchte zum Schluss noch auf eine Beziehung des Genus Psummocarcinus hinweisen, die durch den $P$. multispinatus vermittelt wird. Diese Art scheint nämlich in naher Beziehung zu (ampylostoma matutiforme BELL ${ }^{1}$ ) zu stehen. Es ist vor Allem die Ausbildung des Stirn- und Orbitalrandes, die Bezahnung des Anterolateralrandes, die Verschmïlerung in hinteren Theil des Cephalothorax, sowie eine gewisse Analogie in dem Auftreten der '́uberkel der Oberseite, welche beide Formen einander nahe rückt. Sie unterscheiden sich aber gerade wieder durch letzteren Charakter, gan besonders aber durch die Verschiedenheit in der Lobulirung, die bei $C$. matutiforme knapp angedeutet, während sie bei $P$. multispinatus scharf ausgesprochen ist.

\section{Psammocarcinus multispinatus sp. n.}

Taf. III, Fig. $1-4$.

Die Grössenverhältnisse, sowie der allgemeine Umriss lassen sich nur annäherungsweise angeben, da auch nicht ein Exemplar ganz vollstïndig erhalten ist. Der ovale oder nahezu kreisförmige Cephalothorax ist, wenn man von den langen Seitendornen absieht, etwas länger als breit und ziemlich stark gewölbt. In longitudi-

1) Palaeontographical Society, 1857, pag. 23 , tab. 3, fig. $8-10$. 
naler Richtung senkt er sich rückwärts allmählich, während er sich nach vorn in steilem Bogen abwärts krïmmt; die Stirn folgt jedoch nicht dieser Biegung des vorderen Theiles, sondern springt horizontal vor. Die vordere Hälfte des Cephalothorax ist breit und gerundet; vom letzten Anterolateraldorn an verschmälert sich derselbe schnell und stark rückwärts. Die grösste Breite, welche etwas hinter der Mitte zwischen den beiden Seitendornen liegt, betrïgt bei einem Exemplar, die letzteren nicht mitgemessen, $18^{\text {mm, }}$ inclusive dieser mindestens $30-32^{m m}$; der Hinterrand desselben Exemplares misst nux $9^{\mathrm{mm}}$. Bei einem anderen betrug die grösste Breite 12, die Lünge bis zur Spitze der Stirn gemessen $15 \mathrm{~mm}$.

Die Stirn ist in drei flache, spitze Lappen ausgezogen, die in horizontaler Richtung ziemlich weit vorspringen und durch anscheinend schmale Einschnitte getrennt werden. An der Basis der Stirn, aber etwas weiter seitwärts gerückt, springt ein kleiner breiter und spitzer Lappen nach vorn, welcher wohl den inneren Theil der Augrenhöhlen ïberdeckte. Der hier anschliessende, äussere Theil des Supraorbitalrandes ist durch zwei schmale tiefe Einschnitte doppelt geschlitzt: zwischen beiden bildet er ein kleines Dömchen, und an seinem äusseren Ende, zugleich die Augenhöhle nach aussen abgrenzend, erhebt sich der erste Dorn des Anterolateralrandes. Dieser letztere ist leicht gebogen und trägt vier spitze Dornen, die, durch flache Einsenkungen geschieden, in ziemlich gleicher Distanz auf einander folgen. Die drei ersten sind nur klein, der letzte aber, welcher zugleich die Grenze zwischen Vorderund Hinterseitenrand bezeichnet, erreicht eine unverhältnissmäissige Länge, zuweilen mindestens $5^{\mathrm{mm}}$; er ist drehrund, schlank und springt in ziemlich gerader oder leicht aufwärts gebogener Richtung nach aussen.

Der gerade Hinterseitenrand ist etwa ebenso lang wie der Vorderseitenrand und trägt wie jener zwei kleinere spitze Dörnchen in gleichen Abstïnden unter sich und von seinen Endpunkten. Gegen den schmalen geraden Hinterrand setzt er, einen stumpfen Winkel bildend, in scharfer Ecke ab.

Die Furchen der Oberseite sind, wenn auch schmal, so doch tief, und demgemäss ist die Lobulirung der einzelnen Regionen 
sehr deutlich ausgeprägt. Die Stirn wird durch eine scharfe Furche halbirt, die sich rückwärts, etwa in der Höhe des Supraorbitalrandes, spaltet; wo die beiden Aeste aus einander gehen, erheben sich die epigastrischen Loben in Form zweier kleiner, nicht besonders scharf' begrenzter Hügel.

Der metagastrische Lobus ist in seinem hinteren Theile ziemlich kurz, aber hochgewölbt, und trïgt in der Mitte einen grösseren, stumpf-kegrelförmigen Höcker; nach vorn sendet er einen langen flachen Fortsatz von dolchförmiger Gestalt, der, indem er sich zwischen die verwachsenen proto- und mesogastrischen Loben schiebt, nur allmählich schmäler wird. Diese letzteren bilden einen grossen, leicht grewölbten Hügel, der in seinem hinteren Theile ein kleines Höckerchen trägt. Eine schmale, nicht sehr tiefe Furche, in welcher zwei kleine Grübchen neben einander stehen, trennt den urogastrischen Lobus, der in Form eines schmalen, aber hoch erhabenen Querhöckers deutlich hervortritt.

Die Cardialregion, welche durch eine breite und tiefe Querfurche nach vorn begrenzt wird, ist ziemlich gross, flach gewölbt, verschmälert sich aber bedeutend nach hinten. Im vorderen Theile, dem Epicardiallobus, stehen zwei ziemlich grosse Höcker dicht neben einander, im hinteren Theile, dem Metacardiallobus, ein kleines, in der Mitte durch eine seichte Einsenkung von ersteren geschiedenes Höckerchen. Letzteres ist gerne in transversaler Richtung etwas verlängert. In vorderen Theile der Gatstrociudianalfurche zweigt sich eine anfings etwas nach hinten gerichtete Furche ab, die dann zwischen dem zweiten und dritten Anterolateraldorn am Rande mündet. Sie begrenzt rückwärts eine ziemlich grosse flache Region von dreieckiger Gestalt, welcher die beiden ersten Anterolateraldornen angehören; ich dente sie als Hepaticalregion.

Die Branchialregion, welche den grössten Theil der hinteren Hälfte einnimmt, trägt vier stumpf-kegelförmige Höcker. Drei davon stehen dicht neben einander im vorderen Theile längs der Gastrocardiacalfurche; das äusserste ist am grössten und durch eine scharfe Einsenkung vom mittleren, etwas kleineren, geschieden, und dieses wieder ist nur durch eine leichte Furche vom kleinsten und innersten getrennt. Der vierte Höcker liegt in der Verbin- 
dungslinie des mittleren dieser drei und des hinteren Anterolateraldornes, aber jenem etwas näher gerückt, an Grösse ihm jedoch nachstehend.

Feine und zahlreiche, weit aus einander stehende Körnchen, welche sich jedoch auf der Spitze der Höcker und der Seitenranddoruen etwas mehr drüngen, bedecken gleichmässig die gauze Uberseite.

Vorkommen: Häufig in der Zone $\mathbf{A}_{1}$.

Bemerkungen. Die Merkmale, durch welche P. multispinatus sich ron der folgenden Art unterscheidet, sollen bei dieser besprochen werden.

\section{Psammocarcinus laevis $\mathrm{sp} . \mathrm{n}$.}

$$
\text { Taf. III, Fig. 5-7. }
$$

Diese Art besitzt, so weit erkennbar, die gleiche Körpergestalt wie dic vorige, doch mag wohl der Unterschied zwischen Länge und Breite etwas grösser als bei jener, mithin der Cephalothorax etwas mehr in die Länge gezogen sein. Auch scheint es mir, als ob $P$. Taevis durchschnittlich etwas grössere Individuen umfasse als $P$. multispincetus. Stirn und Orbitalrand sind wie bei der vorigen Art gebildet, nur war der äussere Orbitalzalin ebenso wie der innere Orbitallappen etwas grösser und kräftiger. Der Anterolateralrand trägt fünf Dornen, von welchen der erstere, wie bereits erwähnt, die Augenhöhlen nach aussen begrenzt. In geringer Entfernung hinter ihm folgt der zweite, der vom dritten durch eine flache und breite Eiusenkung getrennt ist. Letzterer und der vierte Dorn stehen wieder sehr nahe jederseits der Branchiohepaticalturche; und wieder eine breite und flache Einsenkung trennt den letzteren von dem fünften Dorn. Die vier ersten sind spitz-konisch und niedrig, der letzte ist lang und schlank, in horizontaler Richtung ziemlich weit nach seitwärts ragend; wahrscheinlich hat er jedoch nicht die Länge erreicht, welche er bei voriger Art entwickelt.

Der ziemlich lange und gerade Posterolateralrand trïgt beinahe dicht an scinem hinteren Ende cin grösseres Dörnchen; da- 
neben finden sich noch drei weit kleinere zwischen diesem und dem letzten grossen Dorn des Vorderseitenrandes.

Die Lobulirung des Cephalothorax ist fast genau so, wie ich sie bei voriger Art beschrieben habe, nur mit dem Unterschiede, dass sïmntliche Loben der charakteristischen spitzen IIöcker entbehren, vielmehr vollkommen gleichmässig flach gewölbt sind. Die einzige Ausnahme bildet die Cardiacalregion: hier sind die drei Höcker (die beiden in einer Querlinie stehenden des Epicardiallobus, sowie der mittlere des Metacardiallobus) vorhanden, jedoch nur eben angedentet, so dass sie nicht im geringsten hervortreten und die gleichmässige Fläche stören.

Die drei Höcker im vorderen Theil der Branchialregion haben sich bei dieser Art in flache, an Grösse von aussen nach innen abnehmende Hügel, die durch tiefe Furchen geschieden werden, umgewandelt.

Die Oberfläche ist wie bei voriger Art mit kleinen Granulationen besïet, nur dass diese anscheinend etwas gröber sind, vielleicht anch, namentlich auf den Branchialregionen, etwas gedrängter stehen.

Vorkommen: Häufig in der Zone $A_{1}$.

Bemerkungen: Man könnte sehr leicht, besonders durch die gewöhnlich schlechte Erhaltungsweise, dazu grebracht werden, die beiden hier beschriebenen Arten I'. laevs und P'. multispinatus nur für eine Art zu halten. Hat man jedoch die Unterschiede einmal erfasst, so erkennt man selbst kleine Brucbstïcke beider Arten sofort mit Sicherheit, wie auch die Abbildungen lehren: dort eine höckerige, dornige Oberfliiche, hier ein vollkommen gleichmässig flacher Cephalothorax, ohne jede Spur dornenartiger Erhöhungen. Dieser Unterschied möchte an sich schon genügen, die beiden Formen auseinander zu halten. Weiter aber unterscheidet sich P. laevis dadureh, dass bei ihm der Anterolateralrand vier Dornen trägt, während er bei $l$. multispinatus nur mit dreien besetzt ist. In Gegensatz hierzu stehen am Hinterseitenrand der letzteren Art zwei grössere Dornen, wïhrend P. luevis deren vier, einen grösseren und drei kleinere, zählt. 
Es könnte num aber die Frage aufgeworfen werden, ob nicht bei der grossen Achnlichkeit beider Arten die angeführten Unterschiede sexueller Natur sèien. Ich glaube diese Frage verneinen zu dürfen, denn dazu sind dieselben doch zu bedentend. Wenn man zwei Formen, bei noch so grosser Achnlichkeit, selbst in Fragmenten an-klaren und präcisen Merkmalen sicher erkenmen und unterscheiden kann, so scheint es mir zweckmässiger, sie so lange mit verschiedenen Namen zu belegen, als nicht der positive Beweis erbracht ist, dass ihre Verschiedenheit nur sexmeller Natur ist. Aber selbst wenn wir dies zugeben, dass also $P$. laevis und $P$. multispinatus nichts anderes, als die verschiedenen Geschlechter einer und derselben Art repräsentiren, so wird hiermit vorläufig nichts gebessert. Denn, welches das männliche und welches das weibliche Individuum sei, liisst sich ohne Konntniss der Unterseite und des Abdomen nicht mit Sicherheit bestimmen. Da aber eine solche zur Zeit noch nicht besteht (alle meine Exemplare zeigen nur die Oberseite), der Versuch, die Unterseite freizulegen, aber vollkommen aussichtslos erscheint (wahrscheinlich fehlt sie überhaupt allen), so kann eiue positive Entselseidung vorläufig nicht erfolgen.

I'. laevis besitzt eine grosse Aehnlichkeit mit P. Hericarti Desn. sp., der sich aber hauptsächlich durch den vollkommen glatten Hinterseitenrand, sowie durch das secundäre Dörnchen an dem stark verlängerten Dorn des Anterolateralrandes unterscheidet.

\section{Coeloma Milne Edwards.}

1865. Mrene Edwanos, Histoire des Ciustacés podophthahmaires. MLonographie des Crustacés fossiles de la Famille des Cancériens. Annales des Seiences naturelles, 4. sér., vol. XVIII, pag. 352.

Cephalothorax von trapezförmiger Gestalt, nur flach gewölbt. Stirn ziemlich breit, vierspitzig. Supraorbitalrand sehr lang, doppelt geschlitzt; Infraorbitalrand etwas vorspringend, meist in einen comprimiten Dorn endigend. Augenhöhlen sehr gross, fast die ganze Breite der Vorderseite einnehmend; Augen auf dicken, plumpen Stielen sitzend. Anterolateralrand mit vier Stacheln be- 
setzt; deren erster stets den äusseren Orbitalwinkel bildet. Zuweilen können die drei vordersten sehr reducirt sein, bei der Mehrzahl der bekannten Arten sind jedoch alle ziemlich stark entwickelt. Posterolateralrand glatt und gerade. Hinterrand gerade oder schwach convex, seitlich etwas ausgeschnitten. Durch mehr oder minder scharfe Furchen stets eine weitgehende Lobulirung der Oberseite ausgebildet. Gastralregion bei allen in vier Loben, Cardialregion nur zuweilen in zwei dentliche Loben zerlegt. Hepaticalregion deutlich begrenzt, Branchialregion in drei verschieden grosse Loben getheilt. Grössere Tuberkeln können auf den einzelnen Loben vorhanden sein oder auch ganz fehlen. Alle Arten sind jedoch auf der Oberseite mit mehr oder minder feinen, dicht gedrängten Granulationen bedeckt. Unterseite glatt, mit vereinzelten cingestochenen Pünktrhen: Ptrygastomialfurche dentlich, Plastron sternale gross, ron breit elliptischem Umriss. Abdomen aus sieben Gliedern zusammengesetzt. Mundlücken gross viereckig. Die äusseren Kieferfüsse mit einer Längsfurche versehen. Erstes Fusspaar stärker als die übrigen, in kräftige Scheeren von meist ungleicher Grösse endigend. Der Oberschenkel der Gehfüsse von vorn nach hinten comprimirt, auf der Oberkante entweder mit Dornen oder Körnchen besetzt.

Vorkommen: In tertiären Schichten weit verbreitet.

Bemerkungen: Mulne Eowaros stellte im Jahre 1865 das Genus Coeloma für eigenthümlich gestaltete Krabben des vicentinischen Tertiärs auf, die durch ihre allgemeine Körpergestalt mit den Galeniden übereinstimmen, von welchen sie sich jedoch durch ihre grossen Augenhöhlen unterscheiden und in diesem Charakter mehr eine Verwandtschaft mit den Macrophthalmen besitzen. In verhältnissmässig kurzer Leit sind nun eine ganze Reihe hierher gehöriger Formen beschrieben worden, durch welche sich das Genus Coeloma zu einem der wichtigsten tertiären Crustaceengeschlechter emporgeschwungen hat. Nicht nur durch seine zeitliche, sondern anch durch seine räumliche Verbreitung nimmt es unser Interesse in Anspruch. Man kennt bis jetat folgende Arten : 


\section{Gruppe: Laeves.}

('oeloma vigil MuLne EDWARDS ${ }^{1}$ ), häufig im vicentinischen Tertiärgebiet. Diese Art unterscheidet sich von allen anderen durch eine fast vollkommen flache Oberseite; nur auf der Metabranchialregion steht ein einzelner Höcker.

C'oeloma balticum SchlüTER ${ }^{2}$ ), ungemein häufig in der Glaukonitformation des Samlandes. Es ist der vorigen Art so nahe verwandt, dass es schwierig ist, beide aus einander zu halten; es unterscheidet sich jedoch hauptsächlich durch die relativ breitere Stirn und durch den Mangel von Dornen auf der Oberkante des Oberschenkels, wo nur kleine Körnchen stehen.

('oeloma gramulosum Milne EDWARDs $\left.{ }^{3}\right)$, aus den oberen Nummulitenschichten von Biarritz, steht den beiden vorgenannten sehr nahe, unterscheidet sich jedoch durch die relativ grössere Breite des Cephalothorax und durch eine verhältnissmässig noch schmalere Stirn, sowie durch das Fehlen eines Höckers auf dem Metabranchiallobus, bei Vorhandensein eines solchen auf dem Epibranchiallobus.

Coeloma Reidemeisteri sp. n. ${ }^{4}$ ), aus den Phosphoritlagern von Büddenstedt und Helmstedt. Eine Coeloma-Art dieser Localitiaten wird von Gernitz auf $C$. balticum bezogen. Soweit ich aber aus, allerdings schlecht erhaltenen, Exemplaren dieses Fundortes ersehen kann, unterscheidet sich dieselbe von C: balticum, gehört aber jedenfalls in die Gruppe der Laeves.

1) Histoire des Crustacés podophthalmaires, Vol. I. Aunales des scionees naturellos. 4. série, 1865, pag. 353, tab. 35, fig. 1, 2, 3.

2) Zeitschr. d. Dentseh. geol. Ges., 1879, Bd. XXXI, pag. 604, tab. 18, tig.. 3.

3) Annales des sciences géologiques, 1880, Vol. XI, Art. No. 2, pag. 5, tab. 22, fig. 3.

t) Gersitz, Die sog. Koprolitheulager von Helmstedt ete. Abhandl. d. naturw. Gesellsch. Isis in Dresden 1883, Ahhandl. 1, prg. 10. - Ueber nene Funde in den Phosplatlageru, ibidem Abhaudl. 5, pag. 41 11. 42. 


\section{Gruppe: Tuberculati.}

Cocloma taunicum v. Merer sp. ${ }^{1}$ ). Nicht gerade selten im Septarienthon ron Breckenheim am Taunus. Unterscheidet sich von den vorgenannten Arten durch das Vorhandenseiu von zwei Höckern auf der Metabranchial-, sowie von solchen auf der Mesobranchialund Cardialregrion ${ }^{2}$ ).

Coeloma Ciredneri Schloth. sp..3), aus dem Oberoligocän der Gegend vou Hildesheim, ist vorigem nahe verwandt, unterscheidet sich aber hauptsächlich dadurch, dass die drei ersten Dornen des Anterolateralrandes sehr redueirt sind, sowie, dass ausser Branchialund Cardial-, auch die Gastral- und Hepaticalregion grössere Tuberkeln tragen.

Die sechs genannten und kurz charakterisirten Arten lassen sich ïbersichtlich in zwei Abtheilungen gruppiren. Die erste $\mathrm{Ab}$ theilung - Lacves - umfasst die Formen, deren Cephalothorax, mit Ausnahme eines grösseren Höckers, fast vollkommen glatt ist. Die Laeves sind augenscheinlich die der Zeit nach ältesten Formen. Die Gruppe der Tuberculati enthält bis jetzt nur zwei, event. drei Arten, die sich durch einen mehr oder minder stark tuberkulirten Cephalothorax auszeichnen; das Extrem wird durch das jüngere C. Credneri gebildet, während das ältere C. tannicum gleichsam in der Mitte zwischen diesem und den Arten der ersten Gruppe steht, mithin den Uebergang zwischen beiden vermittelt. Die Thberculati scheinen für die jüngeren Ablagerungen des Alttertiärs charakteristisch zu sein.

1) Zeitschr. d. Dentsch, geol, Ges., 1871, Bd. XXIII, pag. 679, tab. 16 u. 17, li... $1-1$.

2) Nenerdings erlielt ich durch Herru Triscest in Brüssel cine als Portumu. nodesux vax Baxanx bestimmte, im Argile de Boome vorkommende Krabbe, in

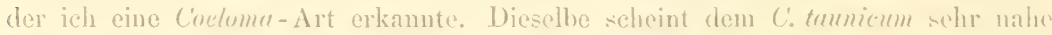
zn stehen, wenn uicht gar mit demselben ident zu sein; es würde sich sumit die Zahl der Species event. anf sicben belaufen.

3) Zeitschr. d. Dentseh. geol. Ges. 1881, Bel. XXX111, pag. 358, tab. 20, fig 1. 
Ich hatte früher ${ }^{1}$ ) die Ansicht ausgesprochen, dass bei den Arten des Genus Coeloma die Tendenz einer weitergehenden Lobulirung, einer schärferen Begrenzung der Regionen und einer reicheren Sculptur von den älteren zu den jüngeren Arten hin sich nicht verkenuen lasse. Ich möchte nach cingehendem vergleichenden Studium der verschiedenen Species dies dabin einschränken, dass wohl die Lobulirung auch bei den älteren Arten ebenso wie bei den jüngeren vorhanden ist, dass aber die begrenzenden Furchen bei ersteren nur schwach sind, demnach die einzelnen Regionen nicht so auffällig hervortreten wie bei den letateren. Die Tendenz richtet sich also hauptsächlich auf ein schärferes Ausprägen der Furchen und auf eine reichere Ornamentirung der Oberseite von den Laeves zu den Tuberculati hin.

BitTner und neuerdings Mrlne Edwards ${ }^{2}$ ) betonten die Möglichkeit einer generischen Identität der Woopwaisu'schen Arten Litoricola glabre:" und Litoricola dentata mit Coelome. Ich wage hierüber kein Urtheil zu äussern, da die Abbildung der beiden Formen zu wenig ausreichend ist; ich gebe aber die grosse Wahrscheinlichkeit dieser Ansicht vollkommen zu. Bei der, wie sich jetzt herausstellt, ansgedehnten Verbreitung des Genus Coeloma stände das Vorhandensein desselben im englischen Tertiïr wohl zu erwarten. Sollte eine neuere Untersuchung die Ansicht des Herrn Mrlne Edwards bestätigen, so gebührte allerdings der Bezeichnung Litoricole die Priorität; es dürfte aber kaum zweckmässig erscheinen, den bereits in der Wissenschaft eingebürgerten Namen Coeloma zu Gunsten des wenig bekannten Nimens Litoricola zu ündern.

Wie weit eine Verwandtschaft zwisehen Portunites BeLl unil Coeloma besteht, auf welche v. Fritsch aufinerksam macht (1. c. pag. (690), ist auch noch zu untersuchen.

1) Zeitschr. d. Deutsch. geol. Ges., 18s1, Bd. XXXIII, pag. 363.

2) Note sur quelques Crustacés fossiles. Anuales des seicnees géologiques 1ss0, Vol. XI, Art. No. 2, pag. 5.

3) Quarterly Journal of the geolog. Society 1873. 


\section{Coeloma balticmu ScHLÜThr.}

Taf. III, Fig. 8; Taf. IV, Fig. 1-5; Taf. V, Fig. 1-5;

Taf. VI, Fig. $1-5$ b.

1879. Coeloma balticum Scrilïter, Zeitschr. d. Deutsch. geol. Ges., Bd. XXXI, pag. 604, tab. 18, fig. 3 .

Diese Art gehört zu den häufigsten Krebsen der Glaukonitformation, für welche sie geradezu als charakteristisches Leitfossil bezeichnet werden muss. Ich habe einige hundert Exemplare untersucht und kann daher eine sehr ausführliche Beschreibung geben.

Die Grösse der Individuen wechselt vielfach; das kleinste der von mir untersuchten Exemplare misst $31^{m \mathrm{~m}}$ Länge auf $37^{\mathrm{mm}}$ Breite ${ }^{1}$ ). Hiernach verhält sich Länge zu Breite wie 1:1,2. Das grösste Exemplar misst mindestens (die Maasse waren leider nicht genau zu nehmen) 83 Länge bei $100^{\text {mm }}$ Breite; Verhältniss etwa 1:1,2. Die Durchschnittsgrösse der Mehrzahl betrug $50^{\mathrm{mm}}$ Länge und $60^{\mathrm{mm}}$ Breite, zuweilen etwas weniger, zuweilen mehr. Man kann also das Verhältniss von Länge zu Breite mit 1:1,2 oder 5:6 als Durchschnitt annehmen.

Die Gestalt des Cephalothorax ist trapezförmig, und zwar ist er, wie sich aus obigen Messungen ergiebt, etwas breiter als lang. Die grösste Breite liegt genau zwischen den beiden letzten Dornen des Anterolateralrandes, etwas vor der Mitte. Die Oberseite ist sehr flach, etwas stärker von vorn nach hinten gekrümmt, als in seitlicher Richtung; dem entsprechend ist auch die Dicke nur gering, da sie nicht mehr, eher noch etwas weniger, als $1 / 3$ der Körperlänge beträgt; es gelang mir nicht darüber zu entscheiden, ob die beiden Geschlechter hierin differiren.

1) Die mitgetheilten Maasse beziehen sich immer in der Lünge vom Hinterrande bis zum mittleren Frontalausschnitt, in der Breite ron Basis zu Basis der letzten Anterolateraldorren. Die Länge der Dornen ist also nicht mitgemessen, da sie nur in den seltensten Füllen vollständig erhalten sind und aus dem liest ihre Länge sich nicht genau berechnen lässt; von Spitze zu Spitze der Dornen gemessen würde die Breite reichlich um $5^{\text {mm }}$, die Länge bis zur Spitze der Frontaldoruen um etwa $2^{\text {mm }}$ grösser sein. 
Die Stim ist breit; sie misst ungeführ $1 / 5$ der Cephalothoraxbreite (bei einem Exemplar beträgt die Stimbreite 11, Körperbreite $54^{\mathrm{mm}}$; bei einem anderen 12 und $60^{\mathrm{mm}}$ ), springt etwa um die In̈lfte ihrer Breite vor und biegt sich hierbei so stark uach unten, dass ihr Vorderrand ziemlich in gleiche Höhe mit den beiden Innendornen des Infraorbitalrandes zu stehen kommt.

Der Vorderrand der Stirn ist in vier ziemlich lange, dünne und runde Dornen ausgezogen, die in fast horizontaler Richtung, leicht nach oben und aussen gekrümmt, nach vorn springen. Zwei der Dörnchen liegen in der Mitte zu beiden Seiten der Längsfurche, welche die Stirn halbirt und sie durch einen schmalen Ausschnitt trennt; je eines steht am äusseren Rande und ist durch eine breite und flache Einsenkung vom inneren greschieden. Da sich die Stirn an den Seitenrändern etwas nach oben biegt, so liegen die inneren Dornen etwas tiefer als die äusseren, welche zugleich den Supraorbitalrand nach innen begrenzen.

Dieser besitzt eine grosse Länge und nimmt den ganzen Vorderrand, von dem äusseren Stirndörnchen bis zum ersten Anterolateralzahn, welcher ihn nach aussen begrenzt, ein. Zwei schmale, kleine Fissuren scheiden einen inneren, bogenförmigen und gewulsteten, von einem nicht gewulsteten und kaum vorspringenden Theil.

Stirn und Supraorbitalrand sind mit einem Saume feiner Knötchen eingefasst, der sich auf der Innenseite des ersten Vorderseiteuranddormes bis zur Spitze hinzieht, von da auf den Infraorbitalrand fortsetzt.

Der Anterolateralrand ist schwach convex, bedeutend kürzer als der Hinterseitenrand und trägt vier starke, spitzige, nach oben gerichtete Dornen, durch welche er wellig ausgeschnitten erscheint. Der vorderste Dorn gleicht einer schlank-dreiseitigen Pyramide, ist gerade nach vorn gerichtet und bildet die äussere Begrenzung der Orbitalhöhle; seine Aussenseiten sind bis zur Spitze mit kleinen Körnchen bedeckt, seine den Augenhöhlen zugewendeten dagegen vollkommen glatt. Durch eine breite und tiefe Einsenkung getrennt, folgt der zweite, seitlich gerichtete, und dicht neben ihm der dritte Dorn; ersterer entspricht der 
Hepatical-, letzterer der Epibranchialregion; wiederum durch einen grossen Ausschnitt getrennt, folgt der letzte, seitwiirts gerichtete Dorn des Mesobranchiallobus. Die letzten drei sind drehrund und allseitig bis zur Spitze mit kleinen Granulationen besetzt. Auf den Steinkernen erscheinen die langen, spitzen Dornen stets als breite, stumpfe Zacken, da es nur in seltenen Fällen gelingt, sie beim Herauspräpariren zu erhalten.

Von dem letzten Dorn biegt sich der lange gerade Hinterseitenrand dem Hinterrande $z u$, mit welchem er einen stumpfen Winkel bildet. Ein regelmässiger Körnchensaum fehlt dem Seitenrand in seiner ganzen Länge.

Der Hinterrand bildet in seinem Gesanmtverlaufe einen ziemlich stark convexen Bogen, jedoch ist er zu beiden Seiten tief und in der Mitte etwas schwächer ausgeschnitten. Er wird seiner ganzen Länge nach von einem perlschnurartigen Saume feiner Granulationen eingefasst, der als Abzweigung eines, den ganzen Unterrand einfassenden Körnchensaumes anzusehen ist, welcher am Hinterrande auf die Oberseite tritt.

Die Deutlichkeit der Regionen und die Schärfe der sie begrenzenden Furchen ist ausserordentlich vom Erhaltungszustande beeinflusst. Im Allgemeinen sind die Furchen nur flach, aber immer deutlich erkennbar.

Die Stirn wird durch eine schmale und ausnahmsweise tiefe Furche halbirt, welche vorn zwischen den beiden Innenzähnen mündet, am Hinterrande der Stirn sich spaltet, um den langen schmalen Fortsatz des metagastrischen Lobns aufzunehmen. Seitlich in dieser Furche treten die epigastrischen Loben in Form zweier flach-erhabener, gerundeter Hügel deutlich hervor. Die verschmolzenen protomesogastrischen Loben sind von annähernd sechsseitiger Gestalt und fast vollkommen flach. Zwischen beide schiebt sich der vordere dolchförmige Fortsatz des metagastrischen Lobus, der hinten breit ist und etwa fünf'seitigen Umriss besitzt. Flache, etwas gebogene, stets sehr undentliche Querfurchen trennen den urogastrischen Lobus einerseits von jenem, andererseits von der Cardiacalregion. Diese, durch Querfurchen nicht weiter lobu- 
lirt, besitzt eine längs-ovale Gestalt und verschmälert sich beträchtlich rückwärts.

Bei gut erhaltenen Steinkernen, aber niemals bei Exemplaren mit der Schale, bemerkt man auf ihr drei kleine flache Höckerchen, von welchen zwei auf' dem breiten vorderen Theil, dein Epicardiallobus, in einer Querlinie, das dritte etwa in der Mitte zwischen dieser und dem Hinterrande median steht.

Die Hepaticalregion ist ziemlich gross, immer scharf begrenzt und zerfällt in zwei flache Hügel, deren äusserer, gewöhnlich etwas gewölbterer, direct neben dem zweiten Dorn des Anterolateralrandes stelit.

Die Epibranchialloben sind, wenn auch klein, so doch deutlich geschieden.

Der Mesobranchiallobus stellt einen flachen und breiten, bogenförmig nach hinten grekrümmten Wulst dar, der vorn von einer etwas schärferen Furche als hinten begrenzt wird.

Der grosse und relativ stark gewölbte Metabranchiallobus trägt im hinteren Theile einen niedrigen kleinen Höcker, der auch bei Exemplaren mit der Schale wahrnehmbar ist. Von diesem Höckerchen aus läuft eine schwache, gerundete Kante, seitlich welcher der Cephalothorax besonders steil abfällt, dem Hinterrande zu.

Auf gut erhaltenen Steinkernen bemerkt man in bestimmten Geyenden des Cephalothorax bandförmige, meist gekrümmte rauhe Male, in welchen wir ohne Zweifel die Haftstellen von Muskeln zu erblicken haben. Die vordersten sind nur klein und beginnen in der Gistrocardiacalfurche etwa da, wo sich die Furche, welche die meta- und protogastrischen Loben scheidet, abzweigt. Zwei etwas grössere, schrïg von innen nach aussen gerichtete, stehen im hinteren Theile des metagastrischen Lobus. Dahinter tritt wieder in der Gastrocardiacalfurche ein doppeltgekrümmtes Mal auf, das gewöhnlich am stärksten markirt ist und vorn beinahe mit einem schräg von inuen nach ausseu gerichteten Mal im vorderen inneren Theile des Metabranchiallobus verfliesst. Zu beiden Seiten der Cardiacalregion, im hinteren Theile derselben, tritt in der Gastro- 
cardiacalfurche ein drittes Mal auf, das, obwohl von betrïchtlicher Länge, doch stets undentlich ist.

Die ganze Oberseite des Cephalothorax ist mit zahlreichen, dicht gedrängten flachen Granulationen bedeckt. Am grössten sind sie auf der gastrischen und dem inneren Theile der Mesobranchialregion, wo sie auch am dichtesten gedrüngt sind. Auf allen übrigeu Regionen stehen sie etwas weiter ans einander und sind kleiner; namentlich an den Rändern erreichen sie kaum die Hälfte der Grösse der medianen.

Betrachtet man den Cephalothorax von vorn, so fallen vor Allem die mächtig grossen und tiefen Augenhöhlen auf, deren durchschnittliche Lünge etwa $1 / 4$ der grössten Cephalothoraxbreite gleichkommt. Wie bereits erwähnt, werden sie innen von dem kleinen Stirnzahne, aussen von dem ersten Anterolateraldorn begrenzt. Der Infraorbitalrand ist leicht nach unten gekrümmt, läuft von dem letzteren nach vorn und endigt schliesslich in einem grossen, breiten, von oben nach unten comprimirten Zahne, der weit nach vorn springt; neben diesem, nur durch einen schmalen tiefen Einschnitt getrennt, gleichsam noch dazu gehörig, steht ein kleineres Zühnchen, das die innere Grenze des Infraorbitalrandes bildet; anch dieser ist, wie der Supraorbitalrand, mit einem Körnchensaume besetzt.

Eine Zweitheilung der Augenhöhle ist nicht scharf ausgesprochen; es verlängert sich wohl der innere Supraorbitalschlitz, sowie derjenige neben dem Infraorbitalzahn in Form kleiner Furchen, die als Grenze der inneren, dem Augenstiele zur Anheftung dienenden Partie gegen den grösseren äusseren zu seiner Aufnahme bestimmten Theil angesehen werden können.

Die Augen sind eigenartig gestaltet; der Stiel ist sehr gross, von plump-keulenförmiger Gestalt und reicht beinahe bis zum äusseren Orbitaldorn. Anf seiner Vorderseite ist er etwa rom ersten Drittel an schräg nach aussen abgestutzt, so dass, wenn die so entstehende elliptische Oeffinung zur Aufnahme des Auges bestimmt war, dasselbe auch eine beträchtliche Länge zeigte. Eine breite schwache Furche läuft auf der Oberseite des Augenstieles bis ganz in die Nähe des Randes. An der Basis war der Stiel ring- 
förmig srewulstet und mit cinigen kleineren Granulationen besetzt, während er im Uebrigen volliommen glatt ist.

Die Flanken bilden im vorderen Theil des Cephalothorax einen sehr spitzen Winkel mit dessen Oberseite, vom letzten Anterolateralzahne an beinahe einen rechten.

Die Pterygostomialfurche ist ungemein dentlich, aber bei den meisten Exemplaren ist die Schale nach dieser Richtung verschoben. Sie beginnt am inneren kleinen Infraobitalzähnchen, lïuft in doppelt-S-förmig gekrümmten Linien auf dem vorderen Theile der Flanken in der Mitte bis in die Gegend des letzten Anterolateralrandes, von wo ab sie dem Oberande näher liegt, und verschwindet etwa zwischen dem dritten und vierten Beinpalare.

Die Flanken sind mit ungemein feinen und zarten, nur hinten und unterhalb der Augenhöhle etwas gröberen, zerstreuten Körnchen bedeckt, so dass sie dem unbewaffineten Auge glatt erscheinen. Der Unterrand ist seiner ganzen Länge nach von einer Körnchenreihe eingefasst, von welcher sich zwischen dem zweiten und dritten Fusspaar eine zweite abzweigt, die nach oben läuft und am Hinterrande auf die Oberseite tritt, welchen sie, wie bereits oben erwähnt, einsäumt.

Die Mundlücke war gross, von viereckiger Gestalt; doch ist leider von den Kieferfüssen stets nur das äussere Paar erhalten, und zwar gewöhnlich verschoben und weit klaffend. Das Hauptglied besitzt eine rechteckige, hinten etwas verschmälerte Form; dem inneren Rande näherliegend läuft auf ihm eine schmale tiefe Längsfurche in schräger Richtung von aussen nach innen. Nach vorn folgt ein beinahe quadratisches Glied, dessen vordere innere Ecke schräg bogenförnig abgestutzt ist; eine seichte Furche beginut an der unteren äusseren Ecke und läuft schräg nach vorn und innen, bis nahe zum Vorderrande. Die Palpe war lang und schmal, vollkommen glatt oder nur mit wenigen eiugestochenen Punkten bedeckt, während sich auf den inneren Gliedern noch eine dichte feine Granulation zeigt.

Vom Epistom und den Antennen konnte leider bei keinem Exemplare etwas beobachtet werden, dagegen gelaug es, vom 
Endostom, wenn auch nur den Abdruck der Innenseite zu beobachten. Darnach besitzt es dieselbe Grestalt, wie sie von v. Fritsci bei Coeloma taunicum beschrieben wurde, doch weichen die Details etwas ab. Es ist eine flache Platte mit geradlinigem Vorderrand, nach hinten in zwei lange spitze Zipfel ausgezogen. Zwei schräge kurze Querwülste convergiren in der Mitte, wo sie mit dem Innenrandsaum verschmelzen, und senden vom Vereinigungspunkt eine schmale mediane Leiste nach vorn; vor ihnen und parallel gerichtet liegen zwei nach innen an Tiefe zunehmende Furchen. Der Innenrand ist seiner ganzen Länge nach von einem etwa halbkreisförmig gebogenen Wulste umsäunt, der auf den Zipfeln von Furchen begleitet wird; ein schwächerer Saum hat wohl auch den Aussenrand der Zipfel eingefasst.

Das Sternalplastron ist ungemein gross, von breit elliptischer Form, jedoch um Beträchtliches länger als breit. Die vorderste Spit\%e ist klein, dreieckig und stets nach oben gebogen; ausser einigen eingestochenen Punkten ist sie im Gegensatz zu den folgenden Gliedern, die völlig glatt sind, mit Körnchen bedeckt. Das folgende Glied ist weit grösser als alle übrigen: die Spitze mit eingerechnet beträgt es etwa die Hälfte der Gesammtlänge des Plastrons; die Furchen im vorderen Theile, welche dem vorderen Ende der Gehfüsse entsprechen, sind mehr oder minder deutlich, reichen aber nicht gan $z$ bis zur Mitte. Hierauf folgen zwei schmale Glieder, welche sich zwischen dem vorhergehenden und folgenden auskeilen, so dass sie nicht in der Mitte zusammenstossen, wohl aber eine schmale tiefe Spalte hinterlassen. Die weiteren vier Glieder bieten nichts Bemerkenswerthes, nur dass sie im Gegensatz zu den vorhergehenden, die senkrecht zur Medianaxe laufen, schräg dagegen gerichtet sind.

Zuweilen sind auch die kleinen Episternien erhalten, die rückwärts in schmale Spitzen ausgezogen sind, welche wenigstens an den vorderen Gliedern bis beinahe zur Naht des folgenden reichen.

Das Abdomen zählt mindestens sieben Glieder, die aber bei keinem Exemplar vollyählig erhalten sind; dasjenige des Männchens 
zeigt eine spitz-dreieckige, dasjenige des Weibchens eine breitovale Form. Wahrscheinlich besass das Abdomen einen Längskiel, der aber so schwach ausgebildet ist, dass man kaum eine Andentung davon zu erkennen vermag. Bei beiden Geschlechtern sind die beiden ersten Glieder am schmalsten und entsprechen in ihrer Breite etwa dem mittleren Theil des Hinterrandes; das dritte Glied füllt die Breite zwischen dem vierten Fusspare vollkommen aus; und während nun beim Männchen die vier folgenden Glieder sich rasch verschmälern, behalten sie beim Weibchen riemlich die gleiche Breite bis zum letzten, welches sich zuspitzt, bei. Die beiden letzten Glieder sind bei beiden Geschlechtern in der Längsrichtung am ausgedehntesten, während alle anderen heträchtlich kürzer sind.

Die Gehfüsse sind gross und kräftig, namentlich ist das erste Paar mit zuweilen mächtigen Scheeren ausgestattet. Bei diesem liegen die drei, ersten kleinen Glieder stets auf der Unterseite, sind aher niemals gut erhalten; das erste endigt an seiner unteren Hinterecke in einen kleinen spitzen Dorn, der in einen besonderen Ausschuitt des zweiten Gliedes des Sternalplastrons eingreift.

Der Oberarm (Taf. VI, Fig. 3, 3b, 4 u. 4a) besitzt dreiseitigprismatische Gestalt und erreicht mit seinem oberen Ende grerade den Anterolateralrand; die beiden Aussenflächen sind flach gewölbt, die Innenfläche ist coneav und wahrscheinlich nur mit einer häutigen, nicht verkalkten Membran überzogen gewesen, da sich auf ihr nie eine Spur von Schale fand. An der oberen und äusseren Vorderecke stehen zwei Dornen (a und $a_{1}$ ), ein breiter flacher (a) am Rande, und durch eine tiefe breite Furche, die sich allmählich verflachend bis zur unteren Ecke hinzieht, geschieden von einem spitzen, etwas nach hinten gelegenen Dorn $\left(a_{1}\right)$. Bei der normalen Lage der Scheeren sieht man ihn von oben dicht neben dem letzten Anterolateralzahne, aber etwas nach vorn gerïckt. Die innere Vorderecke trägt ebenfalls einen flachen breiten Dorn (b) (Fig. 4a), der sich aber so dicht an den der äusseren Ecke anschmiegt, dass beide zu einem einzigen breiten, aber dünnen Zahne zu verschmelzen scheinen, der durch einen scharfen Einschnitt zweitheilig ist. Von oben 
gesehen liegt er bei der normalen Stellung der Scheeren neben dem vorletzten Anterolateraldorn. Die untere und äussere Vorderecke trägt einen grossen, stumpfkegelförmigen Dorn (c), der nach hinten durch eine schmale tiefe Furche abgeschnürt ist.

Die Oberfläche des Vorderarms war, mit Ausnahme der Innenseite, gleichmässig mit feinen runden, nicht sehr dicht stehenden Granulationen bedeckt. Der Vorderarm besitzt, von oben gesehen, einen subquadratischen Umriss, seine innere Vorderecke ist in einen langen spitzigen Dorn (d) ausgezogen, die äussere trägt nur ein kleines kugeliges Tuberkelchen, das in ein Grübchen hinter dem proximalen Höcker des Oberrandes der Hand eingreift; die beiden Hinterecken sind einfach und glatt abgerundet. Dagegen steht wieder ein kleines kugeliges Knötchen (f) (Fig. 3) an der unteren Hinterecke. Wie das vorhergehende Glied ist auch der Vorderarm granulirt; doch ist auf der Oberseite die Granulation etwas gröber.

Die Scheeren sind massig und plump, stets von verschiedener Grösse, und zwar ist immer die linke etwas kleiner als die rechte.

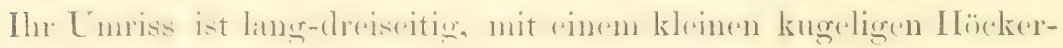
chen am proximalen Ende des Oberrandes, der mit dem äusseren vorderen des Vorderarmes zusammentrifft. Der Unterrand trägt ebenfalls am proximalen Ende einen kleinen runden Höcker (g), der mit dem proximalen äusseren (f) des Vorderarmes und (beim Zusammenziehen) dem distalen unteren (c) des Oberarmes zusammenstösst. Die Aussenseite ist flach gewölbt, am Unterrande läuft eine breite, sehr seichte, meistens kaum wahrnehmbare Furche fast bis zur Mitte des unbeweglichen Fingers.

Die Innenseite ist aufgetrieben, gewölbt und am Oberrande mit einer langen schmalen Furche zur Aufnahme des Vorderarmdornes versehen.

Die Finger sind breit, kurz und tragen runde Kerbzähne, die nach vorn an Grösse abnehmen. Der bewegliche Finger ist etwas breiter und gewölbter als der unbewegliche, dabei leicht lugenfömig. wïhrend letzterer fast gerade ist. Dem unbewaftineten Auge erseheint die Oherflïche der Haud vollkommen glatt, durch die Lupe sieht man jedoch, dass sie mit zahlreichen, sehr feinen kleinen Granulationen bedeckt war. 
Es ist charakteristisch für unsere Art, dass fast alle Exemplare, mit Ausnahme der sehr stark zerbrochenen, das vorderste Fusspaar erhalten haben, und zwar fast stets in gleicher Lage: Ober- und Vorderarm hart an den Cephalothorax angeschmiegt, die Scheeren nach unten und innen gebogen, so dass die Mundpartie völlig verdeckt ist, wobei dann die rechte Scheere etwas über die linke greift. Unter den zahlreichen Exemplaren, die ich untersucht, fand ich auch nicht eines, das eine andere als die vorbeschriebene Lage zeigte, wo etwa die Scheerenfüsse nach aussen gebogen wären und dem Körper nicht fest anlägen.

Die folgenden vier Gehfüsse sind bei keinem der vielen Exemplare gut erhalten; gewöhnlich sind nur die Schenkel einigermaassen gut zu beobachten; dieselben sind ziemlich lang, sehr breit und stark von vorn nach hinten comprimirt, wobei das letzte Paar am flachesten ist. Der gerundete schmale Oberrand trägt zahlreiche kleine und stumpfe Dörnchen, der etwas breitere Unterrand nur vereinzelte feine Granulationen

Vorkommen: Ausserordentlich häufig in den Thonknollen der Zone $A_{1}$.

Bemerkungen: Herr Schlüter hat als Unterschiede seines C'oeloma balticum von Coeloma vigil die folgenden Kennzeichen angegeben:

1) Bei Coeloma balticum ist die die Stirn halbirende Furche weniger entwickelt;

2) statt des längs-ovalen kleineren Hügels hinter dem ersten Seitenzahn in der Lebergegend bei Coeloma vigit ist bei Cocloma bulticum ein grosser quer-ovaler Hügel vorhanden, der sich von der Extramedialregion bis an den zweiten Seitenzahn erstreckt, und es liegt ausserdem noch ein kleiner Buckel vor dem dritten Seitenzahn;

3) es sind die die Inframedialregion begrenzenden Seitenfurchen sehr schwach entwickelt, so dass sie als verwischt bezeichnet werden müssen;

4) der Saum des Hinterrandes ist glatt (bei C. vigil granulirt);

5) bei Coelome balticum fehlt eine Furche anf der Oberseite der Hand (bei C'. vigil eine solehe vorhanden); 
6) der Schenkel der Gehfüsse ist auf der Oberkante mit unregelmässigen, äusserst kleinen Körnchen bedeckt (bei C. vigil statt dieser eine lieihe langer, dünner Stacheln).

Nachdem ich nun, gestïtzt auf ein sehr reiches Material, ScnLÜten's Beschreibung bedeutend ergänzen und erweitern konnte, ergab es sich, dass die sub 1) 3) 4) 5) genannten Unterschiede nicht mehr aufrecht zu erhalten waren; in Bezug auf das sub 2) genannte Merkmal wichen meine Exemplare betrïchtlich ron ScHLÜTER's Abbildung ab und zeigten eine grössere Aehnlichkeit mit $C$ : vigil; es blieb also nur noch als einziges festzuhaltendes Merkmal der differirende Charakter des Obersehenkels beider Arten.

Ich war also wieder auf einem Punkte angelangt, wo Abbildungen, ja selbst die ausführlichste Beschreibung nicht hinreichend sind, um entscheiden zu können, ob die beiden Formen verschieden sind oder nicht. Es konnte also nur eine Vergleichung der Originale den Ausschlag geben, dem hierbei konnte man erst auf die mehr oder minder grossen Eigenthümlichkeiten einer jeden Form anfmerksam werden, die bei der ursprünglich selbstständigen Bcschreibung einer jeden Art anzugeben unmöglich gewesen wäre, da man eben nicht wusste, worauf es hierbei ankommt.

Ich habe daher auch hier wieder die Güte des Herrn BiTrtene in Anspruch genommen, der mit grösster Liebenswürdiøkeit cine Vergleichung der samländischen Formen mit der vicentinischen voruahm und mir seine ausführliche Untersuchung bereitwilligst z.ur Disposition stellte. Ich kann nichts Besseres thun, als die Ansichten dieses gewiegten Kenners über die Verschiedenheit der beiden Arten, Ćoeloma vigil und Coeloma balticum, hier mitzutheilen. Herr BrtTner schreibt: "Die Stirn ist bei Coeloma vigil viel schmaler als bei Ćocloma balticum, bei dem von mir tab. $V$, fig. $4 a^{1}$ ) abgrebildeten weiblichen Exemplar nur 10 oder $11^{\operatorname{mm}}$ auf $49^{\mathrm{mm}}$ Gesammtbreite und $41^{\mathrm{mm}}$ Lünge; bei dem besterhaltenen Exemplar der samländischen Art von $54^{\mathrm{mm}}$ Körperbreite misst die Stirn an derselben Stelle (Umbiegung des Stirnrandes in den

1) Brayehuren des vicentinischen Tertiärgebirges. 
geraden Augenhöhlenrand) $16^{\mathrm{mm}}$ Breite, also ein ganz gewaltiger Unterschied, welche weitaus grössere Stirnbreite für C. balticum ganz constant ist und zu den am meisten in die Augen fallenden Merkmalen gehört.

Bei demselben Exemplar von C. vigil beträgt die Stirnbreite an vorderen Rande $9^{1} / 2^{\mathrm{mm}}$; bei C. balticum $11^{\mathrm{mm}}$. Bei meinem C. vigil ron Castelgomberto, das $61^{\mathrm{mm}}$ breit ist (gegen $54^{\mathrm{mm}}$ des oben erwähnten (. balticum), beträgt die Stirnbreite am Vorderrande erst kaum mehr als $11^{\text {tmm }}$, an der Basis $16^{\mathrm{mm}}$.

Ein weiterer Unterschied, der sich innig an diese Verschiedenheit der Stirn anschliesst, ist der des oberen Augenhöhlenrandes. Der innere Theil zwischen der Stirn und der inneren Seissur ist bei $C$. vigil sehr lang, bei C. balticum unverhältnissmässig kurz. Des besseren Vergleiches wegen folgt hier die etwas schematische, aber genaue Darstellung des Stirn-, Orbital- und Anterolateralrandes beider Arten.

Auf die $11^{\mathrm{mm}}$ Stirnbreite folgt bei dem oben erwähnten Stück von C. vigil eime Distanz von $5^{\mathrm{mm}}$ bis zum ersten, von da $7^{\mathrm{mm}}$ bis zmm zweiten Einschnitt des Supraorbitalrandes, sodann eine Lilcke (der Einsehnitt selbst) von über $2^{\text {mm }}$ bis zum ersten Rande des ersten Seitenrandzahnes in gleicher Linie fortgemessen.

Bei Ihrem oben erwähnten Exemplar des C. balticum folgt auf die Stirn von $16^{\mathrm{mm}}$ Breite eine Distanz von nur $3^{\text {mum }}$ bis zar ersten Scissur, sodann $7^{\mathrm{mm}}$ (mehr also wie bei ('vigil) zwischen erster und zweiter Scissur, sodann gar keine Lücke, sondern knapp anliegend der erste Seitenrandzahn. Die Unterschiede in der oberen Augenhöhlenrandbildung sind also ganz prägnante, doch wird cin wenig vermittelt durch das Exemplar von Castelgomberto, welches eine etwas breitere Stirn besitzt als die Stücke von Val Laverdà, sich aber noch unvergleichlich enger an diese Stücke anschliesst als an die baltischen; fig. 4a meiner $\mathrm{Ab}$ bildungen zeigt diese Verhältnisse ganz vorzüglich. Noch ist zu bemerken, dass bei C'oeloma vigil der zwischen beiden Scissuren gelegene Rand gegen die Lücke hin zahnartig vorgezogen, bei Ćolome balticum gerade an dieser Stelle abgestumpft ist. 
Die Seitenrandzähne stehen bei C.vigil dicht gedrängt, weil ihre Basis verhältnissmässig sehr breit ist, und die zweite breite Orbitalscissur trägt zu dem Eindrucke bei, den man bei flüchtiger Ansicht hat, dass die Art fünf Seitenrandzähne besitze. Bei Coeloma balticum sind die Zähne, besonders an der Spitze, viel dünner, und die Zwischenräume in Folge dessen breit ausgerundet. Von einem welligen Ausgeschnittensein des Vorderseitenrandes durch dessen Bezahnung kann bei C $\therefore$ vigil nicht geredet werden, die Zähne sitzen hier dicht auf einander (fig. 4 a zeigt das sehr gut), die Zähne sind an der Basis glatt, erst an der Spitze drehrund (der letzte ist jedoch schon an der Basis drehrund), im übrigen sind sie granulirt wie die übrige Schale.

Die Breite resp. Länge einer Augenhöhle ist bei C. balticum geringer als die Stirnbreite, bei C.vigil umgekehrt weit beträchtlicher als diese, ca. $1 / 3$ der grössten Körperbreite, wie sich schon aus der Summirung der oben mitgetheilten Maasse ergiebt.

Der Hinterseitenrand ist bei C. vigil ein ganz klein wenig banchig vorgewölbt; was ich von dem feinen, erhabenen, sehr zart granulirten Saume sagte (1. c. pag. 38), der ausser dem Hinterseitenrand auch noch den Hinterrand ungiebt, so musste in Ihrem Sinne (cf. oben in der Beschreibung pag. 150) statt "Hinterseitenrand eigentlich "Unterrand stehen; es ist das wieder eine Uebereinstimmung $z$ wischen beiden Arten.

Der Hinterrand scheint in seiner Configuration ebenfalls recht gut zu stimmen, denn wenn Sie sagen, er sei in der Mitte ausgeschnitten (cf. oben), so beziehen Sie sich auf die ganze Dicke des Cephalothorax; wenn es bei mir heisst (1. c. pag. 38), er sei völlig gerade, so gilt dies von seinem feinen Saume. In Wirklichkeit dürfte da kein Unterschied bestehen.

In der Oberflächenlobulation finde ich, mit Ausnahme des schon von Scrulüter hervorgehobenen Unterschiedes, in der Hepaticalgegend keinen Unterschied, auch die Metabranchialconfiguration ist dieselbe, wenn auch bei C. vigil vielleicht etwas schwächer entwickelt. Auf der Hepaticalregion aber tritt der äussere Höcker, der hinter dem ersten Zahne liegt, also dem zweiten ent- 
spricht, sehr scharf umschrieben hervor, wie das meine Figuren ausgezeichnet zeigen; die Furche, welche diesen Höcker vom dritten 'Zahne trennt, ist ungewöhnlich breit, flach und glatt, der von dem Höcker zum zweiten 'Lahne hinüberführende liücken aber sehr schmal und beinahe unterbrochen, wïhrend er bei C. balticum sehr breit und fast so hoch als der Höcker selbst ist. Sonst sind die Loben exact identisch, ebenso wie die Granulation der Schale.

Der Flankenwinkel (gegen die Oberseite) ist bei beiden Arten übereinstimmend, eine Verschiebung nach der Pterygostomialfurche scheint auch bei $C$. vigil Regel zu sein. Körnelung der Flanken dieselbe wie bei $C$. balticum. - Die Kieferfïsse zeigen dagegen wieder Unterschiede. Die Furche auf dem Hauptgliede der äusseren Kieferfüsse liegt bei (. balticum verhältnissmässig weiter nach innen als bei $C$. vigil, so dass die durch dieselbe getremnten beiden Längsabschnitte bei C. vigil eine viel ungleichere Breite besitzen als bei C. balticum. Eingestochene Punkte oder Grübchen bei beiden Arten gleich; auch von den feinen Granulationen der inneren Glieder sind noch Spuren bei den vicentinischen Exemplaren zu bemerken.

Das Sternalplastron stimmt gut überein, auch die schmalen auskeilenden Platten sind wie bei (;. balticum vorhanden.

Bezüglich des Abdomens ist Neues nicht beobachtet.

Der Oberarm ist, soweit erkennbar, völlig gleichgebildet. Der Vorderarm ist bei $(\therefore$ balticum, besonders rückwïrts, etwas breiter als bei C. vigil, der Dorn der inneren Vorderecke bei dieser Art ïusserst gross, lang und spitz (vergl. l. c. tab. 7, Fig. 4a links); an der äusseren Hinterecke (vergl. Fig. 5) ebenfalls ein scharfer, rückwärts gerichteter Dorm, der auf Fig. 4 a deutlich hervortritt. Nach vorn ist der Aussenrand gekörnelt-gesägt. Das ist also wieder ein sehr scharfer Unterschied beider Arten. Schematisirt wïrde sich also der Umriss des Vorderarmes beider Arten wie unten Texttafel Fig. 4 und 5 darstellen.

Die Bildung der Scheeren ist im Wesentlichen bei beiden gleich, anch die Backen und mahlzahnartigen, zuweilen ansgehöhlten 
Zähne der Finger stimmen überein. Der Unterschied in der Bewehrung der Gehfüsse ist bekannt.

Fassen wir die obige Auseinandersetzung noch einmal kurz zusammen, so sind C.balticum und C. vigil zwei so ausserordentlich nahe stehende Arten, dass es der subtilsten Untersuchung bedarf, um die Merkmale, welche beide Formen unterscheiden, anfzufinden. Diese Merkmale: (vergl. die Skizzen 2 und 3 der Texttafel) die relativ schmale Stirn des Cephalothorax, der breitere Supraorbitalrand und demgemäss eine längrere Augenhöhle mit breiterer äusserer Scissur, die dicht gedrängten Dornen des Anterolateralrandes, das Vorhandensein eines hinteren, äusseren Dornes am Vorderarm, und die Anwesenheit längerer Stacheln auf der Oberkante der Schienen charakterisiren C'oelomu vigit, das Gegentheil der sämmtlichen Kennzeichen, also breite Stirn, schmälerer Supraorbitalrand etc. C. balticum.

\section{Dromilites Succini sp. $n$.}

Taf. VI, Fig. $6-8$.

Der flachgewölbte Cephalothorax ist nicht ganz doppelt so lang als seine grösste Breite beträgt; da die Seitenränder fast vollkommen geradlinig laufen, die Verschmälerung des Cephalothorax anch rorn wie hinten nur sehr geringfügig ist, so zeigt er einen längs-ovalen, beinahe rectangulären Umriss. Die Stirn ist, wenigstens an ihrer Basis, ziemlich breit, leicht nach abwïrts gekrümmt und wird durch eine leicht angedeutete Medianfurche halbirt; über ihr vorderes Ende vermag ich nichts zu sagen, da dies bei keinem Exemplare erhalten ist.

Der innere Theil des Supraorbitalrandes ist leicht gewulstet, der äussere glatt; der innere Orbitalwinkel wird durch einen breiten, aber kurzen, stumpfen Lappen gebildet.

Vorder- und Hinterseitenrand bilden eine gerade, nur an den Enden leicht nach innen gekrümmte Linie, welche mit kleinen spitzen Höckerchen besetzt ist. Am vorderen Theil vor der hinteren Querfurche stehen deren drei, die jedoch beträchtlich grösser sind als die vier, welche sich hinter derselben finden. Der schein- 
bar vollkommen gerade Hinterrand wird von einem scharfen, etwas erhabenen Saume eingefasst.

Die Lobulirung der Oberseite ist sehr wenig ausgeprägt. Die Nackenfurche, welche nur in der Mitte schärfer markirt ist, ist anf den seitlichen Theilen vollständig verwischt. Sie begrenzt die verschmolzenen Gastralregionen (mit Ausnahme des urogastrischen Lobus) und die Hepaticalregionen rückwärts. Zwei kurze, kaum merkbare Einsenkungen, die Fortsetzung der Gastrocardiacalfurche, kann man als die seitlichen Grenzen des metagastrischen Lobus ansehen. Auf diesem stehen zwei niedrige runde Höckerchen ziemlich dicht neben einander, während zwei Gruppen einiger weniger, aber dicht gedrïngter kleinerer Höckex, die etwas nach vorn und seitwärts. von den letztgenannten stehen, den mesogastrischen Loben angehören. Dicht hinter der Stiru, zu beiden Seiten der schwachen Längsfurche, erheben sich wiederum zwei etwas grössere Höckerchen. Der ziemlich grosse urogastrische Lobus wird seitlich von den kurzen, aber tiefen Ueberresten der Gastrocardiacalfurchen begrenzt, rückwärts scheidet ihn eine seichte breite Depression von der Cardiacalregion; er trägt, wie aber nur auf Steinkernen gut sichtbar ist, gleichwie die Cardiacalregion, zwei neben einander stehende, flache, runde Höcker.

Die hintere Querfurche, welche nur auf den Seitentheilen des Cephalothorax deutlich ausgesprochen, in der Mitte jedoch verwischt ist, trennt Antero- und Posterobranchialregion. Auf ersterer steht neben der Gastrocardiacalfurche ein unregelmässiger Höcker von beträchtlicher Grösse. Auf der Posterobranchialregion bemerkt man drei parallele Reihen kleiner runder Höckerchen, welche, schräg nach hinten gerichtet, vom Aussenrande bis beinahe zur Mitte laufen. Die ganze Oberfläche ist mit kleinen, etwas unregelmässigen, dicht gedrüngten Grübchen bedeckt.

Vorkommen: Selten in der Lone $\mathrm{A}_{1}$.

Bemerkungen: Jedenfalls ist für diese Form die Bezeichnung Dromitites vorzuziehen, dit sie sich doch eng an die ron Betu, beschriebenen Arten des Londonthones - Dromilites Buchlandi und Liomilites Lamarchi - anschliesst, obgleich sie nicht 
mit diesen zu verwechseln ist. Man erkennt die samländische Art leicht an der Verschiedenheit des Umrisses, der geringeren Grösse der Seitenranddornen und der abweichenden Sculptur der Oberfläche. Mit Dromia Hilarionis Bitrser (Nene Beiträge ete. pag. 10) hat unsere Form nichts gemein.

\section{Anomura.}

\section{Pagurus Damesii sp. n.}

Taf. VI, Fig. $9-9$ e.

Diese interessante Species ist leider nur in einem einzigen Exemplare erhalten, und auch dieses nur in sehr fragmentarischem Zustande. Das Fossil stellt sich so dar, dass am Ende eines etwas verdrülekten Steinkernes einer Gastropodenschale drei wrkrïmmte langre Füsse grleichsam aus dem Gestein herauszuwachsen scheinen. Man wird also nicht fehl gehen, wenn man annimmt, dass diese Füsse einem Kruster angehörten, der mit seinem weichen Hinterleibe in einem Gastropodengehäuse steckte. Der Verwesung und Zerstörung entgingen nur die härteren Theile, bei diesem Exemplar die drei ersten Beine. Vom Cephalothorax und den übrigen Füissen habe ich nichts beobachten können, und es stände noch zu erwägen, ob dieselben unter den drei ersteren verborgen liegen oder ob dieselben überhaupt nicht mit einem harten Panzer umgeben und demnach nicht erhaltungsfühig waren.

Vom ersten Fusspaar ist nur ein Theil der Hand des rechten Fusses erhalten ${ }^{1}$ ). Die Oberfläche desselben ist höckerig, in Folge zahlreicher, regellos darüber zerstrenter, spitziger oder gerundeter Iörnchen.

Die beiden folgenden Fusspaare liegen so, dass sie das erste und den etwa vorhandenen Cephalothorax von oben verhüllen. Von beiden sind je drei Glieder vorhanden; das erste Glied ist kur\%, ca. $12^{m+1}$ lang, aber nahe die Inalfte so breit wie lang, nämlich $6^{m m}$, und besitzt eine rechteckige Gestalt. Auf der Aussen-

1) In lïg. 9 al nicht ausgedrückt. 
seite läuft in der Mitte eine gebogene Längsfurche; die Oberflïche ist ebenfalls böckerig, die untere Kante aber mit einer Längsreihe spitzer Dörnchen bewehrt.

Das folgende Glied war etwa noch einhalbmal so lang, ca. $16^{\mathrm{mm}}$, aber weit schlanker und leicht in der Spiralrichtung des Gehäuses gebogen. Eine stumpfe Kante scheidet bei ihm eine schräg nach innen abfallende, fast glatte Oberseite von einer tuberkulirten Aussenseite. Die Ï̈̈kerchen sind noch kleiner und spärlicher als auf vorigem, und nur die Unterkante der Aussenseite ist mit einer, vielleicht auch zwei, Dornenreihen besetzt.

Das dritte und letzte Glied ist mindestens zweimal so lang wie das vorhergehende, aber noch viel schlanker, sehr stark gebogen und endigt vollkommen spitz. Der Querschnitt ist fünfseitig, und es sind die beiden äusseren (vielleicht auch die inneren) Kanten mit einer Längsreihe von kleinen, aber dicken, eylindrischen Knötchen besetzt, die in der Mitte ihrer schwach gewölbten Oberfläche ein kleines Grübchen (zur Einlenkung einer Borste?) tragen (Fig. 9e, vergrössert); im Uebrigen ist das Endglied glatt.

Vorkommen: Sehr selten in der Zone $A_{1}$.

Bemerkungen: Die generische Stellung dieser Art des ersten deutschen Vertreters der Gruppe der Paguriden kann noch nicht vollkommen als gesichert gelten. Man dürfte eigentlich nicht ohne weiteres einen Krebs, von dem nur die ersten drei Fussparre bekannt sind, von dem man jedoch weiss, dass der Hinterleib weich war und in einer Gastropodenschale steckte, nur aus letzteren Gründen, dem Genus I'ugurus zuzählen. Ebenso gut könnte man ihn Coenobita oder Bernhardus nennen, da diese beiden in der Sculptur der Beine sich in Nichts von Pagums unterscheiden, mithin hiernach eine Trennung fossiler, generisch verschiedener Formen nicht möglich ist. So lange eben nicht die inneren Antennen bei fossilen Exemplaren gefunden werden, so lange man nicht in der Lage ist, etwaige weiche Anbünge des Abdomen nachweisen zu können, so lange wird man sich dahin bescheiden müssen, die generische Bezeichnung Pagu'us für fossile verwandte Formen nur als Aushülfe anzusehen, welche möglicherweise ganz Verschiedenes in sich vereinigt. 
So weit mir bekannt, sind bisher nur zwei fossile Vertreter dieser Crustaceengruppe beschrieben oder wenigstens genannt worden.

Der eine, Pagune? Desmarestianus Serines, wird von Reuss ${ }^{1}$ ) aus Süd-Frankreich citirt, mit dem ausdrücklichen Ilinzufügen, dass von dieser Art nur der Name bekannt ist, dass es jedoch an einer Beschreibung mit Abbildung fehle.

Der zweite, Pagurus priscus, wird von Broccni²) aus dem Mittel-Miocän von Pest beschrieben. Dic betreftende Art wird auf einige Scheerenfiagmente gegriundet, und für sie gilt in noch höherem Maasse das oben für unsere samländische Art Gesagte. Diese aber ist trotz ihrer mangelhaften Erbaltung dennoch zur Leit als der bestbekannte fossile Vertreter der Paguriden anzusehen, und zwar gewinnt sie ein um so höheres Interesse, als sie die älteste Form dieser Crustaceengrupje repräisentirt.

\section{Macrura.}

\section{Iloploparia Klebsii sp. n.}

Taf. V11, Fig. 1-4a: Taf. VIII; Taf, IX, Fig. 1-1a.

Dieser Krebs erreicht durchschnittlich eine betrïchtliche Grösse. Exemplare, die mit ausgestrecktem Abdomen 40-50 Länge messen, sind die gewöhnlichen; daneben finden sich auch einzelne Scheeren, die auf noch grössere Längre hindeuten. Im Allgemeinen sind die Exemplare schlecht erhalten, stets mehr oder minder verdrückt, was bei ihrer Körpergrösse und einer relativ dünnen Schale nicht auffaillig ist. Am häufigsten sind einzelne, aber auch stets stark verdrückte Scheeren; dass Cephalothorax und Abdomen eines Individuums zusammen vorkommen, ist weit-seltener.

Der Cephalothorax besitzt den allgemeinen Habitus der Astacinen, bei einem der Exemplare misst er, das hostrum nicht

1) Denksehr. d. Wiener Akadem. d. Wiss. Math,-naturw. Cl. 1859, Bd. XVII, pag. 82.

2) Aunales des Sciences géologiques 1883, Bd. XIV, Art, 2 pag. 7, tab. 5 , tig 9. 
eingerechnet, 150mm, bei cinem anderen 200mm. Etwa in der Mitte seiner Länge läuft eine, im Anfing tiefe und breite, später etwas seichter werdende Nackenfurche in etwas nach vorn gewendeter Richtung dem Unterrande zu, ohne jedoch diesen selbst zu erreichen; etwa im letzten Drittel ihrer Länge zweigt sich nach rorn ein kleiner, gleichfills nach innen gerichteter Ast ab, der etwa in gleicher Höhe über dem Unterrande wie der Hauptzweig verschwindet.

In gleicher Höhe, wo sich der Seitenast von der Nackenfurche abzweigt, beginnt im vorderen Theile des Cephatothorax eine zweite, tiefe und breite Furche, die sich an ihrem unteren Ende in einen nach vorn und einen rückwärts gerichteten Ast gabelt. MCor hat sie mach ihrer Gestalt sehr treffend als $\approx \lambda$ like check furrow bezeichnet; der vordere Ast gabelt sich kurz vor seinem Ende noch einmal.

Kwischen den beiden Aesten der IIepaticalfurche, wie BELL dieselbe nennt, und zwischen ihrem hinteren Aste einerseits und der Cervicalfurche andererseits erhebt sich die Schale zu zwei gerundeten flachen Hügeln, deren hinterster der grössere ist.

Der Hinterrand des Cephalothorax ist in der Mitte ricmlich stark ausgeschnitten und wird in einiger Entfernung von einer Furche begleitet, die auf dem liücken nur schmal und flach ist, auf den Flanken jedoch an Breite und Tiefe zunimmt und fast bis zum Unterrande reicht.

Das Rostrum ist ziemlich lang, sehr schmal und trägt an seiner Aussenseite zwei kurze spitze Dornen; eine tiefe Liingsfurche, die sich rückwärts bis zur Nackenfurche fortsetet, halbirt dasselbe. Seitlich der Furche erheben sich auf dem Rostrum zwei starke gerundete Längskiele, die sich etwas auf den eigentlichen Cephalothorax fortsetzen, hier aber bald schwächer werden. In der Verlängerung beider Kiele und gleichsam als F'ortsetzung derselben laufen auf dem Rücken des Cephalothorax zwei lieihen länglicher, spitzer Dornen bis zur Nackenfurche, wo sie zusammentreficin.

Jenseits der letzteren findet sich nur eine mediane Reilse meist kleinerer, dichter gedrängter Döruchen, die bis zum Ilinterrande 
reicht. Sie beginnt mit zwei grösseren, in einer Querlinie stehenden Höckerchen, neben welchen, ziemlich hart an der Nackenfurche, noch ein gleiches steht. Die Augenhöhlen sind gross, von einem gewulsteten Rande umgeben.

Die Postorbitalleiste ist in Gestalt eines hohen, aber rasch niedriger werdenden Kammes entwickelt, der vorn in ein kurzes Dörnchen ausläuft; daneben, aber etwas weiter nach unten und hinten, stehen zwei hakenförmig nach vorn gebogene Dörnchen.

Der ganze Cephalothorax, mit Ausnahme des unteren Theiles der Flanken, ist vollkommen glatt; an dem unteren Rande der Flanken stehen jedoch zahlreiche, aber vereinzelte kleine Granulationen, die in ziemlich breitem Bande bis zum Hinterrande zu verfolgen sind, wo sie sich etwas nach oben ziehen.

Das Abdomen zeigt seine sieben Segmente bei den einzelnen Exemplaren mehr oder minder vollkommen erhalten; seine Gesimntlinge naig etwa derjenigen des Cephalothorax gleichkommen. Das erste Glied ist kürzer und schmaler als alle übrigen und seitlich nur in einen kurzen stumpfen Lappen ausgezogen. Das zweite, dritte, vierte und fünfte Segment besitzen alle etwa die gleiche Länge. Während aber vom dritten bis fünften Gliede die Seitenlappen stumpf zugespitzt sind, ist derjenige des zweiten Gliedes breit, mit abgerundeter vorderer und rechtwinkeliger hinterer Ecke.

Die fünf ersten Segmente besitzen je eine Querfurche, die rom Rücken bis zur Mitte der Seitenlappen herabläuft, von wo ab sie sich beinahe rechtwinkelig nach hinten und oben einbiegt. Mit Ausnahme des ersten Segmentes, wo sie dem Hinterrande genähert ist, liegt sie bei allen übrigen dem Vorderrande näher und scheidet somit einen vorderen schmaleren Theil, welcher ca. ${ }^{1}: \mathrm{s}$ der Gesammtlänge beträgt und unter das vorhergehende Segment geschoben werden konnte, von einem grösseren hinteren. Die Verlüngerung dieser Furche auf die Seitenlappen nimmt auf den letzten Segmenten an Deutlichkeit ab: auf dem zweiten Gliede ist sie am schärfsten und tief'sten, auf dem fünften kaum mehr erkennbar.

Das sechste Segment ist von gleicher Länge wie die vorher- 
gehenden, unterscheidet sich aber hauptsiichlich dadurch, dass bei ihm die Querfurehe dem Vorderrande näher liegt und die Seitenlappen nach hinten zu halbkreisförmig ausgeschnitten sind. Hieran lenkt die aus zwei Theilen bestehende Schwanzflosse vermittelst eines besonderen Schalenstückes ein. Ihr äusserer Theil ist schmal bandförmig und scheint aus zwei Gliedern gleicher Länge bestanden zu haben. Der innere, ans nur einem Stück bestehende Theil ist breit blattförmig.

Das letzte Segment ist bei keinem Exemplare vollständig erhalten; es ist aber beträichtlich länger als alle anderen und spitzt sich nach hinten ziemlich scharf $z u$; es trägt auf dem Rücken zwei breite Längskiele, die sich, ehe sie den Vorderrand erreichen, in einem flachen Querwulste vereinigen; ihr äusseres Ende ist durch einen ziemlich langen, parallel der Längsachse des Abdomen gerichteten Dorn bezeichnet.

Mit Ausnahme des letzten Segmentes, welches zerstreute kleine Höckerchen besitzt, sind alle übrigen mit eingestochenen Grübchen bedeckt, die auf den Seitentheilen etwas dichter stehen als auf" dem Rüicken.

Von den Füssen ist fast ausschliesslich nur das erste Patr sut erhalten, die eigentlichen Gehfüsse meist nur in rudimentären Stummeln, welche nichts Bemerkenswerthes bieten.

Die Scheerenfüsse überragen alle anderen an Länge und Stïrke; die ersten Glieder habe ich nicht beobachten können, erst vom Oberarm an sind die Glieder gut erhalten. Dieser letztere (Taffel VII, Fig. 4 und 4 a) besitzt eine dreiseitig pyramidale Gestalt und eine beträchtliche Länge; seine Aussenseite ist flach gewölbt, die Innenseite tief concav. Am Proximalende trägt er mehrere Dornen, von welchen derjenige der äusseren Vorderecke (a in Fig. 4) am lingsten ist und in eine tiefe Furche des Vorderarmes eingreift; an der inneren Vorderecke, etwas vom Rande entfernt, steht ein etwas kleinerer, nach oben gerichteter Dorn (b in derselben Figur) und an der unteren Ecke ein grosser, kräftiger Doppelzahn (c), zwischen dessen sehr ungleich grossen Spitzen ein schmaler Dorn (G) des Vorderarmes eingreift; etwas dahinter steht ein kleinerer spitzer Stachel (d). 
Der Forderarm besitzt eine gedrungen prismatische Gestalt und ist ziemlich stark gewölbt. Auf seiner Oberseite stehen drei lieihen schräg nach aussen und innen gerichteter Höcker, wovon die innerste leihe drei (A B C), die mittlere zwei (D E) und die äussere nur einen Höcker (F) zählt.

Der letztere steht an der kürzesten Stelle des Oberarmes und gleicht mehr einem schmalen, hoch erhabenen Lüngsrücken; die beiden mittleren sind zu einem zweispitzigen Längskamme verschmolzen: die tiefe Furche zwischen den beiden Rücken ist zur Autuahme des lingen Aussendornes (a) des Oberarmes bestimmt. Die drei Dornen (A B C) der innersten Reihe sind spitz-kegelförmig und stehen weit auseinander, der eine an Proximalende, der andere in der Nähe des Distalrandes und der dritte zwischen beiden, dem ersteren etwas genähert. Auf der Unterseite befindet sich am Proximalende, hart am Rande stehend, ein grosser spitziger Stachel (G), der, wie bereits erwähnt, zwischen die Spitzen des Doppelhöckers (c) des Oberarmes eingreift; weiter nach rorn, etwa in der Mitte der Länge, steht ein ziemlich grosser (II) und am Distalrande ein kleiner spitzer Dorn.

Die Scheeren waren gross, etwas comprimirt; die Oberseite ist flach, auf ihr länft hart an Aussenrande eine breite, seichte Furche, die sich nicht auf den unbeweglichen Finger fortsetzt: die Lnterseite ist bedentend stärker gewölbt, und hier läuft eine breite, tiefe Furche wohl bis zur Spitze des unbeweglichen Fin„eers. Der Ober- oder Innenrand der Hand (Taf. IX, Fig. 1a) trägt fünf spitze, seitlich comprimirte, kräftige Dornen, die in zwei Lüngsreihen - einer inneren oder unteren zu zwei, und einer äusseren oder oberen zu drei - stehen. Der Aussen- oder Unterrand der Hand war seiner ganzen Lünge nach bis zur Spitze des unbewegrlichen Fingers mit zwei Längsreihen kleiner spitzer Stacheln besetzt; etwas grösser stehen sie in nur einer Lüngsreihe auf der Aussenseite des beweglichen Fingers. Da, wo der bewegliche Finger einlenkt, trägt die Hand einen grossen plumpen, etwas weiter nach aussen einen kleineren, spitzen Höcker.

Die Finger sind sehr ungleich. Der bewegliche ist schmal, wahrscheinlich grade und trägt um Proximalende gegenüber 
dem srossen Höcker der Hand zwei etwas kleinere und spitze Dormen.

Der unlewegliche Finger ist mindestens noch einmal so breit wie der bewegliche und zerfällt durch die tiefe Furche der Unterseite in einen inneren hochgewölbten Theil von fast kreisförmigem Querschnitt und in einen äusseren seitlich comprimirten Theil, der grleichsam wie ein Kamm dem immeren aufsitzt.

Beide Finger sind auf ihren Innenseiten mit mächtigen, meist flachen oder stumf-konischen Zähnen besetıt ('Taf. VII, Fig. 2): eine bestimmte Folge in der Grösse scheint nicht obzuwalten: gewöhnlich überragt je ein Zahu des beweglichen und des unbeweglichen Fingers alle anderen an Grösse.

Es scheint, als ob zuweilen die beiden Scheeren eines Individuums beträchtliche Differenzen in der Grösse der Zühne aufweisen. Hierfür sprechen einige Fragmente, welche nur mit sehr feimen spitzen Zähnchen besetzt sind. Bei. dem auf Tat. VII, Fig. 3 abgebildeten Scheerenbruchstück sind beide Finger, mit Ausnahme eines grossen Zahnes, mit kleinen spitzen Zähnchen besetzt. Ob aber in der Regel die eine Scheere stets mit Zühnen geringerer Grösse bewafthet ist wie die andere, liess sich nicht feststellen; jedenfalls hat keine der beiden hierin einen Vorzug vor der anderen, da ich sowohl rechte wie linke Scheeren mit normaler wie verküumerter Bezalınung gefunden habe. Es dürfte die Abweichung demnach nur als zufällige individuelle Verkümmelung anzusehen sein.

Mit Ausnahme der zalihreich eingestochenen Pünktchen, welche Oberarm, Vorderarm und Scheere bedecken, ist die Schale vollkommen glatt.

Vorkommen: Häufig in den Thonknollen der Zone $\Lambda_{1}$.

Bemerkungen: Von allen Vertretern des Genus Hoplopuriu, welche bis jetzt beschrieben wurden, kinn un H. gammaroides BELL aus dem Londonclay mit unserer Art verglichen werden. Die sambandische Art unterscheidet sich aber auf den crsten Blick durch die reichere Sculptur auf dem hücken des Cephalothorax: die drei Dornenreihen, wie sie oben beschrieben, fehlen der englischen Form. 
Auch scheint es, als ob die Zähne der Scheeren der H. gammaroides bei normaler Entwickelung eine geringere Grösse erreichten und in ihrer Form von der kräftigen backzahnartigen Gestalt der II. K/ebsii abwichen. Doch scheint diesem Unterschiede nicht allzu viel Werth beigemessen werden zu dürfen: da das auf Taf. VII, Fig. 3 abgebildete Scheerenfragment gleichsam in die Mitte zwischen der Bezahnung von 11 . gammaroides und H. Klebsii füllt.

Es darf nicht unerwähnt bleiben, dass $H$. Klebsii durchschnittlich bedeutend grösser als $H$. gammaroides zu sein scheint. 


\title{
Vermes.
}

'lat. X.

\section{'T'ubicolate.}

\section{Serpula llagelliformis Soweris.}

\author{
Taf. X, Fig. 1 mud 2.
}

1815. Serpula flagelliformis Sowrens, Mineral Conchology. Bd. VII, pag. 50, tab. 634, fig. $2-3$.

1861. Serpula misera Maren, Faunula des marinen Sandsteines von Kkleinkulıreu. Vierteljahrsschr. d. naturw. Gesellsch. in Zürich. Bd. VI, Heft 1, pag. 121.

Die lange Röhre ist vielfach, aber unregelmässig schlangenartig hin und her gewunden. Die Mehrzahl der Exemplare zeigt gern die Form eines langgezogenen schmalen unregelmässigen IIufeisens. Thre Dicke ist sehr unbedeutend, das stärkste Exemplar misst am oberen Ende wenig mehr als $1^{\text {mm }}$ in Durchmesser und wird gegen die Spitze hin dünn und fadenförmig. Die Stärke der Wand ist ebenfalls sehr gering; der Querschnitt halb kreisförmig. Die Oberfläche ist glatt mit einigen gröberen concentrischen Wachsthumsringen. Die Röhre ist in ihrer ganzen Länge an fremden Körpern, gewöhnlich im Innern von Echiniden- oder Pelecypodenschalen, angeheftet. Diese Form kommt durchweg in Kolonien vor, deren einzelne Individuen in den mannigfachsten Verschlingungen durch einander gewunden sind.

Vorkommen: Nicht sehr häufig in der Zone $A_{1}$ und $A$, nach Sowerby in den Bracklesham Sands. 
Bemerknngen: Von dieser Art lag mir Mayel's Originalexemplar vor, das die Bestimmung Serpula miserc trägt. Ich konnte mich jedoch nicht von der specifischen Selbstständigkeit dieser Species, die alle Charaktere von SowErisy's S. flagelliformis trägt, ïberzeugen. Unsere Exemplare stimmen nicht nur in Bezug auf das kolonieenweise Vorkommen mehrerer Individuen, sondern auch vortrefflich in Bezug auf Gestalt und Biegung der liöhre mit der citirten Art übercin. SowERBr's Abbildungen zeigen sehr deutlich die verzerrt hufeisenförmige Biegung des älteren Theiles der Röhre, die natïrlich bei einzelnen Exemplaren mehr oder minder modificirt sein kann.

\section{Serpula exigua Sowerby.}

Tat. X, Fig. 3 und 4.

1815. Serpula exigue Sowerey, Mineral Conchology, Bd. VII, pag. 50, tab. 643, tig. 4.

Diese sehr kleine, kaum 1,5m im Durchmesser haltende Art besitzt eine anfings spiral nach rechts gewundene Röhre. Nach Beschreibung eines Umganges in horizontaler Ebene löst sich die liöhre los und und dreht sich nach oben. Die enggenabelte Spirale ist mit der Unterseite an fremden Körpern festgewachsen. Die ()herseite ist gewölbt, in der Mitte gerundet gekielt, und glatt. Die Wand ist ziemlich dick, der innere Querschnitt kreisförmig.

Vorkommen: Ziemlich häufig in der 'Lone $\mathbf{A}_{2}$, nach Sowerby im Bartonclay.

Bemerkungen: Die nahe verwandte oberoligocïne $S$. unbiliciformis GOLDF. unterseheidet sich durch eine grössere Zahl ron Windungen und schärfer gekielte Oberseite, die gleichfills unserer Art sehr gleichende S. comiculum GoLDF. aus dem Grobkalk unterscheidet sich ebenfalls durch eine grössere Zahl von Windungen.

Es mag dahingestellt bleiben, ob Sowlanx's fig. 4 a die Windumeg der Röhre richtigr wiedergiebt; nach der in natürlicher Grösso dirgestellen Abbildung seheint dies nicht der Fall zu sein. 


\title{
Serpula lieptagona Sowerir.
}

\author{
Taf. X, Fig. 5-11.
}

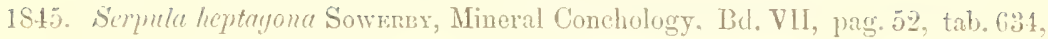
fig. 7.

1861 'Serpula ambuluerum Marer, Famula des marinen Sandsteines rou Kleinkuhren. Vierteljahrsschr. d. maturw. Gesellsch. in Zürich. Bit. VI, Heft 1, pag. 120.

Die gerade, nur anfangs leicht gekrümmte Röhre erreicht eine Länge von über $36 \mathrm{~mm}$; da der Durchmesser von der Spitze gegen die Mündung hin, wo er etwa $6^{m m}$ beträgt, nur sehr langsam an Grösse zunimmt, so besitzt die Röhre eine dentalienartige Form. Entweder ist die Röhre nur mit der Spitze oder auch mit einem kleineren Stück der unteren Partie an fremde Körper festgewachsen, der grössere obere Theil ist jedoch frei. Die Stärke der Wand ist gering, der innere Querschnitt kreisrund. Die Aussenseite ist mit sieben, durch gleiche Abstände getrennte Längsrippen geziert, welche von der Spitze bis zum Oberrande reichen. Im älteren Theil der Röhre sind die Rippen scharf, zuweilen hoch, kammförmig und dünn, gegen die Mündung hin werden sie kräftiger, wobei sie sich gleichzeitig mehr und mehr abrunden. Die Zwischenräume sind leicht concav, nur bei zweien derselben bemerkt man eine scharf eingerissene mediane Längsfurche. Die Oberfläche ist glatt oder in Folge der IVachsthumsstreifen etwas schuppig; letztere, die im Allgemeinen concentrisch laufen, beschreiben auf den gefurchten Zwischenräumen einen spitzen Winkel, dessen Scheitel in der Furche nach vorn liegt.

Bei den Exemplaren aus der Zone $A_{1}$ ist sehr häufig der Abdruck der Unterseite des Operculum vorhanden (Taf. X, Fig. !) und 11). Hiernach zu schliessen besass dasselbe etwas geringeren Durchmesser als das Lumen der Röhre und die leicht concave Unterseite war mit feinen, aber stacheligen Radialrippen bedeckt, wolche von einem, zuweilen schwach excentrisch gelegrenen Punkte. nach der Peripherie hinlaufen. Zuweilen schiebt sich nahe dem Rande zwischen je zwei stäkeren noch eine schwächere hadialrippe ein. 
Vorkommen: Hänfig in der 'Lone $A_{1}$ und seltener in $A_{2}$; in England im Bartonclay; in Belgien im Paniselien.

Bemerkungen: Diese Art ist von SowErisy in den verschiedensten Abänderungen vortreftlich abgebildet, wie sich dieselben auch unter den samländischen Exemplaren wiedererkennen lassen. Junge Exemplare der Serpule heptugonu sind insofern schwer von Serpula crassa Sow. zu unterscheiden, als bei denselben gewöhnlich drei der Längrsippen stärker wie die übrigen, kaun angredenteten, ausgebildet sind; daher ihr äusserer Querschnitt mehr dreiseitig wie bei jener wird, namentlich wenn die Rippen lamellenartig werden und die Röhre sich an einem fremden Körper fest geheftet hat. Es wird aber, wie bereits SowERBy bemerkt, bei einiger Aufmerksamkeit gelingen, wenigstens Andeutungen von zwei oder mehreren Längsrippen zu finden.

Was MAYER unter Serpulu ambulacmum verstanden hat, vermag ich nicht zu eruiren. Wahrscheinlich hat er junge Exemplare der Serpula heptagona, die mit einem grösseren Stück der liöhre fest gewachsen waren, verkannt; wenigstens dentet seine Bemerkung, dass "Grösse und Form der Röhre im Allgemeinen mit der Facies der Serpula crassı Sow. übereinstimmen«, darauf' hin.

\section{Ditrupa strangulata DESH. sp.}

$$
\text { Tar. X, Fig. } 12-17 \text { a. }
$$

1825. Dentulum strangulatum Desnares, Monographie du genre Dentalium, pag.372, No. 39, tab. 16, fig. 28.

Die schlanke, schwach gebogene, cylindrische Röhre wird etwa his $18^{m m}$ lang; ihre Dicke ist gering, sie beträgt $1,5-1,75^{\mathrm{mm}}$ am unteren Ende und nimmt nach obenhin nur wenig zu; kurz unterhalb der Mündung nimmt die Dicke jedoch wieder ab, so dass die cylindrische Röhre am oberen Ende gleichsam einen kurzen konischen Aufsatz trägt. Die Wand ist im Allgemeinen ziemlich dick, an der Mündung jedoch papierdünn und daher der Rand scharf schneidend. Sowohl am oberen wie am unteren Ende ist die Röhre geöflnet. Die Aussenflïche ist glatt, hie und da mit einigen leichten $\mathrm{W}$ achsthumsrunzeln. 
Vorkommen: Sehr häufig in der Zone $A_{1}$, vereinzelt in $A_{2}$. Nach Nyst im ganzen belgischen Tertiär verbreitet, ferner in England und Frankreich.

Bemerkungen: Die samländischen Exemplare gleichen vollkommen solchen, die ich aus der Etage Laekenien besitze. Bemerkenswerth ist das Vorkommen in der Zone $\mathbf{A}_{1}$; wïhrend in $\mathbf{A}_{2}$ nur einzelne Individuen meist recht wohl erhalten vorkommen, treten sie in $A_{1}$ kolonieenweise und unregelmässig durch einander gehäuft auf. Da aber in $A_{1}$ alle kalkigen Schalen zerstört sind, so sieht man hier nur cylindrische Hohlräume, in deren Mitte sich ein Steinkern befindet, der beim Aufschlagen der Thonknollen heransfüllt, so dass nur eine genane Prüfung eine Identitiat mit dem Vorkommen in $\mathbf{A}_{2}$ erweisen lässt. 

Lieferung VI.

Fehinodermated.

Taf. I-VI. 



\title{
Echinodermata.
}

\section{Echinoidea.}

\author{
Coelopleurus Zaddachi sp. n.
}

Taf. I, Fig. $1-7$.

Die Schale besitzt die durchschnittliche Grösse der Coelopleuren und zeigt einen gerundet fünfseitigen Uniriss. Die Oberscite ist mässig grewölbt, die Unterseite flach, am Rande etwas aufgetrieben. Bei etwas grösseren Exemplaren sind die Ambulacralfelder schwach über die flachen Interambulacralfelder erhoben.

Die Porenzonen bestehen aus einfachen, nicht gejochten, runden Porenpaaren, die im oberen Theile in gerader, im unteren Theile leicht gewellter Linie vom Scheitel zum Munde laufen. Dünne spitze Dörnchen treten häufig zwischen den einzelnen Porenpaaren auf, wo dieselben etwas weiter stehen als anf der Unterseite. Die Porenzone selust besitzt kaum die Hälfte der Breite der Interporiferenzone. Zwei dicht neben einander stehende Warzenreihen laufen in der Mitte der Ambulacra rom Scheitel zum Munde, wobei die einzelnen Warzen nach beiden Richtungen etwas an Grösse abnehmen. Die Warzen selbst sind verhältnissmässig gross, undurchbohrt und glatt, von kleinen runden, einander fast berührenden Höfchen umgeben; die Zahl einer Reihe beträgt etwa 8-10. Einige wenige Körnchen finden sich zwischen beiden Reihen in den einspringenden Winkeln, daneben sind unregelmässig zerstreut feine Dörnchen über das ganze Ambulacralfeld verbreitet. 
Auf der Unterseite bemerkt man in nächster Nähe des Peristoms zwischen den beiden Hauptwarzenreihen vier bis sechs rechteckig gerundete Eindrücke, die sich bei den Abdrücken als kleine Knötchen darstellen.

Die Interambulacralfelder sind beinahe doppelt so breit wie die Ambulacralfelder und mit vier Warzenreihen, aus etwa 4 bis 5 Warzen bestehend, besetzt, von welchen die beiden inneren aus Warzen gleicher Grösse wie die der Ambulacralfelder bestehen, wïhrend diejenigen der beiden äusseren aus etwas kleineren Warzen zusammengesetzt sind. Die vier Warzenreihen sind nur anf die Randtheile und Unterseite beschränkt und nehmen nach dem Peristom an Grösse ab. Körnchenwarzen und Dörnchen finden sich in gleicher Weise zerstreut wie anf den Ambulacralfeldern; zuweilen häufen sich die Dörnchen am oberen Ende der beiden inneren Reihen.

Auf dem oberen Theile der Ambulacralfelder ordnen sich die Körnchenwarzen zu einer Reihe an, welche zwischen je einer inneren und ausseren Hauptwarzeureihe entspringt und bis zum Scheitelschilde läuft. Die Körnchenwarzen dieser Reihe sind abwechselnd grösser oder kleiner, zuweilen noch durch einzelne feinere Dörnchen getrennt. Die beiden Reihen begrenzen ein breites glattes Mittelfeld, dessen unterer Theil bei günstiger Erhaltung schwache, zickzackförmig hin und her laufende Furchen zeigt. In dem Raume zwischen diesen Reihen und den Ambulacralfeldern treten ebenfalls spärliche Körnchen auf, ohne sich jedoch zu einer Reihe auzuordnen, die man als Fortsetzung der beiden äusseren Hauptwarzenreihen ansehen könnte.

Dis Scheitelschild ist ziemlich gross, mit grosser runder, von einem Saume eingefasster Afterlücke. Die fünfseitigen, ausgebreiteten Genitaltäfelchen sind weit durchbohrt und mit vier bis sechs Körnchenwarzen geziert, die um die Afterlücke hinter dem Saume einen Kreis bilden. Die kleinen Ocellartäfelchen tragen nur ein Wärzchen, das im Vereinigungspunkte je zweier interambulacralev Körnchenwarzen-Reihen liegt.

Das Peristom ist rund, gross, mit deutlichen, aber wenig tiefen Einschnitten. 
Die nur in Bruchstücken resp. deren Abdrücken bekannten Stacheln besitzen runden Querschnitt und waren wohl ziemlich lang, nach oben etwas zugespitzt; ihre Oberflïche ist mit licht gredrängten tiefen Längsfurchen bedeckt, die ihrerseits wieder fein quergestreift sind.

Vorkommen: Häufig in der Zone $A_{1}$.

Bemerkungen: Coelopleums Zaddachi besitzt grosse Verwandtschaft mit zwei bereits bekannten Arten, mit C. Tournoueri Cotteau, ganz besonders aber mit C. Dellosi Desirarest. Erstere Art unterscheidet sich einmal sehr leicht durch die grössere Zahl kleinerer Warzen der Ambulacralfelder, besonders aber durch die zwei Reihen von Secundürwarzen, welche zu beiden Seiten des glatten Mittelfeldes bis zum Scheitel reichen.

Weit grösser ist die Verwandtschaft mit (. Delbosi, und ich habe mich daher nur schwer dazu entschlossen, die samländische Art neu zu benennen.

Der Hauptunterschied beider Arten besteht in der etwas verschiedenen Länge der äusseren Warzenreihen der Interambulacralfelder. Bei C. Delbosi treten dieselben, wenn auch an Grösse der Warzen abnehmend, auf die Oberseite, reichen aber nicht bis zum Scheitelschilde, sondern verschwinden vorher. Die betreffende Stelle in Cotteau's Beschreibung lautet: "Les rangées latérales sont plus petites et les tubercules dont elles se composent diminuent encore de volume à la face supérieure, deviennent très-espacés et forment, sur le bord des zones porifères, une rangée qui disparaît avant d'arriver au sommet«. Bei Coelopleums Zudduchi dagegen treten an der betreffenden Stelle nur kleine, nicht in einer Reihe angeordnete Körnchenwarzen auf', die aber ebenfalls nicht bis zum Scheitelrande reichen. Es entsteht nun die Frage, hat man diese Körnchenwarzen als Fortsetzung der äusseren Hauptwarzenreihe anzusehen oder nicht? Ich will diese Frage nicht entscheiden, sondern nur bemerken, dass mir in einem Falle durch ein beträchtlich kleineres Hauptwärzchen der Uebergang zwischen der Hauptwarzenreihe und den folgenden Körnchenwarzen f'estgestellt erschien, immerhin war jedoch der Abstand beider zu schroff, um letztere als directe Fortsetzung der ersteren auffassen zu können. 
Sollte sich aber die oben gestellte Frage bejahen, so wiire C. Zaddachi einzuziehen und mit C. Delbosi zu vereinigen, da die anderen Charaktere namentlich mit CoTTEAU's Abbildung sehr gut harmoniren. Es ist vor Allem das granulirte Scheitelschild, dessen Afterlücke bei beiden von einem Wärzchenkranze umgeben ist, die Uebereinstimmung der »cordelette très-régulière des gramules allongés , welche das glatte Mittelfeld der Interambulacralfelder begrenzen, mit der Körnchenwarzenreihe am gleichen Platze bei C. Zaddachi. Ferner ist auch bei Cotreau's fig. 7 der Raum zwischen der »cordelettes und der Porenzone ohne Warzenreihe genau so, wie er sich bei unserer Art darstellt. Allerdings sieht man bei fig. 6 die äussere Würzchenreihe dentlich bis in die Nähe des Scheitelschildes reichen, was annehmen lässt, dass fig. 7 etwas verzeichnet ist.

Weniger stimmt C. Zaddachi mit 'Tounnouen's Abbildung des Coclopleums Delbosi überein, und wenn man hiernach einzig und allein schliessen wollte, so wären beide Arten sicher verschieden. Die äussere Wärzchenreihe ist sehr stark ausgebildet und reicht fist vollstïndig bis zum Scheitel. Auch ist die Wölbung, namentlich aber die Grösse des Peristoms, eine andere. Letzteres zeigt einen viel geringeren Durchmesser als bei unserer Form.

Die gleichen Unterschiede gelten aber auch im Vergleich von Tounnouer's C. Delbosi mit CotTeau's C. Delbosi; ganz besonders ist noch hervorzuheben, dass bei Tounover's Abbildung die »cordelette auf den Interambulatralfeldern fehlt. Ich neige demnach der Ansicht zu, dass Tounnouer's Form einer anderen Art zugehört.

\section{Baueria gen. nov.}

Mässig grosse Seeigel, von rundem oder gerundet-fünfseitigem Umrisse. Ambulacralfelder beträchtlich schmaler als die Interambulacralfelder. Poren rund und nicht gejocht, in geraden Zonen vom Scheitel zum Munde laufend. Warzen ungekerbt und undurchbohrt. Die Hauptwarzenreihen nur auf den unteren Theil der Interambulacral- und Ambulacralfelder beschränkt, deren oberer Theil mit Körnchenwarzen, Dornen oder verticalen und zickzack- 
förmig hin und her luffenden Leistchen seziert ist. Peristom etwa 0,5 des Gesammtdurchmessers betragend, schwach eingeschnitten. Scheitelschild ausser den fünf' grossen Genitalporen mit deutlichen Ocellarporen. Afterlücke klein, central gelegen.

Stacheln rund, lang, etwas zugespitzt und fein lïngs gekerbt. Hierher gehören die Arten:

\section{Banteria Agassizii d'Archiac sp ${ }^{1}$ ).}

1846. Coelopleurus Agassizï $\mathrm{D}^{2}$ Ancume, Deseription des fossiles ree. par M. Thorest dans ees couches ì Nummulines des envirous de Bayoune. Mém. de la Soc. géologique de France, 2. série, tome 11, pag. 205, tals. 111 , lig. $2,1,1$, , , , 1.

aus den Nummulitenschichten von Bayonne.

\section{Bateria geometrica Noething.}

Vorkommen: In der Zone $\mathbf{A}_{1}$ des samländischen Tertiärs sehr hïufig, sehr selten (nur in einem Exemplar) in der Zone $A_{2}$.

Bemerkungen: Das oben charakterisirte Genus besitzt eine grosse Verwandtschaft mit Coelopleums, unterscheidet sich aber didurch, dass die Warzenreihen der Ambulacralfelder ebenso wie diejenigen der Interambulacralfelder nur anf die Unterseite und den Rand beschränkt sind; bei Coelopleurus reichen die Warzenreihen der Ambulacralfelder dagegen bis zum Scheitel. Ferner ist bei Buneric der obere Theil der Interambulacralfelder ausser mit den Längsleisten mit zickzackförmig hin und her lanfenden Querleisten, die mit Körnchen besetzt sind, geziert, während bei Coclopleurus dieser Theil entweder glatt oder nur mit schwachen, zick/zackförmigen Furchen versehen ist. Ausserdem scheint die Afterlücke bei Baueria relativ kleiner als bei Coclopleurus zu sein.

Es könnte den Anschein haben, als ob die Abtrennung genumnter beiden Arten von Coelopleurers und die Aufstellung eines neuen Genus nicht gerechtfertigt wäre. Ich glaube aber, ein derartig bedentender Unterschied der Schalsculptur, welchen die genannten Arten im Vergleich mit typischen Coelopleurus-Formen

1) Des leichteren Vergleiches halber gebe ich hier die Copie von n'Arcunce's Coelopleurus Ayassizii wieder (vergl. unten die Texttafel Fig. 6-(ib)). 
zeigen, genügt, um dieselben auszuscheiden, zumal die Diagnose des Genus Coelopleums, wie dieselbe von DESor atufgestellt ist, für unsere Formen nicht mehr zutriftt. Da überdies der Unterschied in der Schalensculptur ein leicht in die Augen springender ist, zwei geogruphisch weit getrennte Arten denselben aber gemeinsam besitzen, so scheint die Aufstellung des neuen Genus hinlïnglich begründet.

\section{Baneria geometrica sp. n.}

Taf. II, Fig. 1-9.

Eine ziemlich kleine Art, die in ihrer durchschnittlichen Grösse betrïchtlich hinter der französischen zurückbleibt. Die Gestalt schwankt zwischen gerundet-fünfseitigem und nahezu kreisförmigem Umriss. Die Oberseite ist in der Regrel wenig gewölbt, die Höhe der Schale entspricht etwa ibrem halben Durchmesser; einzelne Individuen sind aber etwas aufgetriebener, so dass die Schale stumpf-konisch wird; ich habe solche Formen als var. conica bezeichnet. Die Unterseite ist flach, am Rande etwas gewölbt.

Die Porenzonen bilden gerade Bänder, die nur auf der Unterseite leicht gewellt und aus ungejochten Porenpaaren zusammengesetzt sind; eine Verdoppelung der Porenpare findet nirgends statt, dagegen besteht auf der Unterseite die innere Porenreihe aus grösseren Poren als die äussere, wie die Steinkerne am besten zeigen. Die Porenzonen sind beträchtlich schmaler als die Interporiferenzone, was allerdings auf den Steinkernen nicht sehr deutlich ist.

Die Ambulacralfelder (Taf. II, Fig. 8, vergrössert) sind schmal, etwa halb so breit wie die Interambulacralfelder, und auf ihrer unteren Hälfte mit zwei Reihen zu je etwa 8 bis 9 kleinen Hauptwarzen besetzt. Die Wärzchen sind ungekerbt und undurchbohrt Ind nehmen nach dem Munde zu in Grösse ab. Auf' der Unterseite stehen sie so dicht gedrängt, dass die kleinen elliptischen Höfchen in einander fliessen, nach oben rücken sie etwas auseinander, wobei dicht gedrängte kleine Granulationen sich zwischenschieben; eine Reihe gleicher, dicht gredrïngter Körnchen scheidet auch die beiden Hauptwarzenreihen. 
Als Fortsetzung der beiden Hauptwarzenreihen laufen auf der Oberseite zwei convergirende Längsleistchen, die mit etwa (j bis 7, in umregelmässigen Abständen auf einander folgenden, fein längsgestreiften Dornen von plump-cylindrischer Gestalt besetzt sind. Zwischen den einzelnen Dornen finden sich kleine Körnchenwarzen: wo sie in unregelmässigen Zickzacklinien stehen, zuweilen so eng, diss sie undeutliche Leistchen bilden.

Die breiten Interambulacralfelder (Taf. II, Fig. Sa, vergrössert) sind mit vier Reihen zи zwei Paaren angeordneten Hanptwarzen von gleicher Beschaffenheit wie diejenigen der Ambulacralfelder besetzt, diese aber ebenfalls nur auf die untere Hälfte beschränkt. Sowohl auf der Aussenseite als zwischen beiden Paren bilden die kleinen, dicht an einander gedrängrten Granulationen Längsreihen; in unteren Theile, wo die Hauptwarzen eng an einunder stehen, fehlen zwischen denselben die kleineren Granulationen; nach oben, wo sie weiter aus einander rücken, treten letztere anch zwischen ersteren anf:

Der obere Theil der Interambulacralfelder zeigt vier mit Dornen von gleicher Beschaffenheit wie auf den Ambulacralfeldern besetzte Längssleistchen; die beiden äusseren, etwas stärkeren, nchmen ihren Anfang zwischen je einer äusseren und einer inneren IIuptwarzenreihe und laufen in der Weise nach oben, dass zwei benachbarte Interambulacralfelder convergiren und sich in einen besonders starken, auf' den Ocellartäfelchen, dicht über dem Anfang der Porenzonen gelegenen Dorn vereinigen. Die beiden schwächeren inneren Längsleisten, welche in der Fortsetzung der beiden inneren Inaptwarzenreihen liegen, convergiren mach der Mitte des Feldes und vereinigen sich in einem, dicht an der Afterlücke gelegenen, cbenfalls hervorragend starkem Dorn der Genitaltäfelchen. Die Dornen dieser vier Längsreihen sind durch zickzackmässigr hin und her laufende Querleistchen verbunden, die mit Körnchenwarzen bedeckt sind; letztere treten übrigens auch zerstrent auf der ganzen oberen Hälfte der Interambulacralfelder atuf.

Das Scheitelschild (Taf. II, Fig. 9, vergrössert) ist mittelgross, aus fünf von einer grossen Pore durchbohrten Genitaltäfelchen und fünf von kaum sichtbar durchbohrten Ocellartïfelchen bestehend. 
Tedes der Tüfelchen trïigt einen besonders sturken Dorn, wovon diejenigen der Genitaltäfelchen am äusseren Ende derselben dicht über den Porenzonen liegen. Dic letyteren waren mit ersteren durch gerade, mit Granulationen besetzte Leistchen verbunden, so dass auf dem Scheitelschilde ein zierlicher fünfstrahliger Stern entsteht, dessen Felder gleichfalls Granulationen tragen.

Die kleine runde Afterlücke war, wie ein einziges Exemplar zeigt, von vier schwach gewölbten, gleichgrossen Täfelchen bedeckt.

Das Peristom ist etwa gleich 0,5 des Gesammtdurchmessers, gerundet-fünfseitig, an den Ecken schwach eingeschnitten.

In engster Verbindung mit den Steinkernen und Abdrücken dieser Art kommen vielfach Abdrüicke von Stacheln vor, die derselben aweifelsohne angehört haben. Aus diesen Fragmenten lïsst sich schliessen, diss dieselhen ron kreisförmigem Querschnitt, ziemlich lang und nach oben etwas zugespitzt waren. Die Gelenkfläche, ebenso wie der kurze Stachelkopf, waren glatt, der Stiel selbst fein längsgefurcht, und die Längsfurchen wieder quer grekerbt; der Stachelring ist mit kleinen Knötchen besetzt, welche den Längsfurchen entsprechen.

Eine ähnliche Oberflächensculptur haben jedenfalls auch die Dornen der Intermbulacralfelder und des Scheitelschildes besessen.

Vorkommen: Sehr häufig in der Zone $A_{1}$; in einem Exemplar in der Zone $\mathrm{A}_{2}$ gefunden.

Bemerkungen: Bauric yeometrica ist wahrscheinlich der "Echinus in ZADDACH's Tertiärgebirge des Samlandes, kann aber diese Bezeichnung nicht behalten. Sie unterscheidet sich von allen verwandten Arten besonders durch die charakteristische Sculptur der Interambulacralfelder und des Scheitelschildes.

Grosse Aehnlichkeit zeigt sie mit Coclopleurne Agarsizii. Dieser unterscheidet sich aber besonders dadurch, dass ihm die beiden inneren Längsleisten der Interambulacralfelder, sowie die Dornenreihen auf dem oberen Theile der Ambulatcralfelder fehlen. Im Grossen und Ganzen war C. Agassizii weniger reich seulpturirt als die samländische Species; er scheint auch etwas grösser zu sein. 


\section{Salenia.}

\section{Salenia Pellati Cotteac.}

Taf. II, Fig. $1-1$ b.

1860. Salenic Pellati Cotrrat, Éhinides noureaux ou per connus. Rer. et Mag. de Zool., pag. 40, tab. IT, fig. 11-14.

Schale von kreisförmigem Umriss; die Oberseite ziemlich hoch, gewölbt, Unterseite anscheinend flach, blos an den Ründern etwas gewölbt.

Die Porenzonen waren nicht genau zu beobachten, anscheinend aber von geradlinigem Verlauf; über Grösse, Anordnung der einzelnen Porenzonen, liess sich nichts feststellen, nur dass sie kaum halh so breit wie das Mittelfeld sind. Die Ambulacralfelder sind sehr schmal und mit zwei Reihen von etwa 11 bis 12 kleinen, gehöften (?), etwas entfernt stehenden Wärzchen besetzt, die nach dem Scheitel zu an Grösse abnehmen. Beide Reihen sind durch eine Mittelreihe kleiner dichtstehender Gramulationen getrennt.

Die Interambulacralfelder sind mehr als doppelt so breit als die Ambulacralfelder und tragen zwei Reihen Hauptwarzen von ziemlich ungleicher Grösse; eine oder zwei, in der Mitte der Höhe stehend, zeichnen sich durch Grösse aus, während die anderen beträchtlich kleiner sind; soweit beobachtet werden konnte, betrug die Zahl einer Reihe nicht über vier.

Die Hauptwarzen sind von schmalen, in einander fliessenden Höfchen umgeben, die auf der Innen- und Aussenseite mit einem Kranz von Secundärwarzen besetzt sind. Ǩleinere Granulationen treten zerstreut hie und da auf.

Leider konnte in Folge der Erhaltungsweise nicht untersucht werden, ob die Stachelwarzen gekerbt und durchbohrt waren.

Das Scheitelschild ist von bedentender Grösse und beträichtlich über die Schale erhaben. Soweit die Erhaltung dessen Zusammensetzung zu studiren erlaubt, kann man noch drei grosse Genitaltäfelchen und ebenso viel kleinere Ocellartäfelchen, sowic ein ïberzähliges in der Mitte erkennen. Die Sculptur der Täfolchen 
war nicht zu beobachten, verschiedene Spuren denten jedoch darauf hin, dass diesclben nicht glatt, sondern mit radialen Furchen versehen waren.

Afterliicke und Peristom waren nicht erkennbar.

Vorkommen: Nur ein einziges Exemplar in der Zone $\mathrm{A}_{1}$. In Frankreich im Terrain nummulitique ron Biarritz.

Bemerkungen: Es schien anfangs zweifelhaft, ob die samlïndische Form mit der südfranzösischen Art zu vereinigen sei. Vor Allem war der bedentende Grössen-Unterschied in Betracht zu zichen, - die samländische Form ist fast dreimal so gross als die französische -, dann konnte, wie erwähnt, nicht beobachtet werden, ob der Warzenhals gekerbt war und ob sich an den Porenpaaren eine gleiche Granulation wie bei jener befände. Schliesslich hat mich aber die Uebereinstimmung in der Anordnung und Ausbildung der Haupt- und Secundärwarzen bewogen, unsere Form mit der französischen zu identificiren. Da letztere nur in zwei, erstere nur in einem Exemplar gekannt ist, so ist es nicht unwahrscheinlich, dass von jener sich grössere, von dieser kleinere Exemplare finden werden, oder dass der Grössen-Unterschied durch locale Variation hervorgerufen ist.

\section{Ec hinoeyamus.}

\section{Lehinocyamus piriformis Agassiz.}

Taf. III, Fig. 2-91).

1861 ? Runn Henschei Mayer, Vierteljahrsschrift der Naturforsch. Gesellsch. iu Zürich. Bd. 6, Heft 2, pag. 120.

(Weitere Synonymie ef. Tounsouer, Recensement des Eehinodermes etc., Actes de la société Limncénne de Borleaux, Bil. XXVIII, 1870-72, pag. 269.)

Die Mehrzahl der im samländischen Tertiär gefundenen Exemplare zeigt einen längs-ovalen Umriss, doch variirt derselbe ungemein, wie TourNouer dies anch an den französischen Formen beobachtet hat. Regelmässig längs-ovale Exemplare, die weder nach vorn, noch nach hinten verschmälert resp. verbreitert sind (Fig. 2), sind selten, häufiger sind die von birnförmigem Um- 
riss, d. h. hinten etwas breiter, vorn verschmälert (Fig. 4); daneben treten Exemplare von gerundet-fünfseitigem Umriss auf (Fig. 3), die in der Mitte am breitesten, nach vorn und hinten verschmälert sind. Letztere leiten zu Formen von fast kreisförmiger Gestalt (Fig. 8) hinüber, die anscheinend den samländischen Tertiärablagerungen eigenthümlich sind. Die Oberseite ist mehr oder minder gewölbt, bei der Mehrzahl der Exemplare flach niedergedrückt, bei den selteneren, kreisrunden, dagegen fast halbkugelig gewölbt. Die Unterseite ist bei der Mehrzahl der Exemplare vollkommen flach, bei einzelnen Individuen aber leicht aufgetrieben, zuweilen in der Mitte um das Peristom herum leicht eingesenkt. Der Rand ist mehr oder minder stumpf gerundet.

Die Ambulacrafelder sind subpetaloid, an den Enden leicht geöfthet, zuweilen leicht erhaben. Die Porenzonen sind etwas schmaler als die Interporiferenzone und bestehen aus wenigen, ungejochten Porenpaaren, die in beträchtlicher Entfernung vom Rande verschwinden; die innere Reihe ist gerade, die äussere leicht gebogen.

Das Peristom ist klein, kreisrund und liegt vollkommen central.

Die Afterlücke ist gleichfalls rund, aber weit kleiner, zwischen Peristom und Hinterrand, im Allgemeinen gleich weit von beiden gelegen, doch variirt ihre Lage etwas. Bei Fig. 3 liegt sie etwas weiter vom Peristom entfernt als vom Hinterrand, bei Fig. 9 dagegen demselben stark genähert.

Das Scheitelschild ist klein, zuweilen in Form eines kleinen Knöpfchens erhaben und mit vier deutlichen Genitalporen versehen.

Die Oberfläche ist mit zahlreichen, dicht gedrängten kleinen Wärzchen von gleicher Grösse bedeckt, die von einem schmaleu tiefen Höfchen umgeben werden.

Die Steinkerne ähneln sehr denjenigen der Scutellinu Michelini, unterscheiden sich aber sofort durch die inframarginale Lage der Afteröffnung, sowie durch die weniger starken Einschnitte der radiären Scheidewände.

Vorkommen: Häufig als Steinkern in der Zone $\mathbf{A}_{1}$; ebenso mit erhaltener Schale in $\mathbf{A}_{2}$. In Frankreich vom Eocïn bis Miociän, nach Tournoukr sogar noch lebend. 
Bemerkungen: Tournouer hat 1. c. dieser Art eine äusserst eingehende und lehrreiche Besprechung gewidmet, und kann ich dessen Beobachtungen in Bezug auf die Variation des Umrisses und Schwankungen in der Lage des Afters bestätigen. Dass aber diese Formverschiedenheiten bestimmte Niveaus reprïsentiren, muss ich nach den samländischen Funden bezweifeln, denn hier kommen alle diese verschiedenen Formen neben einander in dem Sande der Zone $\mathrm{A}_{2}$ vor.

Das Samland hat eine bis jetzt nene Varietït geliefert, die ich, dem Beispiele Tournouer's folgend, mit var. C. oder conicu bezeichnen möchte. Den Typus derselben stellt Fig. 5 dar: der Umriss ist wechselnd, es giebt kreisrunde, fünfeckige etc. Individuen, ebenso schwankt die Lage des Afters bei ihnen recht be-

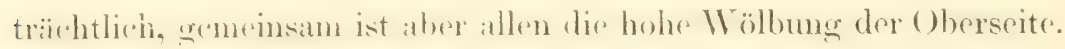

Wenn man die beiden extremsten Formen, welche das Samland geliefert, \% B. Fig. 4 und Fig. 9, vergleicht, so drängt sich die Frage auf, ob es nicht zweckmïssig sei, sie zu trennen und mit besonderem Namen zu belegen. Nach eingehender Untersuchung von ea. 30 Individuen konnte ich mich aber nicht dafür entscheiden, denn beide Extreme sind durch eine Reihe von Zwischenformen verbunden, die eine Trennung beider nicht zulässig erscheinen lassen.

Dass Echinocycmus propinque. Fonßss, wie neuerdings CotTead ${ }^{1}$ ) annimmt, von unserer Art zu trennen sei, glaube ich nach eingehender Vergleichung der genannten Literatur und von Exemplaren aus Belgien mit den samländischen Formen verneinen zu dürfen. Es ist mir unmöglich, Exemplare, wie meine Fig. 4, von Cotteav's E. propinques zu unterscheiden, da auf sie alle Hauptmerkmale zutreffen, welche CoTteav für erstere Art als charakteristisch bezeichnet, z. B. die weniger fünfseitige Gestalt, die mehr nach hinten gerückte Lage des Afters; andererseits konnte ich mich aber anch, wie gesagt, nicht dafür entscheiden, die Formen von Fig. 3 oder 9 abzutrennen.

1) Cotteau, Description des Echinides tertiaires de la Belgique. Mémoires conr. de l'Académ. roy. de la Belgique 1S80, Bd. XLIII, pag. 39 u. 40. 


\section{Lenita Desor.}

Desor betont in der Diagnose des Genus das Fehlen der inneren Scheidewände (point de cloisons à l'intérieur") und betrachtet dies negative Merkmal als einen gewichtigen Unterschied des Genus Lenita von Scutellina und Echinocyamus, denen ersteres in der äusseren Form gleiche. Lenita beweise hierdurch trotz des verschiedenen äusseren Ansehens mehr Verwandtschaft mit Fibularice als mit jenen.

Ich kann diese Ansicht berichtigen. Sowohl durch gut erhaltene Steinkerne als auch durch directe Beobachtung vermitteltst Anschleifen liess sich das $V$ orhandensein von regelmässig angeordneten Scheidewänden im Innern mit Sicherheit feststellen. In der Anordnung besitzen diese Scheidewände grosse Uebereinstimmung mit Scutellina; hiernach muss eine Verwandtschaft mit Fibularic ausgeschlossen werden, hingegen gewinnt die durch die äussere Form bereits angedeutete Verwandtschaft mit Scutellina und Echinocyames durch das Vorhandensein gleicher innerer Merkmale mehr Wahrscheinlichkeit.

Lenita patellaris (Leske) Agassiz.

$$
\text { Taf. IV, Fig. 1-5a. }
$$

(Synonymio ef. Cotreau, Échinides tertiaires de la Belgique. Múmoires couronnés de l'Académie royale de Bolgique 1880, pag. 44.)

Ein kleiner, ziemlich flacher Seeigel, im Allgemeinem von längs-ovalem Umriss, der jedoch mehr oder minder bedentenden individuellen Schwankungen unterliegt. Bei einzelnen ist die Schale vorn etwas verbreitert und zugespitzt, hinten dagegen stark verschmälert und zugespitzt (Fig. 1); andere sind vorn verbreitert, aber abgerundet (Fig. 2); andere zeigen regelmässig längs-ovale, vorn und hinten gerundete Gestalt (Fig. 3), und wieder andere sind vorn verschmälert und gerundet, hinten verbreitert, aber zugespitzt (Fig. 4). Ich habe nicht geglaubt, in diesen kleinen Schwankungen der Form mehr als individuelle Variation erblicken zu sollen, um so mehr, als atuch belgische Exemplare dieselben Schwankungen zeigen. 
Oberseite schwach gewölbt, nach den Seiten abschüssig, älterc Exemplare hierdureh in der Medianlinie schwach gekielt erscheinend. Unterseite meist vollkommen flach, zuweilen an den Rïndern etwas aufgebogen.

Ambulacra mässig gross, nicht bis zum Rande reichend, subpetaloid und an den Enden geöffnet. Porenzonen aus runden ungejochten Porenparen in geringer Zahl gebildet, die am Rande und auf der Unterseite vollkommen fehlen. Auffallender Weise sind selbst bei den wohlerhaltensten Individuen des Krantes die Porenzonen nur sehr schwer zu erkennen, - bei den belgischen Exemplaren ist dies übrigens auch der Fall, - dentlich bemerkt man sie nur an den Steinkernen der Zone $\mathrm{A}_{1}$.

Peristom klein, gerundet fünfseitig, genan central gelegen und nicht vertieft.

Afterlücke klein, rund, supramarginal, aber etwas vom Hinterrande entfernt.

Die Oberfläche wird von zwei Arten von Warzen bedeckt; sehr feine, schwach, aber deutlich gehöfte Wärzchen sind auf die Oberseite beschrïnkt, welche sie dicht gedrängt in unregelmässiger Anordnung hedecken; die anderen, bedentend grösseren Wärzchen sind ron einem tiefen Höfchen umgeben, treten aber nur auf der Unterseite anf, wo sie zwei breite, durch ein scheinbar glattes Band aretrennte Zonen zu beiden Seiten des Peristoms bilden. Unter der Lupe bemerkt man jedoch, dass die anscheinend glatte Zone mit zahlreichen dicht gedrängten Körnchen bedeckt ist, die vereinzelt auch zwischen den Warzen auftreten.

Dis Scheitelschild liegt central, ist aber sehr klein und undentlich; mit der Lupe erkennt man auf den Schalen sehr selten die vier Genitalporen, anf den Steinkernen (Taf. IV, Fig. 5 a, vergrössert) bemerkt man sie auch ohne Iupe, in seltenen Fällen daneben fünf Ocellarporen.

Im Krante sind die Schalen immer erhalten, in der Zone $\boldsymbol{\Lambda}_{1}$ dagegen nur die Steinkerne, die sich leicht von den sehr åhnlichen Scutellinen - Steinkernen unterscheiden lassen. Da ich durch die Einsehnitte der Steinkerne zuerst auf das Vorhandensein innerer 
Scheidewïnde aufmerksam wurde, so beschreibe ich dieselben etwas eingehender.

Betrachtet man den Steinkern Fig. 5 a von oben, so sicht man, dass in den Ambulacralfeldern zwei tiefe convergirende Einschnitte einen dreieckigen Lappen begrenzen, dessen Aussenseite schwach gebuchtet ist; auf den Interambulacralfeldern begrenzen diese Einschnitte einen schmaleren, trapezförmigen Lappen, der seinerseits durch einen mittleren, etwas kürzeren Einschnitt in zwei schmale Zipfel zerspalten ist; der dem hinteren Interambulacralfeld entsprechende Lappen ist nicht getheilt und trägt den Abdruck des Afters. Die Unterseite bietet nichts Bemerkenswerthes dar.

Davon, dass diesen Einschnitten in der That Scheidewïnde im Innern der Schale entsprechen, habe ich mich, wie gesagt, durch Anschleifen überzeugt.

Vorkommen: Im Samlande sowohl in den Zonen $\mathbf{A}_{1}$ und $\mathbf{A}_{2}$, in letzterer häufiger; in Belgien nennt Cotread dieselbe nur aus der Etage Laekenien.

Bemerkungen: Eine genaue Beschreibung dieser Art hat CoTTEAu mitgetheilt. Sie ist hier der Vollständigkeit halber wiederholt. Auch waren kleine Abweichungen zu verzeichnen, die ohne genauere Beschreibung schwer verständlich geblieben wären.

\section{Sentellina.}

Sentellina Michelini Cotreau sp.

Taf. III, Fig. $10-16$ a.

1S61. Simondia Michelini Cotreau, Échinides noureanx ou peu connus. Rer. et Mag. de Zoologie, 1861, pag. 49, tah. VII, fig. $13-15$.

Die verhältnissmässig kleine Art zeigt im Allgemeinen einen gerundeten, schwach fünfseitigen Umriss und ist meist etwas länger als breit, doch variirt diese Form etwas, indem auch fast kreisförmige oder vielmehr ovale Individuen vorkommen; im ersteren Falle ist die Schale nach vorn verbreitert und zugespitzt, nach hinten verschmälert und abgestutzt; zuweilen ist der Hinterrand schwach gebuchtet. 
Die Oberseite ist mässig gewölbt, der höchste Punkt der Wölbung liegt central; die Riinder sind stumpf und gerundet, die Unterseite ist flach und in der Mitte etwas vertieft.

Die Ambulacralfelder sind kurz, subpetaloid, an den Enden weit geöfthet; die Porenzonen schmäler als die Interporiferenzone, aus weniger entfernt stehenden, nicht conjugirten Porenparen bestehend. Die Poren der äusseren Reihe sind etwas grösser als die der inneren. Auf der Unterseite laufen in der Mitte der Ambulacralfelder schwache Furchen dem Munde zu.

Das kleine Peristom ist ron gerundet-fünf'seitiger Gestalt und liegt central.

Das Periprokt ist ebenfialls klein, rundlich und liegt entweder so hart marginal, dass der Hinterrand dadurch leicht gebuchtet ist, oder es liegt etwas inframarginal, immer aber hart an Hinterrande. In letrterem Falle ist es von der Unterseite vollkommen sichtbar, im ersteren Falle nur zum Theil.

Das Scheitelschild liegt central, ist von runder Gestalt und obwohl ziemlich klein, immer deutlich sichtbar; zuweilen, namentlich bei kleineren Exemplaren, ist es als flaches Knöpfchen erhoben (Taf. III, Fig. 15). Vier grosse Genitalporen (Fig. 10) sieht man bei fiast allen Individuen.

Die Oberfläche ist mit zahlreichen, vollkommen gleichmässigen, dicht gedrängten kleinen Wärzchen bedeckt, die von einem schmalen tiefen Höfchen umgeben sind.

In Innern der Schale (Fig. 13) Iaufen zu beiden Seiten der Ambulacralgefässe niedrige radiäre Scheidewände, die, von fünf hohen, aber meist abgebrochenen Auriceln ausgehend, die Schale in fünf grössere (den Ambulacralfeldern entsprechend) und fünf' kloinere Kimnern (den Intrambulateralfeldern entsprechend) theilen. In den Ambulacralkammern erheben sich anf der Únterseite flache concentrische Runzeln, die durch einen glatten radialen Streifen gespalten werden. Durch diese Runzeln wird auf der Unterseite der strinkerne vine charakteristische, fiederförmige Zeichnung (Fig. 13) hervorgebracht, woran die im Uebrigen den Steinkernen der Lenita patellaris sehr ähnlichen Steinkerne leicht keuntlich sind. 
Vorkommen: In der samlïndischen Glatukonitformation sowohl in der 'Lone $A_{1}$ als auch in $A_{2}$ verbreitet, doch in letzterer häufiger. CotTeat nennt diese Species aus dem Eocïn des Plateau du Four (Loire-Inférieure.)

Bemerkungen: Cotrast stellte diese Art zu Sismondia, bezweifelte aber selbst diese generische Bestimmung. Gegen die Zugehörigkeit zu Simmondia sprechen die nicht conjugirten Porenpiare - eine Beobachtung, die übrigens CorTEAU auch anführt -, die kurzen, nicht verlängerten Porenzonen, sowie die einfichen radiären Scheidewände. Coтresu begründete seine Ansicht, wonach Scutellina Michelini eine Sismondiu sei, hauptsächlich auf die inframargrinale Lage des Afters hin. Abgesehen davon, dass keine unzweifelhafte Sismondienspecies bekannt ist, deren After so hart marginal liegt, habe ich oben nachgewiesen, dass durch die hart marginale Lage der Afterlücke dieselbe bei der geringsten Schwankung inframarginal liegt. Ich kann mich nicht dazu verstehen, auf diesen Unterschied der Afterlage, der einen unmessbaren Theil eines Millimeters beträgt, einen generischen Unterschied zu begründen, da alle anderen Merkmale für Scutellina sprechen.

Nahe verwandt mit unserer Art ist Scutellina lenticularis des Pariser Beckens, und auch Correav hat auf diese Verwandtschaft bereits aufmerksam gemacht. Hiemach unterscheidet sich S. Michelini - wie ich überdies aus eigener Anschaumg bestätigen kann - von S. lenticularis durch die stärker gewölbte Oberseite, den stumpfen gerundeten Rand und die etwas gröberen Tuberkeln.

\section{Echinarachuius van PHeLs.}

In der Monographie der Scutellides pag. 68 hat Agassiz dieses Genus wieder hergestellt und die Unterschiede von den Scutellen im engeren Sinne dahin prïcisirt, dass es sich, obgleich jenen sehr ähnlich, durch mehr kreisförmigen Umriss, etwas geöftnetere Ambulacren, und besonders durch die marginale Lage des Periprokts anszeichne.

Halten wir zunächst an dem letztgenannten Charakter, der marginalen Lage des Afters, fest, so bringt ArAssiz selbst 
eine Ausnahme hiervon, da bei seinem E. incisus DEFr. sp. die Afterlücke inframarginal liegt.

In der Synopsis hat Desor demnach auch die Lage der Afterlücke als marginal oder inframarginal angegeben, da auch der von ihm angeführte $E^{*}$. Juliensis DESOR einen inframarginalen After besitzt.

Bei den recenten Formen liegt bei E. parma und atlanticus der After marginal, bei $E$. Rhumphii meist supramarginal, zuweilen auch marginal. Die letztere Schwankung zeigt auch E' porpita Desor aus der Umgegend von Bordeaux, wenn das von TourNover l. e. pag. 15, fig. 6 abgebildete grössere Fragment wirklich dieser Art angehört, im anderen Falle zeigte E. porpita nur supratmarginale Lage der Afterlücke.

Nimmt man nun auch mit Desor an, dass $E$. incisus $A_{G}$. eine Sismondia ist, so ergiebt sich doch aus obiger Auseinandersetzung, dass bei Echinarachnius je nach den Arten die Afterlücke zwischen infra- und supramarginaler Lage schwankt, demnach bei der Bestimmung fossiler Formen nicht gut zu verwerthen ist ${ }^{1}$ ).

Da ferner auch die Form der Ambulacra, - E. atlanticus besitzt z. B. fast ganz geschlossene Ambulacra -, und die äussere Gestalt der Schale wenig von Scutella abweichen, die nur einfach gegabelten Ambulacralfurchen der Unterseite aber nur in den seltensten Fïllen bei fossilen Exemplaren dentlich sichtbar sind, so wäre es schwierig, hierher gehörige Formen sicher zu bestimmen, wenn man nicht die erwähnte Einschränkung in Bezug auf die Lage des Afters zugeben will.

Es ist mir jedoch geglückt ein anderes, sicheres Merkmal in der Anordnung der einzelnen Kalkpfeiler, welche im Innern den peripheren Theil der Schale der Echinarachnius-Arten einnehmen,

1) Ich enthalte mich der Entscheidung, ob innerhalb generischer Grenzen derartige weite Schwankungen zulïssig sind. Sollte aber, was ich vermuthe, E. Juliensis nicht hierher gehören, so wären die Schwankungen in der Lage der Afterlücke weit geringer, denn lebende wie fossile Formen zeigten danu entweder cine marginale oder supramarginale $\Lambda$ fterlücke; und dieser Mehrzahl steht E. Juliensis mit inframarginalem After in der That etwas fremdartig gegenüber. 
antzufinden. Ilieranf brachte mich zunächst ein angreschliflenes Exemplar der Scutellu germanica BEYT, welche an den raudlichen Theilen diese Kalkpfeilerchen in einem sich wiederholenden arabeskenartigen Muster angeordnet zeigte.

Ich zerschnitt demnächst ein von AGassiz als $L$. parma (vergl. unten die Texttafel Fig. 7) bestimmtes Exemplar dieses Genus und war in hohem Grade ïberrascht durch die anfallende Aehnlichkeit in der Anordnung der randlichen Pfeilerchen der recenten mit der fossilen Art.

Um aber sicher zu gehen und um mich nicht über den Werth der Anordnung dieser Kalkpfeilerchen zu täuschen, zerschnitt ich ein Exemplar des wahe verwandten Abachnoides placentule und find hier allerdings auch die Kalkpfeilerchen in einem bestimmten Muster gruppirt, das aber von demjenigen des Echinarachnius ganz verschieden ist.

Soweit mir bekannt und aus der Literatur ersichtlich, findet im peripherischen Theil der echten Scutellen keine regelmässige Gruppirung der Kalkpfeilerchen statt, der Rand ist mit solchen regellos erfüllt, Echinarachnius und Arachnoides zeigen dagegen regelmässige Anordnung der Kalkpfeilerchen, wie ich sie im Folgenden nach einem recenten Exemplar beschreibe (vergl. unten die Texttafel Fig. 7).

Zunächst zeichnen sich die Interambulacralfelder durch zwei nahestehende radiale Scheidewände aus, welche divergirend vom Rande bis zur Mitte der Höhe reichen; in den vorderen vier Interambulacralfeldern treten zwischen denselben zwei oder drei bedentend kurze auf, während im analen Interambulatralfeld dieselben fehlen. Man kann hiernach, selbst wenn die Porenzonen der Ambulacra nicht mehr deutlich sein sollten, die Afterlücke auch nicht mehr vorhanden ist, die Exemplare sehr leicht orientiren.

Der breite Raum zwischen den radiären Scheidewänden, entsprechend den Ambulacralfeldern, wird von mehr oder ininder lingen, zuweilen verzweigten oder auch nur einfache Pfeilerchen bildenden Kalkleistchen eingenommen, die in concentrischen Kreisen angeordnet sind. Genau entsprechend der Mitte der Ambulacralfelder läuft ein schmaler radialer Zwischemram, der diese Kalkpfeilerchen in zwei Gruppen scheidet. 
Die Gruppirung selbst lisst. sich mit Worten kaum wiedergeben. Die unten folgende Texttafel stellt sie in Fig. 7 besser dar, als eine weitläufige Beschreibung dies zu thun vermag. Es kam hier wesentlich darauf an, die allgemeine Anordnung und den Unterschied derselben in den respectiven Feldern zu demonstriren.

\section{Echinarachnius germanicus BEYRICH sp.}

$$
\text { Taf. IV, Fig. } 6-12 \text {. }
$$

1548. Scutella germanica Beynicti, Zur Kenntniss des tertiären Bodens der Mark Brandenburg. Katstex's und v. Decuen's Archiv f. Mineralogie ete. Bd. 22, pag. 101.

1850. Scutella germanica Emax und Henteri, Ueber Tertiärschichten, welche die den Bernstein-führende Brannkohle an der samlïndischen Ostseeküste bedecken. Zeitschr, d. Deutsch. geol. Ges., Bd. 2, pag. 410.

155S. Scutelle fyerminans Desor, Synopsis, pag. 234.

1S60. Scutella germinans Maxer, Die Faunula des marinen Sandsteines von Kleinkuhren hei Künigsherg. Vierteljahrsschr. der naturf. Gesellsch. in Zürich. Bd. VI, Heft 2, pag. 120.

Schale von fast kreisförmigem, bei jüngeren Exemplaren etwas elliptischem Umriss und dann etwas länger als breit; in letzterem Falle vorn verschmälert und gerundet, hinten verbreitert und stumpf zugespitzt; letzterer Charakter tritt aber nur bei jüngeren Individuen deutlich hervor, die dann beinahe fünfseitigen Umriss zeigen. Oberseite fast ganz flach, nur in der Mitte über die flacheren peripherischen Theile etwas aufgetrieben, daher ein hutförmiges Profil zeigend. Unterseite vollkommen eben. Rand scharf und schneidend, leicht gewellt.

Ambulacralfelder sehr klein, weniger als die Hälfte der Entfermung rom sicheitelschild lis zum liande betragend, suhpetaloid und ungleich.

Das vordere unpaare Ambulacrum ist am längsten und am Ende vollkommen geöffinet ${ }^{1}$ ). Die Porenzonen bestehen aus zahlreichen gejochten Porenpaaren, etwa ebenso breit wie die Interporiferenzone; die innere Reihe, aus runden Poren zusammengesetzt, ist

1) In der Abbildung Fig. 10a aus Versehen geschlossen dargestellt. 
vollständig gerade, die äussere heihe mit schlitzförmicren Poren ebenfalls fast gerade, nur am oberen Ende leicht gekrïmmt.

Die parigen Ambulacra sind von ungleicher Grösse, die vorderen etwas länger als die hinteren, am Ende fist vollständig geschlossen. Porenzonen etwas breiter wie die Interporiferenzone, ebenfalls aus gejochten Porenparen gleicher Zusammensetzung wie ersteres bestehend. Innere Porenreihen gerade, äussere stark sckrïinmt.

Auf der Innenseite der Ambulacralfelder sieht man, genau wie bei dem recenten Exemplar, die eigenartige Stellung der einem Porenpar entsprechenden Poren, indem nämlich die inneren Poren vollkommen senkrecht, die äusseren aber sehr schief zur Achse der Ambulacra stehen; sämmtliche Poren sind durch schmale Furchen, in denen man wohl die Rimnen für die einzelnen Ambulacralfüsschen zu erblicken hat, verbunden, und entsprechend der Porenstellung sind die Furchen, welche eine äussere und eine innere Reihe verbinden, schrïg, diejenigen, welche die beiden inneren Reihen verbinden, horizontal gerichtet.

Auf der Unterseite setzen sich die Ambulacra in Gestalt schmaler, kamm sichtbarer Furchen fort, welche sich anscheinend dicht in der Nähe des Mundes, einmal gabeln.

Das Peristom ist klein, rund und liegt genau central.

Das Periprokt ist ebenfalls klein, von ovaler Gestalt, auf der Oherseite nahe dem Hinterrande am Ende einer seichten Furche grelegen (Taf.IV, Fig. 7). Nach dem Alter variirt die Entfernung der Afterlïcke vom Hinterrande etwas; bei kleineren Exemplaren liegt sie demselben näher als bei grösseren Individuen.

Das Scheitelschild ist klein, aber fast bei allen Schalen zerstört, weshalb es auch nicht ausreichend genau untersucht werden konnte. Es liegt anscheinend ganz central oder etwas nach vorm, stets aber im höchsten Punkte der Schale. Die vier grossen Genitalporen waren deutlich, auch wohl auf der Aussenseite, die fünt kleinen Ocellarporen dagegen nur auf der Innenseite der Schale zu sehen.

Die Oberfläche ist mit zahlreichen, aber nicht sehr dicht gedrängten, gleichmässigen, kleinen Wärzchen bedeckt, die von einem schmalen, tiefen Höfchen umgeben werden. 
Der periphere Theil im Innern der Schale (Taf. IV, Fig. 10) ist mit zahlreichen, mehr oder minder gebogenen Kalkpfeilerchen erfüllt, deren Anordnung eine ähnliche wie bei dem recenten Exemplar ist, nur dass sich eine Tendenz zu stärkerer Verzweigung der einzelnen Kalkpfeilerchen kund giebt; die Anordnung ist dadurch etwas mehr arabeskenartig als bei $E$. parma (vergl. unten die 'lexttafel Fig. 7).

Man sieht aber noch deutlich bei E. germanicus die radialen, wenn auch stark zerrissenen und verzweigten Hauptleisten der Interambulacralfelder; mit Ausnahme des analen Interambulacruns, wo der Zwischenraum zwischen den Hauptleistchen frei bleibt, schieben sich zwischen diejenigen der übrigen Ambulacra secundire, aber doch ziemlich lange verzweigte Radialleistchen ein.

Das breite Feld zwischen den interambulacralen Leistchen, entsprechend also den Ambulacralfeldern, ist mit Kalkpfeilerchen in meist concentrischer Anordnung, wie das vordere Ambulacrum noch deutlich zeigt, erfüllt; durch starke Verzweigung ist die concentrische Stellung jedoch etwas verwischt; eine glatte Rinne, entsprechend der Mittellinie des Ambulacrums, theilt auch hier die Kalkpfeilerchen in zwei Gruppen. Die Abbildung bringt diese Verhältnisse besser zum Ausdruck, als die Beschreibung sie zu geben vermag.

Vorkommen: Sowohl in der Zone $A_{1}$ (hier nur als Steinkerne), als auch in der Zone $A_{2}$ (meist mit wohl erhaltener Schale).

Bemerkungen: Berrich hat unsere Art zuerst als Scutella germanica beschrieben. Leider aber war in Folge eines Druckfehlers S. germanica zu lesen. Daraus hat dann Desor S. germinans gemacht und MAYER diesen corrumpirten Namen ohne weiteres acceptirt.

Es kann nicht befremden, dass Berrici diese Art für eine Scutella hielt, denn der ganze Habitus sprach ohne weiteres dafür. Dass ich in Bezug auf die generische Stellung anderer Ansicht geworden bin, verdanke ich einzig und allein einem sehr reichlichen Material, welches mir eine eingehende Untersuchung wichtiger systematischer Charaktere, wie Lage des Afters, Anordnung ler peripheren Kalkpfeilerchen etc., ermöglichte, Merkmale, 
die BEXrici nicht untersuchen konnte. Ich muss hierbei ansdrücklich hervorheben, dass in Folge der eigenthümlichen Erhaltungsweise die Exemplare des Krantes (und solche hat Berricn untersucht) fast niemals die Lage des Periproktes zeigen, Beyticn dasselbe daher auch nicht beobachten konnte.

Nach den oben mitgetheilten Untersuchungen kamn die generische Stellung des E. germanicus nunmehr als gesichert gelten.

In seiner bereits mehrfach citirten Abhandlung hat Tounnover eine Species aus den Asterienkalken vou Bordeaux als Echincrachnius porpita DEson beschrieben, der die grösste Achnlichkeit mit unserem E. germanicus zu besitzen scheint. Leider aber ist seine Abbildung zu wenig zulänglich, um hierüber Gewissheit zu erlangen. Sollte sich aber die Identitit beider Formen bestitigen, so müsste die jüngere Speciesbezeichnung germanicuš der ïlteren "porpitas weichen.

\section{Lechinolampas.}

\section{Echinolampas subsimilis d'A richrac.}

Taf. IV, Fig. $13-14$.

(Literaturnachweise ef. DAsres, Die Echiniden der vicentiniselien ete. Tertiürablagerungen. Palaeontographica Bd. XXIV, 3. F. I, pag. 38.)

Schale von ovalem, fist schwach fünfseitigem Umrisse, hinten etwas breiter als vorn, aber stumpf zugespitzt. Oberseite hoch gewölbt; der Punkt höchter Wölbung im Scheitelschilde, excentrisch nach vorn liegend; Profillinie von hier in mässiger Krümmung nach hinten, etwas steiler nach vorn abfallend. Unterseite flach, nur in der Mitte um das Peristom schwach concav.

Die Ambulacralfelder schwach erhaben, von sehr ungleicher Grösse: das unpaare ist schmäler und kürzer als die anderen, da es nur bis in die Mitte der Entfernung zwischen Scheitelschild und Rand reicht, und am Ende geöffuet. Die Porenzonen sind gleich lang und bestehen aus runden gejochten Porenparren. Die vorderen paarigen Ambulacra sind schwach gekrümmt, breiter und beträchtlich länger als ersteres. Die Porenzonen derselben sind sehr ungleich: die hinteren gekrümmten, etwas stärker 
als die vorderen, reichen bis zu zwei Drittel der Entfernung zwischen Scheitelschild und Rand; die vorderen geraden messen etwa die Hälfte der Länge.

Die hinteren Ambulacra sind am lïngsten; ihre ziemlich geraden Porenzonen besitzen fast die gleiche Länge, die nur wenig kürzer als die der äusseren ist. Auf Steinkernen - und nur solche liegen mir vor - setzen hier die beiden inneren Porenreihen eines jeden Ambulacrums über das Ende der Petaloiden bis zum Peristom fort.

Mundlücke queroval und deutlich pentugonal, in schwacher Einsenkung, genau dem Scheitelschilde gegenüberliegend. Periprokt quer-elliptisch, etwas grösser als erstere, hart am Hinterrande gelegen.

Scheitelschild stark excentrisch nach vorn gerückt, leider bei keinem meiner Exemplare erhalten. Schalenoberfliche nicht erhalten.

Vorkommen: Selten in der Zone $A_{1}$, ferner im Eocïn von Biarritz und im veronesischen Tertiür.

Bemerkungen: Am besten sowohl in Bezug auf Beschreibung als Abbildung stimmt die samländische Echinolampas-Art mit D'Arcunac's Form überein. Besonders hat mich aber die Ausbildung der Porenzonen der verschiecienen Ambulacra, die Daves 1. c. genaner beschreibt, bewogen, unsere Form mit jener zu identificiren.

\section{Sclizaster.}

Schizaster acuminatus Agassiz.

Taf. V, Fig. 1-2b.

(Synonymie ef. Cotriau, Deseription des Eehinides tertiaires de la Belgique. Mémoires cour. de l'Acad. royal de la Belgique, Bd. XLlII, 1S80, pag. 65.)

Ausser dem vorzïglich erhaltenen Abdruck eines Theiles der Oberseite eines grösseren Exemplares besitze ich noch ein verhältnissmässig vollständig erbaltenes, kleineres Individuum. Mit Hülfe beider war es möglich, die Art sicher und gut zu bestimmen, doch musste auf die Beschreibung einiger Theile, wie Hinter- und 
vollständige Unterseite, verzichtet werden, da sie nicht erhalten waren; es ist dieser Mangel jedoch ron keiner Bedeutung für die Bestimmung.

Die Grösse der Schale ist sehr schwankend, ihr Umriss herzförmig, vorn etwas verschmälert und gebuchtet, in der Mitte am breitesten, hinten leicht zugespitzt. Oberseite hoch gewölbt; die Profillinie fällt vom höchsten Punkt, der auf dem Kiele des hinteren Interambulacrums etwas hinter dem Scheitelschilde liegt, in schräger Kichtung nach vorn; nach hinten krümmt sie sich steil dem Hinterrande zu.

Das vordere Ambulacrum liegt in einer langen, geraden und tief'en, an den Kändern gekielten Furche, die den Rand stark buchtet und auf der Unterseite bis zum Peristom reicht. Bei einzelnen Individuen ist die Furche breit, verhältnissmässig flach und verschmälert sich mit dem Aufhören der Porenzonen gegen den liand hin etwas; bei anderen Individuen ist sie schmal, tief und verengt sich gleichfalls dem Rande $z u$; ich weiss nicht, ob die schmale Furche anf Verdrückung zurückzuführen ist. Die letzteren Individuen stimmen sehr gut mit einem etwas verdrückten Exemplar von St. Gilles, während erstere grössere Uehereinstimmung mit Cotreau's fig. 16 zeigen.

Das Ambulacrum selbst ist lang und gerade und unterscheidet sich dadurch von den parrigen Ambulacren, dass es aus zwei Reihen kleiner, dicht geurüngter, schräger Porenpaare besteht, die in schmalen Furchen liegen und durch kleine Bälkchen getrennt sind.

Die paarigen Ambulacren sind gleichfalls sehr stark vertieft, aber an Grösse sehr ungleich; die vorderen sind lang, stark divergirend und leicht $\mathrm{S}$-förmig gekrümmt, die hinteren kaum die Hälfte so lang, stehen sehr nahe und sind am unteren Ende vollkommen abgerundet.

Die Porenzonen, welche zum Theil auf den Wänden der concaven Ambulatren liegen, bestehen aus etwas verlängerten Poren, die durch eine deutliche Furche verbunden sind; die einzelnen Pare werden durch niedrige Leistchen geschieden. Die Interporiferenzone ist bei sämmtlichen paarigen Ambulacren schmaler als die Porenzone. 
Die Interambulacralfelder sind im oberen Theile schmal und zwischen den concaven Ambulacralfeldern stark erhoben; das hintere ist, wie bereits erwähnt, scharf gekielt.

I) as Scheitelschild ist excentrisch nach hinten gerïickt und etwas verlängert; man beobachtet zwei äussere hintere und zwci kleinere vordere Genitalporen (Taf. V, Fig. $2 \mathrm{~b}$, vergrössert). Die Ocellarporen sind wenig dentlich.

Die Oberfläche ist mit kleinen crenulirten und durchbohrten, dicht gedrïngten Wärzchen bedeckt, die auch im vorderen Ambulacralfeld auftreten, während die hinteren glatt sind. Anscheinend nehmen die Wärzchen rom Scheitel nach dem Rande an Grösse zu; sicher beobachten konnte ich nur, dass die Ambulacra von einem Saume etwas grösserer Wärzchen eingefasst sind.

Die Peripetalfasciole, sowie Spuren der Lateralfasciole sind deutlich erkennluar.

Vorkommen: Sehr selten in der Zone $\mathbf{A}_{1}$. CotTeau führt die Art aus den Sables ypresiens supérieurs, dem Laekenien inférieur und dem Wemmelien an.

Bemerkungen: Auch in Ostpreussen scheint die Grösse des Sch. acuminutus in ähnlicher Weise zu variiren, wie CotTEAU dies ron belgischen Exemplaren beschreibt. Auffallend ist mir bei Cotteav's Abbildung, dass er vier Genitalporen angiebt, in der Beschreibung aber nur von zweien spricht; auch sind in fig. 14 die Wärzchen nicht crenulirt gezeichnet, wie es die generische Diagnose verlangt.

Im Uebrigen stimmen die samländischen Formen recht gut mit den belgisehen überein, bis auf eine Verschiedenheit des vorderen Ambulacrums. Cotreat bildet in fig. 11 die Ambulacra vergrössert ab; hieraus ersieht man, dass sich die vordere Furche anscheinend nach dem Rande hin nicht verschmälert und die Porenparare nicht in Furchen, die durch Bäkchen getrennt werden, liegen.

Was nun den letzteren Charakter anhetriftt, so ist er selbst nicht einmal hei den hinteren Ambulacren, deren Poren doch gewiss durch tiefe Furchen verbunden sind, in der Zeichnung ausgedrückt; es ist also immerhin möglich, dass im vorderen Ambulacrum, wo die Furchen und Bälkchen im allgemeinen weniger deutlich sind, dies Merkmal iibersehen wurde. 
Was die Verschmälerung der vorderen Furche nach dem Rande hin angeht, so habe ich bereits bemerkt, dass ein belgisches Exemplar der Etage Laekenien dieselbe dentlich zeigt. Ferner zeigt diese Verschmälerung Golnfuss's fig. $2 \mathrm{a}$, die von Comtrau auch ausdrücklich in der Beschreibung erwähnt wird; ebenfalls zeigt diese Figur die Furche im vorderen Ambulacrum.

Demnach harmoniren in Bezug anf Ausbildung der vorderen Furche die samländischen und ein Theil der belgischen Exemplare mit GoLdruss's Abbildung, während ein anderer Theil der helgischen Exemplare davon abweicht. Da aber CoTTEAU selhst diese Formen mit Golofuss's Abbildung identificirt, so darf in dieser Variation kein wichtiger Unterschied erblickt werden.

Da Schizaster acuminatus von Unter- bis ins Ober-Eocän reicht, wäre es auch möglich, dass die Ausbildung der vorderen Furche je nach dem Niveau verschieden ist.

\section{IIaretia.}

\section{Maretia Sambiensis Berrich sp.}

Taf. V. Fig. $6-8$.

1848. Spratumyn: Srambiensis Bexricru, Zur Kenntniss des tertiatren Bodens der Mark Brandenburg. Karstex's u. v. Denchex's Arehir f. Bergbau ete. Bd. XXII, pag. 100.

1961. Memispatemuns Regiomontanus Mayre, Dic Faunula des marinen Sandsteins von Kleiukuhren. Vierteljahrsschr. der naturf. Gesellsch. in Zürich. Bd. TI, pag. 119.

Schale von breit herzförmiger Gestalt, wenig länger als breit; vorn breit-gerundet und seicht gebuchtet, hinten verschmälert und gerade abgestutzt. Oberseite mässig gewölbt, nach den Seiten dachförmig abfallend. Der Punkt höchster Wölbung liegt im hinteren, flach erhabenen Interambulacralfeld, in etwa ein Drittel der Entfernung zwischen Scheitelschild und Rand. Die Profillinie fällt von hier etwas steiler nach hinten als nach vorn ab. Die Hinterseite ist senkrecht abgestutzt; die Unterseite flach, nur um das Peristom herum vertieft, das Plastron, namentlich im hinteren Theile, flach erhaben (Fig. 7). 
Die Ambulacralfelder sind etwas vertieft und ungleich, das vordere unpaare in einer seichten Furche gelegen und in Folge des Erhaltungszustandes bei keinem der Exemplare dentlich sichtbar. Die geringen, am Ende etwas geöftheten Ambulacren, besitzen unter sich die gleiche Länge, aber etwas verschiedene Breite; die beiden breiteren vorderen divergiren unter sehr stumpfem Winkel; ihre Porenzonen sind ungleich breit, die hintere etwas breiter als die vordere, mit einem mehr als doppelt so breiten Zwischenfeld. Die vordere Porenzone ist stark gebogen und ihre Porenpare verschwinden in der Nähe des Scheitels, die hintere ist weniger gekrümmt und bis zur Spitze deutlich. Die Porenpaare sind zahlreich, gejocht und durch niedrige Leistchen greschieden.

Die hinteren Ambulacralfelder sind etwas schmaler als die vorderen und divergiren unter sehr spitzem Winkel; ihre Porenzonen wie bei vorigen, aber etwas schmaler und weniger gebogen.

Das hintere Interambulacralfeld ist etwas erhaben und stumpf gekielt.

Das Peristom ist sehr gross, von quer-ovaler Gestalt, mit stark vorspringender Unterlippe und liegt nur wenig vor der Mitte.

Das runde Periprokt befindet sich oben an der Spitze der Hinterseite.

Das Scheitelschild ist etwas excentrisch nach vorn gelegen, deutlich aber bei keinem meiner Exemplare zu erkennen.

Die grossen Tuberkeln der Oberseite sind wenig zahlreich, selten mehr denn zwei bis drei in den paarigen Interambulacralfeldern, aber breit und ticf gehöft, daher auch bei schlecht erhaltenen Exemplaren immerhin noch wahrnehmbar. Auf' der Lnterseite sind dieselben etwas kleiner, aber nicht sehr dicht gedrängt, reihenweise angeordnet und nehmen vom Rande nach dem Peristom an Grösse zu.

Das Plastron ist, mit Ausnahme einiger kleineren Wärzchen, auf dem hinteren Theile glatt. Soweit erkennbar, bedecken im Uebrigen zahlreiche kleine gehöfte Wärzchen die ganze Schalenoberfläche.

Bei einzelnen Individuen sind deutliche Fragmente der subanalen Fasciole zu beobachten. 
Vorkommen: Sowohl in der Zone $A_{1}$ als in $A_{2}$, nirgends aber gut erhalten.

Bemerkungen: Obgleich Bexrich diese Art gut beschrieben und namentlich anch die Unterschiede zwischen ihr und dem verwandten Sp. IIofimanni hervorgehoben hat, benamnte K. MAYER in Unkenntniss der einschlïgigen Literatur dieselbe Art neu.

Beyrich rechnete die Species zu Spatangus in weiterem Sinne. Nachdem aber das Vorhandensein einer subanalen Fasciole nachgewiesen werden konnte, eine Peripetalfasciole dagegen fehlt, ist dieselbe zu Hemipatagus = Maretia zu stellen.

Die charakteristischen Merkmale der M. Sambiensis sind die breite Gestalt der Schale, die geringe. Zahl der grossen Tuberkeln anf' der Oberseite, vor Allem aber die nur wenig aus dem Centrum nach vorn gerückte Lage des Peristoms, worauf auch bereits BEYPICH aufmerksam machte. Diese sämmtlichen Kennzeichen, wozu noch einige untergeordnete in der Wölbung und der Richtung der vorderen Ambulacralfelder kommen, unterscheiden die samlïndische Form von allen übrigen bekannten Arten, insbesondere von der verwandten $M$. Hofimanni.

\section{Maretia Grignonensis Desmarest.}

Taf. V, Fig. $3-5 \mathrm{c}$.

(Synonymie ef. Cotreau, Description des Échinides tertiaires etc. Mémoires cour. de l'acad. royal de la Belgique, 1880, Vol. XLIII, pag. 75.)

1861. Hemispatangus Hoffimanni Maxer, Die Faunula des marinen Sandsteius von Kleinkuhren. Vierteljahrsschr. der naturf. Gesellsch. in Zürich. Bd. VI, pag. 119.

Kleine oder mittelgrosse Seeigel von herzförmiger Gestalt, vorn gerundet, durch eine Furche am Rande ziemlich stark gebuchtet, nach hinten versehmälert und gerade abgestutzt. Oberseite mässig gewölbt, Profillinie eine theilweise flache Curve bildend, nach hinten fast horizontal oder nur wenig geneigt laufend, nach vorn in steilem Bogen abwärts gekrümmt. Seitenflïchen ziemlich abschüssig. Unterseite vollkommen flach, nur im hinteren Theile des Plastrons erhaben. 
Die Ambulacralfelder sehr ungleich; das unpare besteht aus wenigen zerstreuten Porenpaaren, die nur auf'Steinkernen deutlich sichtbar sind; die Vorderfurche beginnt erst in einiger Entfernung vom Scheitelschilde deutlich $z u$ werden, buchtet den Rand mehr oder minder aus und reicht anf der Unterseite bis in die Nähe des Peristoms. Die paarigen Ambulacralfelder sind petaloïd, leicht gekrïmmt und an den Enden etwas geöfthet. Die Porenzonen sind nur sehr schwach vertieft, fast ebenso breit wie die Interporiferenzone und bestehen aus verhältnissmässig wenigen, gejochten Porenparen; die Poren der inneren Reihen sind rund, die der äusseren schlityförmig. In àen beiden vorderen Ambulacralfeldern verschwinden die Poren der vorderen Zonen in der Nähe des Scheitels fast vollständig, oder sie werden doch sehr undentlich.

Das Peristom ist mässig gross, quer-oval, mit wenig vorspringender Unterlippe, liegt weit nach vorn und in gleicher Höhe mit der Unterseite der Schale.

Das ziemlich grosse, runde Periprokt liegt an der Spitze der Hinterseite.

Das Scheitelschild ist klein, excentrisch nach vorn gerïckt, mit vier deutlichen grossen Genitalporen, aber fast immer zerstört.

Die grossen, tief und breit gehöften, crenulirten Warzen treten in mehr oder minder grosser Zahl auf der Oberseite in den beiden vorderen und der vorderen Hälfte der beiden hinteren Interambulacralfelder auf; auf der Unterseite finden sie sich, wenn auch beträchtlich kleiner und näher gedrängt, in zwei Zonen zu beiden Seiten des Peristoms, wobei die demselben zunächstliegenden am grössten sind.

Die kleineren, gleichmässig grossen Wärzchen bedecken dicht gedrängt die ganze Oberseite; am Vorderrande und neben der vorderen Furche werden dieselben gern etwas grösser.

Bei einzelnen Fragmenten sind Spuren einer subanalen Fasciole zu bemerken.

Vorkommen: Ausserordentlich häufig, aber nicht gut erbalten in der Zone $\mathbf{A}_{1}$, selten in $\mathbf{A}_{2}$; in Belgien vom Ypresien bis zum Wemmelien, ferner an zahlreichen Localitaten des französischen Eocän. 
Bemerkungen: Die Art ist mit der jüngeren M. Hofimanni ron Bünde, mit welcher MAYER unsere Art verwechselt hat, nahe verwandt. Vor Allem unterscheidet sich W. Grignonensis durch die weit geringere Grösse: die mehrere hundert Exemplare, welche ich aus dem samländischen Tertiär untersuchte, schwanken in ihrer Grösse zwischen den beiden abgebildeten, durch die geringere Breite der Ambulacralfelder, sowie auch durch die geringere Zahl der grösseren Tuberkel auf' der Oberseite der Interambulacralfelder.

Von jüngeren Exemplaren der damit zusammen vorkommenden 11. Sambiensis unterscheidet sich unsere Art durch die etwas schmalere Gestalt, die Wölbung der Oberfläche, vor Allem aber durch die schmaleren Ambulacralfelder und den stärker excentrischen Mund.

\section{La evipatagus gen. nov.}

Umriss breit oval, Oberseite hoch gewölbt, Unterseite flach, nm das Peristom herum etwas concav; Hinterseite vertical abgestutzt, sehr flach vertieft. Unpares Ambulacrum undeutlich in seichter Furche gelegen; parige Ambulacren vollständig petaloid, stark gekrümmt und sehr breit, aus gejochten Porenpaaren bestehend.

Peristom gross, quer-oval, excentrisch nach vorn; vor demselben zwei dicke, blasenförmige Anschwellungen der Schale.

Periprokt längs-oval an der Spitze der Hinterseite liegrend.

Scheitelschild klein, mit vier Genitalporen. Schale auf der Oberseite nur mit kleineren, dicht gedrängten Wärzchen bedeckt, ohne grosse Warzen; auf der Unterseite nehmen die Wärzchen vor und zu beiden Seiten des Peristoms etwas an Grösse zu.

Plastron glatt, nur im hinteren Theile mit kleinen Würzchen. Eine dentliche Subanalfasciole vorhanden.

Bemerkungen: Laevipatugus zeigt eine grosse Verwandtschaft zu Spatangus im engeren Sinne, unterscheidet sich aber vor Allem durch das Fehlen der grossen Tuberkel anf der Oberseite der Interambulacralfelder. Ob die beiden blasenartigen Anschwellungen der Schale vor dem Peristom ein generisches Kiennzeichen 
sind, vermag ich nicht zu sagen. BEYRICI hat (1. e. pag. 100) auf ähnliche Anschwellungen bei allen Exemplaren der Maretia Hoțmanni hingewiesen, die ich an einem Individuum der hiesigen Sammlung constatiren konnte; die Grösse und Form dieser Anschwellungen scheint aber gewissen Schwankungen zu unterliegen, anf welche ich in der folgenden Beschreibung zurückkommen werde.

Von Fasciolen wurde nur eine subanale beobachtet, und ich glaube kaum, dass sich etwa eine Peripetalfasciole vorfindet, da die wenigen gut erhaltenen Exemplare dieselbe sicher hätten erkennen lassen.

Die Combinirung der beiden letzten Charaktere - Anschwellungen der Schale vor dem Peristom, subanale Fasciole - mit den übrigen Merkmalen lïsst das Genus Laevipatagus als nahe verwandt mit Maretia erscheinen, von welcher es sich aber, wie gesagt, durch den Mangel der grösseren Warzen auf' der Oberseite unterscheidet.

\section{Laevipatagus bigibbus BEYrich sp.}

Taf. VI, Fig. $1-6$.

1848. Spretangus (Miorester) bigibhus Bermicn, Zur Kenntniss des tertiären Bodens der Mark Brandenburg. Karsten's und v. Decnes's Archiv, Bd. XXII, pag. 100.

1861. Leiospatentus tulifer Marer, Die Faunula des marinen Sandsteins von Ḱleinkuhren. Vicrteljahrsschr. der naturf. Gesellsch. in Zïrich. Bd. VI, pag. 119.

Schale von breit-ovalem, fast kreisförmigem Umriss, etwas breiter als lang; nach vorn und hinten verschmälert, aber vorn gerundet und ziemlich stark gebuchtet, hinten gerade abgestutzt. Der Punkt der höchsten Wölbung liegt etwa in der Mitte des hinteren Interambulacralfeldes, von wo aus die Schale ziemlich steil nach hinten, etwas flacher nach vorn zum Scheitelschilde abfüllt; von hier lïuft die Profillinie auf kurze Erstreckung horizontal und biegt sich dann fast senkrecht nach unten um.

Die Unterseite ist flach, um das Peristom herum eingesenkt, zuweilen mit stark convexem Plastron. Die Hinterseite ist ver- 
tical abgestutzt, aber seicht ansgehöhlt, so dass der obere und der untere Theil der Schale unmerklich vorspringen.

Die Ambulacralfelder sind ungleich, aber breit und gross, etwas vertieft; das vordere ist undeutlich und liegt in einer mässig tiefen Furche, die am Scheitel beginnt, den. Rand ziemlich tief buchtet und auf der Unterseite kurz vor den Anschwellungen am Peristom authört.

Die vorderen parigen Ambulacralfelder sind sehr breit, am Ende fast vollständig geschlossen und divergiren unter sehr stumpfem Winkel. Die Porenzonen, mit zahlreichen gejochten Porenpaaren, sind etwa ein Drittel so breit wie die Interporiferenzone. Die vordere Porenzone ist stark gebogen, und es werden die Porenpaare derselben in der Nähe des Scheitels undentlich oder verschwinden vollständig; die hintere ist nicht so stark gekrümmt und bis zum Scheitel deutlich zu verfolgen.

Die hinteren Ambulacralfelder sind etwas schmaler als die vorderen und divergiren unter einem sehr spitzen Winkel; Porenzonen wie bei vorigen, nur weniger gebogen. Bei einem Exemplar sieht man, dass die Poren dieser Ambulacralfelder auch auf die Unterseite fortsetzen, wo sie, wenn auch weit vou einander entfernt, auf' den grossen langgestreckten Ambulacraltäfelchen zn beiden Seiten des Plastrons dentlich sichtbar sind. Das Peristom ist gross, von querovaler Gestalt, mit stark vorspringender Unterlippe und liegt excentrisch, wenig vor der Mitte, in tiefer Einsenkung.

Vor dem Peristom am Rande der Einsenkung stehen, schräg zur Medianaxe gerichtet, zwei glatte, dicke, blasenförmige Buckel, welche durch einen schmalen Zwischenraum getrennt werden.

Die Gestalt, Grösse, Richtung und Entfernung dieser, wohl als blasenförmige Ausstülpungen der Schale aufzufassenden Buckel variirt sehr stark. Bei der Mehrzahl meiner Exemplare zeigen dieselben lang-eiförmige Gestalt mit dem breiten Ende nach vorn, und mag ihre Länge etwa der Breite des Peristoms gleichkommen (Fig. 1 a , 2, 3, 5 und 6).

Bei einem Exemplar nun (Fig. 4), bei welchem Abreibung nicht anzunehmen ist, sind diese grossen Buckel zu einer winzig kleinen, aber doch stark aufgetriebenen Anschwellung reducirt; leider fehlt 
an dem Stück die eine Hälfte, doch sieht man noch, dass der Raum zwischen beiden Buckeln hier recht breit war.

Die Breite des Zwischenraumes schwankt, wie die Abbildungen zeigen, ebenso wie die Stellung der Buckel zur Medianaxe innerhalb ziemlich weiter Grenzen.

Als ganz besonders auffallende Ausbildung in der Gestalt dieser Anschwellungen ist ein Exemplar (Fig. 6) hervorzuheben, dis allerdings nur in einem Fragmente des vorderen Theiles erbalten ist. Hier haben sich von dem grösseren eiförmigen Buckel auf der Vorderseite zwei kleinere Anschwellungen abgeschnürt, die, wenn auch noch nicht vollständig getrennt, doch durch eine tiefe Furche davon geschieden sind; eine etwas tiefere Furche scheidet diese Secundäranschwellungen unter einander. Da die beiden Anschwellungen vor dem Munde noch erhalten sind, beide auch die gleiche Gestalt zoigen. so ist hier keinenfialls an eine athnorme Bildung eines dieser Buckel zu denken, sondern das Fragment stellt entweder eine Varietät oder eine andere Art vor. So weit ich erkennen kann, waren die grossen Buckel etwas niedriger als bei den typischen Formen, doch möchte ich hierauf kein zu grosses Gewicht legen.

Das Periprokt ist mässig gross, lüngs-oval und liegt am oberen Ende der Hinterseite.

Das Scheitelschild ist klein, etwas nach vorn gelegen, aber bei keinem meiner Exemplare erhalten, wie die Abdrücke beweisen, mit vier deutlichen Genitalporen versehen.

Die Oberfläche ist auf der Oberseite nur mit kleinen, dicht gedrängten gehöften Wärzchen bedeckt, die sich in der Nähe des Randes in schräge Reihen stellen. Auf der Unterseite nehmen die Wärzchen nach dem Peristom hin an Grösse zu und stehen etwas weiter auseinander.

Das Plastron ist glatt, nur im hinteren Theile (Fig. 5) mit kleinen Wärzchen besetzt.

Eine, weun auch nicht vollkommen geschlossene, subanale Fasciole ist bei mehreren Exemplaren zu beobachten.

Vorkommen: Sehr häufig, aber meist schlecht erhalten, in der Zone $A_{2}$, seltener in den Mergelknollen in der Zone $A_{1}$. 
Bemerkungen: Berricu hat diese Form zuerst als Spatungus (Micraster) bigibbus beschrieben und ihre wesentlichen charakteristischen Kennzeichen angegeben. Da sie jedoch dem Genus Micraster in dessen hentiger Abgrenzung nicht eingereiht werlen kann, so war es nöthig, ein nenes Genus zu errichten.

Da Marer die ältere Artbezeichnung nicht kannte, so hat er unsere Art unter dem Namen Leiospatangus tubifer beschrieben. Eine Gattung dieses Namens habe ich jedoch trotz eifriger Bemühungen in der Literatur nicht auffinden können. Sollte MAYEr für unsere Art damit eine neue Gattung haben aufstellen wollen, so hïtte er eine Diagnose geben müssen, die das Wiedererkennen ermöglichte. Da das nicht geschehen ist, ist die Bezeichnung Leiospatangus zu cassiren.

Als charakteristisches Kennzeichen des Laevipatayus bigibbus muss die Abwesenheit grösserer Warzen auf der Oberseite und das Vorhandensein von zwei grossen dicken blasenartigen Anschwellungen der Schale vor dem Peristom bezeichnet werden. Welche Funktionen diese Anschwellungen gehabt haben, wird kaum zu ermitteln sein, da bei lebenden Formen ein Analogon, bis jetzt wenigstens, nicht bekannt ist.

\section{Asteroidea.}

\section{Crenaster.}

\section{Crenaster poritoides Desmarest.}

\section{Taf. VI, Fig. 7-7c.}

Es liegen mir cinige Randplättchen eines Seesternes vor, die ich nach Vergleich mit belgischen Exemplaren mit dieser Art identificire. Es sind ziemlich dicke, mehr oder minder parallelepipedische Randplaittchen mit glatten, von einem starken Saume eingefassten Seitenflïchen und deutlichem Gelenk auf der Innenfläche. Die Aussenfläche ist flach gekrümmt und mit zahlreichen eingestochenen punktförmigen Vertiefungen bedeckt. 
Vorkommen: Sehr selten in der Zone $A_{2}$, in Belgien in der Etage Laekenien.

Bemerkungen: Leider war es mir nicht möglich, die Literatur dieser Art zu erhalten, und ich muss mich in der Bestimmung einzig und allein an das Vergleichsmaterial aus Belgien halten, mit welchem die Täfelchen des samländischen Tertiärs gut übereinstimmen. 


\section{Erklärung der Texttafel zu Lieferung I. \\ Vertebrata.}

Fig. 1. Chimaera mentiterranea Lisx., Unterkiefer.
a. rechte Dentalplatte.
h. linke Dentalplatte.

Fis. 1 a. Chimaera mediterranea Lisx.. Oherkiefer.
a'. rechte Postdentalplatte.
b'. linke Postdentalplatte.
c. rechte Prïdentalplatte.
d. linke Priidentalplatte.

Fi... 2. Rhinobates Ilorkeli M. und H., Quersehnitt eines Rumpfwirhels; Copie nach $\mathrm{H}_{\text {Asse: }}$

Fi... :. Rhinobates sp. Eocän; Copie nach Hasse.

Fin. 1. Rhinobates cemiculus (․ Sт. HIL., Quersehnitt eines Rumpforirhels: Copie nach Hisse.

Fig. 5. Rhinoluates sp. Eocëu; Copie wach Hasse.
d. centraler Doppelkegel.
a. Innenlage der Aussenzone.
a'. Aussenlage cler Aussenzone.
o. Obertlïchenverkalkungen.

Fig. 6. Urolophus sp. Eociin; Copie nach $\mathrm{H}_{\text {ASSE. }}$
i. Innenzone.
d. centraler Doppelkegel.
a. Innenlage der Aussenzone.
a'. Aussenlage der Aussenzone.

Fin. 7. Astrape rlipterygia M. und H.; Quersehnitt eines Schwanzwirbels; Copie nach Hasse.

Fin. S. Astrape sp., Senon; Cople nach Hasse.

Fing. ?) Torpedo marmorate M. und H.; Quersehnitt eines Rumpfwirhels: Copic nach Hasse. 
Erklïrung der 'Texttafel zu Lieferung I. Vertebrata.

Fig. 10. Torpedo sp.

Fig. 11. Turpedo sp. Crag; Copie nach H.sss.

i. Innenzone.

d. centraler Doppelkegel.

a. Innenlage der Aussenzone.

$a^{\prime}$. Aussenlage der Aussenzone.

Fig. 12. Squatina vulyaris Lisx., Frontalansicht des 6. Rumpfwirhels.

r. Randsaum des centralen Doppelkegrels.

n. Neurapophysen.

h. Hämapophysen.

Fig. 13. Alopias vulpes Lins., Dorsalseite des 7. Rimpfwirbels.

n. Lücken für die Ḱnorpelzapfen der Neurapophysen.

Fig. 13a. Alopias vulpes Lixx., Ventralseite des 7. Rumpfwirbels.

h. Lücken für die Knorpelzapfen der Hämapophysen. 

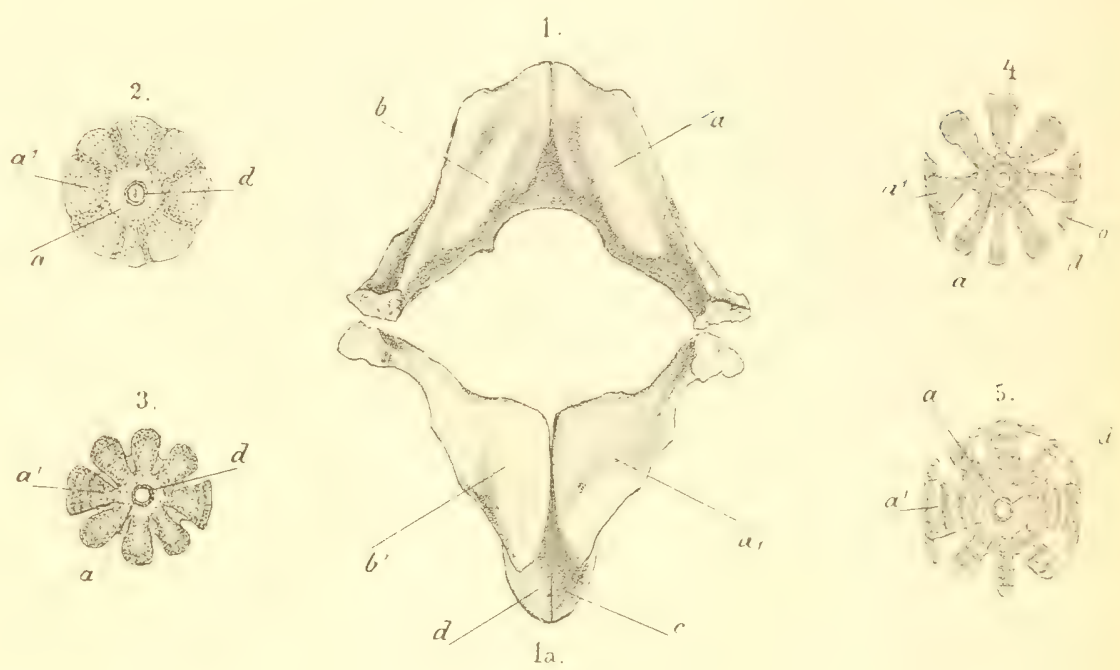

a 9.

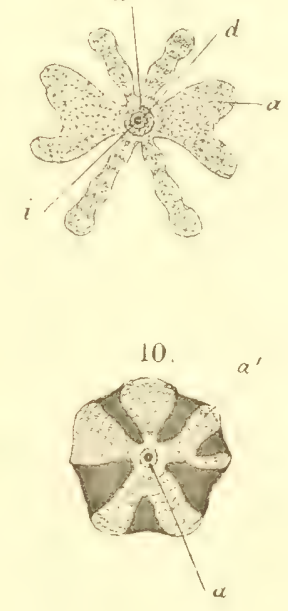

11.
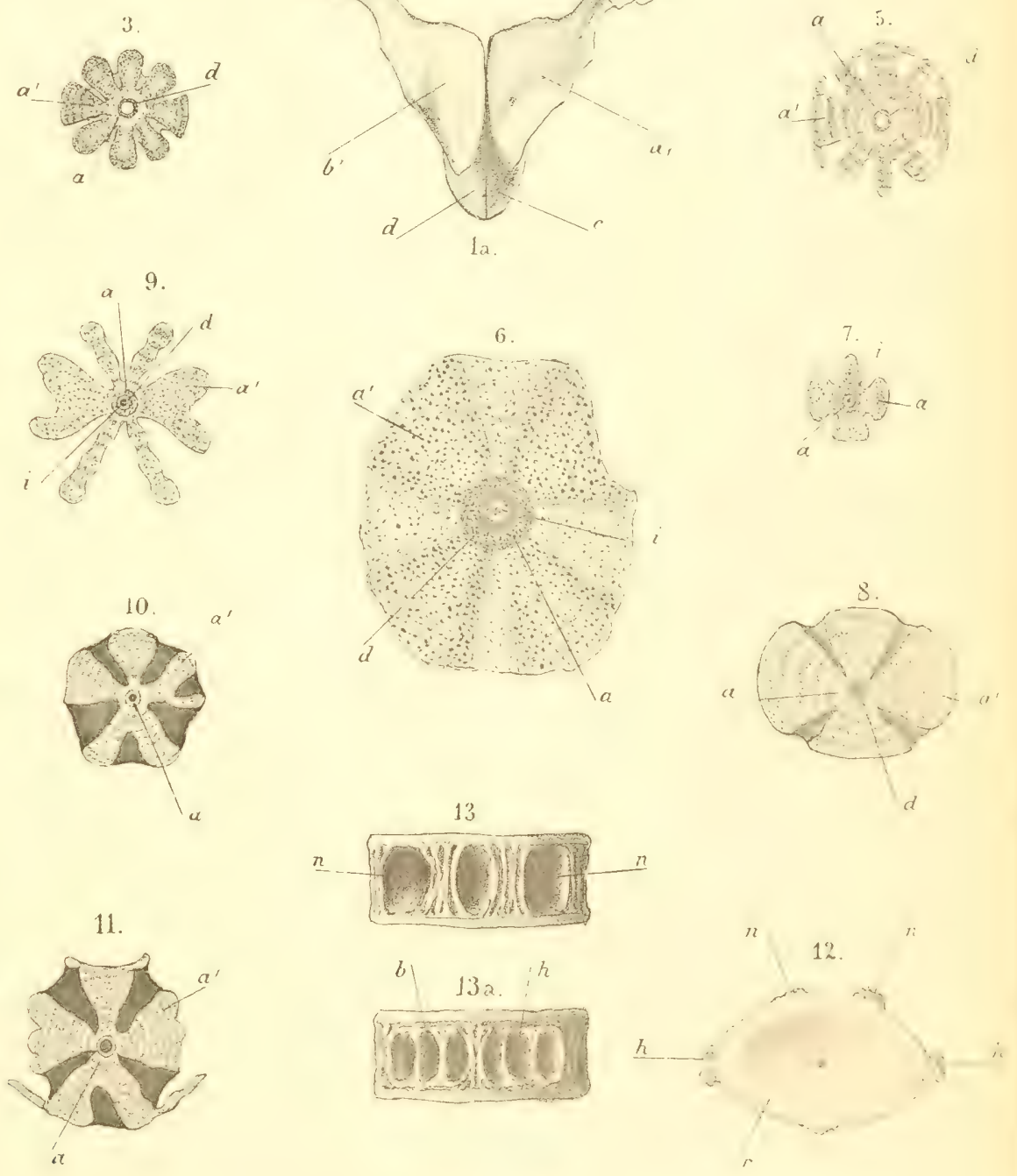

H. Braune àel.

Lichtdruck v A. Frisch Ber!: W 




\section{Erklärung der Texttafel zu Lieferung II und VI. \\ Crustacea und Fchinodermata.}

Fig. 1. Cieluprilie vernucose Mnх EDw.

(Copie aus Bourúr, Palćontologie de Biarritz.)

Fig. 2. Coelome vigil M. Enw. Sehematische Zeichnung der vorderen P'artie des Cephalothorax.

Fin. ש̈. Coeloma balticum Scnuürer. Schematische Zeichnung der vorderen Partie des Cephalothorax.

Fign 4. Coeloma vigil M. Enw. Sehematischer Quersolinitt de's Vorderams.

Fing. 5. Cuclome balticum Scrüürek. Schematischer Querschnitt des Vorderarms.

Fig. 6. Bancria Agassizii n'Anck. sp., Oberseite.

Fiv. 6 a. $\gg$ » $\gg$ Seitenansicht.

Fig. 6 b. 》 》 $\gg$ Ambulacral- und Interambulacralfelder, stark vergrössert.

(Copie nach D'Archice, Desc. des Foss. ete. Mím. de la soc. géol. do France, 2. série, vol. 111 , fig. $2 a, b, c$.

Figr. 7. Echinarachnius parma AGass., recent; Inuentlïche der Oberseite. 

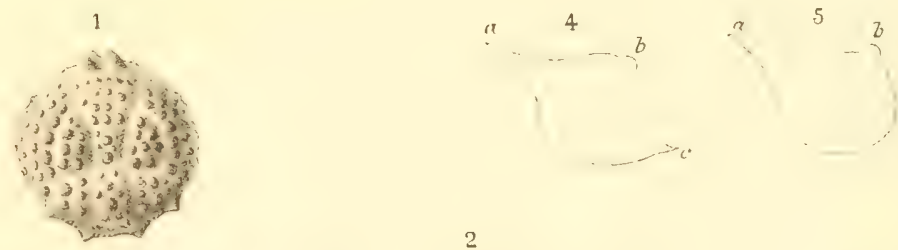

2

3
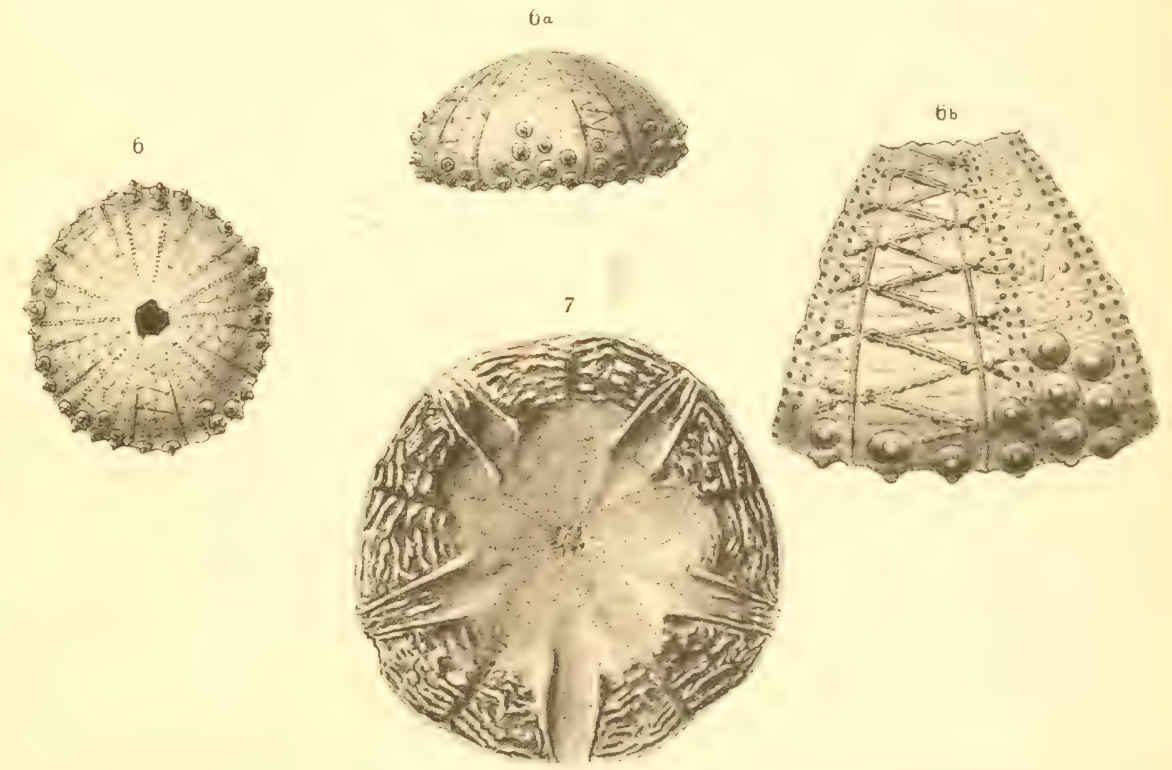

E.Ohmand del. 



\section{Abhandlungen zur geologischen Specialkarte von Preussen und}

den Thüringischen Staaten.

Bd. I, Heft 1. Rïdersilorf nnd Umgegend, eine geognostische MonoMark graphie, nebst 1 Taf, Abbild. von Verstein., 1 geogn. Karte und Profilen; von Dr. H. Eck . . . . . s-

2. Ueber den Unteren Kenper des östlichen Thüringens, nebst Holzschn nud 1 Taf. Abbild. von Verstein.; von Prof. Dr. E. E. Schmid _ _. . . . . .

3. Googn. Darstellung des Steinkohlengebirges und Rothliegenden in der Gegend nördlich von Halle a. S., nebst 1 gr, geogn. Karte, 1 geogn. Uebersichtsblättehen; 1 Taf. Profile und 16 Holzschn.; von Dr. H. Laspeyres

4. Geogı. Beschreibung der Insel Sylt, nebst 1 geogn. Tiate, 2 Taf, Profile, 1 Titelbilde und 1 Holzsehn, $;$ von Dr. L. Meyn

Bu. II, Heft 1. Beiträge zur fossilen Flora. Steinkohlen-Calamarien, mit besonderer Berücksichtigung ihrer Fructificationen; nebst 1 Atlas von 19 Taf. und 2 Holzschn.; von Prof. Dr. Ch. E. Weiss : . . . . . . . . . $20-$

2. + Riidersdorf und Umgegend. Auf geogn. Grundlage agronomisch bearbeitet, nebst 1 geogn.-agronomischen Karte; von Prof. Dr. A. Orth $\quad \cdots \cdots \cdots \cdots$

3. + Die Umgegend von Berlin. Allgem. Erlăuter. z. geogn.agronomischen Karte derselben. I. Der Nordwesten Berlins, nebst 10 Holzschn. und 1 Kärtchen; von Prof. Dr. G. Berendt . . . . . . . . .

4. Die Faana der ältesten Devon-Ablagerungen des Harzes, nebst 1 Atlas von 36: Taf,; von Dr. E. Kayser . . $24-$

Bd. III, Heft 1. Beiträge zur fossilen Flora. II. Die Flora des Rothliegenden von Wünschendorf bei Lauban in Schlesien, nebst 3 Taf. Abbild, von Prof. Dr. Ch. E. Weiss .

2. + Mittheilungen aus dem Laboratorium f. Bodenkunde d. Kgl. Preuss. geolog. Landesanstalt. Untersachangen des Bodens der Umgegend von Berlin; von Dr. E. Laufer und Dr. F. Wahnschaffe . . . . $9-$

3. Die Bodenverhältnisse der Prov. Schleswig-Holstein als Erläut. zu der dazn gehörigen Geolog. Uebersichtskarte von Schleswig-Holstein; von Dr. L. Me y n. Mit Anmerkungen, einem Sehriftenverzeichniss und Lebensabriss des Verf,; von Prof. Dr. G. Berendt . .

4. Geogn. Darstellung des Niederschlesisch-Bölnischen Steinkohlenbeckens, nebst 1 Uebersichtskarte, 4 Taf. Profile ete, von Bergrath A. S chütze . . . . . . $14-$

Bd. IV, Heft 1. Die regnlären Echiniden der norddentschen Kreide, I. Glyphostoma (Latistellata), nebst 7 Tafeln; von Prof. Dr. Clemens Schlüter.

2. Monographie der Homalonotus-Arten des Plieinischen Unterdevon, mit Atlas von S Taf, von Dr. Carl Koch. Nebst einem Bildniss von C. Koch und einem Lebensabriss desselben von Dr. H. v. Dechen . . . 9- 
Bd. IV, Heft 3. Beitrïge zur Kenntniss der Tertiiirflora der Provinz Sachsen, mit 2 Holzschn., 1 Uebersichtskarte und einem Atlas mit 31 Lichtarucktafeln; von Dr. P. Friedrich

4. Abbildungen der Bivalven der Casseler T'ertiärbildungen von Dr. 0. Speyer nebst dem Bildniss des'Verfassers, und mit einem Vorwort von Prof. Dr. A. v. Koenen

Bd. V, Heft 1. Die geologischen Verhältnisse der Stadt Hildesheim, nebst einer geogn. Karte, von Dr. Herm. Roemer.

2. Beiträge zur fossilen Flora. III. Steinkollen-Calamarien II, nebst 1 Atlas von 28 Tafeln; von Prof. Dr. Ch. E. Weiss

3. † Die Werder'scheu Weinlerge. Eine Studie zur Kenntniss des märkischen Bodens von Dr. E. Laufer. Mit 1 Titelbilde, 1 Zinkographie, 2 Holzschnitten und einer Bodenkarte . . . . . . . . . . .

4. Uebersicht uiber den Schichtenaufbau 0sthüringens, nebst 2 vorläufigen geogn. Uebersichtskarten von Ostthüringen, von Prof, Dr. K. Th. Liebe . . . . .

Bd. VI, Heft 1. Beiträge zur Kenntniss des 0berharzer Spiriferensandsteius und seiner Fauna, nebst 1 Atlas mit 6 lithogr. Tafeln, von Dr. L. Beúshaúsen . . . . .

2. Die Trias am Nordrando der Eifel zwischen Commern, Zülpich und dem Roerthale. Von Max Blanckenhorn. Mit 1 geognostischen Karte, 1 Profil- und 1 Petrefakten-Tafel . . . . . . . . . .

: 3. Die Fauna des samländischon Tertiärs. Von Dr. Fritz Noetling. I. Theil. Lieferung 1: Vertebrata. Lieferung II: Crustacea und Vermes. Lieferung VI: Echinodermata. Nebst Tafelerklärungen und zwei Texttafeln. Hierzu ein Atlas mit 27 Tafelu . . .

Bd. VII, Heft ${ }_{3}$. Die Quartärbildungen der Uwgegend von Iagdebarg, - mit besonderer Berücksichtigung der Börde. Von Dr. Felix Walinschaffe Mit einer Karte in Buntdruck und 8 Zinkographien im Text. . . . . $5-$

\section{Sonstige Karten und Schriften.}

1. Höhensehichtenkarte des Harzgebirges, im Maafsstabe von 1:100000

2. Geologische Uebersichtskarte des Harzgebirges, im Maalsstabe von 1: 100000; zusammengestellt von Dr. K. A. Lossen

3. Aus der Flora der Steinkohlentormation (20 Taf. Abbild. d. wichtigsten

Steinkoblenpflanzen m. kurzer Beschreibung); von Prof. Dr. Ch. E. We is s

4. Dr. Ludewig Mleyn. Lebensabriss und Schriftenverzeichniss desselben; von Prof. Dr. G. Berendt. Mit einem Lichtdruckbildniss von L. Meyn

5. Jahrbuch der Königl. Preuss. geolog. Landesanstalt u. Borgakademie für das Jabr 1880. Mit geogn. Karten, Profilen etc @

6. Dassellue für das Jahr 1881. Mit dgl. Karten, Profilen etc. . . . 20-

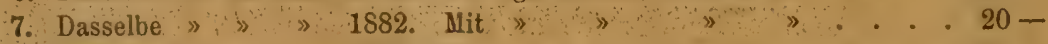

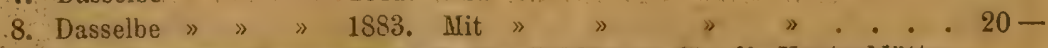

9. † Geognostisch-agronomische Farben-Erklärnng für die Kartenblätter der Umgegend von Berlin von Prof. Dr. G. Berendt . . . 0,50

A. W. Schade's Buchdruckerei (L. Sehade) in Berlin, Stallschreiberstr. 45,46 . 







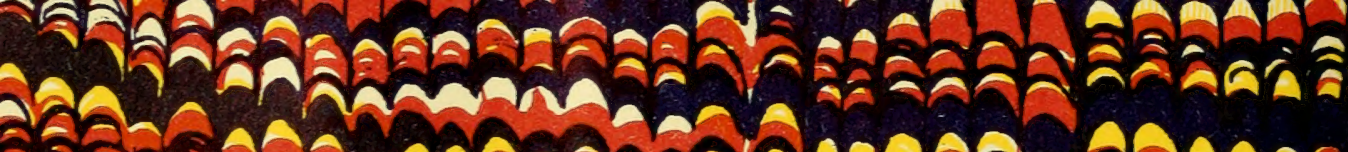

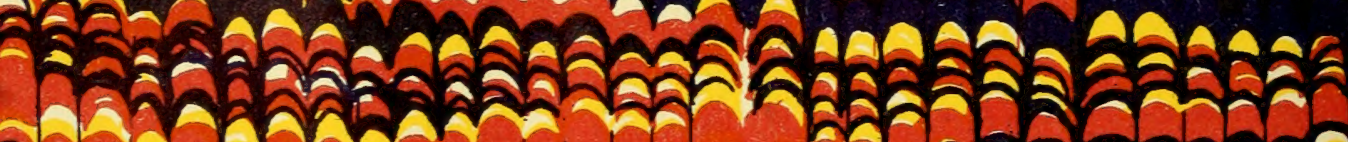

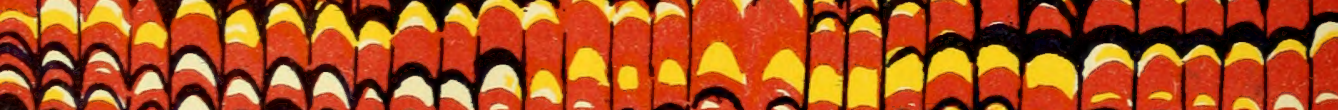

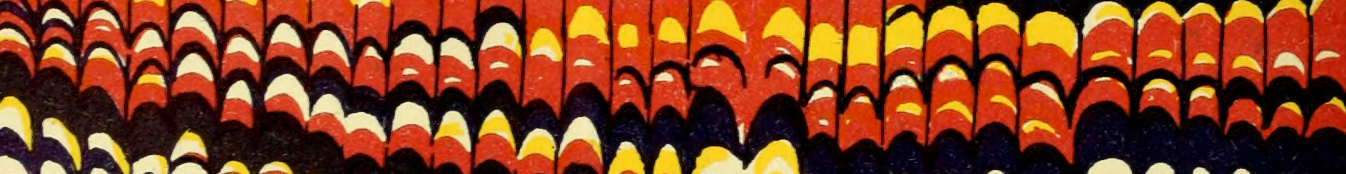
Tha

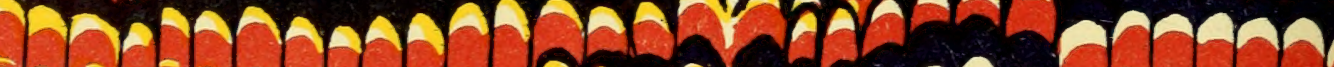

สล่

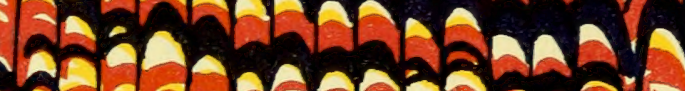

17 บ A

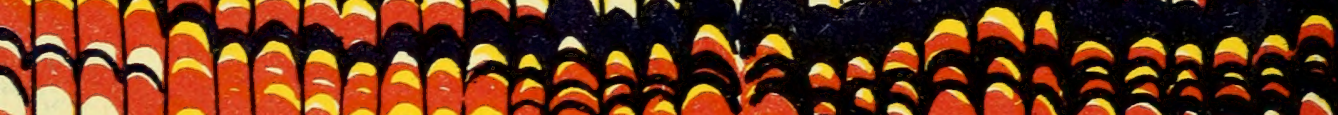
7.

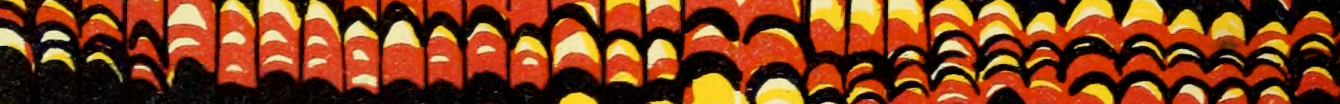

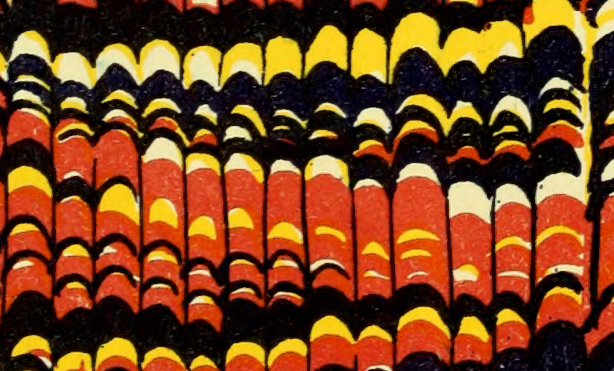

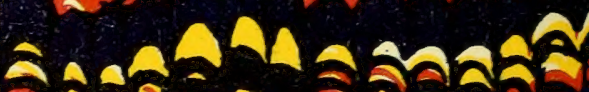

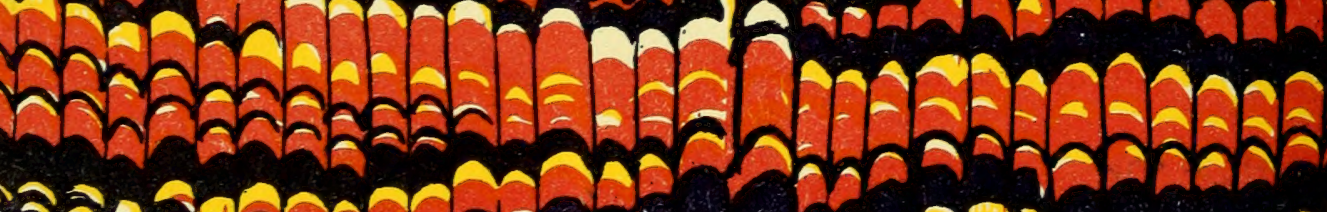

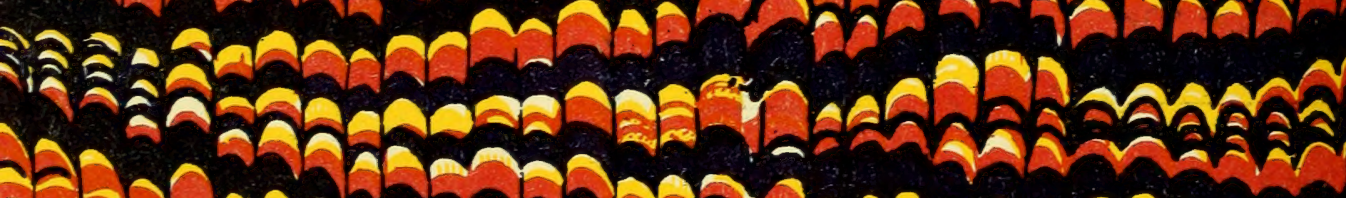
Z 1

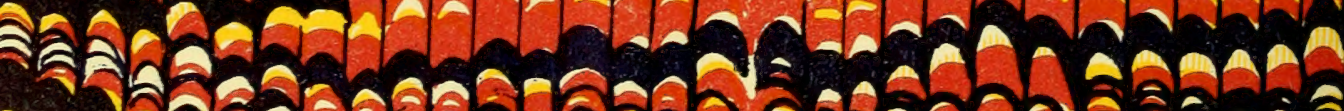

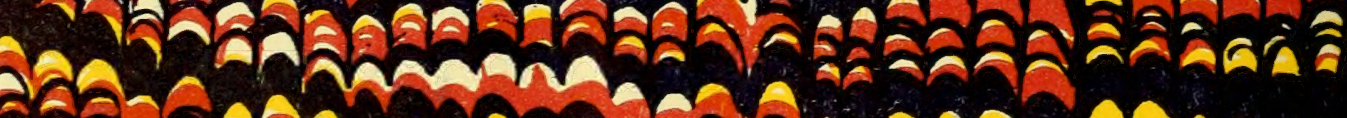
CA *

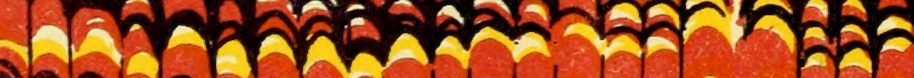
A t ลว

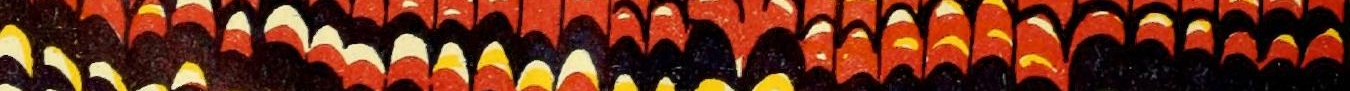

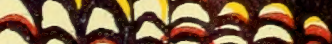




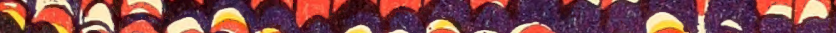

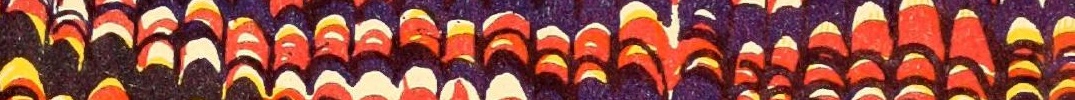

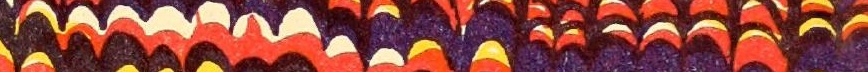

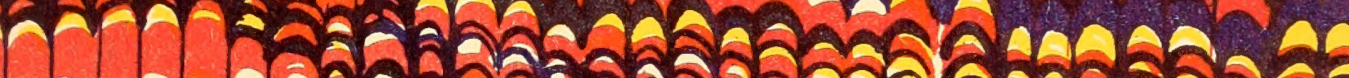

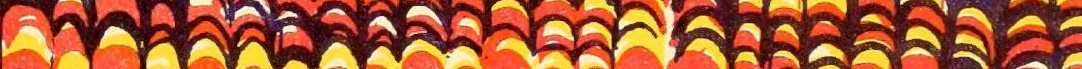

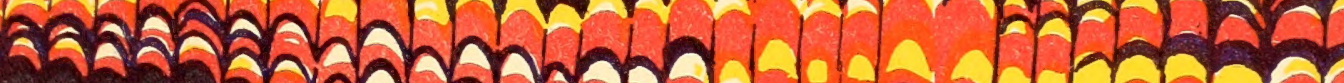
ลas

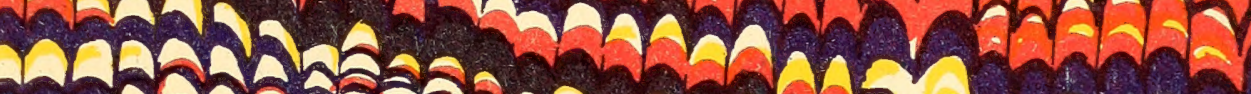

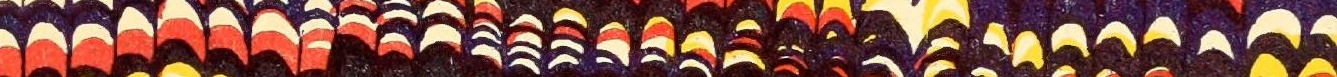

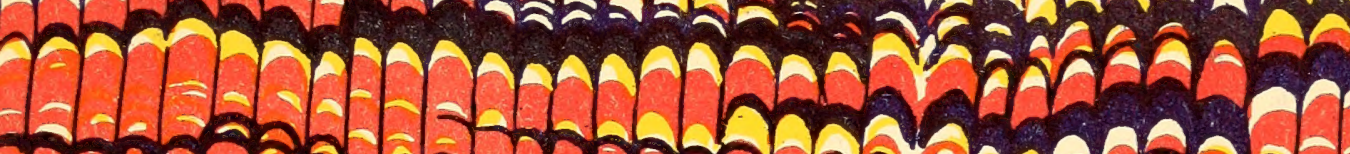

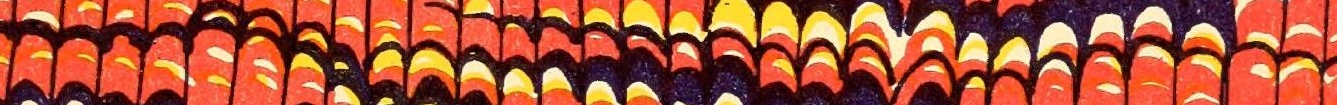

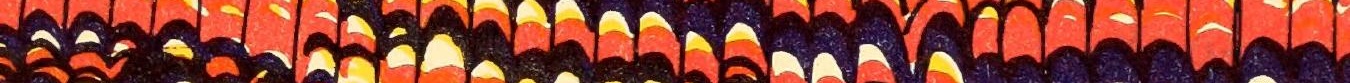
Thm,

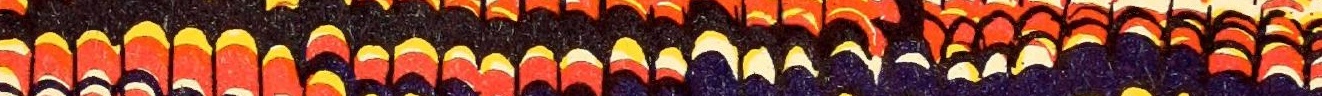
15. ำ

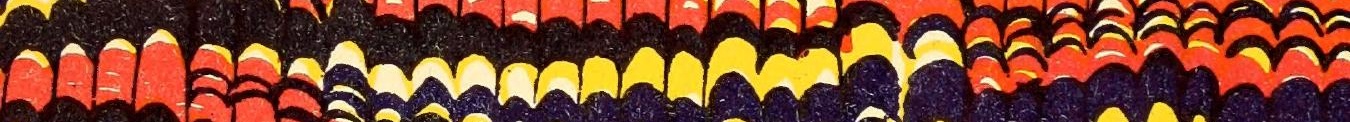

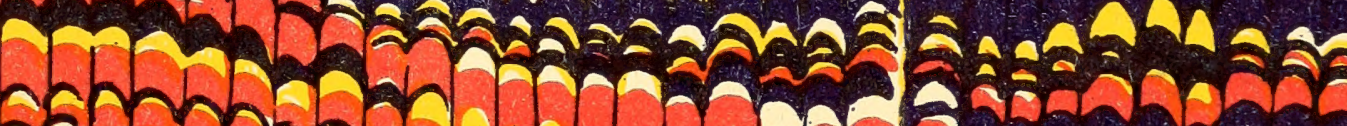
12.

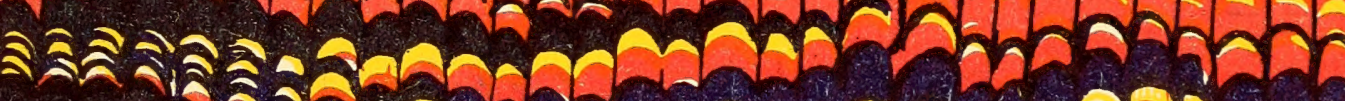

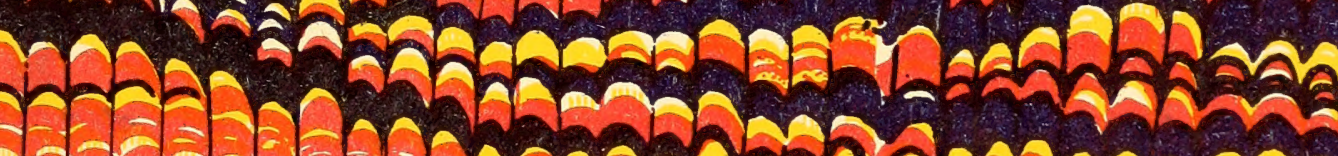

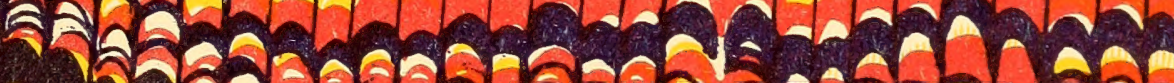

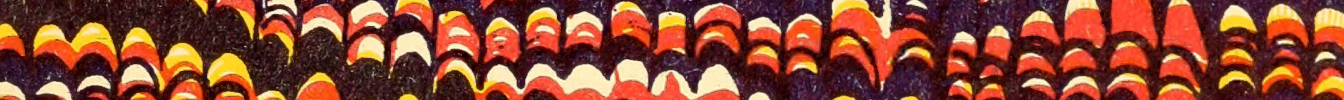

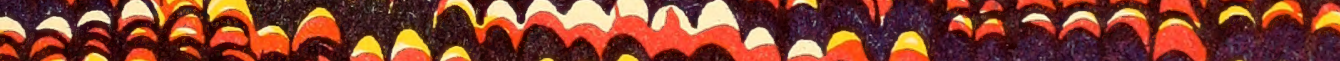

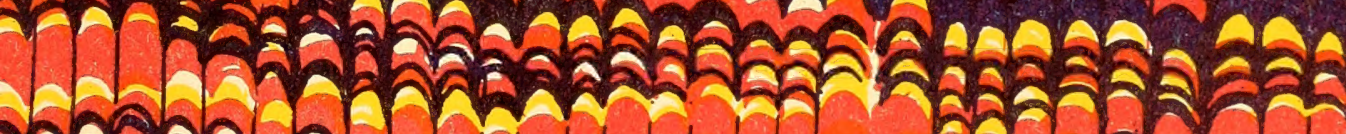
ลคล

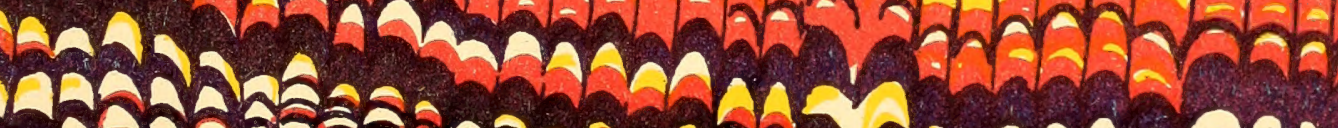


SMITHSONIAN INSTITUTION LIBRARIES 